\title{
COMPLETE CFD ANALYSIS OF A VELOCITY XL-5 RG WITH FLIGHT-TEST VERIFICATION
}

\author{
A Thesis \\ by \\ SHANE MICHAEL SCHOUTEN
}

Submitted to the Office of Graduate Studies of

Texas A\&M University

in partial fulfillment of the requirements for the degree of

MASTER OF SCIENCE

May 2008

Major Subject: Aerospace Engineering 


\title{
COMPLETE CFD ANALYSIS OF A VELOCITY XL-5 RG WITH FLIGHT-TEST VERIFICATION
}

\author{
A Thesis \\ by \\ SHANE MICHAEL SCHOUTEN
}

\begin{abstract}
Submitted to the Office of Graduate Studies of
Texas A\&M University

in partial fulfillment of the requirements for the degree of

MASTER OF SCIENCE
\end{abstract}

\begin{abstract}
Approved by:
Chair of Committee, William S. Saric

Committee Members, Rodney Bowersox

Don Collins

Head of Department, Helen Reed
\end{abstract}

May 2008

Major Subject: Aerospace Engineering 


\author{
ABSTRACT \\ Complete CFD Analysis of a Velocity XL-5 RG \\ with Flight-Test Verification. (May 2008) \\ Shane Michael Schouten, B.S., Texas A\&M University \\ Chair of Advisory Committee: Dr. William S. Saric
}

The Texas A\&M Flight Research Laboratory (FRL) recently received delivery of its newest aircraft, the Velocity XL-5 RG. The Velocity can fly faster than the other aircraft owned by the FRL and does not have a propeller in the front of the aircraft to disrupt the air flow. These are definite advantages that make the Velocity an attractive addition to the FRL inventory to be used in boundary-layer stability and transition control. Possible mounting locations built into the aircraft for future projects include hard points in the wings and roof of the fuselage. One of the drawbacks of the aircraft is that it has a canard ahead of the main wing that could disrupt the incoming flow for a wing glove or research requiring test pieces mounted to the hard point in the wing. Therefore, it is necessary to understand the influence the canard and the impact of its wake on the wing of the aircraft before any in-depth aerodynamic research could be completed on the aircraft.

A combination of in-flight measurements of the canard wake and Computational Fluid Dynamics (CFD) were used to provide a clear picture of the flowfield around the aircraft. The first step of the project consisted of making a 3-D CAD model of the aircraft. This model was then used for the CFD simulations in Fluent. 2-D, 3-D, inviscid, and viscous simulations were preformed on the aircraft. A pressure rake was designed to house a 5-hole probe and 18 Pitot probes that extended forward of the main wing to measure the location and strength of the canard wake at various flight conditions. There were five primary test points that were recorded at multiple times over the course of 
three flights. Once all of the data were collected from the flights, the freestream conditions became the inputs into the final, 3-D CFD simulations on the aircraft.

The good agreement between the CFD results and the in-flight measurements provided the necessary verification of the CFD model of the aircraft. These results can be used in the future planning and execution of experiments involving the Velocity XL-5 RG. 
To my parents, Bob and Suzanne Schouten 


\section{ACKNOWLEDGEMENTS}

I want to extend my gratitude to everyone who has made this possible for me; my family, friends, mentors and coworkers. I would like to thank my family and friends for helping give me encouragement and prayers throughout the last few years. I am sorry I was unable to spend more time with all of you, but thank you for being understanding and supportive. I would especially like to thank my parents for all of their support. A big thank you is also deserved by Andrea Hsu for being there to listen to me and support me throughout the entire project.

To the entire crew at the FRL I would like to extend a giant thank you: Andrew Carpenter, Brian Crawford, Nicolas Flores, Jerrod Hofferth, Lauren Hunt, and Cecil Rhodes. To my coworkers, you get a double thank you since I count you all among my friends as well. But you have been so much more as well. Your direct and indirect support, advice, and caring helped me push through. Andrew, thank you for the direction and help with understanding. Celine, thank you for working with me to fly this experiment. Jerrod, your help in setting up the experiment and being there as a friend, and someone I could bounce ideas off of and receive input from was crucial. Lauren, your help with reviewing my thesis and always asking and caring how my work progressed was greatly appreciated. Last, but definitely not least at the FRL, I would like to thank our mechanic Cecil Rhodes for all of his help through-out his time with us in both building our experiments, keeping the aircraft running, and providing a vast amount of experience and knowledge to the group and myself.

I want to thank Richard Rhodes for all of his help in the past year and a half for teaching me Fluent and Gambit, and also helping to troubleshoot any problems I encountered with my simulations.

I would like to take this time to thank the entire wind tunnel staff. The Director, Jorge Martinez, Engineering Staff: of Ross Flach and Chris Adcock, and the Engineering Technicians: Will Seward, Carl Johnson, Byron Cotsonis, and John Kochen 
all played vitals roles in giving advice, helping build my experiment and letting me borrow tools and use their experience.

I would like to thank my committee members, Dr. Bowersox and Dr. Collins for their reviews and inputs on my research and thesis. Dr. Reed, I would like to thank you for all the wisdom and time you spent with me during our weekly meetings to discuss my progress and CFD problems.

Most of all, I want to thank Dr. Saric. Without you, none of this would be possible. I thank you for taking me on as a graduate student and letting me learn and grow in this unique environment. The facilities, staff, and crew that you have put together have been amazing and I am thankful for all of the time and work I got to do. I also thank you for your advice, wisdom, and insight throughout the project. I also thank you for finding a way to fund this research without it having direct support. 
TABLE OF CONTENTS

Page

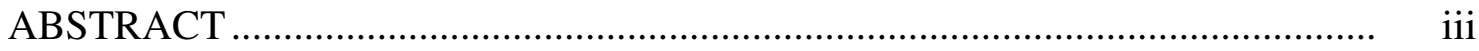

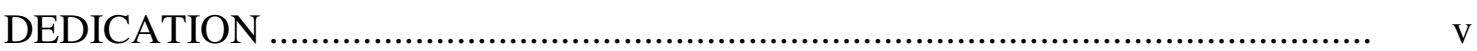

ACKNOWLEDGEMENTS ………..................................................... vi

TABLE OF CONTENTS ...................................................................... viii

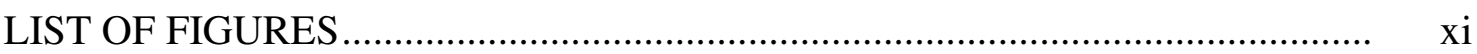

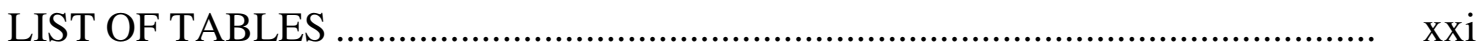

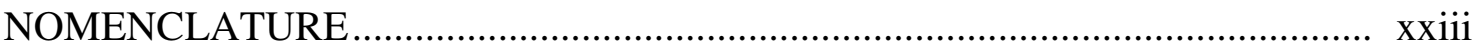

CHAPTER

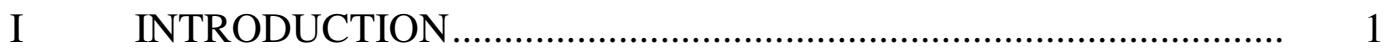

$1.1 \quad$ Aerodynamic Research ..................................................... 1

$1.2 \quad$ Experimental Aerodynamic Research ................................. 1

1.3 Texas A\&M University Flight Research Laboratory ......... 3

1.3.1 N632AM Velocity XL-5 RG...................................... 4

$1.4 \quad$ Available Resources ........................................................... 6

1.5 Objectives ...................................................................... 7

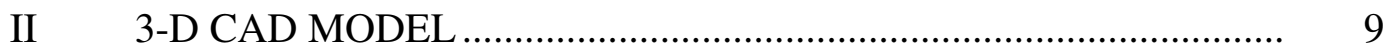

2.1 Developing the 3-D CAD Model of the Aircraft .............. 9

2.2 Measurements with the Coordinate Measurement Machine 10

2.3 Creating the Geometry from the Measurements ................ 12

III CFD SIMULATIONS .................................................................... 15

3.1 CFD Simulations ............................................................ 15

3.2 2-D Simulation Studies ……………………………..... 18

3.2.1 2-D Grid Sizing Study .............................................. 19

3.2.2 2-D CFD Turbulence Model Study ………………..... 23

3.2.3 2-D Velocity Study....................................................... 25 
3.2.3.1 Isolated Velocity Wing...................................... 26

3.2.3.2 Velocity Canard-Wing Interaction....................... 27

3.2.3.3 Velocity Canard Cross-Section: Real vs. Simplified 27

3.3 3-D Simulations............................................................. 28

3.3.1 Determining the Control Volume Size.................... 28

3.3.2 Preliminary 3-D Simulations of the Aircraft............ 31

3.3.3 3-D Simulation Mesh Development....................... 32

3.4 Simulations after the In-Flight Measurements ................. 33

3.4.1 Post-Flight 2-D Simulations................................. 33

3.4.2 Post-Flight 3-D Simulations................................... 33

IV GROUND AND IN-FLIGHT EXPERIMENTS ............................ 35

4.1 Designing the Experiment........................................... 35

4.2 Designing the Pressure Rake ............................................ 39

4.3 Wind Tunnel Tests ......................................................... 42

4.4 Baseline Flights in the Velocity .................................... 43

4.5 Mounting the Pressure Rake to the Aircraft .................... 46

4.6 Preflight Testing of the Pressure Rake............................. 46

4.7 Velocity Flights with the Pressure Rake .......................... 48

4.7.1 Flying Qualities .................................................... 48

4.7.2 Pressure Rake Experiments ................................... 48

V COMPARISON OF FLIGHT AND COMPUTATIONAL RESULTS 51

5.1 In-Flight Measurements ........................................... 51

5.2 Flight Test Error Production ........................................ 51

5.2.1 Wind Tunnel Testing.............................................. 52

5.2.1.1 Setting up the Wind Tunnel Test........................ 53

5.2.1.2 Wind Tunnel Tests ............................................ 54

5.2.1.3 Wind Tunnel Test Results ................................ 54

5.3 Flight Test Corrections ................................................... 56

5.4 Post-Flight CFD Simulations ...................................... 57

5.5 Computational Errors ...................................................... 57

5.6 Final Comparison between In-Flight Measurements and CFD Simulations ................................................. 58

VI CONCLUSIONS AND RECOMMENDATIONS............................ 60

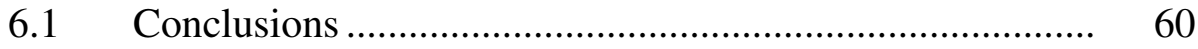

6.2 Recommendations ............................................... 62 


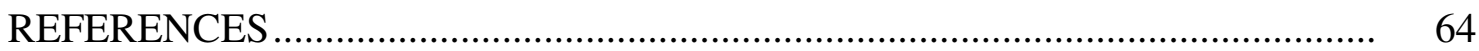

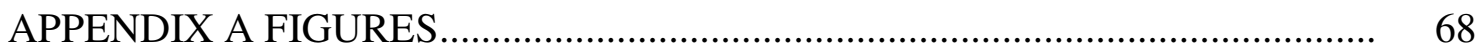

APPENDIX B EXPERIMENTAL RESOURCES ............................................ 232

APPENDIX C LIST OF WIND TUNNEL TESTS …...................................... 234

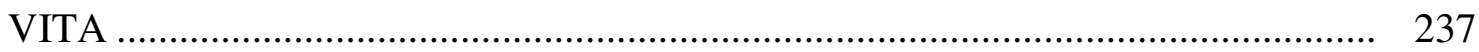




\section{LIST OF FIGURES}

FIGURE

Page

A.1 Velocity XL-5 RG, N632AM............................................................ 69

A.2 NASA Photo Number: EC96-43508-9 of the F-16XL\#1

Taken on March 4, 1996 ................................................................... $\quad 70$

A.3 CAWAPI CFD Results: Pressure-colored Streamlines and X-vorticity Component for FC50 with TENASI Solver ....................... 71

A.4 Factory Supplied Three-view of the Velocity XL-5 RG..................... 72

A.5 Velocity XL-5 RG on Aircraft Jacks during Surface Measurements...... 73

A.6 CMM Configuration during Measurements with Stand, Coordinate System Origin and Acquisition Program.......................... 74

A.7 Aircraft Split into 19 Sections for Measurements ............................... 75

A.8 CMM on Scaffolding over the Top of the Aircraft Wing ..................... 76

A.9 Using the CMM on the Scaffolding above the Aircraft ....................... 77

A.10 2-D Splines from CMM of the Top, Center Fuselage of the Velocity with the Engine Inlet ...................................................... 78

A.11 Example of Rough Surface during Initial Lofting of the Aircraft Surfaces 79

A.12 Top View Comparison of 2-D Splines vs. Section Surface Lofts.......... 80

A.13 Picture of the Main Gear of the Velocity with the Gear Well

A.14 Three-view CAD Model of the Velocity XL-5 RG ............................ 82

A.15 3-D CAD Model to Photograph Comparison........................................ 83

A.16 $C p$ Plots of a NACA 0012 Airfoil at $5^{\circ} A o A, 100 \mathrm{~m} / \mathrm{s}$ for Various Boundary-Layer Height Ratios 
A.17 $C p$ Plots of a NACA 0012 Airfoil at $5^{\circ} A o A, 100 \mathrm{~m} / \mathrm{s}$ for Various Leading Edge Grid Clusterings.

A.18 Cp Plots of a NACA 0012 Airfoil at $5^{\circ} A o A, 100 \mathrm{~m} / \mathrm{s}$

for All Grid and Boundary-Layer Meshes

A.19 Gauge Total Pressure Measurements in the Wake of the NACA 0012 Airfoil at $5^{\circ} A o A, 100 \mathrm{~m} / \mathrm{s}$

A.20 Visualization of the Mesh for the 2d0012-1 Grid Study Case ............... 88

A.21 Visualization of the Mesh for the 2d0012-2 Grid Study Case .............. 89

A.22 Visualization of the Mesh for the 2d0012-3 Grid Study Case .............. 90

A.23 Visualization of the Mesh for the 2d0012-4 Grid Study Case .............. 91

A.24 Visualization of the Mesh for the 2d0012-5 Grid Study Case ............... 92

A.25 Visualization of the Mesh for the 2d0012-6 Grid Study Case ............... 93

A.26 Visualization of the Mesh for the 2d0012-7 Grid Study Case ............... 94

A.27 Visualization of the Mesh for the 2d0012-8 Grid Study Case ............... 95

A.28 Visualization of the Mesh for the 2d0012-9 Grid Study Case .............. 96

A.29 Visualization of the Mesh for the 2d0012-10 Grid Study Case ............ 97

A.30 Visualization of the Mesh for the 2d0012-11 Grid Study Case ............. 98

A.31 Visualization of the Mesh for the 2d0012-12 Grid Study Case ............. 99

A.32 Visualization of the Mesh for the 2d0012-s1 Grid Study Case............. 100

A.33 Visualization of the Mesh for the 2d0012-s2 Grid Study Case............. 101

A.34 Visualization of the Mesh for the 2d0012-s3 Grid Study Case............. 102

A.35 Visualization of the Mesh for the 2d0012-s4 Grid Study Case.............. 103

A.36 Visualization of the Mesh for the 2d0012-s5 Grid Study Case............. 104 
FIGURE $\quad$ Page

A.37 Visualization of the Mesh for the 2d0012-s6 Grid Study Case.............. 105

A.38 Cp Plots of the Twelve Different Turbulence Models and

Model Options on a NACA 0012 Airfoil at $10^{\circ} A o A, 100 \mathrm{~m} / \mathrm{s}$............. 106

A.39 $C p$ Plots of the Five Best Turbulence Models on a

NACA 0012 Airfoil at $10^{\circ}$ AoA, $100 \mathrm{~m} / \mathrm{s}$............................................ 107

A.40 Total Pressure Measurements with Different Turbulence Models

of the Wake of a NACA 0012 Airfoil at $10^{\circ} \mathrm{AoA}, 100 \mathrm{~m} / \mathrm{s}$................ 108

A.41 Cross-Section View of the Canard on the Velocity ........................... 109

A.42 Cross-Section View of the Proposed Simplified Canard

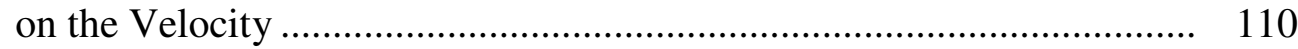

A.43 Hybrid Mesh around the Wing of the Velocity................................ 111

A.44 Control Volume of the Isolated Wing of the Velocity with the

Reference Line for the Static Pressure Plot......................................... 112

A.45 Static Pressure of the Isolated Wing of the Velocity at Four

Different $A o A$ s at $100 \mathrm{~m} / \mathrm{s}$

A.46 Mesh between the Canard and Wing Used for the 2-D Study of the

Interaction of the Canard Wake on the Wing of the Velocity

A.47 Gauge Total Pressure Plot of the Velocity Canard and Wing

Using the Spalart-Allmaras Turbulence Model at $-5^{\circ}$ AoA, $100 \mathrm{~m} / \mathrm{s}$......

A.48 Gauge Total Pressure Plot of the Velocity Canard and Wing

Using the Spalart-Allmaras Turbulence Model at $0^{\circ} A o A, 100 \mathrm{~m} / \mathrm{s} \ldots \ldots . .$.

A.49 Gauge Total Pressure Plot of the Velocity Canard and Wing

Using the Spalart-Allmaras Turbulence Model at $5^{\circ} A o A, 100 \mathrm{~m} / \mathrm{s}$.

A.50 Gauge Total Pressure Plot of the Velocity Canard and Wing Using the Spalart-Allmaras Turbulence Model at $10^{\circ}$ AoA, $100 \mathrm{~m} / \mathrm{s} . . . .$.

A.51 Gauge Total Pressure of the Canard Wake at $508 \mathrm{~mm}$ in Front of the Leading Edge of the Wing of the Velocity over a Range of $A o A \mathrm{~s}$ 
A.52 Gauge Static Pressure along the Reference Line Running the Length of the Control Volume over Range of AoAs

A.53 Gauge Total Pressure Plot of the Velocity Canard and Wing Using the Spalart-Allmaras Turbulence Model at $-5^{\circ} A o A, 100 \mathrm{~m} / \mathrm{s}$......

A.54 Gauge Total Pressure Plot of the Velocity Canard and Wing

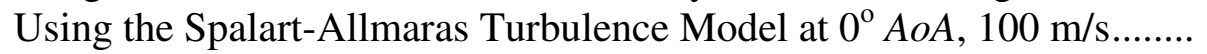

A.55 Gauge Total Pressure Plot of the Velocity Canard and Wing Using the Spalart-Allmaras Turbulence Model at $5^{\circ} A o A, 100 \mathrm{~m} / \mathrm{s}$.

A.56 Gauge Total Pressure Plot of the Velocity Canard and Wing Using the Spalart-Allmaras Turbulence Model at $10^{\circ}$ AoA, $100 \mathrm{~m} / \mathrm{s} \ldots \ldots$.

A.57 Comparison of Real and Simplified Canard Total Pressure Wakes at $100 \mathrm{~m} / \mathrm{s}$ for the Four Different AoAs

A.58 Comparison of the Real and Simplified Canard Static Pressure at $100 \mathrm{~m} / \mathrm{s}$ for the Four Different $A o A s$

A.59 View of the 3-D Model of the Velocity Used for the Initial Simulations and Control Volume Sizing Study

A.60 Body Forces Versus Control Volume Length ................................. 128

A.61 Body Forces Versus Control Volume Height .................................. 129

A.62 Body Forces Versus Control Volume Width ...................................... 130

A.63 Body Forces Versus Distance from the Rear of the Aircraft to the Control Volume Exit

A.64 Body Forces Versus Distance from the Front of the Aircraft to the Control Volume Inlet

A.65 Pathlines around the Canard of the Velocity at $0^{\circ} A o A, 100 \mathrm{~m} / \mathrm{s}$.

A.66 Pathlines Clustered around the Canard Tip Vortex to Visualize the Size and Range of Influence of the Tip Vortex at $0^{\circ} A o A, 100 \mathrm{~m} / \mathrm{s}$ 
A.67 Pathlines Exploring the Spanwise Range of Influence of the Tip Vortex at $0^{\circ} A o A, 100 \mathrm{~m} / \mathrm{s}$......

A.68 Control Volume and Sub-Volumes Used to Create a Structured Mesh around the Canard and Boundary-Layer of the Wing

A.69 Structured Mesh around the Canard and Boundary-Layer of the Wing with a Tetrahedral Mesh in the Remainder of the Control Volume.

A.70 Control Volume and Sub-Volumes Used to Create an Unstructured Mesh that Includes the Pressure Rake and Maintains Grid Refinement around the Canard....

A.71 Unstructured Mesh around the Velocity with the Pressure Rake.

A.72 Available Attachment Points at the Crank Location on the Upper and Lower Surface of the Wing of the Velocity

A.73 Predicted Locations of the Wake at $\pm 5^{\circ} A o A$ 141

A.74 12-inch and 24-inch 5-hole Probes Produced by Aeroprobe ..... 142

A.75 Standard and Cross-Section Views of Stepped and Straight Designed Pitot Probes

A.76 Mid-plane Total Pressure Plot Comparison of Isolated Pitot Probe and Multiple Pitot Probes Checking for Interference between Probes.

A.77 3-View and Cross-Section of SolidWorks Design of Pressure Rake ...... 145

A.78 SolidWorks Drawings of the Pressure Rake Mounting Location and Interior of the Rake

A.79 CFD Plots of the 2-D Simulations of the Pressure Rake Cross-Section . 147

A.80 CFD Plots of the 3-D Simulations of the Pressure Rake with the Cross-Section Replaced by the NACA 0012 .....

A.81 Loads Applied to the Pressure Rake in COSMOSWorks for Stress Analysis 
A.82 Maximum Von Mises Stress Concentration from COSMOSWorks for 1.5 Times a Collision Avoidance Maneuver Loading

A.83 Factor of Safety Distribution from COSMOSWorks for 1.5 Times a Collision Avoidance Maneuver Loading

A.84 Maximum Predicted Deflection from COSMOSWorks for 1.5 Times a Collision Avoidance Maneuver Loading.

A.85 24-inch 5-hole Probe Mounted in the 3' $x$ 4' ELD Wind Tunnel

A.86 12-inch 5-hole Probe Mounted in the 3'x4' ELD Wind Tunnel Isolated and with the Pitot Probes on Either Side at the Spacing Used in the Pressure Rake.

A.87 Angle of Attack Sweep Plots for 12 and 24-inch 5-hole Probes 155

A.88 Wind Tunnel Comparison of 12-inch 5-hole Probe to Pitot Probes....... 156

A.89 Computational Results in Support of Wind Tunnel Experiments 157

A.90 24-inch 5-hole Probe Extending out the Nose of the Velocity 158

A.91 Aircraft Angle of Attack vs. Airspeed with Zero Elevator Deflection during Baseline Measurements

A.92 Rudder Doublet of the Velocity in Clean Configuration at $100 \mathrm{KIAS}(51 \mathrm{~m} / \mathrm{s})$ and 8,500 feet

A.93 Rudder Doublet of the Velocity in Clean Configuration at $140 \mathrm{KIAS}(72 \mathrm{~m} / \mathrm{s})$ and 8,500 feet

A.94 Pitch Doublet of the Velocity in Clean Configuration at $100 \mathrm{KIAS}(51 \mathrm{~m} / \mathrm{s})$ and 8,500 feet 162

A.95 Pitch Doublet of the Velocity in Clean Configuration at $140 \mathrm{KIAS}(72 \mathrm{~m} / \mathrm{s})$ and 8,500 feet

A.96 Clean Flying Qualities in the Velocity - Gear Down, Power Off Stall at 8,000 feet. 
A.97 Clean Flying Qualities in the Velocity - Gear Up, Power Off Stall at 8,000 feet.

A.98 Stages of Construction on the Wing Glove and Attachment to the Pressure Rake

A.99 Static Load Testing of the Pressure Rake and Struts with $86 \mathrm{~kg}(190 \mathrm{lbs})$

A.100 Side Load of $86 \mathrm{~kg}$ Applied to the Pressure Rake While Mounted to the Aircraft 168

A.101 Monitoring for Deflections or Yielding in the Pressure

Rake during Static Load Test.....

A.102 Hanging $20 \mathrm{~kg}$ (45 lbs) From the Pressure Rake to Simulate a 2-G Pull-up 170

A.103 Wing Glove and Pressure Rake Completed and Ready for Flight 171 A.104 Engine Run-up Test with the Pressure Rake. 172

A.105 Flight $101007-1$ at $3^{\circ} A o A, 143$ KIAS at 8,500 feet. 173

A.106 Flight $101007-1$ at $4^{\circ} A o A, 128 \mathrm{KIAS}$ at 8,500 feet. 174

A.107 Flight $101007-1$ at $5^{\circ} A o A, 120 \mathrm{KIAS}$ at 8,500 feet. 175

A.108 Flight $101007-1$ at $6^{\circ} \mathrm{AoA}, 112 \mathrm{KIAS}$ at 8,500 feet........................... 176

A.109 Flight $101007-1$ at $7^{\circ} \mathrm{AoA}, 105$ KIAS at 8,500 feet........................... 177

A.110 Rudder Doublet of the Velocity with the Pressure Rake at $100 \mathrm{KIAS}(51 \mathrm{~m} / \mathrm{s})$ and 8,500 feet

A.111 Rudder Doublet of the Velocity with the Pressure Rake at $140 \mathrm{KIAS}(72 \mathrm{~m} / \mathrm{s})$ and 8,500 feet

A.112 Flight $101007-2$ at $3^{\circ} \mathrm{AoA}, 147 \mathrm{KIAS}(76 \mathrm{~m} / \mathrm{s})$ at 8,500 feet 180

A.113 Flight $101007-2$ at $4^{\circ} A o A, 130 \mathrm{KIAS}(67 \mathrm{~m} / \mathrm{s})$ at 8,500 feet 
A.114 Flight $101007-2$ at $5^{\circ} A o A, 120 \mathrm{KIAS}(62 \mathrm{~m} / \mathrm{s})$ at 8,500 feet 182

A.115 Flight $101007-2$ at $6^{\circ} A o A, 106 \operatorname{KIAS}(54 \mathrm{~m} / \mathrm{s})$ at 8,500 feet 183

A.116 Flight $101007-2$ at $7^{\circ} A o A, 105 \operatorname{KIAS}(54 \mathrm{~m} / \mathrm{s})$ at 8,500 feet 184

A.117 Flight 101007-2 High-Speed Pass of 170 KIAS $(87 \mathrm{~m} / \mathrm{s})$ at 8,500 feet.. 185

A.118 Flight 101007-2 High-Speed Pass of $170 \mathrm{KIAS}(87 \mathrm{~m} / \mathrm{s})$ at 6,500 feet.. 186

A.119 Flight $101107-1$ at $3^{\circ} A o A, 138 \operatorname{KIAS}(71 \mathrm{~m} / \mathrm{s})$ at 8,500 feet 187

A.120 Flight $101107-1$ at $4^{\circ} A o A, 128 \mathrm{KIAS}(66 \mathrm{~m} / \mathrm{s})$ at 8,500 feet 188

A.121 Flight $101107-1$ at $5^{\circ} \mathrm{AoA}, 123 \mathrm{KIAS}(63 \mathrm{~m} / \mathrm{s})$ at $8,500 \mathrm{feet}$ 189

A.122 Flight $101107-1$ at $6^{\circ} A o A, 110 \mathrm{KIAS}(57 \mathrm{~m} / \mathrm{s})$ at $8,500 \mathrm{feet}$ 190

A.123 Flight $101107-1$ at $7^{\circ} A o A, 105 \operatorname{KIAS}(54 \mathrm{~m} / \mathrm{s})$ at 8,500 feet 191

A.124 Flight 101107-1 High-Speed Pass of 170 KIAS $(87 \mathrm{~m} / \mathrm{s})$ at 8,500 feet.. 192

A.125 Flight 101107-1 High-Speed Pass of $170 \mathrm{KIAS}(87 \mathrm{~m} / \mathrm{s})$ at 6,500 feet.. 193

A.126 Pressure Rake Mounted in the Oran W. Nicks Lowspeed Wind Tunnel at $0^{\circ} A o A$ and $0^{\circ} A o S$. 194

A.127 Error during Calibration Check at $-34 \mathrm{kPa}$ (-5 PSI) Prior to Wind Tunnel Tests 195

A.128 Error during Calibration Check at $-17 \mathrm{kPa}$ (-2.5 PSI) Prior to Wind Tunnel Tests 196

A.129 Error during Calibration Check at $0 \mathrm{kPa}$ (0 PSI) Prior to Wind Tunnel Tests 197

A.130 Error during Calibration Check at $17 \mathrm{kPa}$ (2.5 PSI) Prior to Wind Tunnel Tests 198

A.131 Error during Calibration Check at $34 \mathrm{kPa}$ (5 PSI) Prior to Wind Tunnel Tests 
A.132 Error during Calibration Check at $0 \mathrm{kPa}(0 \mathrm{PSI})$ of Pressure Ports Used in the Flight Experiment Prior to Wind Tunnel Tests.

A.133 Mounting Pressure Rake to the Sting with Pressure Lines and Data Cables Secured in the Wind Tunnel

A.134 Average Standard Deviation of All Probes in the Pressure Rake 202

A.135 Results of Simulations Aimed at Testing the Average Offset of Port \#21, Used as the 5-hole Total Pressure during Flight Tests

A.136 Plots of the Comparison between Tunnel Velocity and the 5-hole Velocity during Wind Tunnel Tests.....

A.137 Pressure Rake and Freestream $A o A$ and $A o S$ Time Traces for Test Point \#1 205

A.138 Pressure Rake and Freestream Airspeed in Knots for Test Point \#1 ..... 206 A.139 Averaged Total Pressures from the Pressure Rake at Test Point \#1 ...... 207

A.140 Pressure Rake and Freestream $A o A$ and $A o S$ Time Traces for Test Point \#2.

A.141 Pressure Rake and Freestream Airspeed in Knots for Test Point \#2 ..... 209

A.142 Averaged Total Pressures from the Pressure Rake at Test Point \#2 _..... 210

A.143 Pressure Rake and Freestream $A o A$ and $A o S$ Time Traces for Test Point \#3

A.144 Pressure Rake and Freestream Airspeed in Knots for Test Point \#3 ..... 212

A.145 Averaged Total Pressures from the Pressure Rake at Test Point \#3 ...... 213

A.146 Pressure Rake and Freestream $A o A$ and $A o S$ Time Traces for Test Point \#4

A.147 Pressure Rake and Freestream Airspeed in Knots for Test Point \#4 215

A.148 Averaged Total Pressures from the Pressure Rake at Test Point \#4 ....... 
A.149 Pressure Rake and Freestream $A o A$ and $A o S$ Time Traces for Test Point \#5

A.150 Pressure Rake and Freestream Airspeed in Knots for Test Point \#5 ..... 218

A.151 Averaged Total Pressures from the Pressure Rake at Test Point \#5 ...... 219

A.152 Averaged Total Pressures from the Pressure Rake with Red Lines Signifying the Experimental Error Margins for Test Point \#1

A.153 Averaged Total Pressures from the Pressure Rake with Red Lines Signifying the Experimental Error Margins for Test Point \#2.

A.154 Averaged Total Pressures from the Pressure Rake with Red Lines Signifying the Experimental Error Margins for Test Point \#3....

A.155 Averaged Total Pressures from the Pressure Rake with Red Lines Signifying the Experimental Error Margins for Test Point \#4.

A.156 Pressure Averaged Total Pressures from the Pressure Rake with Red Lines Signifying the Experimental Error Margins for Test Point \#5

A.157 Computational Differences due to Turbulence Model and Pressure-Velocity Coupling Scheme

A.158 Comparison Differences due to Error in AoA Readings by the 5-hole Probe

A.159 Comparison between Experiment and CFD for Test Point \#1 Including Computed Errors

A.160 Comparison between Experiment and CFD for Test Point \#2 Including Computed Errors

A.161 Comparison between Experiment and CFD for Test Point \#3 Including Computed Errors.

A.162 Comparison between Experiment and CFD for Test Point \#4 Including Computed Errors

A.163 Comparison between Experiment and CFD for Test Point \#5 Including Computed Errors... 


\section{LIST OF TABLES}

TABLE Page

1.1 Comparison of FRL Aircraft ........................................................... 5

2.1 Options for Mapping the Surface of the Velocity ................................ 10

2.2 Comparison of Velocity XL-5 RG Dimensions .................................... 14

3.1 Description of Boundary-Layer and Grid Meshing Around the NACA 0012 Airfoil............................................................. 20

3.2 Description of Cases for Varying the Starting Height

Ratio of the Boundary-Layer.

3.3 Description of Cases for Varying the Leading Edge

Clustering and Cell Count of the Boundary-Layer

3.4 Listing of Different Turbulence Models Tested in the Turbulence Study . 24

3.5 Control Volume Sizing Study: Volume Sizes and Resultant Forces ........ 30

3.6 Final Control Volume Dimensions .................................................. 31

4.1 Comparison of Pressure Rake Designs ................................................. $\quad 38$

4.2 Summary of Pressure Rake Forces from Computations ........................ 40

4.3 Test Parameters during Velocity Baseline Flights ................................ 44

4.4 Test Parameters during Velocity Pressure Rake Flights ........................ 50

5.1 Pressure Ports Used during Flight-Test Experiments ............................ 55

5.2 Test Points Used for Comparison to CFD ......................................... 56

5.3 Experimental and Computational Errors and Magnitudes ....................... 59

B.1 List of Wind Tunnels Operated by Texas A\&M University Aerospace Engineering 
TABLE Page

C.1 Summary of Tests Completed at the Oran W. Nicks Lowspeed Wind Tunnel ................................................................... 235 


\section{NOMENCLATURE}

$\begin{array}{ll}\text { AoA } & \text { Angle of Attack } \\ \text { AoS } & \text { Angle of Sideslip } \\ \text { CAD } & \text { Computer Aided Design } \\ C G & \text { Center of Gravity } \\ C p & \text { Coefficient of Pressure } \\ \varepsilon & \text { Turbulent Dissipation } \\ k & \text { Turbulence Kinetic Energy } \\ \text { MIT } & \text { Massachusetts Institute of Technology } \\ \text { OD } & \text { Outer Diameter } \\ \text { RAE } & \text { Royal Aircraft Establishment } \\ \text { RPM } & \text { Rotations per Minute } \\ \text { x/c } & \text { x-coordinate / chord } \\ \omega & \text { Specific Dissipation Rate }\end{array}$




\section{CHAPTER I}

\section{INTRODUCTION}

\subsection{Aerodynamic Research}

Aerodynamic research was, for considerable time, a combination of theory and experiment. Once large-scale computational fluid dynamics became available, some argued that it would become the primary focus of aerodynamics. John Anderson ${ }^{1}$ stated that he believed all three parts are necessary to work together for future progress in aerodynamics:

"However, to keep things in perspective, computational fluid dynamics provides a new third approach - but nothing more than that. It nicely and synergistically complements the other two approaches of pure theory and pure experiment, but it will never replace either of these approaches (as sometimes suggested). There will always be a need for theory and experiment. The future advancement of fluid dynamics will rest upon the proper balance of all three approaches, ..."1 (Courtesy of McGraw-Hill)

\subsection{Experimental Aerodynamic Research}

Experimental aerodynamic research has split primarily into two parts: wind-tunnel testing and flight testing. There are hundreds of different wind tunnels that have been used for aerodynamic research, each specific to certain flight regimes or flight conditions. Wind tunnels provide controlled test conditions so that the data are easier to understand compared to flight data, which have many more variables to be taken into

This thesis follows the style of the AIAA Journal. 
account during analysis. Flight tests are incredibly valuable but carry higher risk and cost to attain the data. The benefits of flight testing include being able to test at the actual conditions instead of simulated test conditions and that all parameters of the experiment could be applicable to a particular flight regime. Wind tunnels typically cannot match every parameter of the flow conditions that would be encountered in flight and as such, to get the "full test", flight testing must be performed. Ever since the Wright Brothers, successful flight research or design of new aircraft has consisted of using both techniques, wind tunnel and flight testing, to gain a full understanding of the problems at hand. Aerodynamic research through flight test has been conducted since the first flight of aircraft. Many of the first pilots also built and designed their own aircraft and as such, each flight served as a test for improvement. Over time, flight testing evolved and became more of a science than a "seat-of-your-pants" operation. As it evolved, so did the aerodynamic research that was conducted. Braslow and Muraca wrote A Perspective of Laminar-Flow Control ${ }^{2}$ summarizing the progress of flight test investigations in laminar flow control aerodynamics from the 1940's to the 1960's. One of the first major flight test programs to study laminar flow control was conducted by the National Advisory Committee for Aeronautics (NACA) in 1941. They used a B-18 bomber to test the effectiveness of suction slots along the wing of the aircraft. The 1950's saw research conducted on the Vampire by the RAE testing porous surfaces of the wing for flow control. The 1960's witnessed the complex flight test program of the X-21, sponsored by the US Air Force and the Northrop Corporation, to perform more research into laminar flow control. The X-21 project was one of the first major aerodynamic research projects that used flight data for comparison and validation of both wind tunnel and analytical studies. This was the first major study in which analytical studies were for comparison along with wind tunnel results and theoretical predictions.

The military and private companies were not the only organizations getting involved with aerodynamic flight testing. NASA Dryden has flown projects on a variety of aircraft over the decades, including the F-104, F-111, F-14, F-15, and the F-16. One of the most easily recognizable was the F-16XL flight test program; also known as 
Cranked-Arrow Wing Aerodynamics Project (CAWAP) ${ }^{3}$ and its follow-on project of Cranked Arrow Wing Aerodynamics Project International (CAWAPI) ${ }^{4}$, involved several hundred engineers to perform a large project that combined wind tunnel testing, flight testing and Computational Fluid Dynamics (CFD). The CAWAP project was conducted in 1995 and 1996 using a General Dynamics F-16 outfitted with newly designed wings that were heavily instrumented. After all of the flights with the F-16XLs were concluded, a follow-on project called the CAWAPI was initiated that allowed groups from around the world to conduct CFD investigations of the flight and compare the accuracy of their results with the tests. There have been at least 13 papers published on the CFD comparisons of the project alone in the 11 years following the completion of the actual experiment. This is a project that took hundreds of engineers to do all of the design, predictions, test flights and computational simulations.

Flight testing has always been considered an integral part of any program due to its ability to be the final test for every new aircraft or technology before production begins. This means that the responsibility of proving the safety, effectiveness and/or robustness of the system is dependent on flight testing at the actual flight conditions. While the projects listed here are by no means a complete list of the different aerodynamic flight tests that have been completed in the past, it should give an adequate representation of the variety and intensity of projects that have been performed. All of the projects described above have focused on flight tests dealing with laminar flow control research which can be considered a subset of aerodynamic flight tests.

\subsection{Texas A\&M University Flight Research Laboratory}

The Flight Research Laboratory (FRL) at Texas A\&M University is located at Easterwood Airport, College Station, TX and is a part of the Aerospace Engineering Department. The specialty of the FRL is boundary-layer stability and laminar flow control. The FRL was developed to take the next step in boundary-layer research. This type of research requires a low turbulence environment to isolate stability and transition phenomenon. There are very few wind tunnels in the world with turbulence levels that 
are low enough to conduct this type of research; the Klebanoff-Saric Unsteady Wind Tunnel (KS-UWT) is one such tunnel. Unfortunately wind tunnels are limited to certain test conditions, and the KS-UWT is no different. Boundary-layer transition is sensitive to many variables, including surface roughness, freestream turbulence levels and the Reynolds number. As research progressed at the KS-UWT, it became necessary to test at Reynolds numbers higher than the tunnel could achieve. Thus to take the next step forward in the research, the FRL was formed. The laboratory performs experimental boundary-layer research at higher Reynolds numbers in the low disturbance environment of flight. The FRL first acquired a Cessna O-2 Skymaster and then a Stemme S-10 motorglider. While each of these aircraft was unique and had their own advantages, both were limited by combinations of speed, propeller flow disruptions, and/or useful load constraints. The Velocity was able to reach higher speeds and did not have a propeller in the front of the aircraft to disrupt the airflow. These were definite advantages that made the Velocity an attractive addition to the FRL inventory.

\subsubsection{N632AM Velocity XL-5 RG}

The TAMU FRL acquired a Velocity XL-5 RG (Figure A.1) kit-built aircraft in the summer of 2006. This aircraft is a single engine, composite, canard aircraft. The Velocity can seat 4 passengers, has a useful load of 1100 pounds and has a maximum speed of 200 knots with its Continental IO 550 engine capable of 310 horsepower. Table 1.1 contains a comparison of the three aircraft operated by the FRL. 
Table 1.1

Comparison of FRL Aircraft

\begin{tabular}{|l|l|l|l|}
\hline Aircraft & \multicolumn{1}{|c|}{$\begin{array}{c}\text { 1995 Stemme } \\
\text { S10-V }\end{array}$} & Velocity XL-5 RG \\
\hline Tail Number & N630AM & N631 AM & N632AM \\
\hline Engine & 2 2) $210 \mathrm{HP}$ & $85 \mathrm{HP}$ & $310 \mathrm{HP}$ \\
\hline Gross weight & $4300 \mathrm{lb}$ & $1874 \mathrm{lbs}$ & $2900 \mathrm{lbs}$ \\
\hline Useful Load & $1700 \mathrm{lb}$ & $412 \mathrm{lbs}$ & $1100 \mathrm{lbs}$ \\
\hline Wing Span & $38 \mathrm{feet}$ & $75 \mathrm{feet}$ & $31 \mathrm{feet}$ \\
\hline Cruise Speed & $140 \mathrm{KIAS}$ & $140 \mathrm{KIAS}$ & $180 \mathrm{KIAS}$ \\
\hline Electrical Power & $1200 \mathrm{Watts}$ & Battery only & 1000 Watts \\
\hline Seating & Four & Two & Four \\
\hline Seating and Instrumentation & Four & One - two & Two - three \\
\hline Mounting & Four wing pylons & None at present & $\begin{array}{l}\text { Two wing, one } \\
\text { fuselage on roof }\end{array}$ \\
\hline Engine Mounting & Inline tractor-pusher & Retractable prop & Single pusher \\
\hline Maximum Ceiling & 18,000 feet & 30,000 feet & 20,000 feet \\
\hline
\end{tabular}

The Velocity was the newest aircraft of the three and as such, the least was known about its performance and capabilities. Since this was an experimental, kit-built aircraft, little to no information regarding its design, performance limitations and safety procedures were provided by the manufacturer or other home-builders. In contrast, the Cessna O-2 came with maintenance books, dimensioned drawings, and performance details from its military use and required FAA certifications. To be able to plan for future research projects with the Velocity, it was essential to know the baseline characteristics and flowfield around test articles. Possible mounting locations built into the aircraft for future projects included hard points in the wings and roof of the fuselage. The wing is likely the preferred mounting location for any test piece due to decreased risk to the aircraft engine and propeller. Any test article mounted on the roof of the aircraft would be in-line with the propeller and run the risk of blocking, or reducing, the airflow into the engine air inlets. The wing mounting location is not without its own disadvantage; that is the canard ahead of the main wing that could disrupt the incoming flow for research requiring test pieces mounted to the hard point in the wing or a wing glove. Therefore, it was necessary to understand the influence from the canard and the 
impact of its wake on the wing of the aircraft before aerodynamic research could be completed on the aircraft.

\subsection{Available Resources}

As mentioned before, there are a variety of tools that can be used to work on a problem such as understanding the wake on the canard. This includes wind-tunnel testing, flight testing, and CFD simulations. The Aerospace Engineering Department at Texas A\&M University has continued to expand its capabilities over the years to include an assortment of tools to solve a multitude of engineering problems. For this research, the aerodynamic tools and experience that have been acquired over the years were put to use. These resources included aircraft with instrumentation for aerodynamic research, a wide variety of wind tunnels, CFD, and the expertise of department faculty and staff. Several different wind tunnels that can test a wide range of flight conditions are located across campus. A table listing all of the different wind tunnels that the Aerospace Engineering Department operates is located in Appendix B. In support of this research, wind tunnel tests were performed in the 3'x4' Engineering Laboratory Design Wind Tunnel and in the 7'x10' Oran W. Nicks Lowspeed Wind Tunnel. As mentioned previously, the FRL at Texas A\&M has three aircraft with which to conduct research. In addition to the aircraft, the FRL also has a wide range of instruments that can be used for various projects. A listing of the instrumentation available is located in Appendix B.

The time, personnel, and funding limitations were obviously not going to allow for a project as in-depth and detailed as the CAWAP (Figures A.2 - A.3), but the ability to get useful, accurate flowfield predictions about areas of interest were still considered attainable.

This was especially important for the FRL which needed flow-field data of the aircraft before any significant research could be conducted. The CFD resources available at Texas A\&M included access to three supercomputer clusters operated by the Texas A\&M Supercomputing Center. In addition to the computers, there were licenses available for Fluent which is a commercially-available, finite-volume, CFD solver. 
Access to Gambit, the preprocessor for Fluent, is also available to all students with accounts registered at the Supercomputing Center. While there are several different software programs for CFD simulations, Fluent is a very popular commercial code that has found application in a wide variety of fluid flows.

CFD has progressed at an amazing rate; this is due to the increased capabilities of the modern computer. John Anderson summed up the progress of CFD in relation to performing 3-D simulations on an entire aircraft in his textbook Computational Fluid Dynamics, The Basics with Applications ${ }^{1}$ as:

"In today's CFD, 3-D flowfield solutions are abundant; they may not be routine in the sense that a great deal of human and computer resources are still frequently needed to successfully carry out such 3-D solutions for applications like the flow over a complete airplane configuration, but such solutions are becoming more and more prevalent within industry and government facilities." ${ }^{\prime 1}$ (Courtesy of McGraw-Hill)

To achieve a 3-D CFD solution, it must be shown in this project that computers and CFD advances have progressed to the point that an individual can perform the CFD of an entire aircraft within a reasonable time frame for the project.

\subsection{Objectives}

The objective of the research presented in this thesis was to gain an understanding of the flowfield around the Velocity XL-5 RG through a combination CFD and in-flight measurements on the aircraft. The CFD simulations were performed for the entire aircraft and validated by in-flight measurements that were taken in one area of the flow at multiple flight conditions. A secondary objective of the experiment was to build a database of information on the flow conditions at the hard point on the wing of the aircraft. 
To achieve these objectives, the first step was to obtain an accurate 3-D model of the aircraft for performing the CFD simulations and designing the experiment. After acquiring a model of the aircraft, preliminary simulations were conducted. These initial simulations help design the experiment that would be conducted to supplement and verify the full-scale computations. Once the in-flight measurements of the pressure rake were completed, the CFD simulations were rerun with the actual test conditions used as the boundary conditions for the simulations. After the simulations, final comparisons between the flight results and CFD simulations were made to determine the validity of the results. 


\section{CHAPTER II}

\section{3-D CAD MODEL}

\subsection{Developing the 3-D CAD Model of the Aircraft}

To create an accurate CFD model of the aircraft, it was necessary to have an accurate 3-D CAD model of the aircraft. An accurate model would have the correct dimensions and more importantly, the correct airfoil coordinates. The starting point then became to obtain a 3-D exterior CAD model of the aircraft.

Multiple resources were consulted to see whether a detailed model of the Velocity was available. The Velocity Inc. website ${ }^{5}$, the Owner's Manual ${ }^{6}$, and the Builder's Manual $^{7}$ only provided very basic dimensions such as length and width of the aircraft (Figure A.4). These dimensions only give a starting point in understanding and measuring the complex geometry of the aircraft. Velocity Inc. employees were directly contacted to discuss what drawings and dimensions they created for the aircraft. Unfortunately, Velocity Inc. only had 2-D drawings of the aircraft and to their knowledge no 3-D model had been created. An online search to see if any other aircraft builder had undertaken the task of making and sharing a 3-D model of the turned up the same 2-D measurements already provided by Velocity, Inc.

Since no detailed 2-D or 3-D drawings of the Velocity were available, the only option left was to create the entire model of the aircraft from scratch. A few options were discussed as to how to create a model. Options for creating the model included:

- Making a laser scan of the aircraft to precisely map its surface

- Splitting the aircraft up into a grid and do point to point measurements by hand with a ruler, tape measure, and calipers

- Use a Coordinate Measurement Machine (CMM) 
The laser scan solution required hiring a company with the equipment and experience to come in and perform the work. This process would cost a couple thousand dollars, but was very accurate. Splitting the aircraft into a grid system was the cheapest solution, costing close to nothing, but required lots of booking keeping and assumptions in the high curvatures regions. It would be the least accurate model of the three options. Using a CMM had a very low cost because the Oran W. Nicks Wind Tunnel at Texas A\&M University had acquired a Cimcore/Romer CMM. While being inexpensive, it was also more accurate than measuring by hand, but was less accurate than a laser scan. Another disadvantage of the Cimcore CMM is that its measuring arm only has a range of 1.2 meters; therefore to use it, the surface of the aircraft would have to be measured in sections and then spliced together in SolidWorks ${ }^{8}$ afterwards. The measuring in sections and then splicing together afterwards created the opportunity for increased error. Careful attention to detail was required to minimize this possibility. Based on the comparison in Table 2.1, the Cimcore CMM was chosen as the best option for this project.

Table 2.1

Options for Mapping the Surface of the Velocity

\begin{tabular}{|l|l|c|}
\hline Method & Accuracy & Cost \\
\hline $\begin{array}{l}\text { Laser scan of the entire aircraft } \\
\text { by Direct Dimensions Inc. }\end{array}$ & $0.13 \mathrm{~mm}$ over entire span & $\$ 10,000$ \\
\hline $\begin{array}{l}\text { Point to point measurements by } \\
\text { hand }\end{array}$ & $\sim 2.5 \mathrm{~mm}$, unknown in regions of curvature & $\$ 0$ \\
\hline $\begin{array}{l}\text { Coordinate measurement } \\
\text { machine }\end{array}$ & $\begin{array}{c}\$ .3 \mathrm{~mm} \text { over entire span of single spline } \\
\text { borrowed }\end{array}$ \\
\cline { 2 - 3 } & $\begin{array}{l}\sim 9.5 \mathrm{~mm} \text { with splicing multiple features } \\
\text { together }\end{array}$ & $\begin{array}{l}\$ 65,000, \text { if } \\
\text { purchased }\end{array}$ \\
\hline
\end{tabular}

\subsection{Measurements with the Coordinate Measurement Machine}

After the CMM was acquired, the first week was spent becoming familiar with its operation, and setting up the aircraft onto a level and stable mounting configuration. It was important that the aircraft not move during the measurements so it was placed on jacks to keep it off of the wheels (Figure A.5). This also allowed the aircraft to be 
leveled, which helped ensure that the Velocity was parallel with the reference plane for the CMM. Figure A.6 shows the CMM mounting configuration.

To reduce the time to measure the aircraft, it was decided to only map the starboard half of the aircraft. The full range of the arm on the Cimcore CMM was 1.2 meters; thus it was necessary to divide the aircraft into 19 different sections (Figure A.7). Every time the Cimcore CMM was moved to a new station, it was necessary to define a new coordinate system. To assist in making the mating of the sections easier, a coordinate system was defined on the table to which the Cimcore was mounted. To keep the orientation between the different sections correct for splicing, different factors had to be taken into account when moving between each section. This included the position and orientation of the origin at each section along with the reference points between each section. The position and orientation was managed by ensuring the table was always level and by making sure that the end of the table was perpendicular to the centerline of the aircraft. With the origin and axis defined on the table parallel and oriented correctly, a reference was needed to attach the sections to each other. This was achieved by physically marking the last plane measured on the aircraft which allowed for the splines from each section to be mated together to finalize the mating. The table was the mount and reference point for every section except for the center of the inboard wing and the center of the fuselage. These locations were too far away from the edge of the aircraft to allow the CMM to reach the entire section from the table. To solve this problem, scaffolding was constructed to extend over the wing of the aircraft (Figure A.8). The operator and equipment could then take the measurements of the upper surface of the wing and center fuselage sections without resting on the surface of the aircraft (Figure A.9). Figure A.9 also shows how the measurements were made by the operator. To properly align these sections, reference lines on three sides were used to mate up the splines. Mating the lines on three sides removed the possibility of having any orientation errors.

The software that incorporated the Cimcore CMM into SolidWorks was called Revworks ${ }^{10}$. It tracked the points being measured by making planes off of the axis that 
was defined at the start of each section. Revworks allowed the user to define planes at any distance and spacing in the $x, y$ and $z$ directions of the axis. It recorded exactly onto those planes; therefore it was imperative to make sure that a particular measurement point was correctly aligned with the desired plane. Fortunately Revworks provided feedback, allowing the user to see where the tip of the Cimcore arm was in relation to that plane before the measurement was taken. After all the points on one plane were taken, Revworks created a 2-D spline of those points.

Once the entire section was measured, multiple splines created the "surface" of that section. Figure A.10 shows the upper surface of the center of the fuselage with the NACA inlet for the engine air intake. This is an example of what a section looked like after it was measured and its points were turned into 2-D splines, but not yet lofted. Once each section was finished, the table was moved to a new section and realigned. As mentioned previously, the reference between each section was chosen to be the last spline on each end of that section. To mate up the different sections, the splines on the edge of each section were matched and then mated. Physically on the aircraft, the last spline of each section was traced with pencil to make sure the same location was measured on the aircraft for both sections.

It took approximately $2 \frac{1 / 2}{2}$ weeks to complete the measurements of the aircraft with the Cimcore CMM. It was noted during the measurements that the either the Cimcore CMM or the Revworks software was very sensitive to not being aligned to the surface correctly. This would create small deviations in the spline, giving it a slightly wrinkled appearance. Problems and irregularities such as this were fixed in SolidWorks once the measurements were complete.

\subsection{Creating the Geometry from the Measurements}

Each spline consisted of roughly 50 to 80 points, making a large file for each section and wavy surfaces due to very small perturbations in the points (Figure A.11). Figure A.11 shows the wing to fuselage junction and the waviness of lofting the splines without cleaning them up. To clean up the surfaces and reduce the file sizes, the "Simplify 
Spline" tool in SolidWorks was used. This feature dropped the number of points used by the spline by approximately a factor of four. It did this by removing the points that do not fit into a smooth curve. The overall shape was still kept, but the surface waviness removed (Figure A.12). Comparisons between the simplified spline and the full spline were made to verify that the smoothing did not affect the actual geometry of the part.

The wing required significant work before the final surface lofting. This was due to limitations in the range of the Cimcore CMM arm. The leading and trailing edge sections of the wing had to be measured separately and mated afterwards. To get a smooth loft on the wing, it was important for each airfoil to be one spline, not a combination of two to three splines. The splines were laid out together in SolidWorks and then one single spline was traced over the top of the different splines to make the airfoil. Once this was completed at each span location on the wing, the large composite splines were then used to create the loft of the wing. This same process was used for the fuselage sections that could not be measured as one. The final surface lofts of the aircraft were split into four sections: the fuselage, canard, wing and rudder.

Once the full model of the aircraft was completed, it became useful to look at the model from the perspective of using it for CFD simulations; in particular, simplifying certain features on the aircraft. Questions such as do the NACA air inlets for the engine on the top of the cabin need to be analyzed to get an accurate CFD model of the flow on the wing. Multiple simplifications were reviewed such as:

- Removing the landing gear

- Removing the cabin air inlets in the nose and cabin roof

- Removing the engine air inlets

- Simplifying the cross-section geometry of the canard

The landing gear simplification included removing the bulge from the wheel cover and filling in the gear well on the bottom, inboard section of the wing Figure (A.13). Two engine inlets on the top of the cabin were removed along with the cabin air inlets. There 
were two cabin air inlets with one located on the top of the cabin and the other was located on the nose of the fuselage, ahead of the canard. The simplified canard crosssection started from the idea of simplifying the geometry of the canard to assist in creating a structured mesh around the canard. It was desired to achieve a very smooth mesh along chord and span of the canard, but the geometry of the canard was complicated by the elevator. The elevator created a step on the upper surface and a channel in the lower surface that prevented it from being a smooth airfoil shape. As will be discussed in the CFD simulations, 2-D simulations were ran to study the difference between a simplified airfoil versus using the actual geometry of the canard airfoil. Figure A.14 shows the standard three views of the solid 3-D model of the aircraft. Also shown are comparisons of the 3-D model of the aircraft to actual photographs of the Velocity (Figure A.15).

Once the final surfaces were mated and simplified, the solid 3-D CAD model was imported and tested with the meshing software, Gambit ${ }^{11}$. A few iterations of sorting out small bugs in the geometry and lofts resulted in the final model of the aircraft. This was the configuration of the aircraft in the preliminary CFD work. CFD work performed after the experiment also included the pressure rake. The pressure rake was designed in SolidWorks. Once design was completed, it was easily incorporated into the 3-D model of the aircraft and imported into the CFD meshing software. The wing glove that the pressure rake was mounted to was not modeled in SolidWorks, or the CFD simulations. Table 2.2 summaries the various dimensions from the different methods of modeling the aircraft.

Table 2.2

Comparison of Velocity XL-5 RG Dimensions

\begin{tabular}{|l|c|c|c|}
\cline { 2 - 4 } \multicolumn{1}{c|}{} & Velocity Inc. & 3-D CAD Model & Tape Measure \\
\hline Length & $6.1 \mathrm{~m}(240 ")$ & $5.8 \mathrm{~m}(230 ")$ & $5.9 \mathrm{~m}(232 ")$ \\
\hline Height & $2.4 \mathrm{~m}\left(93^{\prime \prime}\right)$ & $2.3 \mathrm{~m}(92 ")$ & $2.4 \mathrm{~m}(93 ")$ \\
\hline Wing Span & $9.4 \mathrm{~m}(372 ")$ & $9.5 \mathrm{~m}(374 ")$ & $9.6 \mathrm{~m}(376 ")$ \\
\hline Canard Span & $4.8 \mathrm{~m}(188 ")$ & $4.9 \mathrm{~m}(192.5 ")$ & $4.9 \mathrm{~m}(191 ")$ \\
\hline
\end{tabular}




\section{CHAPTER III}

\section{CFD SIMULATIONS}

\subsection{CFD Simulations}

Computational Fluid Dynamics (CFD) is a tool that allows for the modeling of the fluid flow in or around an object. For the work presented in this research, it is the airflow around the exterior of the Velocity XL-5 RG aircraft. There are many different CFD solvers and preprocessors that are commercially available. There are many more that are developed in house by companies or graduate students to solve certain types of complex flows; however developing a CFD solver from scratch was not in the scope of the work performed for this thesis. Instead, the focus was to use a solver, already commercially available, to develop and study the flow around the complex geometry of the Velocity aircraft and then validate that information with actual flight data.

Many times, CFD simulations can be generalized into either research-oriented or application-oriented work. Academia has a history of performing the research-based simulations where large assumptions are made or in-depth studies of simplified or localized flow are conducted. On the other end of the spectrum, the application-based work is generally considered large-scale simulations where entire rotor blades or aircraft are simulated but the details of the smaller research simulations are often not present. Larger simulations are often concerned with the wake of an aircraft that is multiple aircraft lengths downstream or at what flight conditions will separation and stall occur. When performing flight tests to perform basic research, these two types of CFD simulations are blended. Combining these two types of simulations introduce new challenges and obstacles to overcome. Performing the fundamental aerodynamic research that is conducted at the FRL, it is important to have reliable information for setting up and understanding the experiments that are conducted. At the same time, it is important to know how the aircraft will perform, where to place the test article and how they will influence each other. These demands mean that there must be full-scale 
simulations completed while maintaining as much detail as possible. Simulations of this magnitude require a large amount of computational resources. Better meshing schemes and use of available resources ensures that the simulations requirements are completed in the most efficient manner.

The Supercomputing Center at Texas A\&M allows for students and faculty to sign up for accounts that allow them a set amount of computing hours for the year. These accounts vary from 500 for a student account to thousands of hours for an account registered to a professor. Two systems at the Supercomputing Center were primarily used for the Velocity simulations. Agave $^{12}$ was an IBM Regatta p690, with 32 processors operating at $1.3 \mathrm{GHz}$ each with $1.65 \mathrm{~TB}$ of disk space. The second supercomputer was Cosmos ${ }^{13}$, a SGI Altix 3700, which uses 128 processors with 256 GB of main memory. Also used was a computer cluster called Lfcomp1, built and run by Richard Rhodes, a graduate student in the Aerospace Engineering Department at Texas A\&M. Rhodes has been performing similar full scale simulations on the FRL's other aircraft, the Cessna O-2 Skymaster. His computer system has 2 dual-core Intel Xeon processors, each operating at $2.8 \mathrm{GHz}$, with $16 \mathrm{~GB}$ of RAM and $160 \mathrm{~GB}$ of storage space.

The two software programs used were Gambit 2.3.16 and Fluent 6.3.26 ${ }^{14}$, which are both developed and sold commercially by Fluent Inc., which was acquired in 2006 by ANSYS Inc. These were used because they were the only CFD software licenses available from the Supercomputing Center. Gambit is a preprocessor for Fluent designed to help build and mesh models for CFD applications. Fluent is a finite volume solver that can be used for 2-D or 3-D, laminar or turbulent, steady or unsteady, and incompressible or compressible flows. For low-speed, incompressible flows the pressure-based solver is used. Since the Velocity flights were in this flight regime, the density-based solver was not used at all. Fluent is capable of performing simulations ranging from a coarse inviscid simulation to a Large Eddy Simulation (LES). The primary solvers for this project were the inviscid, laminar, one- and two-equation turbulence solvers. All of these solvers except LES fall under the classification of the 
Reynolds-averaged Navier-Stokes (RANS) modeling; LES is considered a "filtered" Navier-Stokes model.

The inviscid model solves the Euler equations and neglects the effect of viscosity. It is appropriate to use in flows were the pressure forces are dominant over the viscous forces. The laminar model computes the viscosity and takes into account the viscous effects on the flow; it does not take into account any turbulence in the flow though, that requires a turbulence model to be used. Spalart-Allmaras ${ }^{15}$ is the fastest turbulence model available. This is because it solves only one equation for the turbulence transport, a modified turbulent kinematic viscosity. The $k$ - $\varepsilon$, two-equation, turbulence model solves for the turbulent kinetic energy $(k)$ and the turbulent dissipation, $\mathcal{E}$. Fluent has three options under the $k-\varepsilon$ model: standard, RNG, and realizable. The standard $k-\mathcal{E}^{16}$ is a semi-empirical model that is very popular and used for a wide range of flows due to its accuracy, stability, and speed. The $k$ - $\varepsilon \mathrm{RNG}^{17}$ model differs from the standard $k-\varepsilon$ model due to its use of a technique called renormalization group theory. This is an analytical technique that attempts to improve the accuracy and range of flows applicable to the standard $k-\mathcal{E}$ model by accounting for a range of scales of motion. The third model is the realizable $k$ - $\varepsilon^{18}$. The realizable $k$ - $\varepsilon$ attempts to improve upon the standard $k-\varepsilon$ by satisfying certain constraints of the Reynolds stresses. The other two-equation model that was used in simulations was the $k$ - $\omega$ model. There are two variants of this model: the standard and Shear-Stress Transport (SST) versions. The standard $k$ - $\omega$ model in Fluent is based off of the Wilcox $k$ - $\omega^{19,20}$ that solves for the transport equations for the turbulence kinetic energy, $k$, and the specific dissipation rate, $\omega$. It is an empirical model that is more accurate at predicting free shear flows. The $k$ - $\omega \mathrm{SST}^{21}$ blends the near-wall of the standard $\mathrm{k}-\omega$ with the freestream of the $k-\varepsilon$ to make it more applicable to a larger range of flows.

Simulating the flowfield around the aircraft involved creating a drawing in the CAD program SolidWorks, importing it into Gambit, meshing and applying boundary conditions to the object and then running Fluent. Once the first CAD model of the Velocity was constructed, Gambit was used as the first "test" of the whole 3-D model. 
Gambit generated an error if corrupt or highly deformed geometry was meshed. By monitoring the meshes created by Gambit, bad surface lofts could be determined if skewed or inverted cells were created. There were a couple iterations to be worked through to solve some lofting problems at the trailing edge of the rudder before all the lofts and surfaces of the aircraft were compatible with Gambit.

The biggest benefit of using Fluent was that Fluent can solve structured, unstructured and hybrid meshes. Structured cells consisted of hexahedral volumes that could be mixed with wedge volume. The unstructured cells included tetrahedral and pyramidal elements. Several different meshing schemes were employed throughout the various simulations on the Velocity. Structured meshes were the most difficult to construct on the 3-D velocity model. Simplifications were made to ease the structured meshing as required. 2-D simulations were used throughout the project. One large benefit of the 2-D simulations was that very refined, structured 2-D simulations could be made without having to worry about the increased computational time of a fine 3-D mesh. Another was that the mesh was simplified by not having to be concerned with trying to extrude a fine structured mesh over a curved surface. Most structured meshes were confined to the 2-D studies. 2-D simulations were made testing various refinements of a structured grid of the canard, the wing, a combination of the canard and wing. Corresponding 2-D unstructured meshes were constructed as well. One 3-D case was developed with a structured mesh around a simplified canard with a hybrid mesh around the rest of the aircraft. Other 3-D meshes included fine unstructured meshes around the canard and the rest of the aircraft.

\subsection{2-D Simulation Studies}

It was decided to get a good understanding of how to use the Fluent software with all of its options and to see what the Fluent solver was capable of by performing some studies with 2-D simulations. Three different 2-D studies were conducted to support future 3-D simulations on the aircraft. The first study consisted of testing various grid refinements and boundary layer options on a NACA 0012 airfoil during the meshing. The second test 
consisted of comparing the results of the various turbulence models on the $C p$ of the NACA 0012 airfoil. The third 2-D study began looking at the initial simulations of the canard wake of the Velocity and where it impacts the wing. For the first two studies, the NACA 0012 airfoil was chosen because the results were easily verified.

\subsubsection{2-D Grid Sizing Study}

The NACA 0012 airfoil was used as a test case to examine the effect of changing the grid size and boundary layer sizes on the $C p$ results from Fluent. Twelve different grids, or meshes, were generated for this study. All cases were run using the Spalart-Allmaras, $\mathrm{S}$-A, turbulence model at $5^{\circ} A o A$ with a freestream inlet velocity of $100 \mathrm{~m} / \mathrm{s}$. The Spalart-Allmaras model was chosen due to its computational speed while still being able to model turbulent flow. Being able to solve for turbulent flow for an $0.46 \mathrm{~m}$ chord airfoil at $100 \mathrm{~m} / \mathrm{s}$ may not seem necessary for a Reynolds number of approximately 2.7 million, but the Velocity wing had a chord Reynolds number of 9 million under the desired experimental test conditions.

Below Table 3.1 shows the differences between the various meshes that were developed for the 12 cases. It shows that the finest case was the 2d0012-s6 case with a starting boundary layer cell height of $0.05 \mathrm{~mm}$. The coarsest mesh was the $2 \mathrm{~d} 0012-12$ case which had a starting cell size of $15 \mathrm{~mm}$ per cell. 
Table 3.1

Description of Boundary-Layer and Grid Meshing Around the NACA 0012 Airfoil

\begin{tabular}{|c|c|c|c|c|c|c|c|}
\hline \multirow[b]{2}{*}{ File } & \multicolumn{3}{|c|}{ Boundary Layer } & \multirow{2}{*}{$\begin{array}{c}\text { Face } \\
\text { Growth } \\
\text { Rate }\end{array}$} & \multirow{2}{*}{$\begin{array}{c}\text { Mesh } \\
\text { Max. } \\
\text { Size } \\
(\mathbf{x} / \mathbf{c})\end{array}$} & \multirow{2}{*}{$\begin{array}{c}\text { Line } \\
\text { Airfoil } \\
\text { Size of } \\
\text { LE Cells } \\
(\mathbf{x} / \mathbf{c})\end{array}$} & \multirow{2}{*}{$\begin{array}{c}\text { Mesh on } \\
\text { Surface } \\
\text { Total } \\
\text { Number o } \\
\text { Nodes }\end{array}$} \\
\hline & $\begin{array}{c}\text { Cell } \\
\text { Height/Length } \\
\text { Ratio }\end{array}$ & $\begin{array}{c}\text { Growth } \\
\text { Rate }\end{array}$ & $\begin{array}{c}\text { Number } \\
\text { of } \\
\text { Rows }\end{array}$ & & & & \\
\hline $2 \mathrm{~d} 0012-\mathrm{s} 6$ & $0.1: 1$ & 1.1 & 10 & 1.1 & 0.12 & 0.0002 & 444 \\
\hline 2d0012-s7 & $0.5: 1$ & 1.1 & 10 & 1.1 & 0.12 & 0.0002 & 444 \\
\hline $2 \mathrm{~d} 0012-1$ & $0.2: 1$ & 1 & 20 & 1.1 & 0.12 & 0.001 & 180 \\
\hline $2 \mathrm{~d} 0012-2$ & $0.2: 1$ & 1.2 & 20 & 1.1 & 0.12 & 0.001 & 180 \\
\hline $2 \mathrm{~d} 0012-3$ & $0.4: 1$ & 1.1 & 20 & 1.1 & 0.12 & 0.001 & 180 \\
\hline $2 d 0012-4$ & $1: 1$ & 1.1 & 20 & 1.1 & 0.12 & 0.001 & 180 \\
\hline 2d0012-s1 & $1: 1$ & 1.1 & 10 & 1.1 & 0.12 & 0.0002 & 440 \\
\hline 2d0012-s2 & $0.5: 1$ & 1.1 & 10 & 1.1 & 0.12 & 0.0004 & 370 \\
\hline $2 \mathrm{~d} 0012-\mathrm{s} 3$ & $0.3: 1$ & 1.1 & 10 & 1.1 & 0.12 & 0.0006 & 348 \\
\hline $2 \mathrm{~d} 0012-6$ & $0.4: 1$ & 1.1 & 10 & 1.1 & 0.12 & 0.002 & 216 \\
\hline $2 \mathrm{~d} 0012-7$ & $0.5: 1$ & 1.1 & 10 & 1.1 & 0.12 & 0.004 & 450 \\
\hline $2 \mathrm{~d} 0012-10$ & - & - & - & 1.2 & 0.12 & 0.011 & 184 \\
\hline $2 \mathrm{~d} 0012-11$ & - & - & - & 1.2 & 0.12 & 0.022 & 92 \\
\hline $2 \mathrm{~d} 0012-12$ & - & - & - & 1.2 & 0.12 & 0.033 & 62 \\
\hline
\end{tabular}

The changes in the boundary layer and grid sizing were split into two different scenarios: variation in the boundary layer cell starting height and clustering of the cells around the leading and trailing edge. Table 3.2 contains the cases for the boundary layer starting height variations.

Table 3.2

Description of Cases for Varying the Starting Height Ratio of the Boundary-Layer

\begin{tabular}{|c|c|c|c|c|c|c|c|}
\cline { 2 - 8 } \multicolumn{1}{c|}{} & \multicolumn{4}{c|}{ Boundary Layer } & \multicolumn{2}{c|}{ Face } & \multicolumn{2}{c|}{$\begin{array}{c}\text { Line Mesh } \\
\text { Airfoil Surface }\end{array}$} \\
\hline File & $\begin{array}{c}\text { Cell } \\
\text { Height/Length } \\
\text { Ratio }\end{array}$ & $\begin{array}{c}\text { Growth } \\
\text { Rate }\end{array}$ & $\begin{array}{c}\text { Number } \\
\text { of Rows }\end{array}$ & $\begin{array}{c}\text { Growth } \\
\text { Rate }\end{array}$ & $\begin{array}{c}\text { Max. } \\
\text { Size (x/c) }\end{array}$ & $\begin{array}{c}\text { Main } \\
\text { Surface } \\
\text { Nodes }\end{array}$ \\
\hline 2d0012-s6 & $0.1: 1$ & 1.1 & 10 & 1.1 & 0.12 & 144 & 300 \\
\hline $2 \mathrm{~d} 0012-\mathrm{s} 7$ & $0.5: 1$ & 1.1 & 10 & 1.1 & 0.12 & 144 & 300 \\
\hline $2 \mathrm{~d} 0012-1$ & $0.2: 1$ & 1 & 20 & 1.1 & 0.12 & 30 & 150 \\
$2 \mathrm{~d} 0012-2$ & $0.2: 1$ & 1.2 & 20 & 1.1 & 0.12 & 30 & 150 \\
$2 \mathrm{~d} 0012-3$ & $0.4: 1$ & 1.1 & 20 & 1.1 & 0.12 & 30 & 150 \\
$2 \mathrm{~d} 0012-4$ & $1: 1$ & 1.1 & 20 & 1.1 & 0.12 & 30 & 150 \\
\hline
\end{tabular}


Figure A.16 shows the $C p$ plots for all six different meshes that studied the effects of changing the starting height ratio on the boundary layer.

Table 3.3

Description of Cases for Varying the Leading Edge Clustering and Cell Count of the Boundary-Layer

\begin{tabular}{|c|c|c|c|c|c|c|c|}
\hline \multirow[b]{2}{*}{ File } & \multicolumn{3}{|c|}{ Boundary Layer } & \multirow{2}{*}{$\begin{array}{c}\text { Face } \\
\text { Growth } \\
\text { Rate }\end{array}$} & \multirow{2}{*}{$\begin{array}{c}\text { Mesh } \\
\text { Max. } \\
\text { Size }(x / c)\end{array}$} & \multicolumn{2}{|c|}{$\begin{array}{l}\text { Line Mesh on } \\
\text { Airfoil Surface }\end{array}$} \\
\hline & $\begin{array}{c}\text { Cell } \\
\text { Height/Length } \\
\text { Ratio }\end{array}$ & $\begin{array}{c}\text { Growth } \\
\text { Rate }\end{array}$ & $\begin{array}{l}\text { Number } \\
\text { of Rows }\end{array}$ & & & $\begin{array}{l}\text { Size of LE } \\
\text { Cells }(x / c)\end{array}$ & \begin{tabular}{|c|} 
Total \\
Number \\
of Nodes
\end{tabular} \\
\hline $2 \mathrm{~d} 0012-\mathrm{s} 1$ & $1: 1$ & 1.1 & 10 & 1.1 & 50 & 0.0002 & 440 \\
\hline 2d0012-s2 & $0.5: 1$ & 1.1 & 10 & 1.1 & 50 & 0.0004 & 370 \\
\hline 2d0012-s3 & $0.3: 1$ & 1.1 & 10 & 1.1 & 50 & 0.0006 & 348 \\
\hline $2 d 0012-6$ & $0.4: 1$ & 1.1 & 10 & 1.1 & 50 & 0.002 & 216 \\
\hline $2 \mathrm{~d} 0012-7$ & $0.5: 1$ & 1.1 & 10 & 1.1 & 50 & 0.004 & 450 \\
\hline $2 \mathrm{~d} 0012-10$ & - & - & - & 1.2 & 50 & 0.011 & 184 \\
\hline 2d0012-11 & - & - & - & 1.2 & 50 & 0.022 & 92 \\
\hline 2d0012-12 & - & - & - & 1.2 & 50 & 0.033 & 62 \\
\hline
\end{tabular}

Figure A.17 shows the $C p$ plots for all eight meshes that studied the effects of changing the node clustering around the leading edge along with the total number of cells around the surface of the airfoil; the varied parameters are shown in Table 3.3. Figure A.18 shows the $C p$ plots for all 14 cases, they all recovered to the same $C p$ by approximately $0.2 x / c$. As expected the finer meshes captured the peak in the $C p$ plot at the leading edge much better than the coarser meshes. Cases 2d0012-1, 2, s3, s4, s5, s6 are almost identical at the leading edge in capturing the pressure spike. That provided valuable information in selecting the correct starting size and ratio of cells for the canard without wasting valuable CPU time and resources on extra cells and refinement that wouldn't improve the results. The results from this study led to the selection of a meshing scheme with a cell height to length ratio of $0.2(0.1 \mathrm{~mm}$ length) with 150 nodes as the starting size for the boundary layer of the canard.

While the $C p$ on the surface of the airfoil was being monitored, the change in the wake of the airfoil was also being observed. The purpose of monitoring the wake behind the airfoil was to gain insight into the effect of grid sizing around an airfoil and how that 
affects the resolution of the wake. It was important to understand this relation because the experimental measurements taken to verify the CFD analyses were total pressure measurements in the wake of the canard. The results from monitoring the wake behind the canard showed that the coarse meshes show a larger pressure drop in the wake than the finer grids (Figure A.19). This part of the simulations did not have experimental data with which to compare with previous experimental data like the $C p$ measurements. It is reasonable to assume that the difference between the coarser meshes having a stronger wake at a fixed location behind the airfoil compared to the finer mesh is due the difference in the number of cells between the meshes. The CFD solver can only change parameters in the flow between cells, the coarser meshes have fewer cells over the same distance as the finer meshes; thus if a flow disturbance is decaying, the finer mesh will allow it to decay faster since it is traveling through more cells in the same distance. If the cells are larger, then they cannot change as quickly and thus they will predict the wake to have a much larger pressure drop than it really does.

In summary, there appeared to be no difference between a growth rate of 1.0 or 1.2 for the boundary layer with a starting cell height of $0.1 \mathrm{~mm}$. Once the meshing got so coarse that a boundary layer was not used, the resolution of the pressure peaks was lost but the rest of the $C p$ was compared adequately with the finer meshes. Also the two coarsest meshes, 2d0012-11 and -12, did poorly at modeling the wake; while the 2d0012-9 modeled it quite well. Anything with an initial cell size below $5 \mathrm{~mm}$ created an acceptable model of the wake; though the finer the mesh the better. As a result, the best grid sizing to use for the Velocity's canard is grid that resembles the -2 case study. This would allow for good data on the surface of the canard and also for capturing the wake of the canard as it travels towards the wing. Accurately modeling the pressures on the surface of the wing was more important than modeling the wake of the wing for matching with the experimental results. For the time and capabilities of the research being presented in this thesis, it was decided to mesh the wing of the aircraft following a sizing scheme similar to that of the 2d0012-9. Figures A.20 through A.37 show the meshes developed for the all of the different cases used in this study. 


\subsubsection{2-D CFD Turbulence Model Study}

The NACA 0012 airfoil was also used to test the effect of changing the turbulence model selected in Fluent. All the test cases ran with the same grid and at the same test conditions, $10^{\circ} A o A$ at $100 \mathrm{~m} / \mathrm{s}$. The 2d0012-2 mesh from the previously discussed grid sizing study was the grid selected for this comparison. There were a total of twelve cases ran using three different turbulence models/model options. Fluent allows the user to pick from 8 different turbulence models with different options within each model. They are:

- Inviscid

- Laminar

- Spalart-Allmaras

(2 options)

- $k-\varepsilon$ (16 options)

- $k-\omega$

(6 options)

- Reynolds Stress (12 options)

- Detached Eddy Simulation

(7 options)

- Large Eddy Simulation

(7 options)

Of these 52 different possibilities, only the one and two equation turbulence models were examined. The laminar and inviscid cases were not examined as discussed in the use of the S-A model for the grid sizing study. The Reynolds Stress, DES and LES were all very computational demanding and would require too many resources to reasonably use for simulations on the entire Velocity. Table 3.4 lists the various solver and solver options that were used for the 12 different cases that were examined. 
Table 3.4

Listing of Different Turbulence Models Tested in the Turbulence Model Study

\begin{tabular}{|c|l|l|}
\hline Case & \multicolumn{2}{|c|}{ Model } \\
\hline $0012-1$ & $k-\omega$ & Standard \\
\hline $0012-2$ & Spalart-Allmaras & Vorticity based \\
\hline $0012-3$ & $k-\omega$ & Standard, Transitional Flows \\
\hline $0012-4$ & $k-\omega$ & Standard, Transitional \& Shear Flows \\
\hline $0012-5$ & $k-\omega$ & SST \\
\hline $0012-6$ & $k-\omega$ & SST, Transitional Flows \\
\hline $0012-7$ & Spalart-Allmaras & Strain/Vorticity based \\
\hline $0012-8$ & $k-\varepsilon$ & Standard \\
\hline $0012-9$ & $k-\varepsilon$ & Standard, Enhanced Wall Treatment, Pressure Gradient \\
\hline $0012-10$ & $k-\varepsilon$ & RNG \\
\hline $0012-11$ & $k-\varepsilon$ & RNG, Enhanced Wall Treatment, Pressure Gradient \\
\hline $0012-12$ & $k-\varepsilon$ & Realizable \\
\hline
\end{tabular}

Figure A.38 presents the $C p$ plots for all 12 cases. The first problem encountered was with the "enhanced wall treatment" option of the $k$ - $\varepsilon$ model on cases 0012-9 and 11. The 0012-11 case was not included on the plot because it was off of the chart and 0012-9 was included to show how erroneous its results were. It should be noted that neither were converging when the simulations were ran. The specific reason as to why this model option would not converge was not determined, but it was ruled out as acceptable model option for this type of simulation. The next big inconsistency that was noted was that some of the solvers were reporting $C p$ values of above +1 . This is not expected since the speed being ran for these cases is $100 \mathrm{~m} / \mathrm{s}$, this is still in the incompressible airspeeds; just at Mach $=0.3$. Testing different inputs and different controls for the models did not help. While it is understood that this speed is at the borderline of the incompressible assumption, the models with $C p$ values higher than 1 were then dropped from the list of possible models to use. The models/model options that had been eliminated thus far were 1, 3, 4, 8, 9, 10, and 11. Figure A.39 shows the remaining turbulence models/model options along with experimental data for reference. The experimental data were run at the same conditions, but with a Reynolds number of $4 \times 10^{6}$. The data come from McAlister, Carr, and Pucci, McCroskey ${ }^{22}$ performing wind tunnel tests at AMRDL-Ames 7' x 10' subsonic wind tunnel. 
The results thus far point to only five out of the twelve cases as being viable options to use for a turbulence model. Two are based off of the Spalart-Allmaras turbulence model which is a one-equation model. Two are from the $k$ - $\omega$ model with the SST (shear stress transport) model option, and one was from the $k$ - $\varepsilon$ model. Both the $k-\omega$ and $k-\mathcal{E}$ are two-equation turbulence models. Due to the problems encountered with the other $k$ - $\varepsilon$ models, it was decided to concentrate on just the Spalart-Allmaras and $k-\omega$, SST models.

The Figure A.40 shows the results of the computed wake behind the NACA 0012 airfoil by the four selected turbulence models. The two $k-\omega$ models and two Spalart-Allmaras models were offset, where the Spalart-Allmaras model wakes appeared weaker than the $k-\omega$, SST solutions. The referenced literature had no data available for wakes of a NACA 0012 to determine the accuracy of these solvers in the wake region. This was sorted out when comparing results between the computations and data collected in the flight experiment.

\subsubsection{2-D Velocity Study}

Before work on the 3-D CFD simulations of the Velocity continued to move forward, further 2-D analyses were needed to help determine sizing and location of the pressure rake for the aircraft. 2-D simulations were created to study the region of influence that the wing has on static pressure, the interaction between the canard and wing of the aircraft at various angles of attack and lastly, to test the proposed simplified model of the canard for the 3-D CFD work. The proposed model of the canard was a simplified version of what is actually on the aircraft. The canard on the aircraft has a channel on the lower surface where the elevator pivots when deflected. There is also a step on the upper surface between the canard and the elevator (Figure A.41). The simplified model of the canard removed the step on the upper surface and the channel on the lower surface (Figure A.42). A comparison of the wakes of both canard models was made by comparing the wake profile of each at various angles of attack. 


\subsubsection{Isolated Velocity Wing}

The first section of the aircraft to be studied in the 2-D analyses was the wing and its pressure influences. The test conditions for the simulations were $100 \mathrm{~m} / \mathrm{s}$ at sea level with four angles of attack: $-5^{\circ}, 0^{\circ}, 5^{\circ}$ and $10^{\circ}$. The Spalart-Allmaras turbulence model was selected with a hybrid mesh around the wing (Figure A.43). The hybrid mesh consisted of a structured boundary layer with an unstructured, tetrahedral growth off of the boundary layer. The sizing of the mesh came from the results of the previously discussed 2-D grid sizing study. The primary goal of studying the wing without the canard was to gain an understanding of the static pressure influence region that the wing produces. This was later compared with simulations that included the canard. Freestream static pressure for these simulations was $101 \mathrm{kPa}$. The pressure reported by Fluent is the gauge static pressure; all plots produced by Fluent are reported in gauge pressure. So for example, if the output from Fluent read as $101 \mathrm{~Pa}$; that means that the static pressure at that location is really 101,426 Pa. That would also be considered as the static pressure being $99.9 \%$ of the freestream static pressure. The static pressure was plotted on a line that runs the length of the computational volume and travels through the leading and trailing edges of the wing (Figure A.44). The static pressure begins to noticeably increase about $3.8 \mathrm{~m}$ in front of the leading edge of the wing (Figure A.45). In the plot of the static pressure it should be noted that the leading edge of the wing was located at -1.8 meters. The static pressure values for $99.9 \%, 99.5 \%, 99.3 \%$ and $99 \%$ of the freestream static pressure were also marked.

The preliminary location of the pressure rake was expected to be approximately $381 \mathrm{~mm}$ in front of the wing. The results from the isolated wing show that the original location was at approximately $99.2 \%$ of freestream static pressure at the worst condition of $0^{\circ} \mathrm{AoA}$. The actual location of the pressure rake inlets is $584 \mathrm{~mm}$ in front of the leading edge. This location correlates to approximately $99.7 \%$ of the freestream static pressure, from influences due to just the wing of the aircraft. 


\subsubsection{Velocity Canard-Wing Interaction}

The next 2-D study examined the interaction between the canard and wing of the Velocity (Figure A.46). This was done with the same test conditions as the previous 2-D case over the same four different angles of attack. The primary focus of this study was to study the location of the canard wake with a secondary goal of studying the static pressure between the wing and canard. Also compiled were two plots showing the location and strength of the canard wake at $381 \mathrm{~mm}$ in front of the leading edge of the aircraft and the static pressure around the canard and wing over the four different $A o A s$. Figures A.47 through A.50 show the total pressure wake of the canard at the four AoAs; Figure A.51 shows the total pressure wake versus angle of attack and Figure A.52 shows the static pressure versus angle of attack.

The results from these simulations provided a clear picture of how far the canard wake moved between angles of attack and where it impacted the wing. The magnitude of the pressure drop in the wake was also easily identified. The static pressure influence regions show that there is no location between the canard and wing that was truly free of influence from either surface. Therefore when the location of the pressure rake was determined, the priority was to make sure that the rake was placed in a location of a steady static pressure influence instead of trying to isolate the rake from any static pressure influence.

\subsubsection{Velocity Canard Cross-Section: Real vs. Simplified}

The last part of this study looked at the difference between the real and simplified canard models and the effect of this geometry change on the location of the wake in reference to the wing of the Velocity. This was done over the same four different angles of attack: $5^{\circ}, 0^{\circ}, 5^{\circ}$, and $10^{\circ}$. The same data sets were collected including images of the wake (Figures A.53 through A.56), total pressure versus angle of attack plots (Figure A.57) and the static pressure versus angle of attack plot (Figure A.58).

Overall, the static pressure plots showed no difference in magnitude nor location between simplified and real canard models at various angles of. The total pressure plots 
show that, in general, the real canard model had a slightly stronger wake and that the wake was displaced more than the simplified canard model.

At the various angles of attack, the total pressure helped determine that the location of the pressure rake needed to be as low as $-0.45 \mathrm{~m}$ for $-5^{\circ} \mathrm{AoA}$ up to $0.4 \mathrm{~m}$ for $5^{\circ} \mathrm{AoA}$; giving an overall height of $0.85 \mathrm{~m}$. If it is desired to test up to $10^{\circ} \mathrm{AoA}$, then the upper limit would need to be pushed to $0.75 \mathrm{~m}$; resulting in an overall height of $1.2 \mathrm{~m}$. All of these heights are referenced to the leading edge of the wing being at 0.0 meters.

\subsection{3-D Simulations}

The initial simulations with the aircraft tested the 3-D model to ensure that nothing unexpected occurred, such as velocity gradients in the wing due to a poor loft or mesh. The first model had some corrupt geometry at the bottom of the rudder that was due to a difficult loft. The first simulations then were conducted without the vertical tail and rudder. These simulations ran without error and their residuals converged nicely. Therefore the only correction to the 3-D model of the aircraft was to recreate the loft of the vertical tail and rudder. Inviscid, laminar, Spalart-Allmaras and $k-\varepsilon$ solvers were tested to verify that no singularities or unexpected residual divergence would occur in later simulations when different solvers were used. The test conditions for all of these simulations were $100 \mathrm{~m} / \mathrm{s}$, sea-level, at $0^{\circ} A o A$ and $A o S$.

\subsubsection{Determining the Control Volume Size}

The next big test was to determine how large the control volume around the aircraft needed to be to not influence the computational results. For example, the Masters thesis completed by $\operatorname{Vos}^{23}$ of Delft University in 2006 reported a control volume size of $60 \mathrm{~m}$ long, $60 \mathrm{~m}$ tall and $40 \mathrm{~m}$ wide for simulations on a Cessna Citation II business jet. Studies to find the needed minimum solution volume found that solving for the entire aircraft made for an unacceptably large file once a fine mesh was placed around the aircraft. As a result, only the starboard side of the aircraft was modeled (Figure A.59). This side was chosen for two reasons: first it was the side that was measured with the 
CMM; and second, it was the side on which the experiment was conducted. This simplification will not affect the results of the simulations as long as no simulations required side slip with the aircraft turned right.

Due to the number of increased hours it takes to run a viscous solution versus solving for an inviscid solution; the sizing study of the control volume used the inviscid computations in Fluent. The aerodynamic forces generated in an inviscid simulation will not include the viscous forces; but this study was focused on monitoring the pressure forces and not the viscous forces. The pressure forces are susceptible to influence from the surrounding the control volume where the viscous forces are not as sensitive to this influence. An unstructured, tetrahedral mesh was used during the study to speed up the meshing process. The criteria used to determine when the volume size was no longer affecting the flow solution were the lift, drag, and side forces. The height, width, and length of the box were all changed and plotted versus the change in the aircraft forces. Figures A.60 through A.64 show the change in the forces with respect to length, height and width of the box. It was noted that the width of the box had little effect on the forces generated. Table 3.5 lists the various dimensions that were tested along with their resultant forces and cell count. 
Table 3.5

Control Volume Sizing Study: Volume Sizes and Resultant Forces

(Dimensions in Terms of Aircraft Length)

\begin{tabular}{|c|c|c|c|c|c|c|c|}
\hline Width & Height & Length & $\begin{array}{c}\text { Distance to } \\
\text { Exit }\end{array}$ & $\begin{array}{c}\text { Distance to } \\
\text { Inlet }\end{array}$ & Lift (N) & Drag (N) & Side (N) \\
\hline 1.5 & 1.8 & 3 & 0.7 & 0.3 & 26525 & 1010 & -843 \\
\hline 1.5 & 1.8 & 4 & 1.7 & 0.3 & 26664 & 1024 & -877 \\
\hline 1.5 & 1.8 & 5 & 2.7 & 0.3 & 26635 & 1005 & -911 \\
\hline 1.5 & 1.8 & 6 & 3.7 & 0.3 & 26625 & 1003 & -947 \\
\hline 1.5 & 1.8 & 7 & 4.7 & 0.3 & 26661 & 1012 & -971 \\
\hline 1.5 & 1.8 & 8 & 5.7 & 0.3 & 26581 & 1022 & -1004 \\
\hline 1.5 & 1.8 & 10 & 7.7 & 0.3 & 26561 & 1013 & -1052 \\
\hline 1.5 & 1.8 & 12 & 9.7 & 0.3 & 26593 & 1016 & -1092 \\
\hline 1.5 & 1.8 & 14 & 11.7 & 0.3 & 26653 & 1025 & -1105 \\
\hline 1.5 & 1.8 & 16 & 13.7 & 0.3 & 26678 & 1024 & -1106 \\
\hline 1.5 & 1.8 & 18 & 15.7 & 0.3 & 26619 & 1024 & -1098 \\
\hline 1.5 & 1.8 & 20 & 17.7 & 0.3 & 26599 & 1005 & -1069 \\
\hline 4 & 1.8 & 2 & 1.7 & 0.3 & 26173 & 963 & -778 \\
\hline 1.5 & 4 & 2 & 1.7 & 0.3 & 25362 & 855 & -792 \\
\hline 4 & 4 & 2 & 1.7 & 0.3 & 25057 & 813 & -769 \\
\hline 4 & 4 & 4 & 3.7 & 0.3 & 25329 & 843 & -764 \\
\hline 4 & 4 & 6 & 5.7 & 0.3 & 25414 & 871 & -768 \\
\hline 4 & 4 & 7 & 5.7 & 1.3 & 25328 & 925 & -759 \\
\hline 4 & 4 & 9 & 7.7 & 1.3 & 25419 & 942 & -755 \\
\hline 4 & 4 & 11 & 9.7 & 1.3 & 25401 & 930 & -761 \\
\hline 4 & 4 & 19 & 17.7 & 1.3 & 25436 & 940 & -776 \\
\hline 4 & 6 & 19 & 17.7 & 1.3 & 25253 & 910 & -767 \\
\hline 4 & 6 & 11 & 9.7 & 1.3 & 25289 & 920 & -755 \\
\hline 4 & 8 & 11 & 9.7 & 1.3 & 25243 & 919 & -747 \\
\hline 4 & 8 & 19 & 17.7 & 1.3 & 25206. & 903 & -755 \\
\hline 6 & 8 & 19 & 17.7 & 1.3 & 25159 & 897 & -757 \\
\hline 8 & 8 & 19 & 17.7 & 1.3 & 25143 & 880 & -753 \\
\hline
\end{tabular}

The results from this study showed that the final dimensions of the control volume around the aircraft needed to be at least 15 aircraft lengths long by 8 tall by 8 wide with the inlet to the control volume being at least one length ahead of the aircraft and the exit at least 14 behind the rear of the aircraft. Table 3.6 lists the final control volume dimensions in both aircraft lengths and meters. 
Table 3.6

Final Control Volume Dimensions

\begin{tabular}{|l|c|c|}
\hline \multicolumn{1}{|c|}{ Dimension } & Aircraft Lengths & Meters \\
\hline Control Volume Height & 8 & 46.4 \\
\hline Control Volume Width & 8 & 46.4 \\
\hline Control Volume Length & 17 & 98.6 \\
\hline Distance to Control Volume Exit & 14.5 & 89.9 \\
\hline Distance to Control Volume Inlet & 1.5 & 8.7 \\
\hline
\end{tabular}

\subsubsection{Preliminary 3-D Simulations of the Aircraft}

Preliminary 3-D simulations were run to find an idea of the flow around the aircraft. Features such as the canard tip vortex, canard downwash and regions of influence of the aircraft wing and fuselage were studied. These components were considered the most likely to alter the planning and results of the experiment. Figures A.65 through A.67 show some results of the initial simulations that studied the effects of the canard tip vortex, fuselage effects, wing influence, and canard wake. Figure A.65 shows the flow that interacts with the canard, fuselage and tip vortex. This figure had dual purpose; first was that it showed there was no spanwise influence, or distortion, of the flow at the crank in the wing due to either fuselage or the canard tip vortex and second it allowed for comparison to the 2-D simulations. Verifying that there was little influence at the crank location from the fuselage and canard tip vortex was important because the experiment was to be placed at this location on the wing. Figure A.66 concentrated on visualizing the core of the canard tip vortex while Figure A.67 focused on how far inboard the canard tip vortex modified the flow onto the wing. These figures showed that the location chosen for the experiment had minimal spanwise influence from the fuselage and canard tip vortex while still encountering a developed wake being shed off of the canard.

The comparison between the preliminary 2-D and 3-D simulations showed that the 2-D simulations agreed with the 3-D simulations on the location of the canard wake but computed a smaller pressure drop in the wake. 


\subsubsection{3-D Simulation Mesh Development}

While the previous sections of the 3-D simulations were performed at the same time as the 2-D simulations, this section was completed once the 2-D simulations were completed. The focus at this point was two-fold: first was to develop a structured mesh around the canard and second was to develop a mesh around the aircraft that included the pressure rake in the simulations.

The structured mesh around the canard was developed to capture the flow around the canard and allow that to transmit downstream. Creating a structured mesh involved creating a hybrid mesh for the entire volume. An unstructured mesh was created around the fuselage, rudder, canard tip and outer volume that matched up with the structured regions around the wing and canard. A structured mesh around the tip of the canard was never achieved; the complex curvature of the region resulted in highly skewed or negative volumes when a structured mesh was attempted around this region. Figure A.68 shows the entire control volume and the smaller, embedded volumes used to control the mesh refinement. The final plot in Figure A.68 shows the volumes that contained structured meshes. Figure A.69 showed the refinement of the mesh around the canard and the boundary layer of the wing. The boundary layer meshes that were used were based off of the results of the 2-D grid study that was discussed earlier.

A second mesh was developed that did not concentrate on developing a nice, structured mesh on the canard, but instead created a reasonable, unstructured mesh on the canard along with an unstructured mesh around the pressure rake. Small volumes were created around the surfaces of the pressure rake and canard that allowed for refinement along the surface but contained the refinement so that the total cell count of the file did not exceed the computational limits of the systems used for the simulations. An extra volume was used in the development of this mesh to ensure that the cells between the canard and wing did not grow larger than desired. Creating this extra volume allowed for the control and refinement of the cells between the pressure rake and canard while not forcing all of the cells around the aircraft to maintain the same refinement. This was another method used to allow for refinement of the mesh in certain 
areas of interest while not letting the number of cell exceed the computational limits of the systems used. Figure A.70 shows the control volume and sub-volumes used to create the mesh around the aircraft that included the pressure rake. Figure A.71 shows the grid around the pressure rake and canard.

\subsection{Simulations after the In-Flight Measurements}

Once the flight experiments where completed, simulations were begun with the inputs being modified to replicate the in-flight conditions that were encountered during each test point. Over the course of three flights, 5 different test points were measured at least 6 times. This meant that in order to match up the experiment with the simulations, multiple simulations were run to get an accurate comparison. This section simply summarizes the process that was undertaken once the flights were completed. The results of these simulations and their comparison with the in-flight measurements are located in Chapter 5.

\subsubsection{Post-Flight 2-D Simulations}

To help speed up the results, 2-D simulations were used along with the full 3-D simulations. The purpose of running 2-D simulations was to check to see how close the experiment came to the simulations. The 2-D simulations were much less demanding of computational time. The 2-D simulations allowed for the testing of the four different turbulence models that were selected during the turbulence model study that was discussed in Section 3.1.2.

\subsubsection{Post-Flight 3-D Simulations}

While 2-D simulations were ran get an initial check with the experiment, the 3-D simulations were the final step in comparing the flight experiment to the CFD simulations. The 2-D simulations are much easier and faster, but using their results means that the flow has been assumed to be 2-dimensional in that area. While this was a nice approximation, and the goal of locating the pressure rake at this location, it is still 
an assumption that adds error to the final results. Therefore any final comparison required a 3-D simulation to exactly match the in-flight results. Based off of the results of the 2-D simulations and the preflight 3-D simulations, the primary mesh that was used for the 3-D simulations was the mesh without the pressure rake but included a structured mesh around the canard. This selection was made due to comparisons made between simulations using the structured mesh around the canard and the fine, unstructured mesh that included the pressure rake. Both 2-D and 3-D simulations were ran that showed no difference in the location of the wake downstream of the canard. 


\section{CHAPTER IV}

\section{GROUND AND IN-FLIGHT EXPERIMENTS}

\subsection{Designing the Experiment}

Being able to answer which type of data will be used is just the first part of determining the verification data; second is determining which part of the flow around the aircraft to measure for the comparison. Feasibility of measuring the location, flow complexity and usefulness of the experimental results for planning and preparation of future projects all factored into the decision of where to measure the flow around the aircraft. As discussed in the motivation for this project, any wing gloves, or models, attached to the aircraft will most likely be behind the canard and mounted to the crank in the wing. This location on the wing has no control surfaces, the ability to easily test two different sweep angles, and has attachment points that are currently installed on the wing (Figure A.72). A pressure rake located at the crank in the wing can capture the important features of the canard wake for future projects, be easily mounted to the aircraft and allow the FRL to gain experimental data that can be used for future projects.

To properly design the pressure rake, it was crucial to understand what data were needed to accurately verify the CFD simulations, what instrumentation was needed to gather this data, and what background information was available from previous pressurerake experiments. Design considerations for the rake included the number of probes needed in the wake, the distance between each probe to minimize the effect of neighboring probes, the response time of the probes and what information needs to be collected from each probe.

It would be desirable to gain every bit of information possible from the experiments, but that is neither feasible nor the primary concern of the project. To be able to do this, one would have to install high frequency response probes that can measure total pressure, static pressure, angle of attack and angle of sideslip. These probes are very expensive and are therefore not a reasonable choice for the budget of this 
research project. It was desired to record the flow pressure and angles in and around the wake. To solve this dilemma, two 5-hole probes were purchased from Aeroprobe. The 5hole probes can solve for total and static pressure, $A o A$ and $A o S$. When complemented by pitot probes, the characteristics of the wake can be quantitified in just a few flights. A 24-inch 5-hole probe was purchased to extend out the nose of the aircraft to measure the freestream data, while a 12-inch 5-hole probe was purchased to measure local conditions in the pressure rake. The other 18 probes were then strictly pitot probes that provided the location and strength of the canard wake. The interior of the pressure rake was designed to allow the 5-hole probe to be moved into different locations between flights so that data may be gathered below, inside and above the wake of the canard.

2-D and 3-D CFD simulations at assumed test conditions provided the initial estimates for the sizing and location of the pressure rake. To design an effective rake requires that accurate predictions of the size and location of the canard wake be known. The location of the wake depends on the aircraft speed and AoA. Unfortunately, it was necessary to assume test conditions for the design of the pressure rake to keep the design, and building, of the pressure rake on schedule. The reason the actual test points were not known was due to the fact the 5-hole probes were not yet available for baseline flights in the Velocity. Preliminary test conditions included a velocity range of 100 to 170 knots and -5 to 5 degrees $A o A$. 2-D simulations specified the vertical and longitudinal location of the rake location. The 3-D simulations showed the proposed spanwise location of the pressure rake was acceptable and determined the canard tip vortex would not have a strong influence at this location. For the assumed test conditions, the CFD simulations showed that the pressure rake needed to be $0.8 \mathrm{~m}$ tall (Figures A.47-A.50, A.53-A.56, A.73). It also showed that the vertical location of the center of the pressure rake needed to be slightly below the leading edge of the wing of the aircraft, while the spanwise location was located at the crank in the wing. The longitudinal location of the pressure rake was harder to determine. Originally it was desired that the pressure rake would be placed outside of the static pressure influence of the wing. But to minimize the static pressure influence of the wing, the rake would be 
pushed so far forward that it would be unable to fulfill its original purpose of measuring the canard wake at the wing of the aircraft. As a result of this, it was decided to move the pressure rake close to the wing. Even though this increased the flow complexity at the pressure rake due to static pressure influence from the wing, it allowed for more accurate measurements of the flow where future projects would be located.

The next consideration was the design and spacing of the pitot tubes that would go in the rake. Several sources were used to help determine the best design. First, the spacing issue was addressed. Research papers published by $\mathrm{MIT}^{24}$, NASA Dryden ${ }^{25}$, and Beechcraft $^{26}$ were all reviewed to see how different pressure probe spacing and diameters vary depending on the types of measurements needed. MIT had built and used different pressure rakes in their wind tunnels. One for measuring boundary-layers on a surface, which is not applicable to this project; and the second for measuring pressure wakes which is quite relevant to this design. NASA Dryden had two pressure rakes to measure boundary-layers in supersonic flow and one large pressure rake being built for wake measurements with 5-hole probes. Beechcraft had built two 21-probe rakes. One rake had a spacing of $13 \mathrm{~mm}$ between probes and the second rake had a spacing of 41 $\mathrm{mm}$ between probes. The dimensions of the actual 5-hole probes used in the rakes were not listed. Both rakes were used for in-flight measurements in many different locations on the Beechcraft Starship. Table 4.1 shows the various parameters referenced during the design. 
Table 4.1

Comparison of Pressure Rake Designs

\begin{tabular}{|c|c|c|c|c|}
\hline Company & Type of Rake & Probe OD (mm) & $\begin{array}{c}\text { Spacing } \\
\text { between } \\
\text { probes }(\mathrm{mm})\end{array}$ & $\begin{array}{c}\text { Spacing } \\
\text { Between } \\
\text { probes (OD) }\end{array}$ \\
\hline MIT & $\begin{array}{l}\text { Subsonic Pressure Wake } \\
\text { Survey Rake }\end{array}$ & 3.2 & 13 & 4 \\
\hline MIT & $\begin{array}{l}\text { Subsonic Boundary Layer } \\
\text { Rake }\end{array}$ & 0.9 & 2.5 & 2.8 \\
\hline \begin{tabular}{|l|} 
NASA \\
Dryden \\
\end{tabular} & $\begin{array}{l}\text { New B.L. Rake for F-15B } \\
\text { Test Bed }(M=2)\end{array}$ & 1.0 & $2-4$ & $2-3.75$ \\
\hline \begin{tabular}{|l|} 
NASA \\
Dryden
\end{tabular} & $\begin{array}{l}\text { Old B.L. Rake for F-15B Test } \\
\text { Bed }(M=2)\end{array}$ & 4.8 & $6-25$ & $1.3-5.3$ \\
\hline \begin{tabular}{|l|} 
NASA \\
Dryden
\end{tabular} & PFTF 9 5-Hole Probes Rake & 3.2 & 46 & 14.4 \\
\hline Beech & $\begin{array}{l}215 \text {-Hole Probe Rakes on } \\
\text { Starship } \\
\text { (if } 5 \text {-Hole probe is } 1 / 8 " \text { OD) } \\
\text { (if } 5 \text {-Hole probe is } 1 / 4 " \text { OD) }\end{array}$ & $\begin{array}{c}\text { unknown } \\
3.2 \\
6.4 \\
\end{array}$ & $\begin{array}{l}13-41 \\
13-41\end{array}$ & $\begin{array}{l}4-12.8 \\
2-6.4 \\
\end{array}$ \\
\hline TAMU FRL & Straight Pitot Tube Design & 6.4 & 16 & 2.5 \\
\hline TAMU FRL & Stepped Pitot Tube Design & 3.2 & 16 & 5 \\
\hline
\end{tabular}

The external sizing for the pitot tubes became fixed due to the size of the 5-hole probe attached to the pressure rake. To make the pressure rake capable of mounting the 5-hole probe at any location, the probe locations inside the pressure rake must have the same dimensions as the 5-hole probe manufactured by Aeroprobe. An outer diameter of $6.4 \mathrm{~mm}, 305 \mathrm{~mm}$ long with a $10 \mathrm{~mm}$ square mounting block that is $38 \mathrm{~mm}$ long at the rear were the external dimensions for all of the probes (Figure A.74). The spacing was determined by the need to place at least 3-5 probes inside of the wake to determine the location but not be too close together to affect the surrounding probes. A spacing of 46 $\mathrm{mm}$ was chosen, giving a spacing of 7.2 outer diameters from center to center with approximately 4 probes inside the canard wake. An OD spacing of 7.2 falls within the upper range of pressure rakes that were studied. While the wake location can be determined adequately with a minimum of 3 pitot probes, it was decided to increase the design to get approximately four probes into the wake.

The next design consideration was the design of the pitot probe inlets. The inlet design relied heavily on a report published by William Gracey ${ }^{27}$ published in 1980 that 
discusses multiple designs for pitot tubes and how the inlet design of a fixed pitot probe can decrease the sensitivity of the probe to angle of attack. In support of the decision to space the probes at 1.8 ODs apart and the inlet design based on research by Gracey ${ }^{28}$; simple CFD simulations were carried out to verify that the effects of the probes and rakes did not skew the total pressure measurements. The final inlet design for the pitot tubes had a $30^{\circ}$ chamfer with a sharp leading edge (Figure A.75). Figure A.76 CFD analyses of the pitot tubes showed that there was no noticeable total pressure influence from the surrounding probes. The static pressure between probes did not recover to freestream static pressure which meant that the static pressure readings from the 12 -inch 5-hole probe were going to be inaccurate. Placing the probes far enough apart to minimize the static pressure influence was not possible while still adequately locating the wake. The error in the static pressure readings was deemed an acceptable error in the experiment since the freestream static pressure was still captured by the 24-inch 5-hole probe that extended out the nose of the aircraft.

\subsection{Designing the Pressure Rake}

As alluded to previously, the interior design of the pressure rake was defined by the desire to place the 5-hole probe at any probe location in the rake. The exterior design of the rake was dictated by the need to minimize the aerodynamic forces of the rake and its influence on the wing downstream of the rake. The parameters that factored into the internal and external design of the pressure rake included:

- Probe spacing

- Probe size

- Bend radius of pressure tubing

- Mounting of probes

- Aerodynamic loads

- Attachment to the aircraft 
The external shape of the pressure rake was a stretched hexagon with an angle of $20^{\circ}$ at the leading and trailing edges. Three struts supported the pressure rake, with the center strut housing the pressure tubing from the probes (Figure A.77-A.78). The upper and lower strut were $25 \mathrm{~mm}$ square aluminum bar while the center strut was $25 \mathrm{~mm}$ by 50 $\mathrm{mm}$ aluminum box channel with $3 \mathrm{~mm}$ walls. These struts bolted into the pressure rake and into the fiberglass mold of the wing that allowed the use of all the attachment hard points on the wing.

Stress analysis of the design needed to be completed to clear the pressure rake for its static load testing which needed to occur before the first flight. A stress analysis to calculate the stress loads and concentrations along with the factor of safety (FOS) at the worst case conditions meant that the loads on the pressure rake must be determined for a worst case condition. Worst case loading was a collision avoidance maneuver; which was at 200 knots, with $7^{\circ} A o S$ during a 2'g pull-up. Both 2-D and 3-D simulations of the pressure rake at this condition were performed (Figure A.79). The 3-D simulations with the pressure rake had difficulties converging and were predicting low side force values. To resolve this problem, simulations of the pressure rake with a NACA 0012 crosssection were performed and compared to the actual pressure rake design (Figure A.80). Table 4.2 lists the forces that were computed from the various 2-D and 3-D simulations of the pressure rake and NACA 0012 representation of the pressure rake at $0^{\circ}$ and $7^{\circ}$ AoS.

Table 4.2

Summary of Pressure Rake Forces from Computations

\begin{tabular}{|c|c|c|c|c|}
\hline Cross section shape & Type of Study & AoS & Side Force (N) & Drag (N) \\
\hline NACA 0012 & 3-D & 7 & 542 & 13 \\
\hline NACA 0012 & 2-D & 7 & 907 & 92 \\
\hline Diamond & 2-D & 7 & 796 & 40 \\
\hline NACA 0012 & 3-D & 0 & 2.8 & 24 \\
\hline NACA 0012 & 2-D & 0 & 4 & 14 \\
\hline Diamond & 2-D & 0 & 2.4 & 14 \\
\hline
\end{tabular}


The NACA 0012 pressure rake, as expected, produced greater lift at $A o S$ than the actual pressure rake in the 2-D studies. This greater lift from the NACA 0012 was due to having a round leading edge; this geometry did not have separated flow as soon, so the flow remained attached and generated side force at higher AoS. For extra margins of protection, the loads predicted by the 3-D NACA 0012 simulations were used for the maximum loading for the pressure rake. The $542 \mathrm{~N}$ is equivalent to 122 pounds. A factor of safety of 1.5 was then applied resulting in a load of $814 \mathrm{~N}$ for the stress analysis and static load testing. A FOS of 1.5 is considered a standard for both industry and the FRL.

SolidWorks was used to design the pressure rake and COSMOSWorks ${ }^{29}$ was used to perform the stress analysis of the rake and support struts. The loads applied in COSMOSWorks were $814 \mathrm{~N}$ of side force, $44 \mathrm{~N}$ of drag and 3g's totaling $185 \mathrm{~N}$ down (Figure A.81). The side force and drag force were evenly distributed pressure forces. The weight was a point loading at the center of the pressure rake. The final minimum factor of safety for the pressure rake was 4.8 to yield which is well beyond what was required (Figure A.82 - A.84). The accuracy of COSMOSWorks was proved by $\mathrm{McKnight}^{30}$ in 2006. Therefore, an independent study of the accuracy of COSMOSWorks was not preformed behind performing a static load test of the pressure rake.

Once design and stress analysis of the pressure rake were completed, the pressure rake, support struts and pitot probes were constructed. The pressure rake was machined at the machine shop of the Oran W. Nicks Lowspeed Wind Tunnel. The pitot probes were made in-house at the Flight Research Laboratory. During construction of the pressure rake and pitot probes, work began on the wing mold. The wing mold was made out of fiberglass and carbon fiber. It was fitted to the wing and accessed all the attachment points available on the wing to distribute any loads developed by the pressure rake. No stress analysis was performed on the composite wing mold and attachment points. The static load testing of the wing mold on the aircraft was used for flight safety verification. This was performed after all construction was completed. A quick summary of details of the pressure rake: 
- One 5-hole probe

- 18 pitot probes

- 3 support struts

- 0.91 meters tall

- 203 millimeters long

- 19 millimeters wide

- $20^{\circ}$ leading and trailing edges

- Stretched hexagon cross-section

- Carbon fiber/ fiberglass wing mold

\subsection{Wind Tunnel Tests}

Before flight tests started, the 5-hole probes were used in wind tunnel test to familiarize the FRL personnel with their use and performance. The goals of the wind tunnel tests were to test the $L a b V I E W^{31}$ programs that were written for the data acquisition during the flights, check the calibrations of the 5-hole probes, verify the pressure scanner was operating correctly after repairs, and check the probe spacing from the pressure rake design. The tests were conducted over two days in the 3' x 4' Engineering Laboratory Design (ELD) Wind Tunnel in the basement of the Bright Building. The tests consisted of testing both 5-hole probes and the pitot probes. On the first day of testing, both pitot probes were tested while using the new Honeywell pressure transducers. The 24-inch 5hole probe was run by itself in the middle of the tunnel while performing an angle of attack sweep in 1 degree increments from 5 to -5 degrees (Figure A.85). The smaller 12-inch 5-hole probe was tested from 5 to -5 degrees both isolated and with a pitot probe on either side. During the second day of testing, the 12-inch 5-hole probe was mounted with the pitot probes and recorded using the Pressure Systems ESP 64 channel pressure scanner (Figure A.86). The angle of attack range for this test was 10 to -6 degrees. During the flight tests, the 12-inch 5-hole probe and the pitot probes all plugged into the pressure scanner while the 24 inch 5-hole probe used the Honeywell pressure transducers. 
The results from the testing showed that the LabVIEW acquisition was operating and all of its bugs were worked out. The pressure transducers worked to specifications and the 5-hole probes matched their calibration curves. The angle of attack readings at the upper and lower limits of the tests showed a slight increase in the error compared to the readings at $0.0^{\circ} A o A$ (Figure A.87). While the errors were small, they were unexpected. There were two possibilities that could feed into this slight increase in error. First is that the maximum velocity of the tunnel for the tests was $41 \mathrm{~m} / \mathrm{s}$ which is lower than the slowest calibration speed, $45 \mathrm{~m} / \mathrm{s}$, that Aeroprobe used to develop the calibrations. The second contributing factor is that it is possible the wind tunnel mount could slightly move with increased aerodynamic loads at high and low angles of attack. A very slight movement would be multiplied by extension of the probes whose measurements are 305 and $610 \mathrm{~mm}$ in front of the mount. With this stated, the results from the wind tunnel tests showed that the hardware and software for the data collection were ready for flight. Also tested was the difference between the total pressure of the 5hole probe and the upper and lower pitot probe. Experimental comparison between the probes total pressure and velocity are shown in Figure A.88. Figure A.89 shows the CFD work performed in support of the wind tunnel testing that tried to predict any differences between the total pressure recordings of the probes. The CFD showed the probes to be close to together but the 5-hole probe to have a slightly larger total pressure; the experiment agreed with this observation.

\subsection{Baseline Flights in the Velocity}

Baseline flights in the Velocity followed the wind tunnel tests. The purpose of these flights was to determine the test points used in the flights when the pressure rake was attached. The 24-inch 5-hole probe was mounted in the nose of the aircraft. This location was chosen to minimize any influence from the aircraft on the probe measurements. The 24-inch 5-hole probe was installed in the aircraft parallel to what was considered aircraft level from the measurements made with the Cimcore CMM. This probe will be dedicated to all future projects in the Velocity to acquire freestream static and total 
pressure, $A o A$ and $A o S$ (Figure A.90). With the 5-hole probe and pressure transducers installed, flights to measure the $A o A$ of the aircraft began.

The baseline flights recorded the actual speed of the aircraft (versus the indicated airspeed of the aircraft which must be corrected for aircraft effects on its measurements), its angle of attack range for trimmed zero elevator deflection, and the flying qualities of the aircraft at 170, 140 and $100 \operatorname{KIAS}(87,72$, and $51 \mathrm{~m} / \mathrm{s})$. All test points during the flights with the pressure rake were conducted at zero elevator deflection. This was done because the model of the aircraft used for the CFD simulations had zero elevator deflection. Three flights were conducted to determine the test points for the pressure rake experiments along with two additional flights to measure the clean flying qualities of the aircraft. Table 4.3 below shows the aircraft configuration, along with the angle of attack and speed ranges for each flight in determining the test points for the pressure rake flights.

Table 4.3

Test Parameters during Velocity Baseline Flights

\begin{tabular}{|l|c|c|c|c|}
\hline Flight Number & Weight kg (lb) & CG mm (in) & AoA Range (deg) & Speed KTAS (m/s) \\
\hline $083007-1 \mathrm{M}$ & $1,118(2464)$ & $3,310(130.3)$ & $2.0-7.5$ & $95-150(49-77)$ \\
\hline $090807-1$ & $1,197(2639)$ & $3,274(128.9)$ & $2.75-8.5$ & $100-150(51-77)$ \\
\hline $091007-1$ & $1,285(2834)$ & $3,249(127.9)$ & $1.5-3.5$ & $135-180(69-93)$ \\
\hline
\end{tabular}

The results from the flights were quite informative in that the angle of attack range of the aircraft with zero elevator deflection was smaller than assumed in the preliminary simulations. Also learned was that the aircraft flies at a greater $A o A$ than assumed in preliminary simulations. Table 4.3 shows that a variety of weight and $C G$ locations were tested. These were varied to see if the range of $A o A$ with zero elevator deflection could be increased, unfortunately it did not have an effect. A range of only 3 to 8 degrees angle of attack could be achieved with zero elevator deflection. Figure A.91 shows a plot of the angle of attack versus airspeed for acceptable test points. Acceptable test points required a trimmed condition in which the aircraft can maintain steady flight 
with zero elevator deflection. After reviewing the recordings from the flights it was decided to not include the $8^{\circ}$ test point due to the limited ability of the aircraft to maintain a trimmed condition at that higher angle.

From the results of these three flights, five test points were chosen to perform the pressure rake experiments. The test points were:

- 3 degrees $A o A$ at $150 \mathrm{KIAS}(77 \mathrm{~m} / \mathrm{s})$

- 4 degrees $A o A$ at $130 \mathrm{KIAS}(67 \mathrm{~m} / \mathrm{s})$

- 5 degrees $A o A$ at $120 \mathrm{KIAS}(62 \mathrm{~m} / \mathrm{s})$

- 6 degrees $A o A$ at $110 \mathrm{KIAS}(57 \mathrm{~m} / \mathrm{s})$

- 7 degrees $A o A$ at $100 \mathrm{KIAS}(51 \mathrm{~m} / \mathrm{s})$

Initial plans for the flights with the pressure rake expected called for flights. Subsequent flights would be performed as required to repeat a bad flight, if there was equipment failure, or it was determined that more flights to acquire different information were necessary. During each flight, all five test points were recorded twice. For each of the planned three flights, the 5-hole probe was moved to a different location. The locations were below the wake (bottom probe location), above the wake (top probe location), and in the wake (at port $356 \mathrm{~mm}$ below the leading edge of the wing). Since the angles of attack were higher than anticipated in the initial planning of the experiment, the location of the pressure rake needed to be adjusted. Post-flight 2-D simulations of the chosen test points showed that the previously planned location of the pressure rake was too low. As a result, the location of the rake was shifted so that the center of the rake was $90 \mathrm{~mm}$ above the center of the leading edge of the aircraft.

With the baseline flights for the pressure rake completed clean flying qualities of the Velocity were recorded. These measurements were necessary to compare with the flying qualities with the pressure rake to ensure there were no adverse effects on the controllability of the aircraft by adding the pressure rake. The test points for the clean flying qualities included $140 \mathrm{KIAS}(72 \mathrm{~m} / \mathrm{s})$ clean, $170 \mathrm{KIAS}(87 \mathrm{~m} / \mathrm{s})$ clean, and 100 
KIAS $(51 \mathrm{~m} / \mathrm{s})$ with the gear down. At each speed a test block was executed that included rudder doublets, pitch doublets, 30-to-30 degree banks and wind-up turn maneuvers. After completing the test matrix, stalls were performed in various configurations. Figures A.92 through A.97 are from the flying qualities measurements of the Velocity. They show the rudder doublets and pitch doublets of the aircraft without the pressure rake.

\subsection{Mounting the Pressure Rake to the Aircraft}

With a better understanding of where to place the pitot probes and 5-hole probe to capture the canard wake, the location of the pressure rake was adjusted according to the post baseline flight simulations. A temporary fixture was constructed to hold the pressure rake in the exact location in relation to the wing mold and wing. Each strut had

a fiberglass glove molded around it while in the fixture to get the proper angles. The strut gloves were constructed to allow the struts to slide in and out for easy attachment and removal from the aircraft. The glove for each strut had two bolts for final attachment to ensure that the support struts could not move. After the attachments from the struts to the wing mold had cured, the pressure rake was removed, and the wing mold was reinforced with one layer of carbon fiber to help distribute the load from the attachment points to the struts (Figure A.98).

\subsection{Preflight Testing of the Pressure Rake}

Static load testing was split into two phases. First phase consisted of applying a load of $814 \mathrm{~N}$ to the pressure rake/support strut assembly. The pressure rake assembly was monitored throughout the entire loading and unloading of the test. No deformations, cracking, or bending was found. Figure A.99 shows the static load test on the isolated pressure rake and support struts while fully loaded. The testing did not include strain gauges, nor was a test to failure conducted to verify the accuracy of the stress analysis simulation. The static testing was intended to show the system was capable of experiencing 1.5 times the maximum expected loads without yielding or having large 
deformations. The second phase of testing involved the entire assembly on the aircraft exactly as it would be in flight. The first load applied during the static load test on the aircraft was the maximum expected side loading on the rake of $814 \mathrm{~N}$ (Figure A.100). The force was applied for five minutes and throughout the test, the entire assembly was closely monitored with no noted deflections (Figure A.101). The second load was the 2g pull-up; $200 \mathrm{~N}$ were hung down from the model to complete this test (Figure A.102). The inspection after the testing showed no damage or strain to the pressure rake, support struts, wing mold or wing of the aircraft. The entire assembly was monitored during the test and inspected afterwards by the FRL crew and FAA licensed Airframe and Propulsion (A\&P) mechanic Cecil Rhodes who is also an FAA Authorized Inspector (AI). Once the static load tests were completed, the wing mold was coated in primer and sanded smooth. The pressure lines were ran from the rake to the scanner inside the wing and held down with tape. Figure A.103 shows the pressure rake in its flight ready configuration.

After the static testing of the rake, dynamic testing of the system was performed. This included an engine run-up and a high-speed taxi test. The engine run-up was to verify that the pressure rake did not suffer from severe vibrations or enter a natural frequency mode throughout the entire aircraft engine RPM range. The aircraft was ran from idle to full power with the pressure rake assembly being both videoed and monitored by the Flight Research Lab graduate students and A\&P mechanic (Figure A.104). After the run up was completed, a post test inspection was performed with no noted deformations, cracking, or excessive vibrations.

After the engine run-up, a high-speed taxi was conducted to again test if any vibrations would be excited. Also being tested was to see if the pressure rake produced any adverse effects on the control of the aircraft at low speed. As with the engine run-up and static load test no concerns were raised during the test or the inspection afterwards. With all of the ground tests completed, the pressure rake was cleared for its first flight to test the handling qualities of the aircraft with the pressure rake attached. 


\subsection{Velocity Flights with the Pressure Rake}

The first flight in the Velocity with the pressure rake consisted of only the pilot, Celine Kluzek, and a video camera recording the pressure rake and wing of the aircraft from engine start-up to shut down. The second, third and fourth flights were all flown with a pilot and flight test engineer (FTE). During the experiments, the FTE informed the pilot when test conditions were reached, the pilot called on condition, then the FTE conducted the data acquisition with both the Pressure Systems 64 channel pressure scanner and the LabVIEW program.

\subsubsection{Flying Qualities}

The first flight of the Velocity with the pressure rake was to test the flying qualities of the aircraft. No data except for qualitative pilot comments on the flying qualities and video were taken during this flight. The pilot noted that the aircraft flew with increased side force as expected during straight and level flight due to increased drag on the right side of the aircraft. The flying qualities tests were performed in the same order as the clean tests; performing maneuver test blocks at $140(72 \mathrm{~m} / \mathrm{s}), 100(51 \mathrm{~m} / \mathrm{s})$ and then 170 $(87 \mathrm{~m} / \mathrm{s})$ KIAS. The pilot noticed slightly lighter damping during the rudder doublets, especially the low speed, $100 \mathrm{KIAS}(51 \mathrm{~m} / \mathrm{s})$, condition. Also slight buffeting on the wing was noticed during the 30-to-30 degree banks if the maneuvers were abrupt. The aircraft performed adequately and the only recommendation after the flying qualities was to increase the landing speed up to $100 \mathrm{KIAS}(51 \mathrm{~m} / \mathrm{s})$ whenever the pressure rake is attached to ensure that there was adequate lateral control of the aircraft.

\subsubsection{Pressure Rake Experiments}

Three flights were planned for the experiment once data collection began. During each flight, all five test points that were developed in the baseline flights were tested at least twice. The difference between each flight was the location of the 5-hole probe that was located in the pressure rake. The data acquisition for the experiment consisted of running the Pressure Systems 64 channel pressure scanner, whose reference was the freestream 
static pressure from the 24-inch 5-hole probe, along with recording freestream static and total pressure, angle of attack, angle of sideslip, and temperature.

During the first flight, the 5-hole probe was placed in the lowest probe location (probe \#19) in the rake. This location correlates to $0.322 \mathrm{~m}$ below the leading edge of the wing. This location was picked for the first flight because simulations predicted this area of the flow to be uninfluenced by the wake of the canard. Figures of the graphs and plots of the flight data are discussed in Chapter 5 when discussing the comparisons between the flight data and the CFD simulations. Figures A.105 through 109 are the results of the data collected from the first flight with measurements. These figures are the plotted $A o A$ and total pressure from the rake for the best of the two collection sets at each test point. In addition to the five planned test points, certain parts of the flying qualities test blocks were repeated so that quantitative data could be recorded and compared with the clean configuration performance. In particular, acquiring data about the change in the rudder doublets and damping by adding the pressure rake (Figures A.110 and A.111).

The only difference between flight one and two was the location of the 5-hole probe in the pressure rake. For the second flight, the 5-hole probe was moved up to the probe \#14 location, or 0.093 meters below the leading edge of the wing. Additional data collected on the second flight included high speed data at off test conditions. This meant that the zero elevator deflection requirement was dropped. The purpose of this data was not to compare with CFD but to instead build up a database of information that could be applied to future projects. The goal of the high speed data was to gather information at higher Reynolds numbers. Three conditions were tested: $170 \mathrm{KIAS}(87 \mathrm{~m} / \mathrm{s})$ at 8,500 feet $(2,590 \mathrm{~m}), 172 \mathrm{KIAS}(88 \mathrm{~m} / \mathrm{s})$ at 6,500 feet $(1,980 \mathrm{~m})$ and $200 \mathrm{KIAS}(103 \mathrm{~m} / \mathrm{s})$ at 6,500 feet $(1,980 \mathrm{~m})$ while diving at 1,000 feet per minute (305 meters per minute). Figures A.112 through A.118 are the results from the second flight of data collection with the pressure rake.

For the third flight with the pressure rake, the 5-hole probe was moved to the top of the pressure rake. The goal of placing the 5-hole probe in the top probe location of the rake was to get above the canard wake influence. The top location in the pressure 
rake was considered probe location \#1 and was $0.501 \mathrm{~m}$ above the leading edge of the wing. On this flight, more off-condition, high-speed data were taken after the primary test points were finished. For the third flight, the high-speed test conditions were 172 $\operatorname{KIAS}(88 \mathrm{~m} / \mathrm{s})$ at 8,500 feet $(2,590 \mathrm{~m})$ and $170 \operatorname{KIAS}(87 \mathrm{~m} / \mathrm{s})$ at 6,500 feet $(1,980 \mathrm{~m})$; each with approximately 6 mm elevator deflection up. Figures A.119 through A.125 are the results of the third flight. Table 4.4 lists the aircraft configuration, along with the $A o A$ and speed ranges that were tested in each flight.

Table 4.4

Test Parameters during Velocity Pressure Rake Flights

\begin{tabular}{|l||c||c|c|c|}
\hline Flight Number & Weight kg (lb) & CG mm (in) & AoA Range (deg) & Speed m/s (KTAS) \\
\hline $101007-1$ & $1,199(2643)$ & $3,282(129.2)$ & $3.0-7.0$ & $105-143(54-74)$ \\
\hline $101007-2$ & $1,179(2600)$ & $3,297(129.8)$ & $1.8-7.3$ & $106-200(55-103)$ \\
\hline $101107-1$ & $1,179(2600)$ & $3,297(129.8)$ & $1.7-7.0$ & $105-175(54-90)$ \\
\hline
\end{tabular}




\section{CHAPTER V}

\section{COMPARISON OF FLIGHT AND COMPUTATIONAL RESULTS}

The comparison and verification of the flight data with the CFD simulations was the final step. During the comparisons there were many different topics that had to be addressed such as experimental results and errors, simulation results and errors, along with understanding and correcting discrepancies in the results of the two methods.

\subsection{In-Flight Measurements}

Data reduction began immediately after completion of the in-flight measurements. Freestream conditions at each test point served as boundary conditions for the simulations. Parameters reduced from flight and used as inputs for boundary conditions included freestream static pressure, temperature, density, and velocity components in the

$\mathrm{x}, \mathrm{y}$, and $\mathrm{z}$ axes. A MATLAB ${ }^{32}$ code extracted freestream data originally recorded by LabVIEW from the 24-inch 5-hole probe and the temperature probe. The pressure rake data were collected with reference to the freestream static pressure and were also reduced by the same $M A T L A B$ code. Time stamps on the freestream data and the pressure scanner allowed for accurate time correlation for the comparison of data over the five second runs. The $A o A$ traces and total pressure plots from the best test points of each flight were referenced in Chapter 4 (Figures A.105 - A.125). These results had only the calibrations of the 5-hole probe applied. As such, there were small deviations between each pitot probe and also a difference between the pitot probes and the 5-hole probe once the calibration was applied.

\subsection{Flight Test Error Production}

To be able to understand and trust the data that were collected, it was desirable to better understand, quantify, and if possible, reduce the error from the in-flight measurements. Several different parameters could have added to the error. When looking at the total 
pressure plots from the pressure rake, there were uncertainties in the location and magnitude of the wake. With the probes spaced $46 \mathrm{~mm}$ apart, the accuracy of the vertical location of the wake in relation to the leading edge of the wing could only be assumed to be within $+/-23 \mathrm{~mm}$. That was an easy error to account for, but other errors included:

- Mounting accuracy of the pressure rake and 5-hole probe in the nose

- Differences between the pitot probes and the 5-hole probe due to different inlet geometry

- Static difference between the various pitot probes

- Accuracy of the 5-hole probes

- Variations in the accuracy and offset of the pressure scanner ports

The first error source listed was easily examined after the flights. Measurements of the pressure rake and 24-inch 5-hole probe in the nose were made in relation to the aircraft. An error of $1.8^{\circ}$ in the $A o A$ orientation of the 24-inch 5-hole probe was discovered. This changed the $A o A$ range of the test points from $3^{\circ}-7^{\circ}$ to $1.2^{\circ}-5.2^{\circ}$. The pressure rake had a small, $0.67^{\circ}$, toe-out angle from the centerline of the aircraft. Manufacturer's stated accuracy of instrumentation also had to be taken into account. The pressure scanner had an error of $0.05 \%$ of its full scale range of $10 \mathrm{psi}(70 \mathrm{kPa})$. This resulted in a total error of $34 \mathrm{~Pa}$. The 5-hole probes had a stated accuracy of $0.5^{\circ}$. The other sources of error were not as easily identifiable. It was decided that testing the entire pressure rake in a wind tunnel would be the best solution. Testing in a wind tunnel allows the isolation of variables to study the impact and error of each variable (i.e. probe manufacturing discrepancies, pressure port variations, pressure scanner fluctuations, etc.)

\subsubsection{Wind Tunnel Testing}

Certain questions, which arose during review of the flight data, were of particular interest during the second round of wind tunnel testing. Upon review of the initial flight data, it was noted that the 5-hole probe appeared to have a higher total pressure reading 
than the pitot probes and when the correction for the total pressure from the 5-hole was applied, the error was magnified. There was also some random scatter between the various pitot probes on the average of $30-40 \mathrm{~Pa}$. To sort out from where these errors were originating and reduce them, it was necessary to perform more wind tunnel testing. The Oran W. Nicks Lowspeed Wind Tunnel (LSWT) at Texas A\&M University is a 7'x10' subsonic wind tunnel capable of reaching $90 \mathrm{~m} / \mathrm{s}$. The benefits of using this wind tunnel over the ELD Wind Tunnel included a test section large enough to mount the entire pressure rake, ability to move the pressure rake in both $A o A$ and $A o S$ at the same time and achieve speeds equal and over what was tested in-flight. The control room at the wind tunnel was well-equipped to run the tests and also had a Pressure Systems 8400 Pressure Scanner system that was capable of performing calibration checks at a series of designated pressures on the Pressure Systems 64 channel DTCnet pressure scanner that was used in the wind tunnel and flight tests.

\subsubsection{Setting up the Wind Tunnel Test}

The goal of the wind tunnel tests were to mimic flight conditions with the entire pressure rake and then use the steady, repeatable test conditions that a wind tunnel can provide to troubleshoot the errors and differences in the flight data. The mounting configuration for this test consisted of the pressure rake at the top of a single strut that was attached to the turn table used to control the yaw of the model. A knuckle on the top of the strut held the sting that protruded from the rake allowing the $A o A$ of the model to change between runs. A mount was designed and built to attach the pressure rake to the sting and knuckle (Figure A.126). The mount attached the pressure rake to the sting and also held the pressure scanner and DTCnet converter for the scanner. In addition to the pressure lines from the rake, scanner ports were connected the tunnel total pressure, tunnel static pressure, and calibration lines. Outside static pressure was used as the reference line for the scanner. 


\subsubsection{Wind Tunnel Tests}

Before the pressure rake was mounted in the wind tunnel, a calibration check of all 64 channels on the pressure scanner was performed at $-34.5,-17,0,17$, and $34.5 \mathrm{kPa}(-5$, 2.5, 0, 2.5 and 5 psi). Figures A.127 through A.131 show the results of the channels at each pressure setting. Special attention was paid to the results of the calibration around the zero pressure setting since the in-flight dynamic pressures were around $2 \mathrm{kPa}$. Figure A.132 shows the offset between the scanner ports that were used by the pressure rake and the calibration pressure. Once the calibration check was completed, the pressure rake was mounted into the tunnel and the tubing was connected and secured (Figure A.133). A multitude of tests were conducted including velocity sweeps from $25-75$ $\mathrm{m} / \mathrm{s}$, tunnel beta sweeps (AoA sweep on the rake) from -10 to 10 degrees at different tunnel $A o A$, along with standard, steady runs with both five second and two minute acquisitions. The velocity sweeps were conducted with no change in the AoA or AoS. The five second, two minute, and $A o A$ sweep acquisitions were all conducted at 50 and $75 \mathrm{~m} / \mathrm{s}$. Also tested was switching the ports of the 5-hole probe total pressure to isolate if there was just an error with the port or the probe design. Table C.1 in Appendix C contains a list of all the different tests performed at the wind tunnel.

\subsubsection{Wind Tunnel Test Results}

The results from the wind tunnel were very informative in both isolating and quantifying the errors in the pressure rake in-flight measurements. Several attempts were made to find a correction for each pressure port based off of the calibration checks with no avail. The posted accuracy of the scanner of $34 \mathrm{~Pa}$ proved to be the limiting factor in the random scatter of pressure ports. For reference, Table 5.1 lists the various pressure lines running into the scanner and their corresponding pressure ports. 
Table 5.1

Pressure Ports Used during the Flight-Test Experiments

\begin{tabular}{|c|c|}
\hline Pitot Probe Number & Pressure Scanner Port Number \\
\hline 1 & 1 \\
\hline 2 & 2 \\
\hline 3 & 3 \\
\hline 4 & 4 \\
\hline 5 & 5 \\
\hline 6 & 6 \\
\hline 7 & 7 \\
\hline 8 & 8 \\
\hline 9 & 9 \\
\hline 10 & 10 \\
\hline 11 & 11 \\
\hline 12 & 12 \\
\hline 13 & 13 \\
\hline 14 & 14 \\
\hline 15 & 15 \\
\hline 16 & 16 \\
\hline 17 & 17 \\
\hline 18 & 18 \\
\hline \multicolumn{2}{|l|}{12 Inch 5-Hole Probe } \\
\hline Total / Probe 19 & 21 \\
\hline Alpha (Bottom) & 22 \\
\hline Alpha (Top) & 23 \\
\hline Beta (Port) & 24 \\
\hline Beta (Starboard) & 25 \\
\hline Static & 26 \\
\hline
\end{tabular}

Any attempt at a single correction for every test point would not translate into a smaller range of reported pressures than the 30-40 $\mathrm{Pa}$ scatter that was present without any correction. This was true for all ports except port \#21. This port had shown a higher offset than the other probes. A correction of $-14 \mathrm{~Pa}(-0.002 \mathrm{psi})$ brought the port to the average of the other 18. The standard deviation for all of the ports used in the pressure rake was around $16 \mathrm{~Pa}$, which is just below half of the stated accuracy of the pressure scanner (Figure A.134). This result was the average standard deviation for 45 different five second and two minute acquisitions. Figure A.135 plots the average difference in total pressures between those in the pressure rake and the wind tunnel reference. Figures 
A.135(a) and A.135(b) show how the increase in pressure would follow port \#21. Port \#21 was the only port in which a general correction could be applied that would work for all test points. All other probes oscillated within the stated accuracy of the pressure scanner. Figure A.136 compares reported tunnel velocity and the velocity recorded by the 5-hole probe with tubing in the normal configuration and then with the total pressure port switched. Once the minimum calibrations speed was reached, the difference between the reported wind tunnel speed and the speed reported from the 5-hole probe were within $1 \%$ of each other.

\subsection{Flight Test Corrections}

With the errors taken into account, a correction of $-14 \mathrm{~Pa} \mathrm{(-0.002} \mathrm{psi)} \mathrm{was} \mathrm{applied} \mathrm{to} \mathrm{the}$ 5 -hole total pressure port. Other changes to the data reduction included a comparison of all the total pressure measurements in the rake as raw pressures from the scanner and with the calibration of the 5-hole probe total pressure applied to all probes in the rake. The best of each test point was used for the final comparison to CFD. The velocity, AoA, and $A o S$ of every test point was compared and the most stable recording for that test point was used as the input for the corresponding simulations. Table 5.2 lists the test points and their conditions that were used for the final comparisons.

Table 5.2

Test Points Used for Comparison to CFD

\begin{tabular}{|c|c|c|c|c|c|c|c|}
\hline $\begin{array}{c}\text { Test } \\
\text { Point }\end{array}$ & $\begin{array}{c}\text { Flight } \\
\text { Number }\end{array}$ & $\begin{array}{c}\text { Test Point } \\
\text { Number }\end{array}$ & $\begin{array}{c}\text { Ps } \\
\text { (Pa) }\end{array}$ & $\begin{array}{c}\text { Density } \\
\text { (kg/m3) }\end{array}$ & $\begin{array}{c}\text { Velocity } \\
\text { (KIAS) }\end{array}$ & $\begin{array}{c}\text { AoA } \\
\text { (degrees) }\end{array}$ & $\begin{array}{c}\text { AoS } \\
\text { (degrees) }\end{array}$ \\
\hline $\mathbf{1}$ & $101007-1$ & 3degrees2 & 74,570 & 0.908 & 138 & 1.2 & 0.8 \\
\hline $\mathbf{2}$ & $101007-2$ & 4 degrees2 & 74,380 & 0.908 & 129 & 2.1 & 0.4 \\
\hline $\mathbf{3}$ & $101007-2$ & 5 degrees2 & 74,390 & 0.908 & 118 & 3.2 & 1 \\
\hline $\mathbf{4}$ & $101007-1$ & 6degrees1 & 74,190 & 0.906 & 111 & 4.2 & 1 \\
\hline $\mathbf{5}$ & $101007-2$ & 7degrees3 & 74,400 & 0.912 & 106 & 5.4 & 0.8 \\
\hline
\end{tabular}

Figures for each test point include $A o A, A o S$, and velocity time traces along with results from the pressure rake averaged over the acquisition. Figures A.137 - A.151 plot the results from all five test points used for comparison. The experimental errors due to the pressure scanner and the spacing between Pitot probes were combined to produce 
error plots over the mean plot for each test point (Figures A.152 - A.156). The blue line is the experimental mean and the red lines are the different combinations of the two errors.

\subsection{Post-Flight CFD Simulations}

The simulations after the flight experiments concentrated on matching the freestream static pressure, aircraft velocity, $A o A$ and $A o S$ as the boundary conditions for the 3-D simulations. The first results from the CFD showed the wake to be larger than the measured wake from the experiment and that the location of the computed wake had a larger variation in location versus $A o A$ compared to the in-flight measurements. Initial studies of refining the mesh with 2-D simulations did little to improve the discrepancies. Only refinement of the 3-D meshes resulted in a correction of the problem. The 2-D simulations repeatedly calculated the location of the wake as higher than actual. 2-D simulations were bound to be inaccurate due to their inability to account for the 3-D effects. While the choice in location of the rake was picked to minimize the 3-D effects, it was impossible to completely remove them from the experiment. The only solution was to decrease the cell size in the wake of the mesh to roughly $10 \mathrm{~mm}$. With the canard wake region mesh refined, the wake was properly captured by the simulations and compared well with the in-flight measurements.

\subsection{Computational Errors}

The accurate depiction of uncertainty and errors in CFD is an actively disputed topic to this day. There still has not been community-wide agreement of what can contribute to errors, what should be included, and how to calculate the errors and uncertainty in both simulations and meshing. Open forums and discussions are currently focused on trying to come to a consensus on uncertainty analysis and errors in CFD work. One such example was the Mesh Quality and CFD Solution Accuracy Session at the 2008 AIAA Aerospace Science Meeting. Errors in CFD simulations may originate from many different variables such as mesh refinement, mesh skewness, turbulence model selection, 
boundary conditions, input accuracy, and solver accuracy. Isolating and examining many of these errors requires an extensive set of simulations that isolate single variables and examine them in-depth.

For this research, it was decided to focus on sources of errors that can be best examined and controlled by the user of a commercial available solver. This means that errors due to factors that depend on the code developer, such as discretization schemes, will not be examined. The error sources examined in this research include grid refinement, choice of turbulence model, mesh refinement, boundary conditions, and input accuracy. 2-D simulations focused on determining mesh sizes and turbulence models that provided repeatability, robustness, and agreement with experimental data. Results from the 2-D simulations showed that the mesh refinement and turbulence models of Spalart-Allmaras and $k$ - $\omega$ agreed well with previous data and were not contributing any noticeable error or uncertainty. Once the final mesh was constructed, a second series of tests looking at the turbulence model and also the pressure-velocity coupling was conducted. Figure A.157 plots the differences between these simulations by looking at the differences in pressure drop and location of the pressure minimum in the wake of the canard. The results concluded that there was a $3 \mathrm{~Pa}$ discrepancy between coupling methods and a $4 \mathrm{~Pa}, 20 \mathrm{~mm}$ difference due to the turbulence model choice.

Errors due to input accuracy were also examined through a series of simulations. These simulations included the experimental error of the 5-hole probes in static pressure, velocity and angles. Stated accuracies were $\pm 0.5^{\circ}$ for $A o A$ and $A o S, 10 \mathrm{~Pa}$ for freestream static pressure and $0.125 \mathrm{~m} / \mathrm{s}$ for freestream velocity. The freestream velocity and static pressure errors made no difference in the results of the simulations. The accuracy of the $A o A$ angle being within $\pm 0.5^{\circ}$ did create errors of up to $6 \mathrm{~Pa}$ and $16 \mathrm{~mm}$. Figure A.158 plots the differences due to $\pm 0.5^{\circ}$ for $A o A$ on simulations for Test Point \#1.

\subsection{Final Comparison between In-Flight Measurements and CFD Simulations}

The final comparison of the computational and experimental work must also include quantified errors from the different parts of the project. Over the previous sections, 
several different sources and magnitudes of errors were discussed. Table 5.3 provides a listing of the different errors, their magnitudes, and whether they were applied to the experimental or computational results.

Table 5.3

Experimental and Computational Errors and Magnitudes

\begin{tabular}{|l|c|c|c|}
\hline \multicolumn{1}{|c|}{ Description } & $\begin{array}{c}\text { Pressure } \\
\text { Magnitude (Pa) }\end{array}$ & $\begin{array}{c}\text { Location } \\
\text { Magnitude (mm) }\end{array}$ & $\begin{array}{c}\text { Applied to } \\
\text { Results of }\end{array}$ \\
\hline Probe Spacing & N/A & 23 & Experiment \\
\hline Pressure Scanner Accuracy & 17 & N/A & Experiment \\
\hline 5-Hole AoA Accuracy & 6 & 16 & Computations \\
\hline 5-Hole Ps Accuracy & 0 & 0 & Computations \\
\hline 5-Hole Velocity Accuracy & 0 & 0 & Computations \\
\hline Turbulence Model & 4 & 20 & Computations \\
\hline Pressure-Velocity Coupling & 3 & 0 & Computations \\
\hline
\end{tabular}

The total errors for the computations from the various sources added up to $13 \mathrm{~Pa}$ and $36 \mathrm{~mm}$, while the total errors for the experiment added up to $17 \mathrm{~Pa}$ and $23 \mathrm{~mm}$. Another source of error in the experiment was error introduced from the generation of the CAD model of the aircraft. Unfortunately, no reasonable way to quantify this error, short of completely remapping the aircraft and comparing CAD models, has been determined.

Figures A.159-A.163 present the final comparisons between the experimental and computational results with the appropriate errors applied to each. Each test point matched up well between the experimental and computational results. When the error bars for both the experimental and computational work were applied, the agreement was reinforced. During the comparisons, it was noticed at the highest speed 138 knots (71 $\mathrm{m} / \mathrm{s}$ ), the pressure drop was not completely captured; but at all other test conditions, the location and total pressure drop agreed. This disagreement is likely due to the assumption of holding a steady test condition and the process in which the data were acquired. During the first flight, the freestream measurements are recorded approximately $2-3$ seconds longer than the pressure rake data. A small change in flight conditions could have occurred resulting in the test condition averages being slightly skewed away from when the pressure rake data were recorded. 


\section{CHAPTER VI}

\section{CONCLUSIONS AND RECOMMENDATIONS}

\subsection{Conclusions}

A combined computational and experimental study into the canard wake of the Velocity has been completed. In-flight measurements verified the full-scale 3-D CFD simulations. Besides the verification with in-flight measurements, the CFD results were validated by grid convergence, control-volume size, and turbulence-modeling studies that were successfully completed. These tests provided results that were just as important as the inflight measurements to prove the robustness of the generated mesh and the solver that were used. The comparisons between the CFD simulations and the in-flight measurements agreed quite well. All test points match up within the experimental and computational error. In addition to the focused CFD on the wake, simulations were performed on the entire aircraft. Also, a database of results were built that included information not used in this study to verify the CFD simulations such as flying qualities and high speed dives with the elevator deflected.

The agreement of the two methods in the prediction and measurement of the canard wake makes any future projects feasible in this region of the aircraft. The location and strength of the wake has been determined at multiple $A o A$ s and can be predicted for future projects. This study has shown that a wing glove can be used, but it would encounter the wake of the canard which would introduce another variable that must be taken into account. The hard points in the wing would easily allow an object to be placed below, or above, the regions of influence from the canard.

There are hundreds of different options that can be selected when creating and running a CFD simulation. Ideally, a study of the difference due to each would be performed, but this is often impractical due to time and computational constraints. As that is not possible at the current time, performing as many studies as possible, i.e. grid refinement, control size, boundary conditions, turbulence models, etc is the next best 
solution. The ability of the user to effectively perform simulations also comes with experience and proper discretion when setting up and running the simulations.

The project proved that CFD has matured to the point where it can be performed by a single individual for an entire aircraft within a reasonable time frame. It is noted that as the user gains more experience with the software, the faster the work can progress. In regards to the computational resources, CFD simulations still require a large amount of man-hours, particularly for developing the meshes, and an even larger amount of processor time and memory. While the systems run by the Supercomputing Center have the physical capabilities of running a refined mesh over the entire aircraft that can capture the entire flowfield at once, they have limitations applied to the user that prevent this from being possible. Progress in the simulations required continual requests for access to larger amount of memory. The Supercomputing Center limited the amount of memory and time that a single job can consume in order to facilitate the other users on the system. These limits mean that only certain parts of the aircraft can be adequately studied at one time. From the 3-D results of this study, it has been determined that very accurate simulations require a very fine mesh that has a large computational demand. Therefore if flow over any other part of the aircraft is desired outside of the area of interest from this research, a new mesh would be required that focused on a refined mesh in that region of the flow.

Preliminary simulations of the canard wake predicted it to be larger and be more sensitive to angle of attack than experimentally measured. Both of these errors were due to problems with the meshes that were used. The preliminary 3-D meshes were too coarse to adequately capture the wake and the 2-D simulations did not properly model the flow in the area due to the fact that 3-D effects were ignored. With the turbulence models applied to the 3-D meshes, the wake would dissipate too quickly if the cells were larger than $20 \mathrm{~cm}$ in the wake. Due to the incorrect preliminary modeling of the wake, two primary design factors were incorrect: 
- The pressure rake was much taller than needed due to the belief that the wake location was more sensitive to $A o A$

- The spacing of the pitot probes in the pressure rake was too distant to resolve the pressure drop in the wake as well as desired

Another parameter that affected the sizing of the pressure rake was the angles of attack that the aircraft was able to achieve with zero elevator deflection. This problem was not preventable due to the fact that design of the pressure rake needed to begin before the 24-inch 5-hole probe could arrive, be installed and flown to determine the test points. This lack of knowledge of the proposed test points prior to the design of the experimental equipment should be avoided by any future projects now that the equipment is available in the FRL inventory.

The procedure of assembling all components of the experiment and testing before they are installed into the aircraft eased any problems that might have arisen with running the experiment. Due to the set-up and recordings in the ELD Wind Tunnel, there were no problems with the software, data acquisition, or interfaces with the experiment once it was installed in the aircraft. The only additional preparation for flight tests that should have been completed was the testing of the entire pressure rake in the LSWT. This was done after the flight test, instead of before, which wasted time during the postflight data reduction. This would have shown the variations to expect in the experiment and allowed the team to determine which pressure ports were acting irregularly. This should have been the intermediate step between the testing of the problems and software in the ELD wind tunnel and the flight experiments.

\subsection{Recommendations}

Over the course of this research project, several conclusions were made that could improve this experiment and supplement this study. Recommendations for future work include: 
- Use of a pressure transducer with a smaller pressure range and less uncertainty at lower pressures

- Test the entire pressure rake in a wind tunnel before the flight test rather than after; this would have saved time and effort during post-flight processing of data

- Use the CMM to measure the aircraft with the 24-inch 5-hole probe in the nose and the pressure rake on the wing to verify the exact orientations of each with respect to the aircraft CFD model

- Machine the pressure rake with a tighter spacing for the pitot probes to obtain better resolution of the wake

- Recalibrate the pressure scanner and perform regular recalibration checks

- Collect $C p$ data from the canard to check for the differences and discrepancies between structured and unstructured meshes

- Trip the flow over the canard to verify that is turbulent and look for any changes in the measured wake

- Develop a time relation for the lag between the freestream measurements and the pressure rake so that CFD simulations of instantaneous flow conditions instead of averaged conditions could be conducted

- Create meshes of the canard with the elevator deflected and then measure the corresponding flight conditions with the canard deflected. This would allow for a greater range of $A o A$ s to be tested

Though there are many recommendations that have been made to improve or supplement the research that has been presented; the agreement between the CFD simulations and the in-flight measurements give confidence in the results presented about the size, strength and location of the canard wake. These results give an accurate depiction of the flow about the aircraft that can be used for the planning and execution of future research projects. 


\section{REFERENCES}

${ }^{1}$ Anderson, John D., Computational Fluid Dynamics: The Basics with Applications, $1^{\text {st }}$ Edition, McGraw-Hill Book Co., New York, 1995, Chapter 1.

${ }^{2}$ Braslow, Albert L., and Muraca, Ralph J., "A Perspective of Laminar-Flow Control”, AIAA Paper 1978-1528, NASA Langley Research Center, Hampton, VA, 1978.

${ }^{3}$ Lamar, John E., and Obara, Clifford J., "Review of Cranked-Arrow Wing Aerodynamics Project: Its International Aeronautical Community Role", AIAA Paper 2007-487, NASA Langley Research Center, Hampton, VA, 2007.

${ }^{4}$ Boelens, O.J., Spekreijse, S.P., Sytsma, H.A., and de Cock, K.M.J., "Comparison of measured and simulated flow features for the full-scale F-16XL aircraft", AIAA 2007489, National Aerospace Laboratory NLR, Amsterdam, The Netherlands, 2007.

${ }^{5}$ Velocity Incorporated Website, http://www.velocityaircraft.com, [cited 5 January 2007].

${ }^{6}$ Velocity Owner's Flight Manual \& Weight \& Balance - XL Series Aircraft, Velocity Incorporated, Sebastian, FL, December 2003.

${ }^{7}$ Velocity XL Retractable Gear Builders Manual, Velocity Incorporated, Sebastian, FL, December 2003.

${ }^{8}$ SolidWorks, Software Package, Ver. 2007 SP3.1, SolidWorks Corporation, Concord, MA, 2007.

${ }^{9}$ Direct Dimensions Product and Service Catalog, Direct Dimensions, Incorporated, Owings Mill, MD, http://www.dirdim.com/pdfs/DDI_Product_Service_Catalog.pdf, [cited 13 Dec 2007].

${ }^{10}$ Revworks, Software Package, Ver. 6, Revware Incorporated, Raleigh, NC, 2006.

${ }^{11}$ Gambit, Software Package, Ver. 2.3.16, Fluent Incorporated, ANSYS Incorporated, Lebanon, NH, 2006.

${ }^{12}$ IBM Regetta p690 Hardware Configuration, Texas A\&M University Supercomputing Facility, College Station, TX, http://sc.tamu.edu/systems/agave/hardware.shtml, [cited 10 August 2006]. 
${ }^{13}$ SGI Altix 3700 Hardware Configuration, Texas A\&M University Supercomputing Facility, College Station, TX, http://sc.tamu.edu/systems/cosmos/hardware.shtml, [cited 10 August 2006].

${ }^{14}$ Fluent, Software Package, Ver. 6.3.26, Fluent Incorporated, ANSYS Incorporated, Lebanon, NH, 2006.

${ }^{15}$ Spalart, P., and Allmaras, S., "A One- Equation Turbulence Model for Aerodynamic Flows”, Technical Report AIAA Paper-92-0439, AIAA, 1992.

${ }^{16}$ Launder, B.E., and Spalding, D.B., Lectures in Mathematical Models of Turbulence, Academic Press, London, England, 1972.

${ }^{17}$ Yakhot, V., Orszag, S.A., Thanjam, S., Gatski, T.B., and Speziale, C.G., "Development of Turbulence Models for Shear Flows by a Double Expansion Technique”, Physics of Fluids, Vol. 4, No. 7, 1992, pp. 1510-1520.

${ }^{18}$ Shih, T.H., Liou, W.W., Shabbir, A., Yang, Z., and Zhu, J., “A New K- $\varepsilon$ EddyViscosity Model for High Reynolds Number Turbulent Flows - Model Development and Validation" Computers Fluids, Vol. 24, 1995, pp. 227-238.

${ }^{19}$ Wilcox, D.C., Turbulence Modeling for $C F D$, DCW Industries, Inc., La Canada, CA, 1998.

${ }^{20}$ Wilcox, D.C., "Re-assessment of the Scale-determining Equation for Advanced Turbulence Models", AIAA Journal, Vol. 26, 1988, pp 1414 - 1421.

${ }^{21}$ Menter, F.R., "Two-equation Eddy-Viscosity Turbulence Models for Engineering Applications", AIAA Journal, Vol. 32, 1994, pp.1598-1605.

${ }^{22}$ McAlister, K.W., Pucci, S.L., McCrosky, W.J., and Carr, L.W., “An Experimental Study of Dynamic Stall on Advanced Airfoil Sections, Volume 2. Pressure and Force Data”, NASA Technical Memorandum 84245, Ames Research, Moffett Field, CA, September, 1982.

${ }^{23}$ Vos, W.G.M, "The Verification and Validation of Preliminary CFD Results for the Construction of an A Priori Aerodynamic Model", M.S. Thesis, Aerospace Engineering Dept., Delft University of Technology, Delft, The Netherlands, 2007.

24“"Information for Use by Industry", $4^{\text {th }}$ Edition, MIT Wright Brothers Wind Tunnel, Massachusetts Institute of Technology, Cambridge, MA, 2002. 
${ }^{25}$ Bui, Trong T., Oates, David L., and Gonsalez, Jose C., "Design and Evaluation of a New Boundary Layer Rake for Flight Testing", NASA Technical Memorandum - 2000209014, January 2000, NASA Dryden Flight Research Center, Edwards, CA.

${ }^{26}$ Pfeiffer, Neal J., "Wake Rake Studies Behind a Swept Surface, Canard Aircraft", A88-2552-CP, Beech Aircraft Corporation, Wichita, KS, 1988.

${ }^{27}$ Gracey, William, "Measurement of Aircraft Speed and Altitude", NASA Reference Publication 1046, Langley Research Center, Hampton, VA, May 1980.

${ }^{28}$ Gracey, William, Letko, William, and Russell, Walter R., "Wind Tunnel Investigations of a Number of Total-Pressure Tubes at High Angles of Attack, Subsonic Speeds", Langley Aeronautics Laboratory, Langley Field, VA, April 1951.

${ }^{29}$ COSMOSWorks, Software Package, Ver. 2007 SP3.0, SolidWorks Corporation, Concord, MA, 2007.

${ }^{30}$ McKnight, Chris W., "Design and Safety Analysis of an In-flight, Test Airfoil", M.S. Thesis, Aerospace Engineering Dept., Texas A\&M University, College Station, TX, 2006.

${ }^{31}$ LabVIEW, Software Package, Ver. 8.2, National Instruments, Austin, TX, 2007.

${ }^{32}$ MATLAB, Software Package, Ver. R2006b, The MathWorks, Inc., Natick, MA, 2006

${ }^{33}$ Karman, Jr., Steve, Mitchell, Brent, Sawyer, Shane, and Whitt, Justin, "Unstructured Grid Solutions of CAWAPI F-16XL by UT SimCenter", AIAA Paper 2007-0681, University of Tennessee at Chattanooga, Chattanooga, TN, 2007.

\section{SUPPLEMENTAL SOURCES CITED}

Stern, Fred, Wilson, Robert V., Coleman, Hugh W., and Paterson, Eric G., "Comprehensive approach to Verification and Validation of CFD Simulations-Part 1: Methodology and Procedures", Journal of Fluids Engineering, Vol. 123, Dec. 2001, pp $793-802$.

Stern, Fred, Wilson, Robert V., Coleman, Hugh W., and Paterson, Eric .G., "Verification and Validation of CFD Simulations", IIHR Report No. 407, Iowa Institute of Hydraulic Research, The University of Iowa, Iowa City, Iowa, Sept. 1999. 
Lombardi, G., "Canard Tip Vortex Splitting in a Canard-Wing Configuration: Experimental Observations", Journal of Aircraft, Vol. 32, No. 4, Aug. 1995, pp 875 877.

Anderson, John D., Fundamentals of Aerodynamics, $4^{\text {th }}$ Edition, McGraw-Hill Book Co., New York, 2005.

Coleman, Hugh W. and Steele, W.Glenn, Experimentation and Uncertainty Analysis for Engineers, $2^{\text {nd }}$ edition, Wiley \& Sons, Inc., New York, 1999.

Garcia, E., van Nispen, A., and Slingerland, R., "Downwash at the Tail of SweptWing Transports with High-Lift Devices", AIAA 2001-5237, Delft University of Technology, Delft, The Netherlands, 2001.

Silverstein, Abe, Katzoff, S., and Bullivant, W.K., "Downwash and Wake Behind Plain and Flapped Airfoils", NACA Report No. 651, Langley Memorial Aeronautical Laboratory, Langley Field, VA 1938, pp 179-206.

Silverstein, Abe, and Katzoff, S., "Design Charts for Predicting Downwash Angles and Wake Characteristics Behind Plain and Flapped Wings", NACA Report No. 648, Langley Memorial Aeronautical Laboratory, Langley Field, VA 1938.

Lee, Tacheng, and Lan, C.Edward, "Navier-Stokes Calculation of Wing Wake Structure", AIAA-94-1882-CP, Aero Industry Development Center, Taichung, Taiwan, 1994.

Griffin, K.E., and Jonas, F.M. "Wake Characteristics and Interactions of the Canard/Wing Lifting Surface Configuration of the X-29 Forward-Swept Wing Flight Demonstrator", AIAA-83-1835, United States Air Force Academy, Colorado Springs, CO, 1983.

Krause, Lloyd N., "Effects of Pressure-Rake Design Parameters on Static-Pressure Measurements for Rakes Used in Subsonic Free Jets", NACA Technical Note 2520, Lewis Flight Propulsion Laboratory, Cleveland, OH, 1951.

Abbott, Ira H., and von Doenhoff, A.E., Theory of Wing Sections: Including a Summary of Airfoil Data, Dover Publications Inc., New York, 1959. 
APPENDIX A

FIGURES 


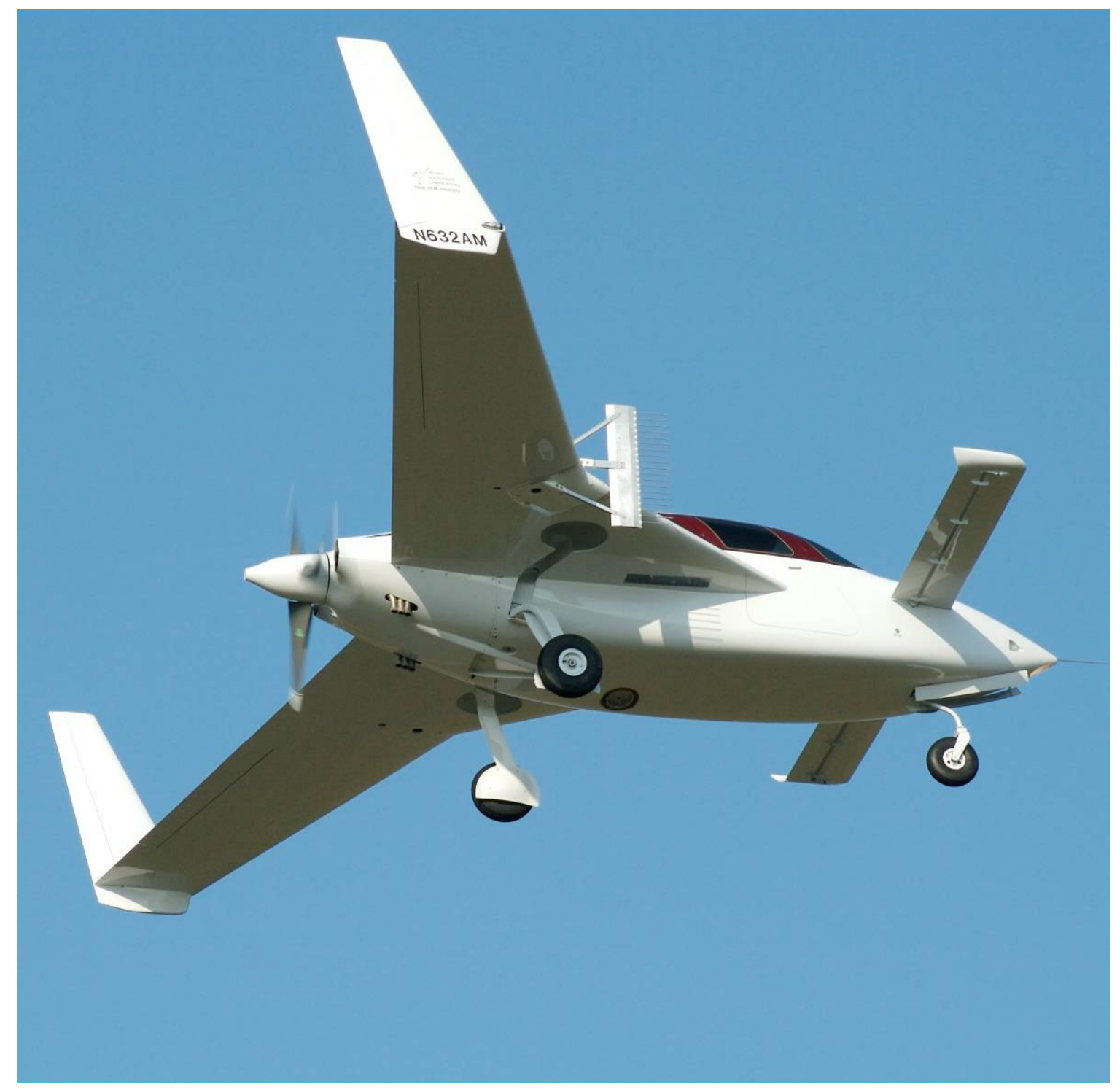

Figure A.1 Velocity XL-5 RG, N632AM 


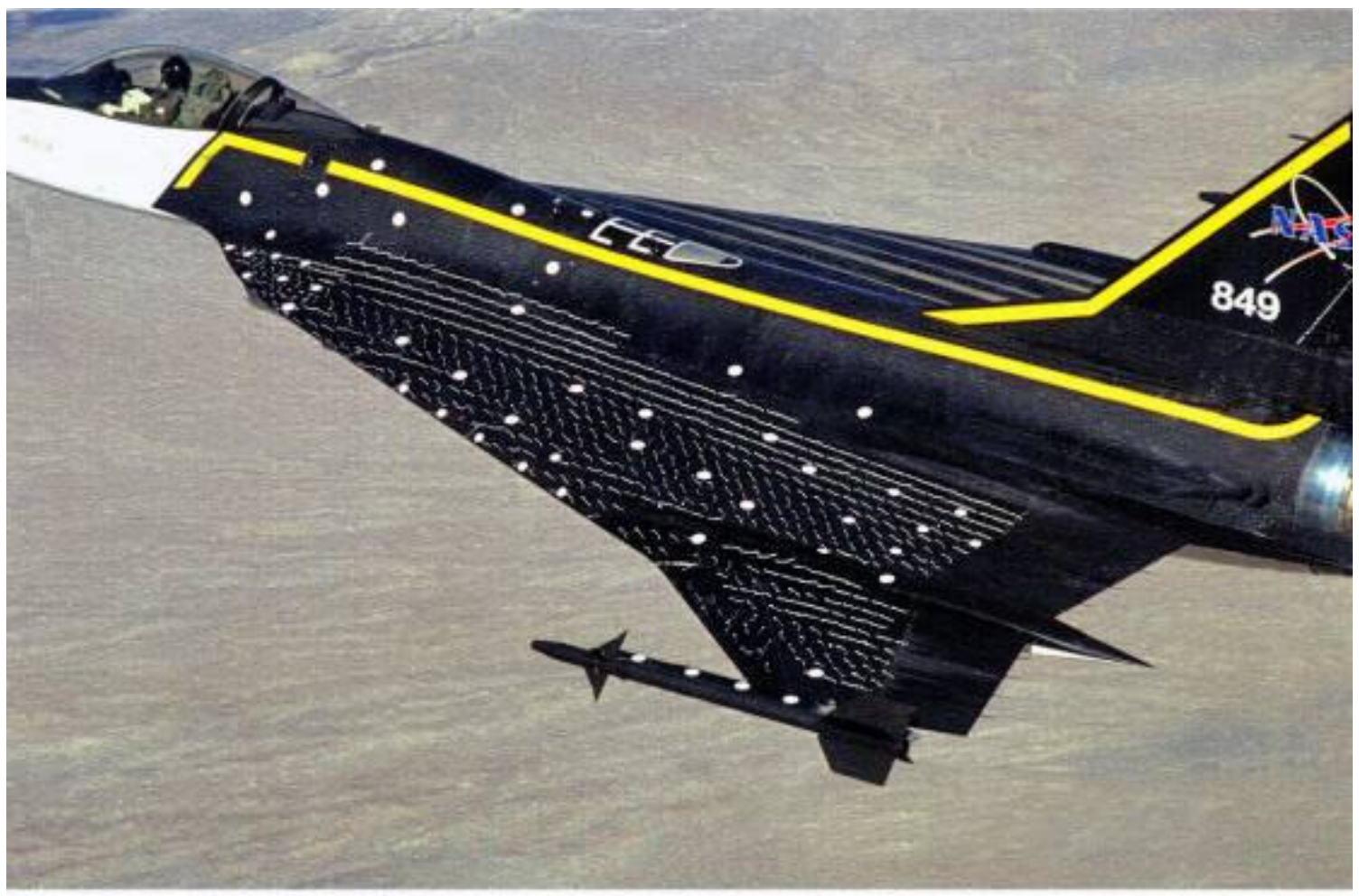

Dryden Flight Research Center EC96-43508-6 Photographed 1996 $\mathrm{F}-16 \mathrm{XL \# 1}$ CAWAP al pha $=10^{\circ}$, bet $\mathrm{a}=-5^{\circ}, \mathrm{hp}=10,000 \mathrm{ft}$. (NASA photo)

Figure A.2 NASA Photo Number: EC96-43508-9 of the F-16XL\#1 Taken on March 4, 1996 (Courtesy of NASA Dryden) 


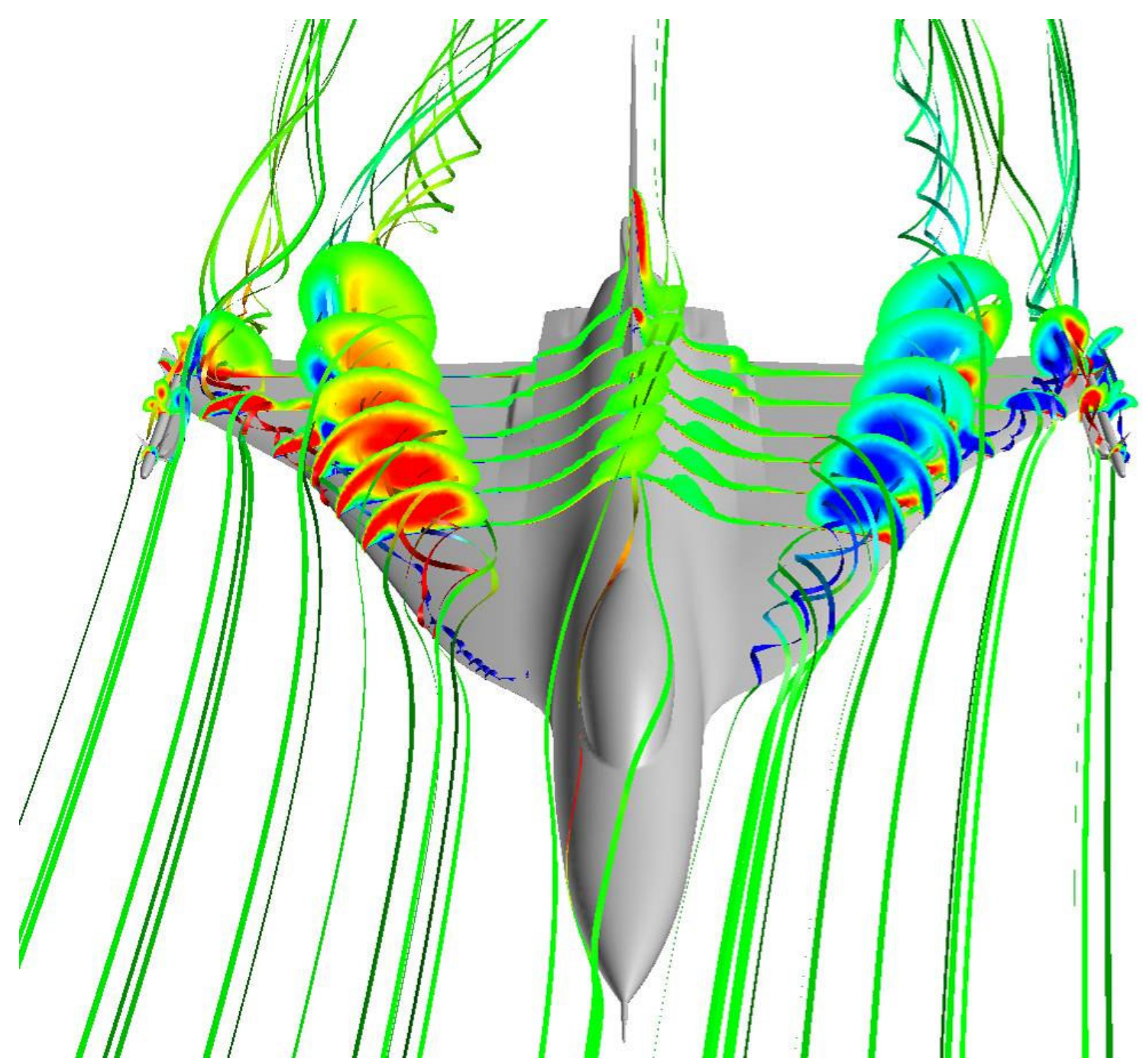

Figure A.3 CAWAPI CFD Results: Pressure-colored Streamlines and X-vorticity Component for FC50 with TENASI Solver (Courtesy of Dr. Steve Karman) ${ }^{33}$ 

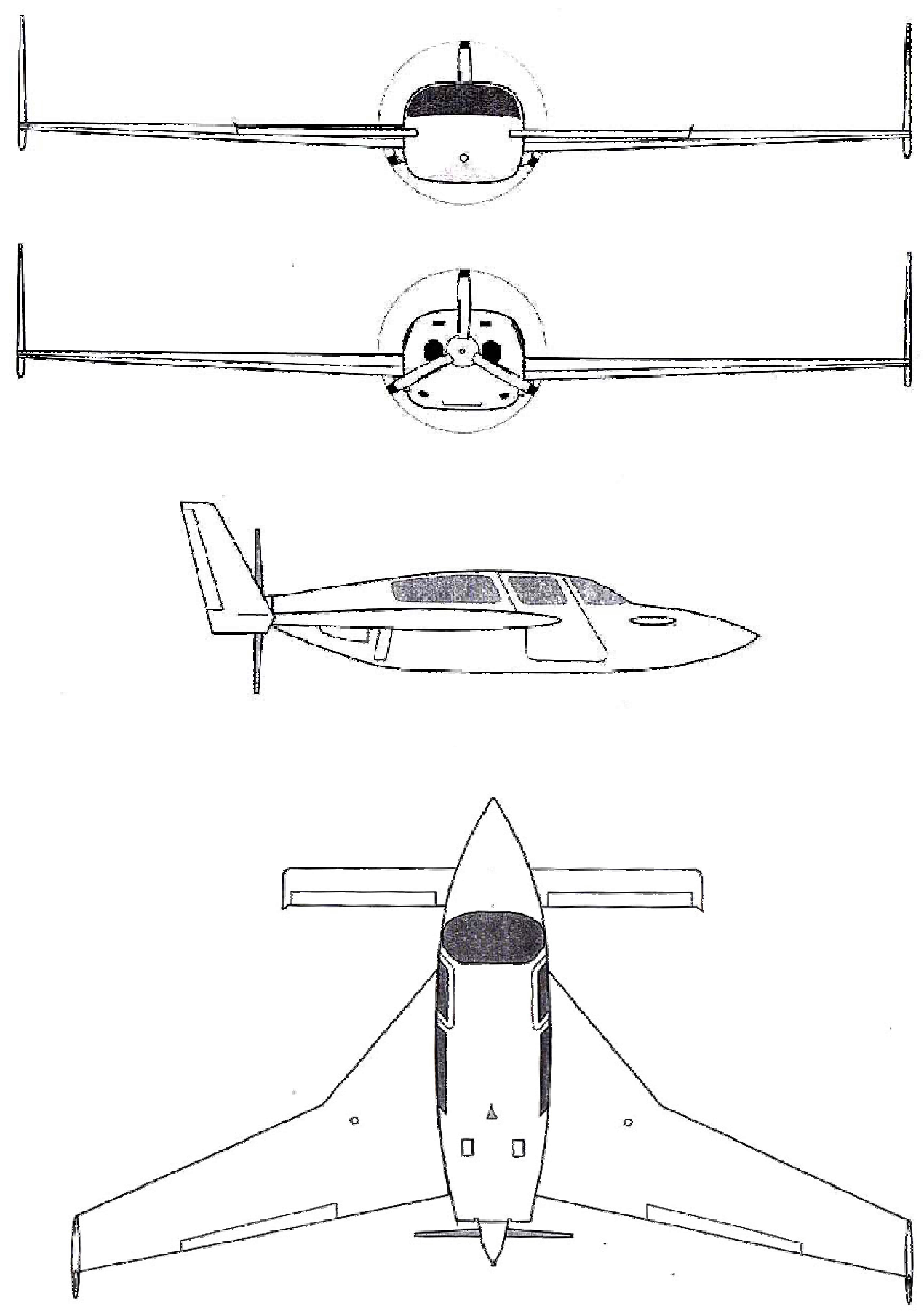

Figure A.4 Factory Supplied Three-view of the Velocity XL-5 RG 


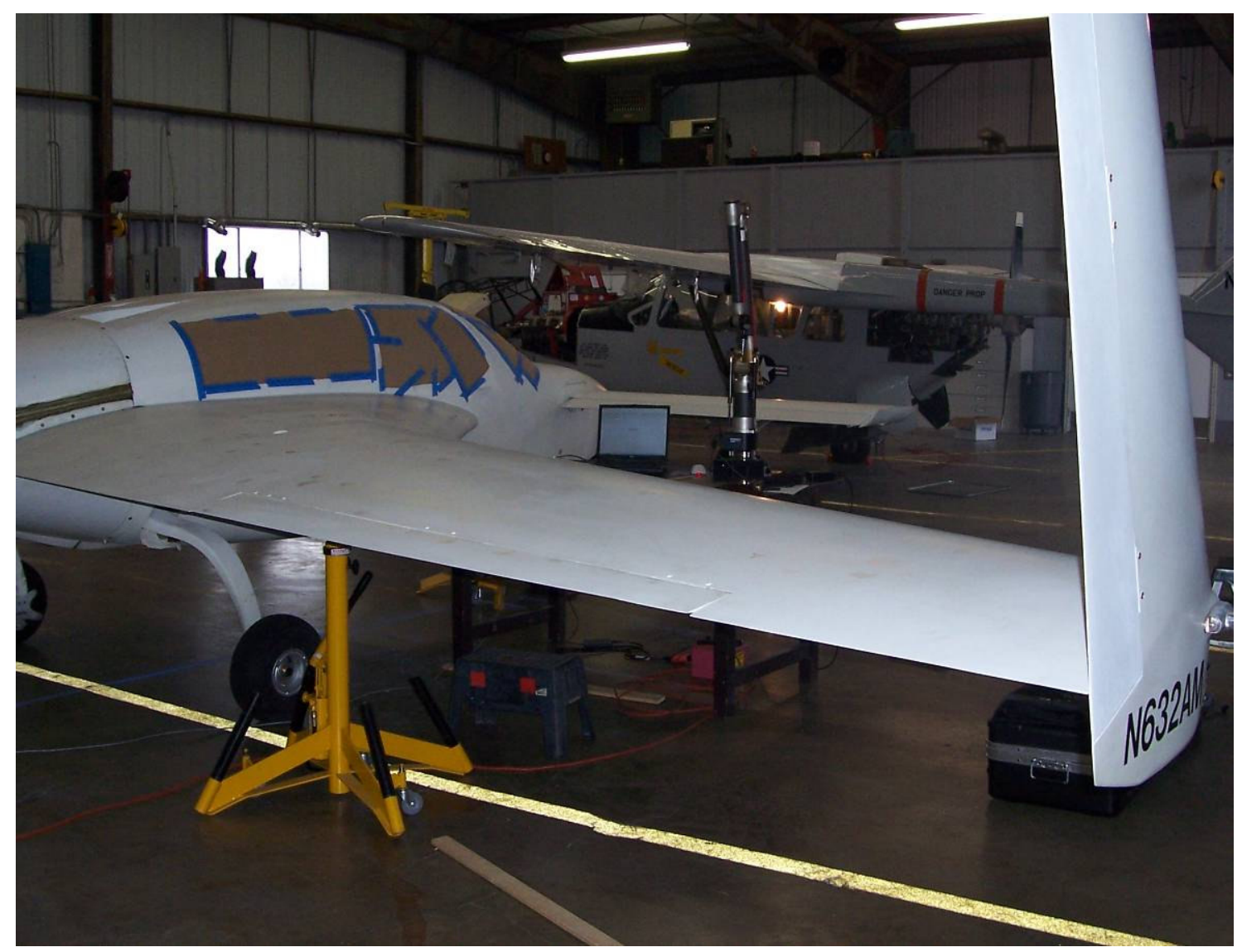

Figure A.5 Velocity XL-5 RG on Aircraft Jacks during Surface Measurements 


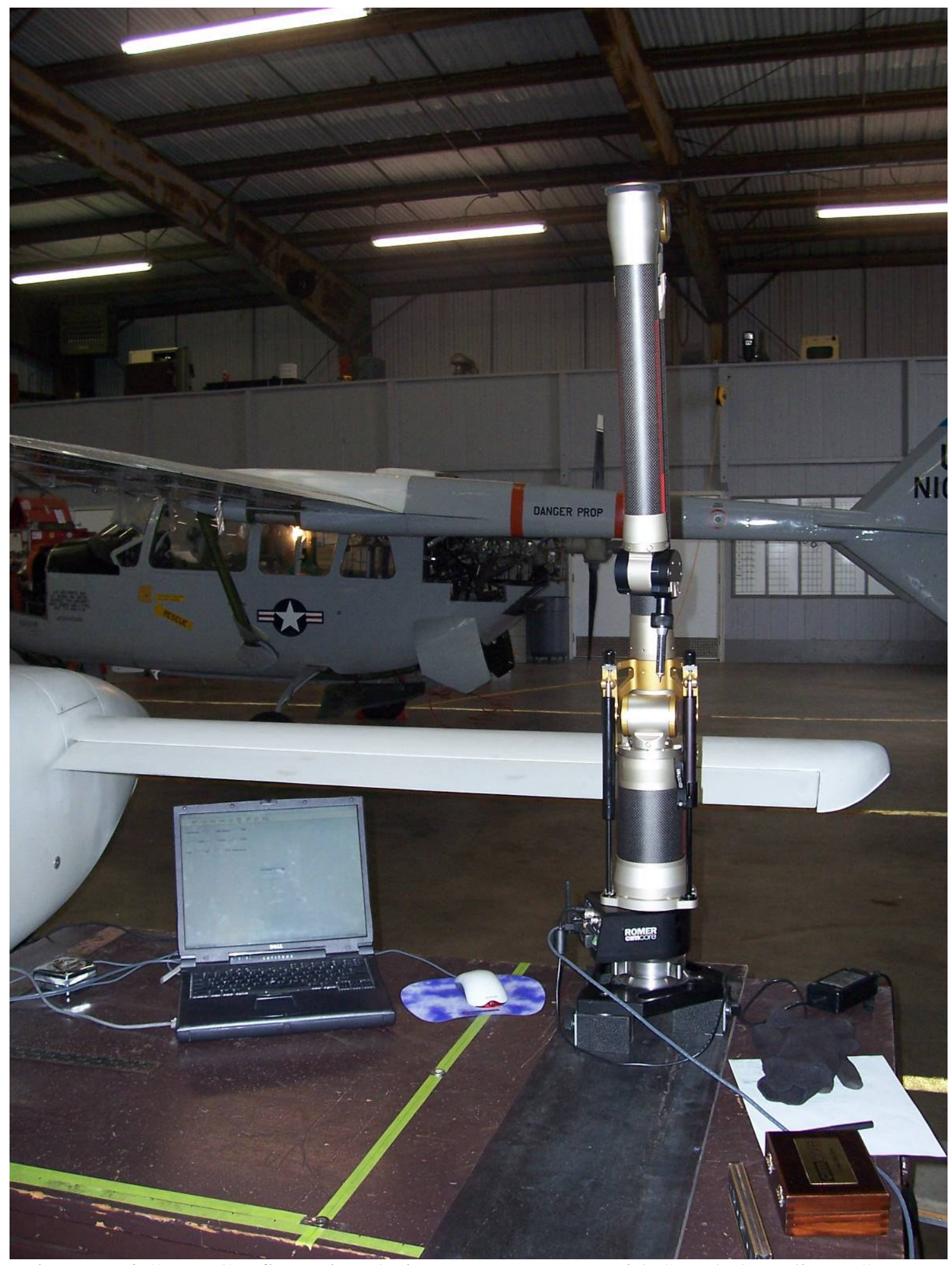

Figure A.6 CMM Configuration during Measurements with Stand, Coordinate System Origin, and Acquisition Program 


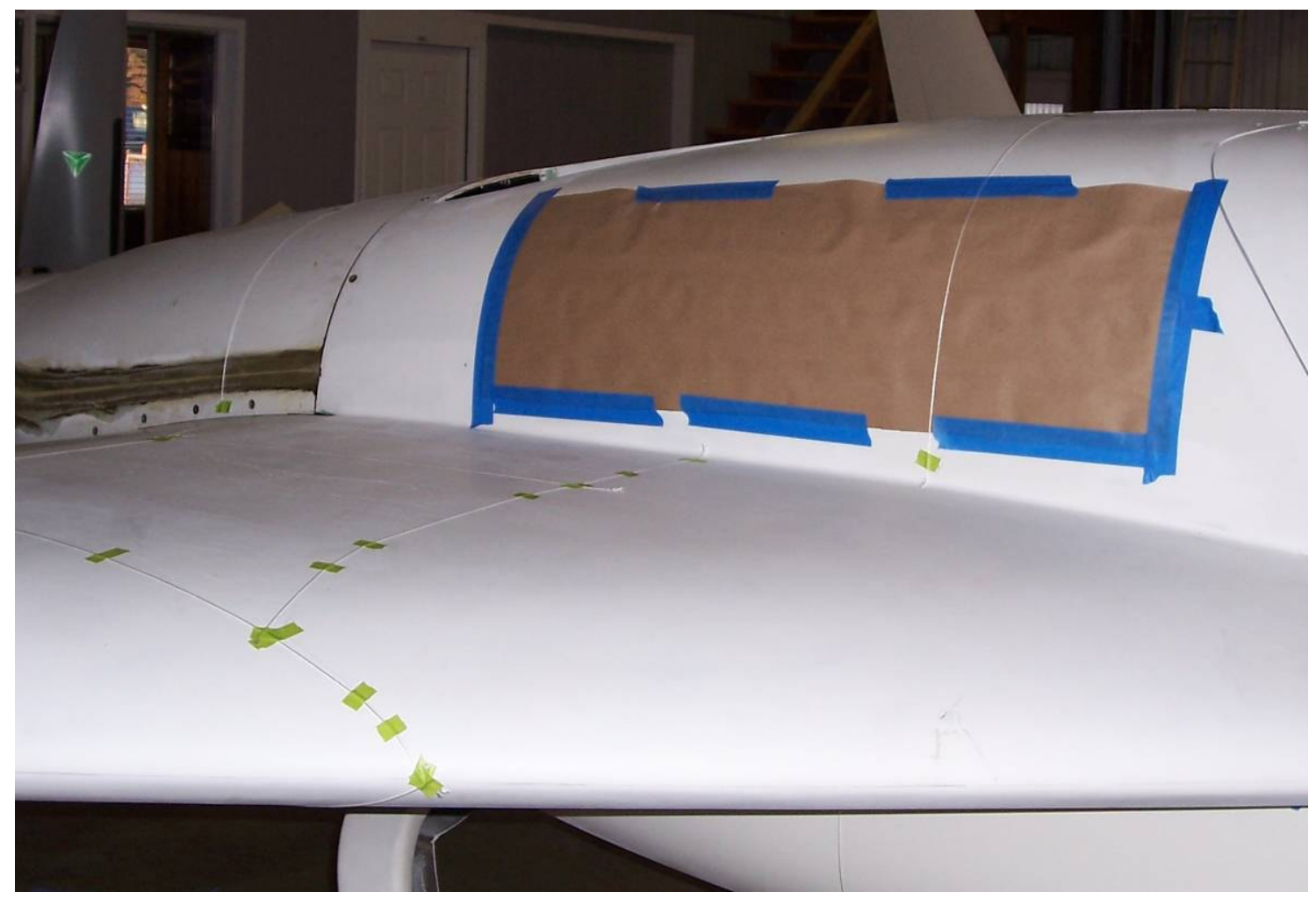

Figure A.7 Aircraft Split into 19 Sections for Measurements 


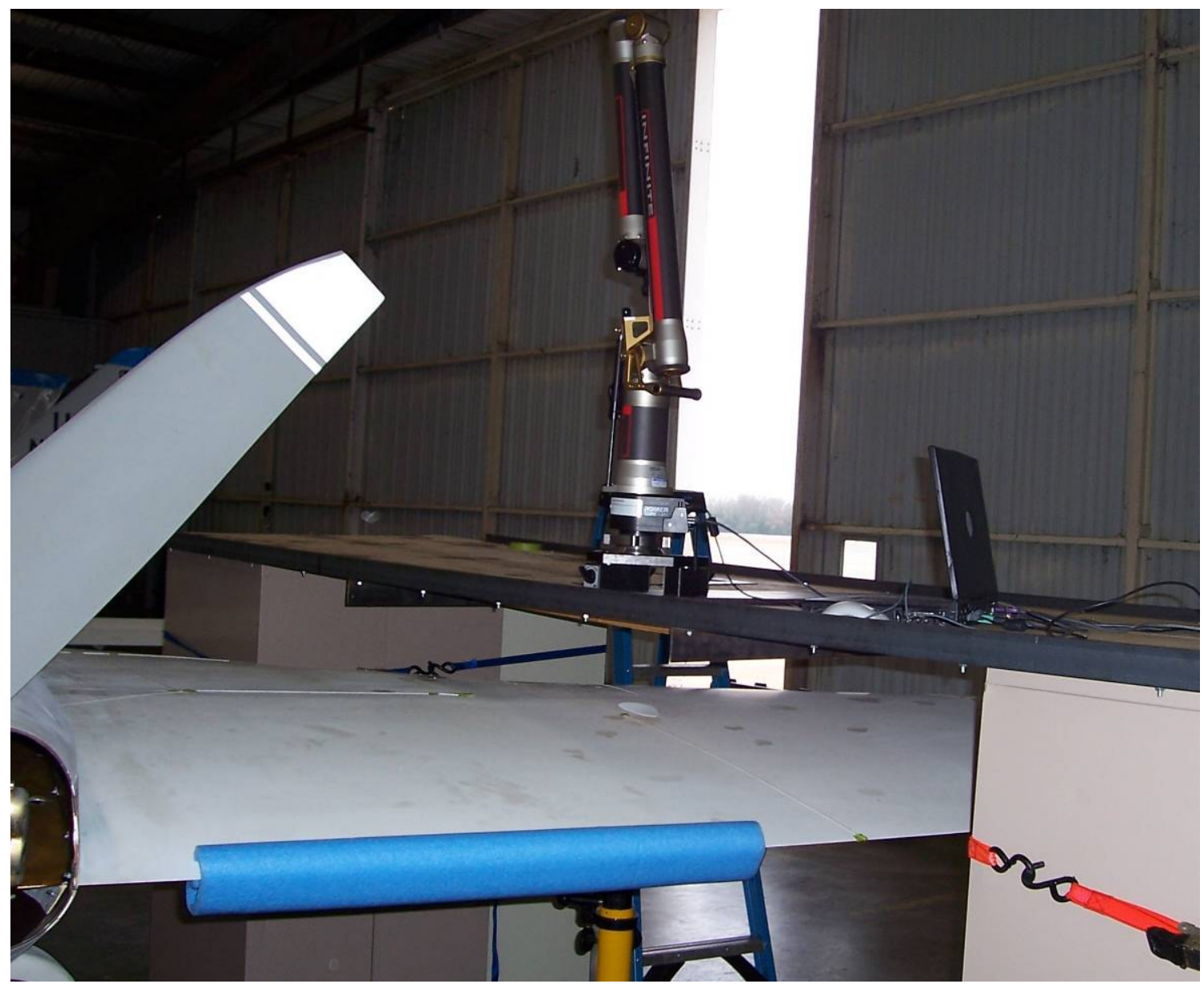

Figure A.8 CMM on Scaffolding over the Top of the Aircraft Wing 


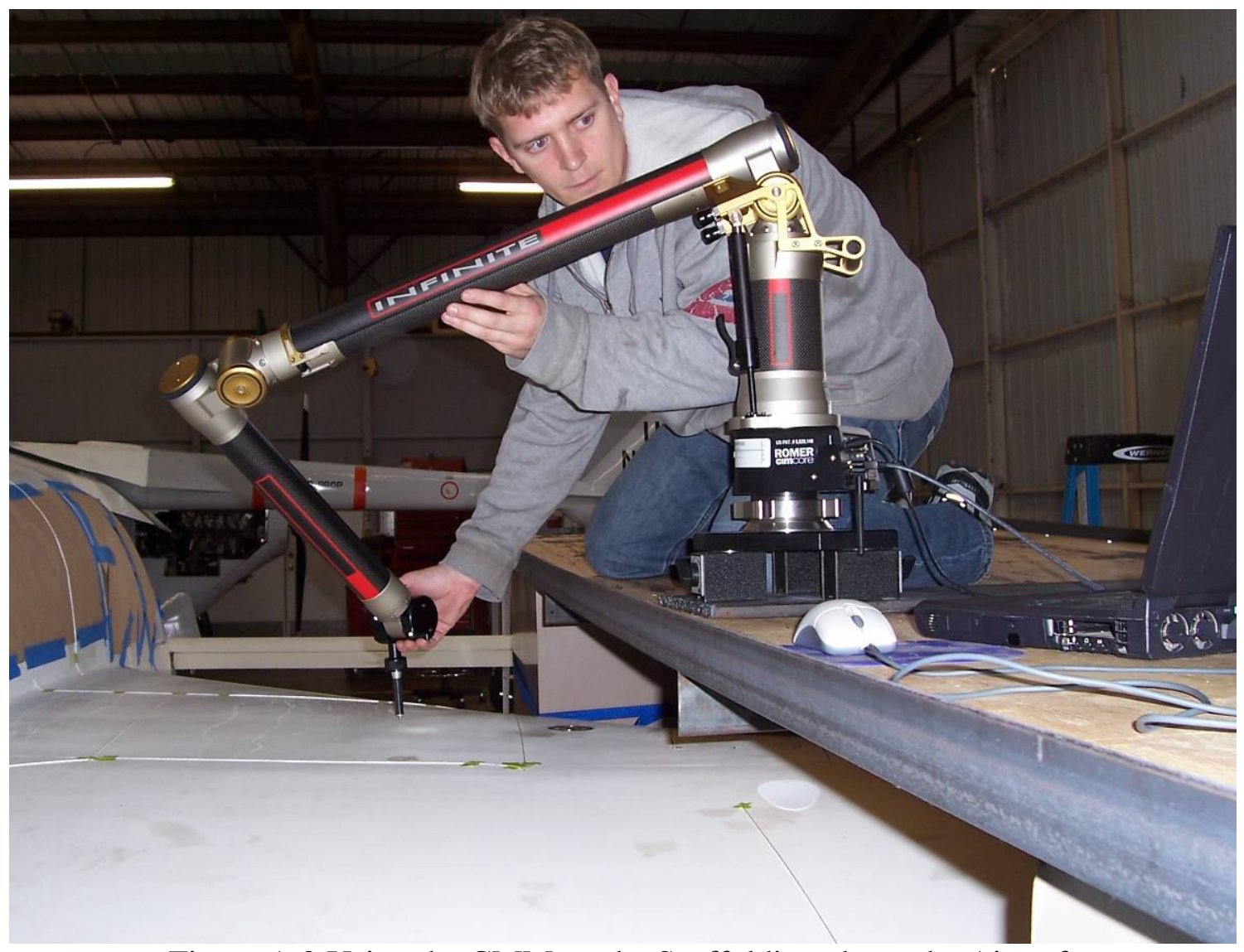

Figure A.9 Using the CMM on the Scaffolding above the Aircraft 


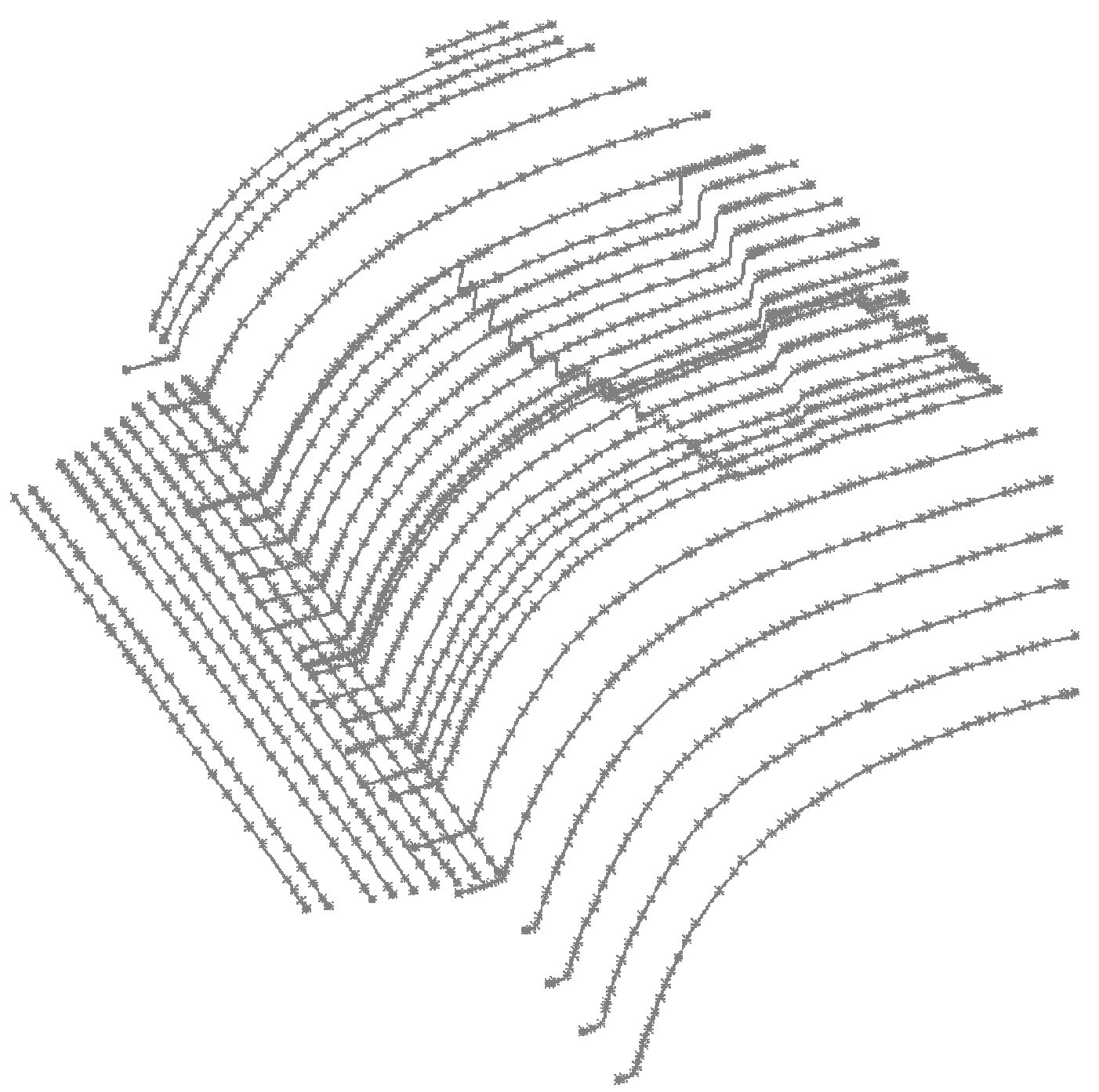

Figure A.10 2-D Splines from CMM of the Top, Center Fuselage of the Velocity with the Engine Inlet 


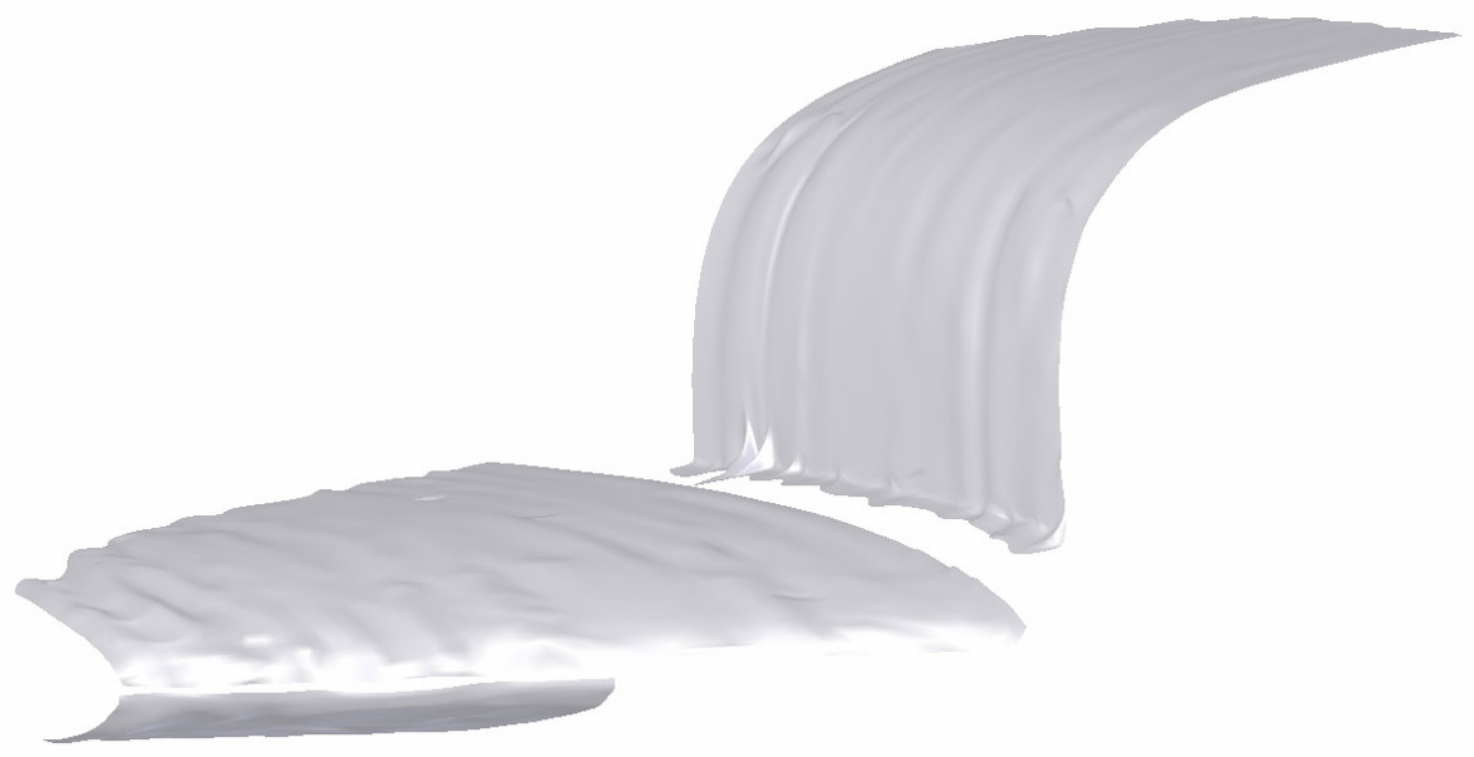

Figure A.11 Example of Rough Surface during Initial Lofting of Aircraft Surfaces 

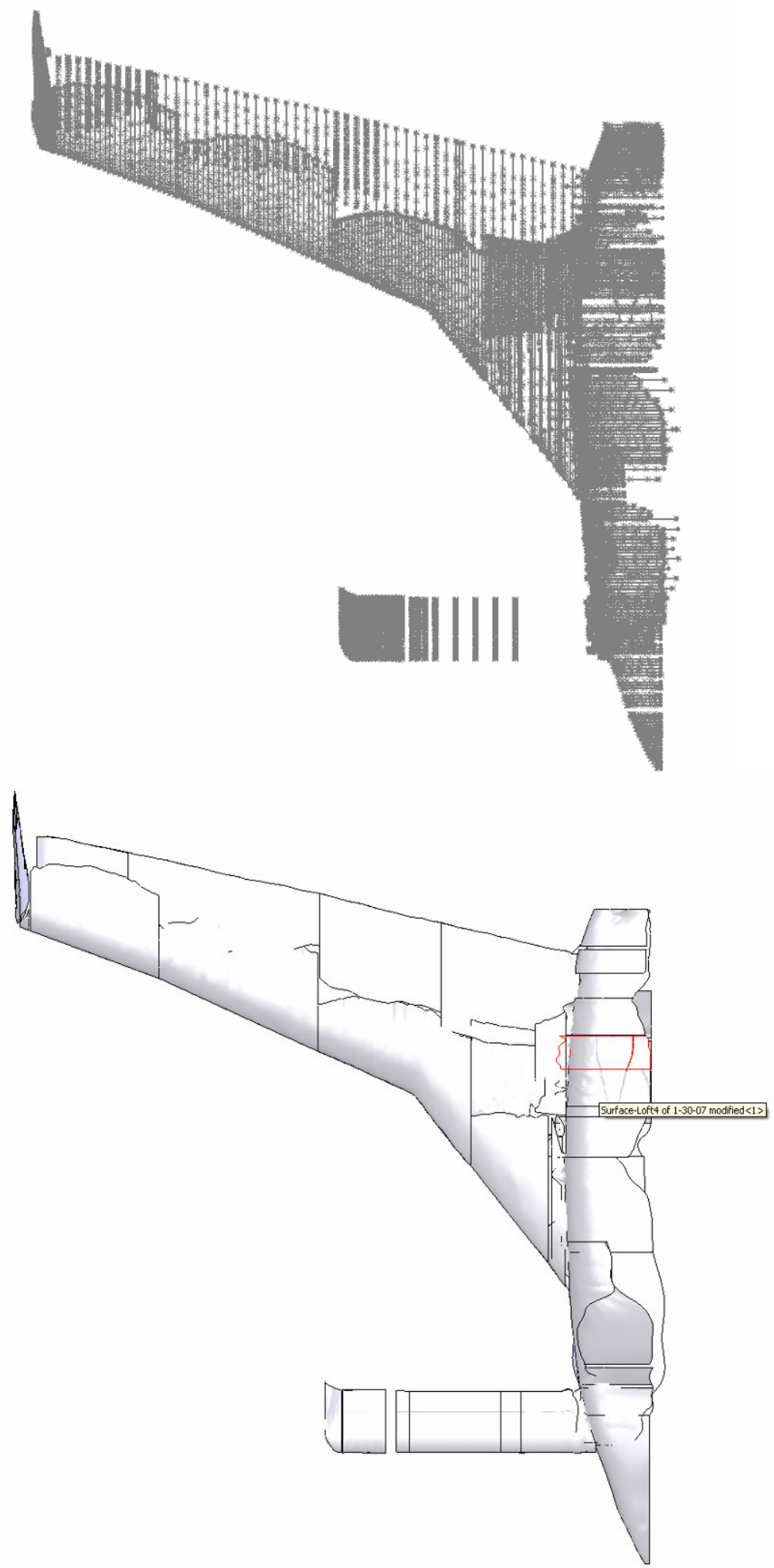

Figure A.12 Top View Comparison of 2-D Splines vs Section Surface Lofts 


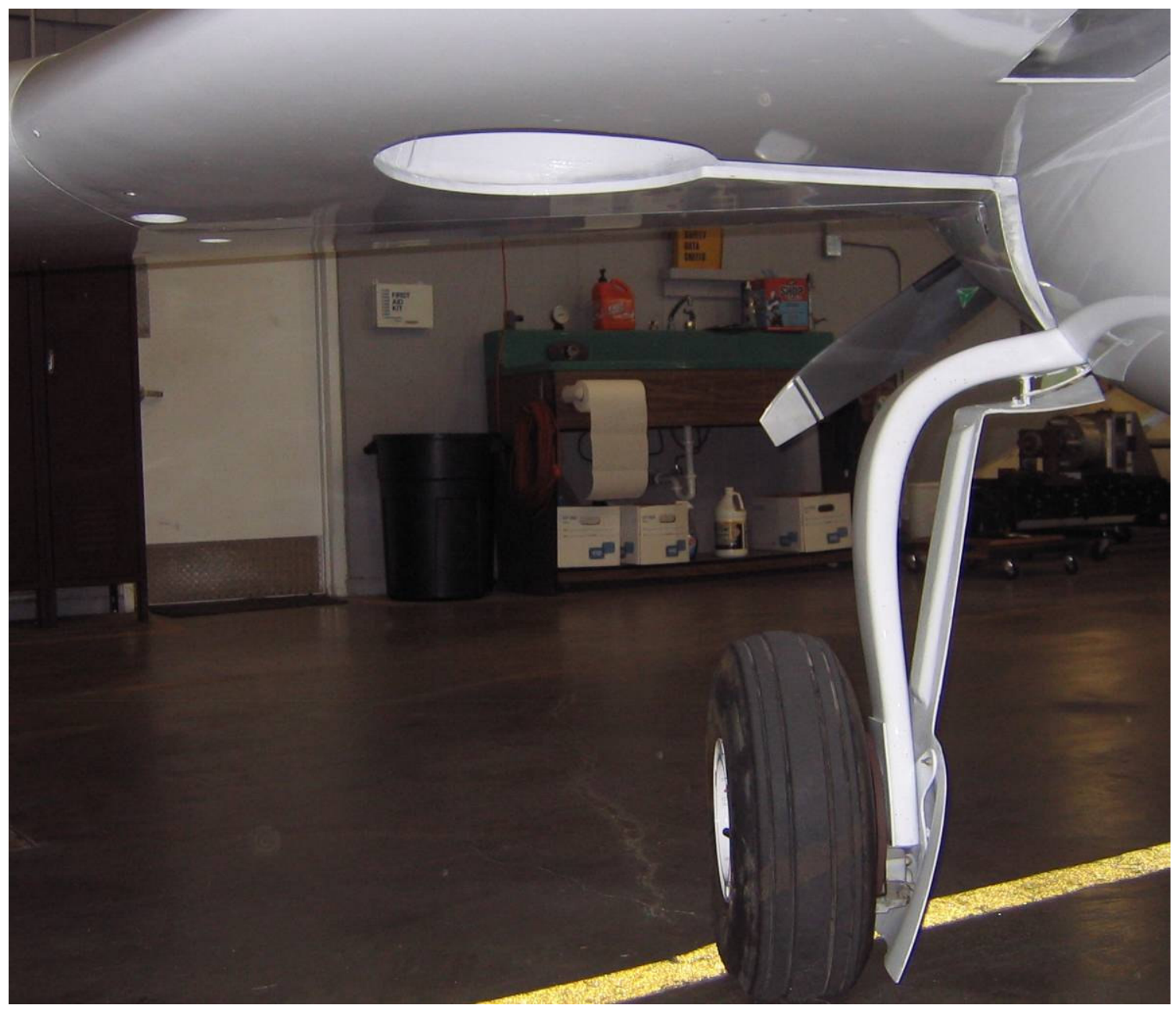

Figure A.13 Picture of the Main Gear of the Velocity with Gear Well and Wheel Cover Visible 

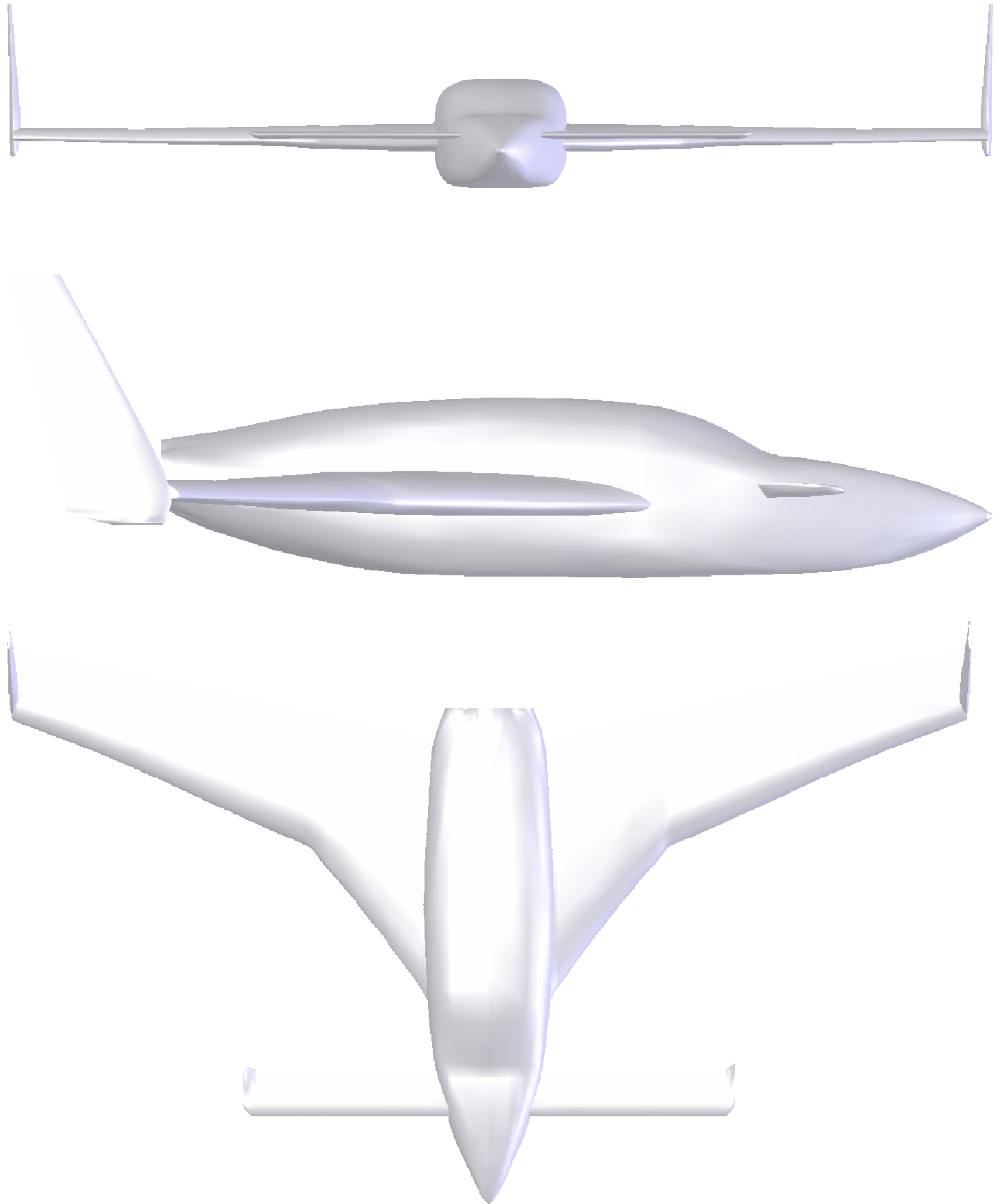

Figure A.14 Three-view CAD Model of the Velocity XL-5 RG 

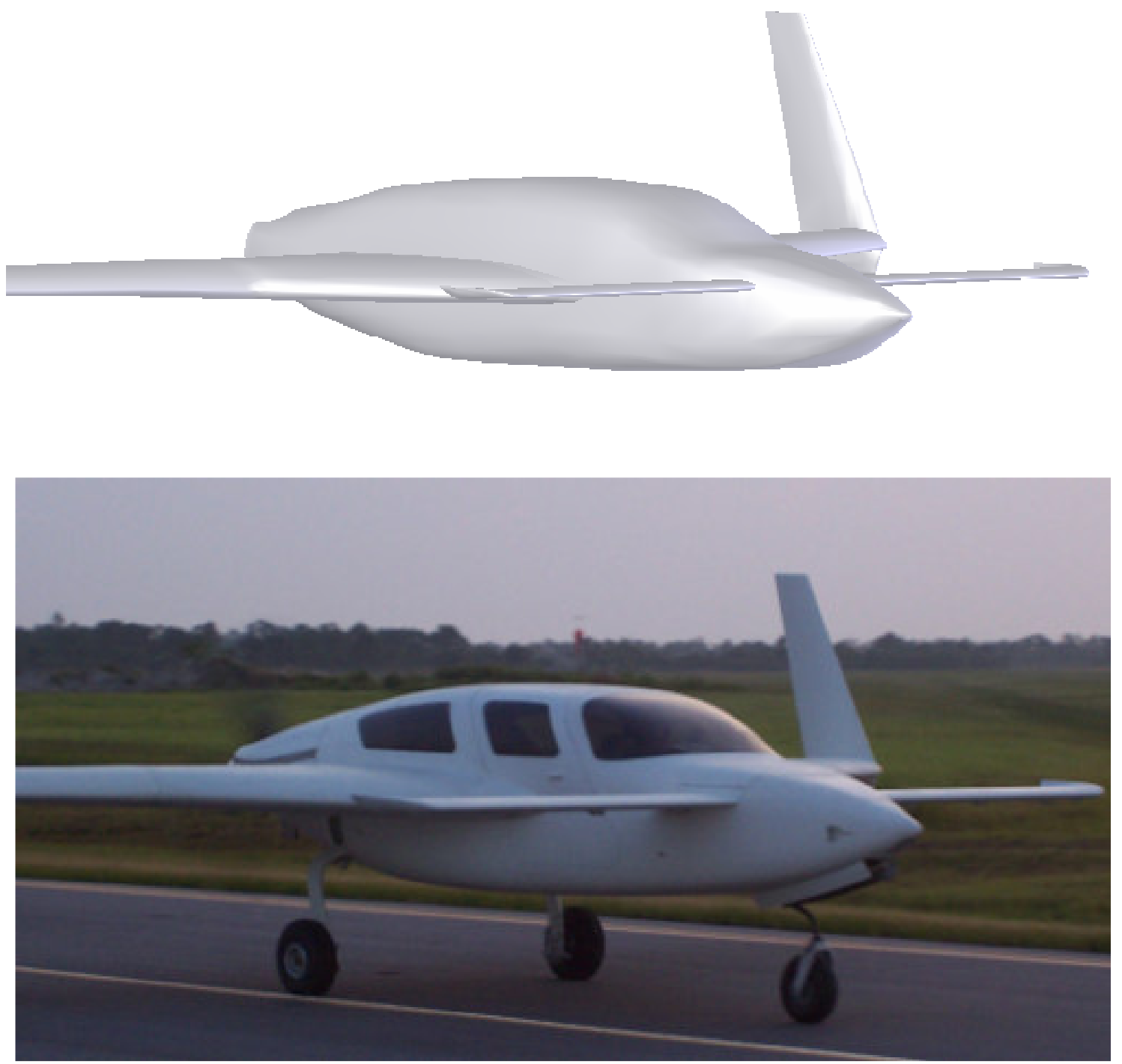

Figure A.15 3-D CAD Model to Photograph Comparison 


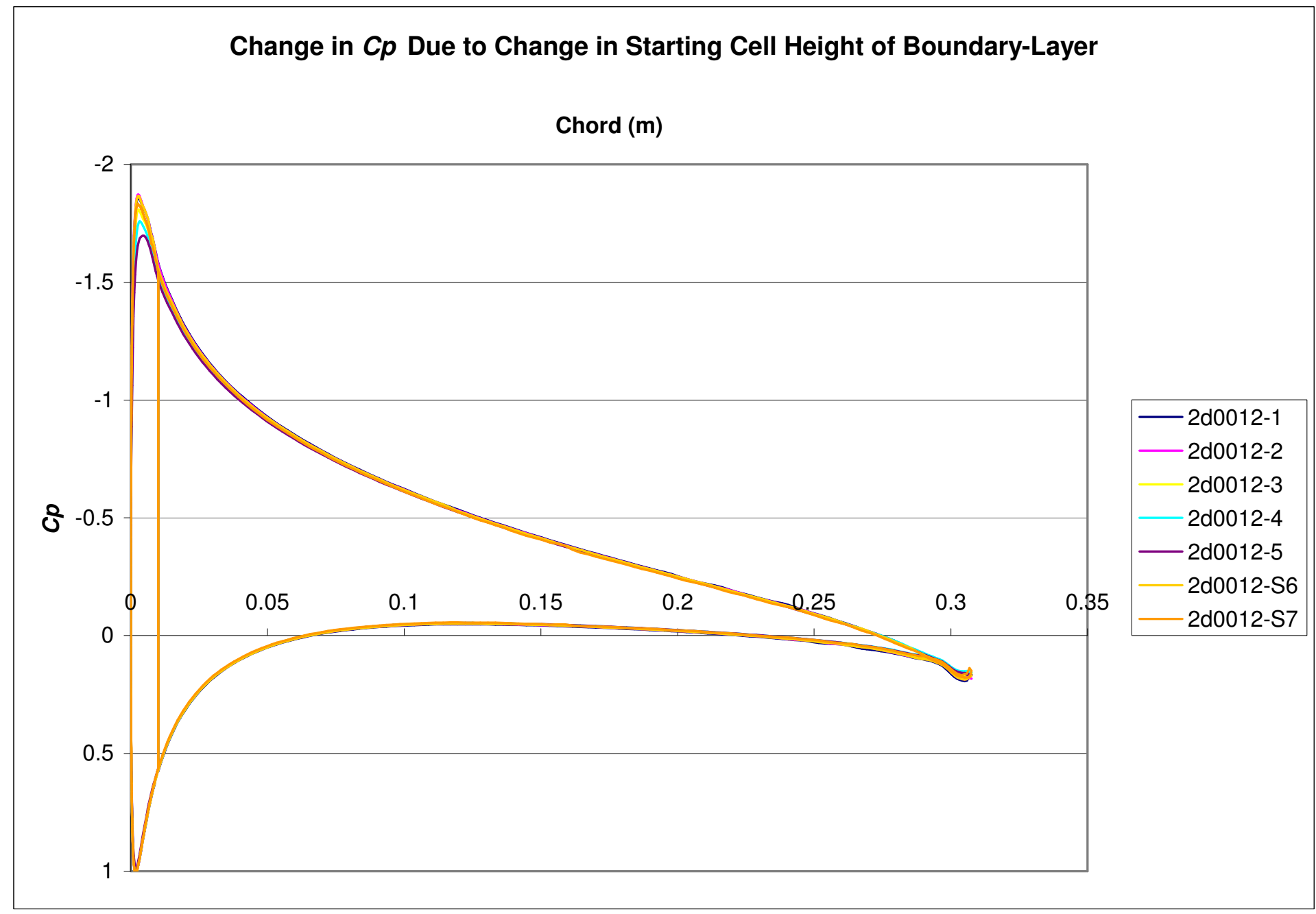

Figure A.16 Cp Plots of a NACA 0012 Airfoil at $5^{\circ} A o A, 100 \mathrm{~m} / \mathrm{s}$ for Various Boundary-Layer Height Ratios 


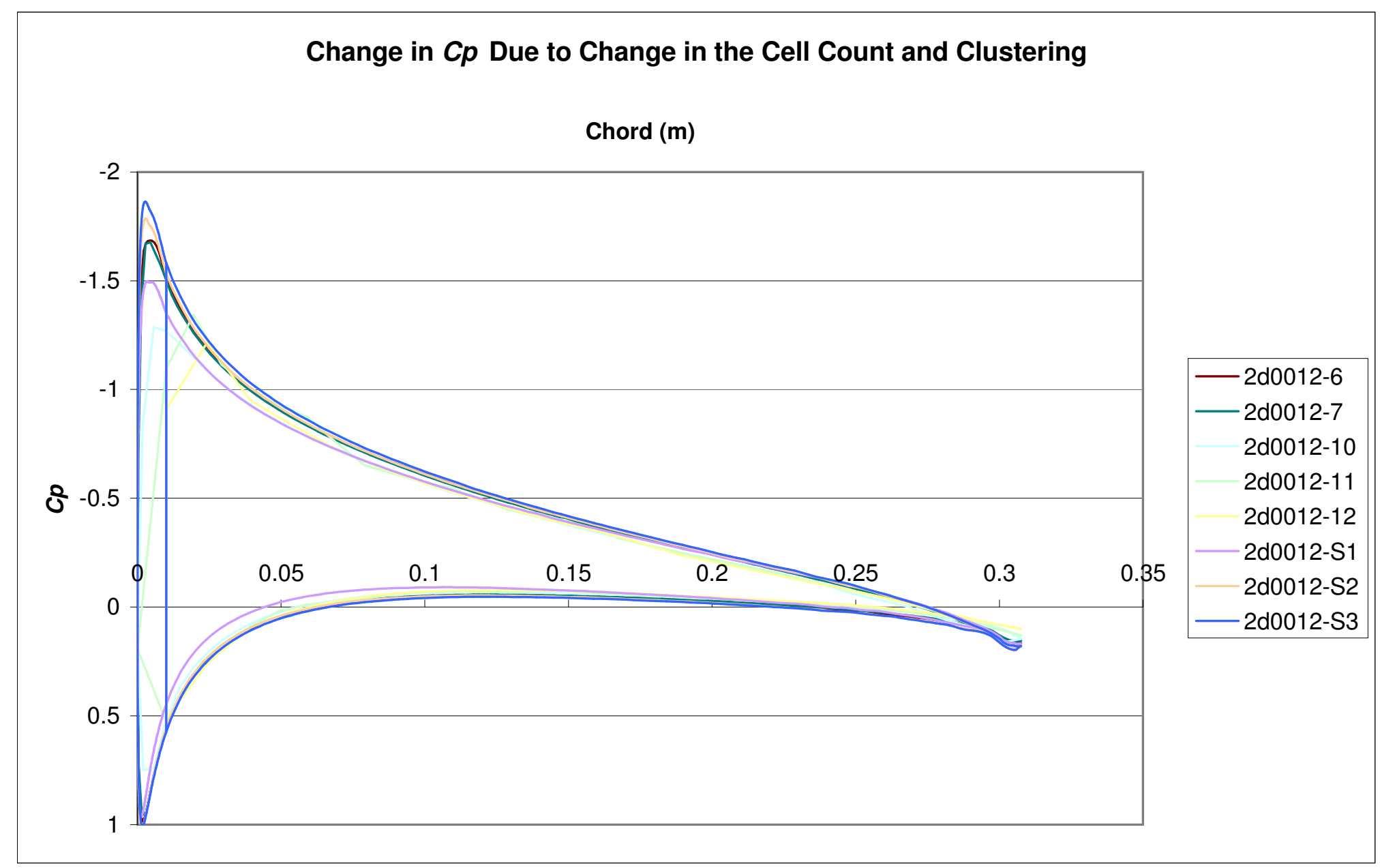

Figure A.17 Cp Plots of a NACA 0012 Airfoil at $5^{\circ} A o A, 100 \mathrm{~m} / \mathrm{s}$ for Various Leading Edge Grid Clusterings 


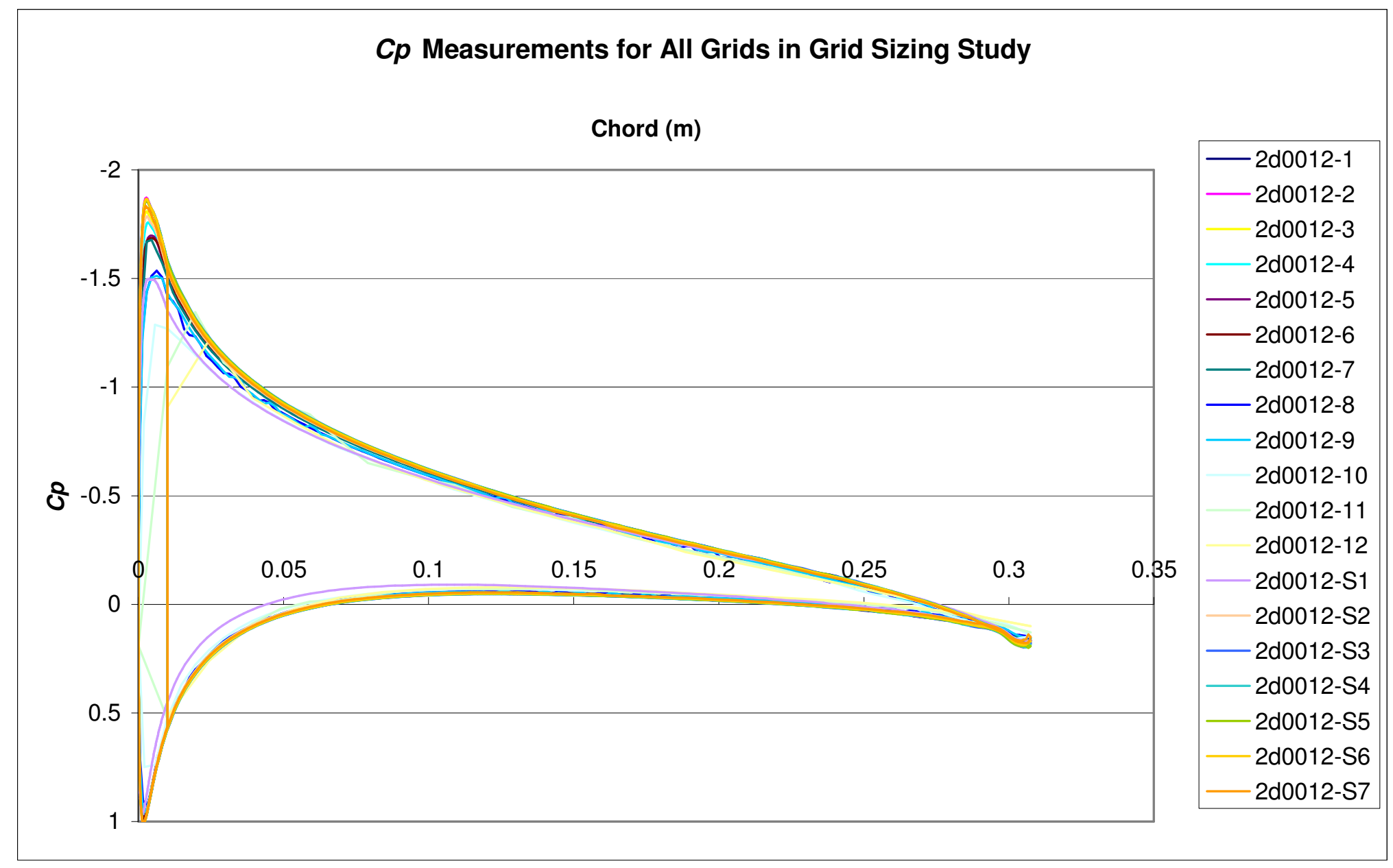

Figure A.18 Cp Plots of a NACA 0012 Airfoil at $5^{\circ} A o A, 100 \mathrm{~m} / \mathrm{s}$ for All Grid and Boundary-Layer Meshes 


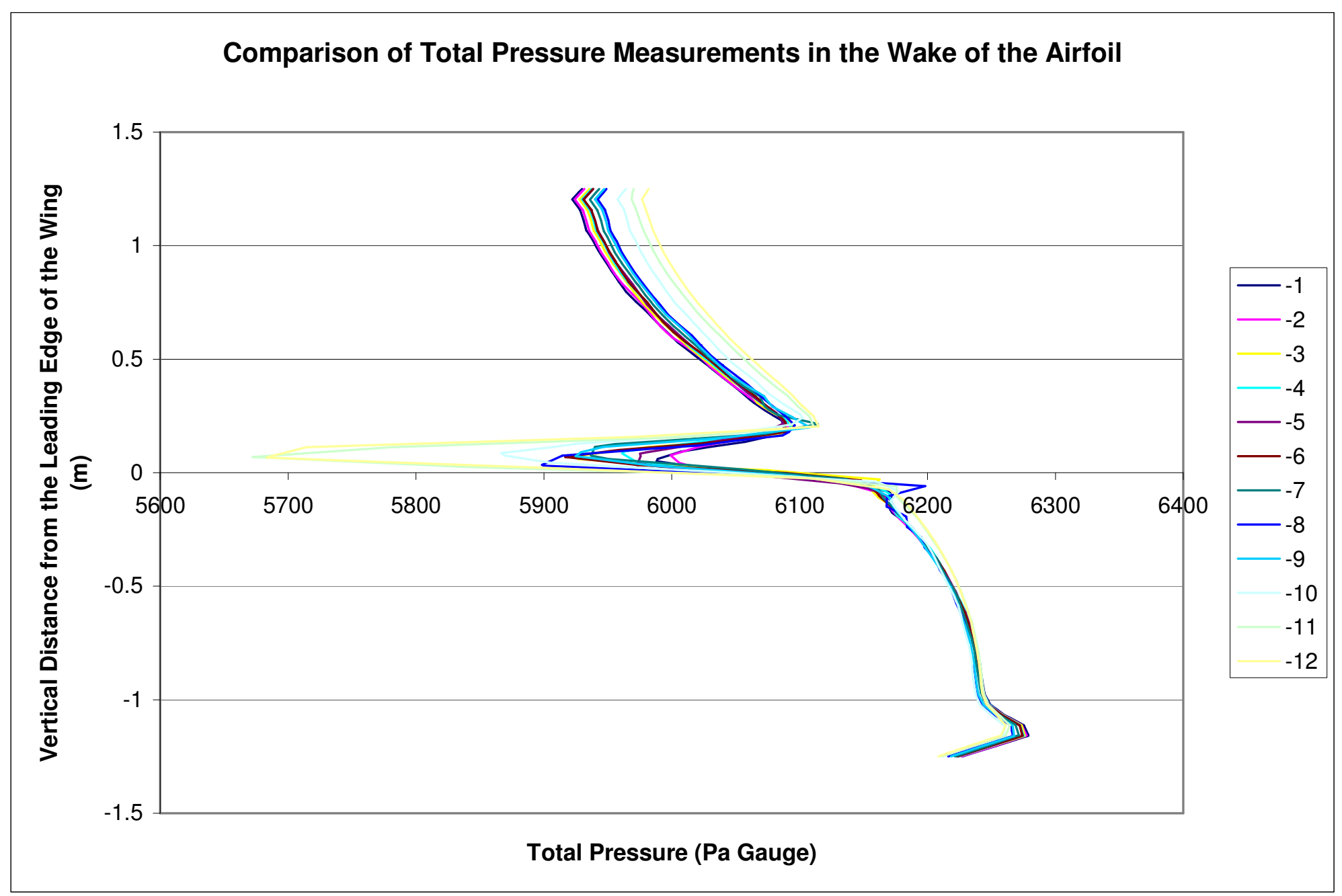

Figure A.19 Gauge Total Pressure Measurements in the Wake of the NACA 0012 Airfoil at $5^{\circ}$ AoA, $100 \mathrm{~m} / \mathrm{s}$ 


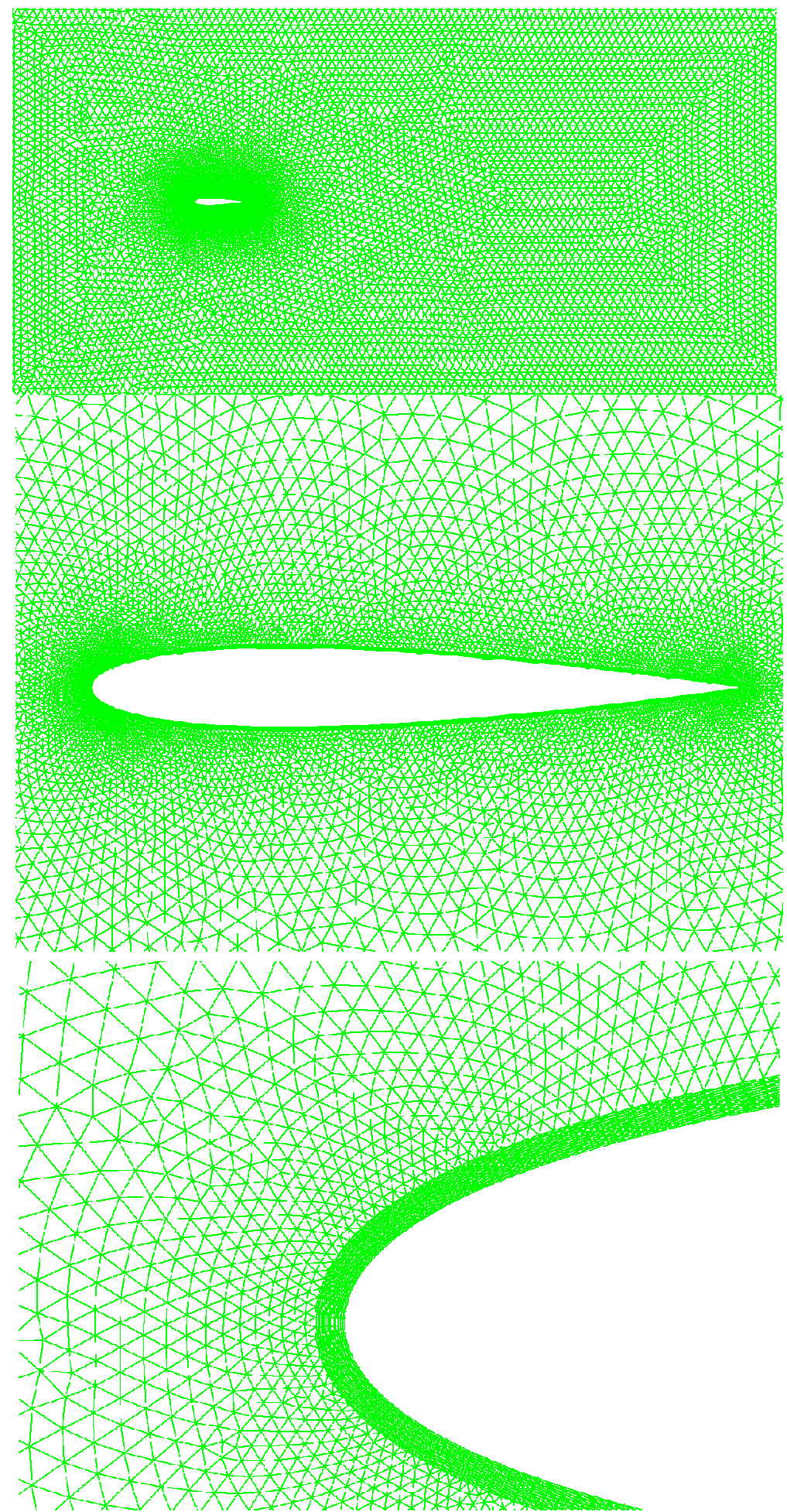

Figure A.20 Visualization of the Mesh for the 2d0012-1 Grid Study Case 


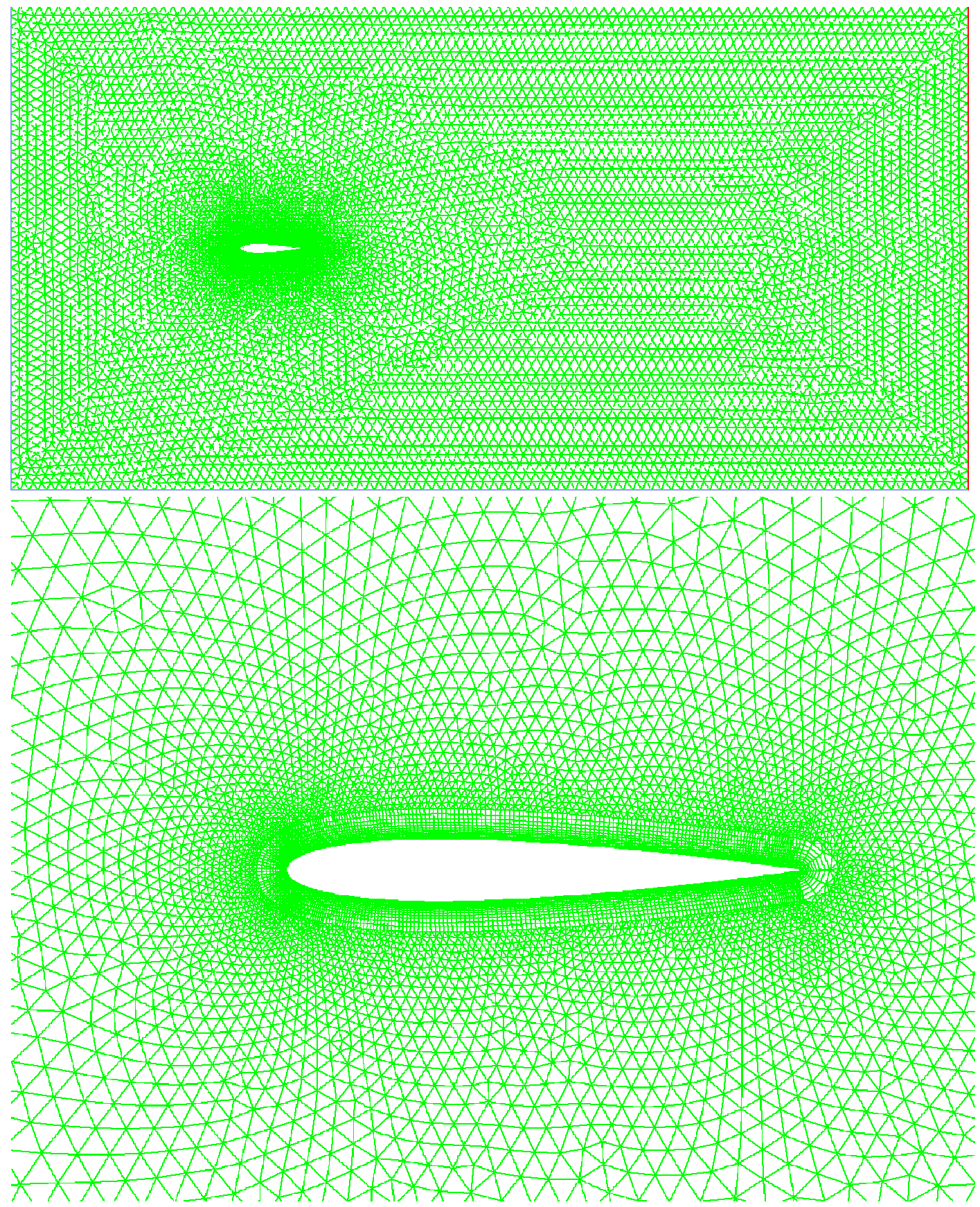

Figure A.21 Visualization of the Mesh for the 2d0012-2 Grid Study Case 

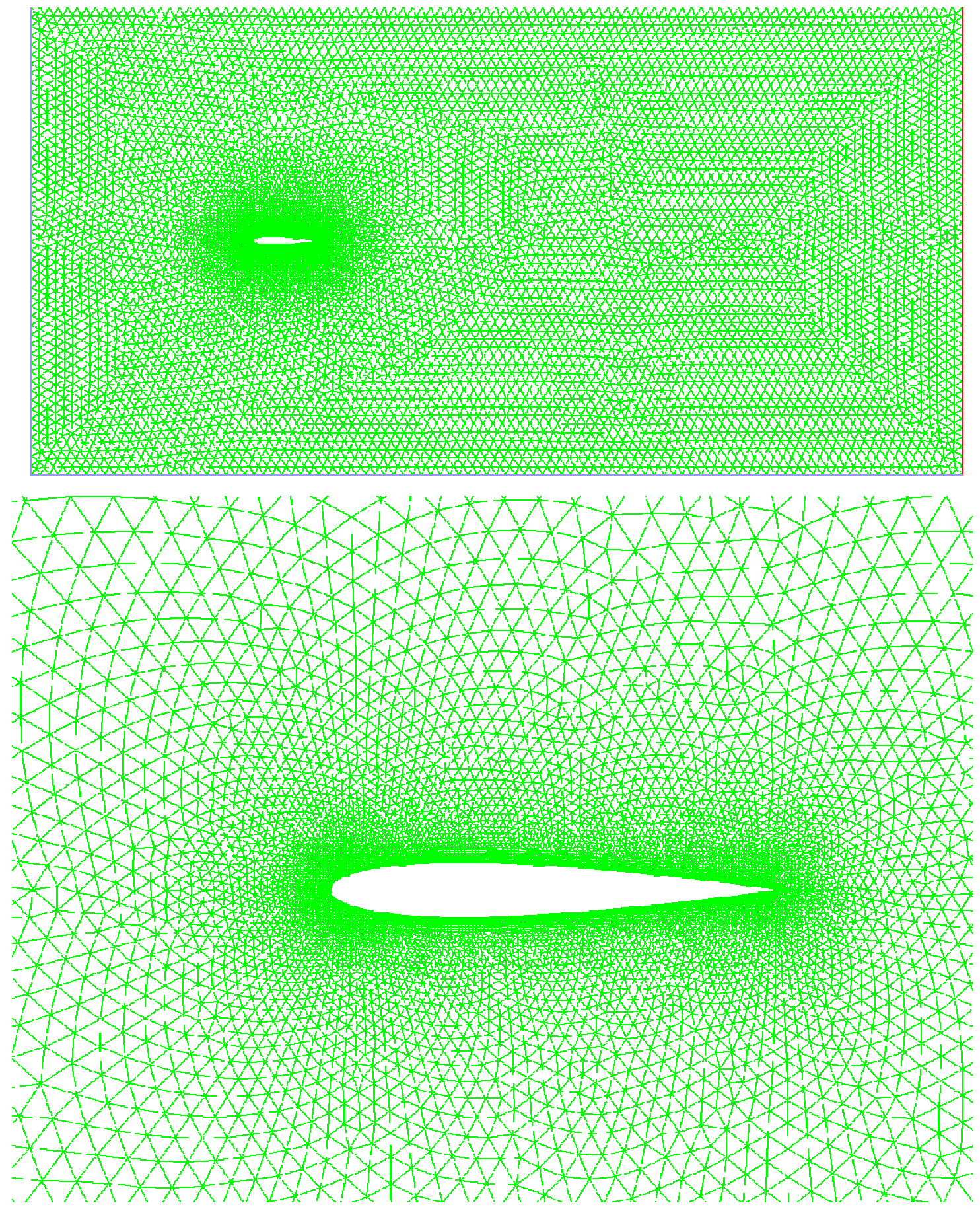

Figure A.22 Visualization of the Mesh for the 2d0012-3 Grid Study Case 

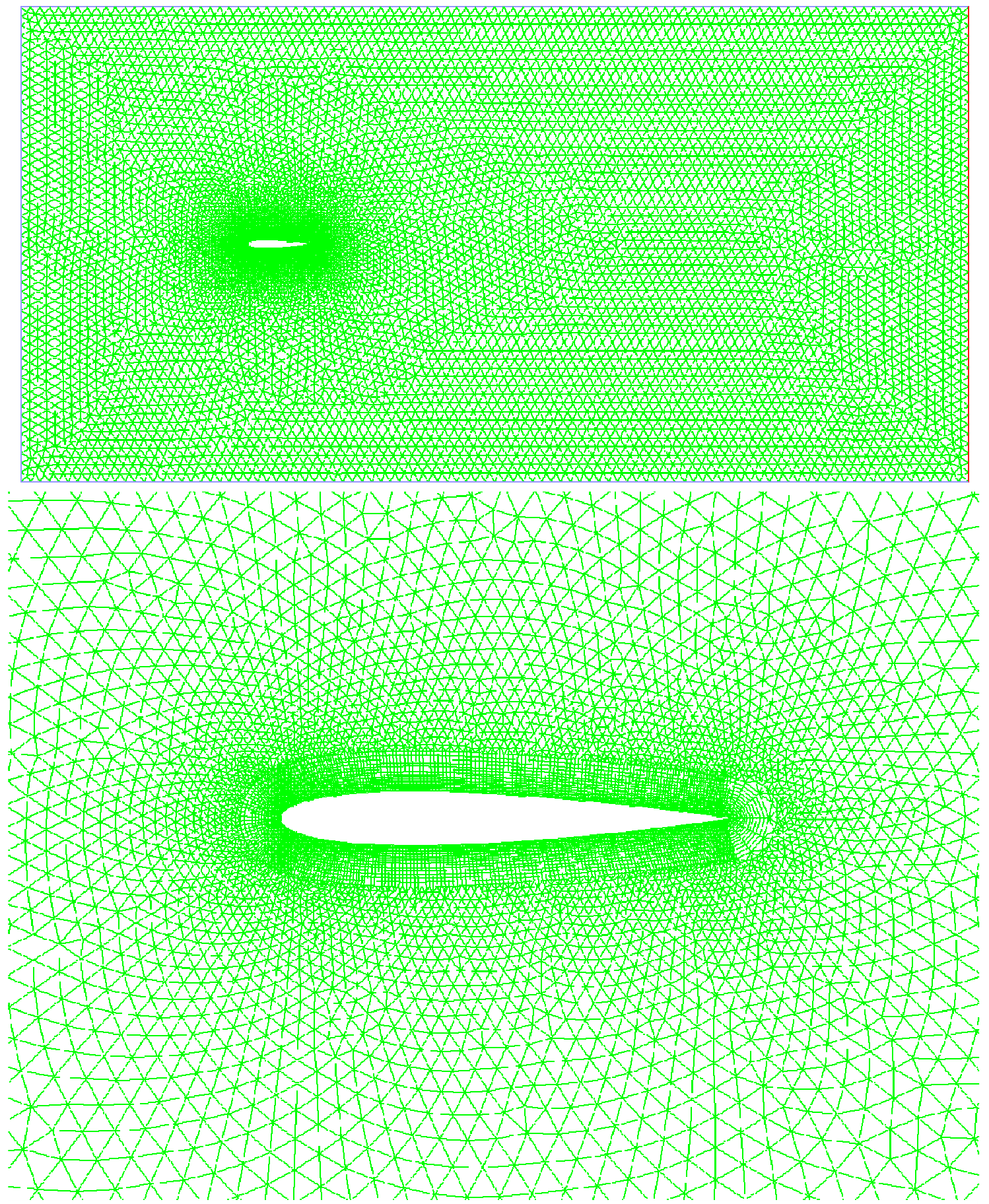

Figure A.23 Visualization of the Mesh for the 2d0012-4 Grid Study Case 


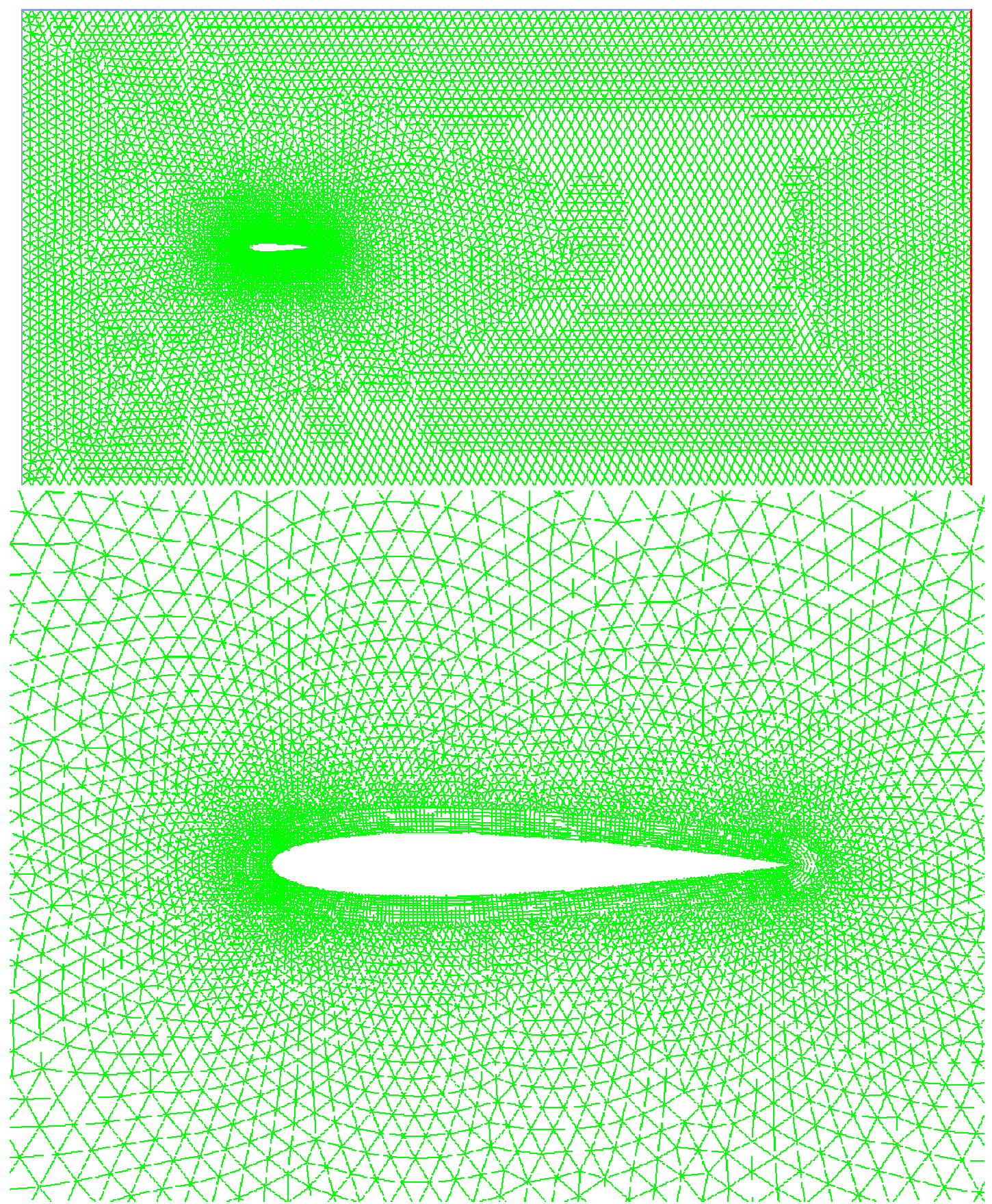

Figure A.24 Visualization of the Mesh for the 2d0012-5 Grid Study Case 

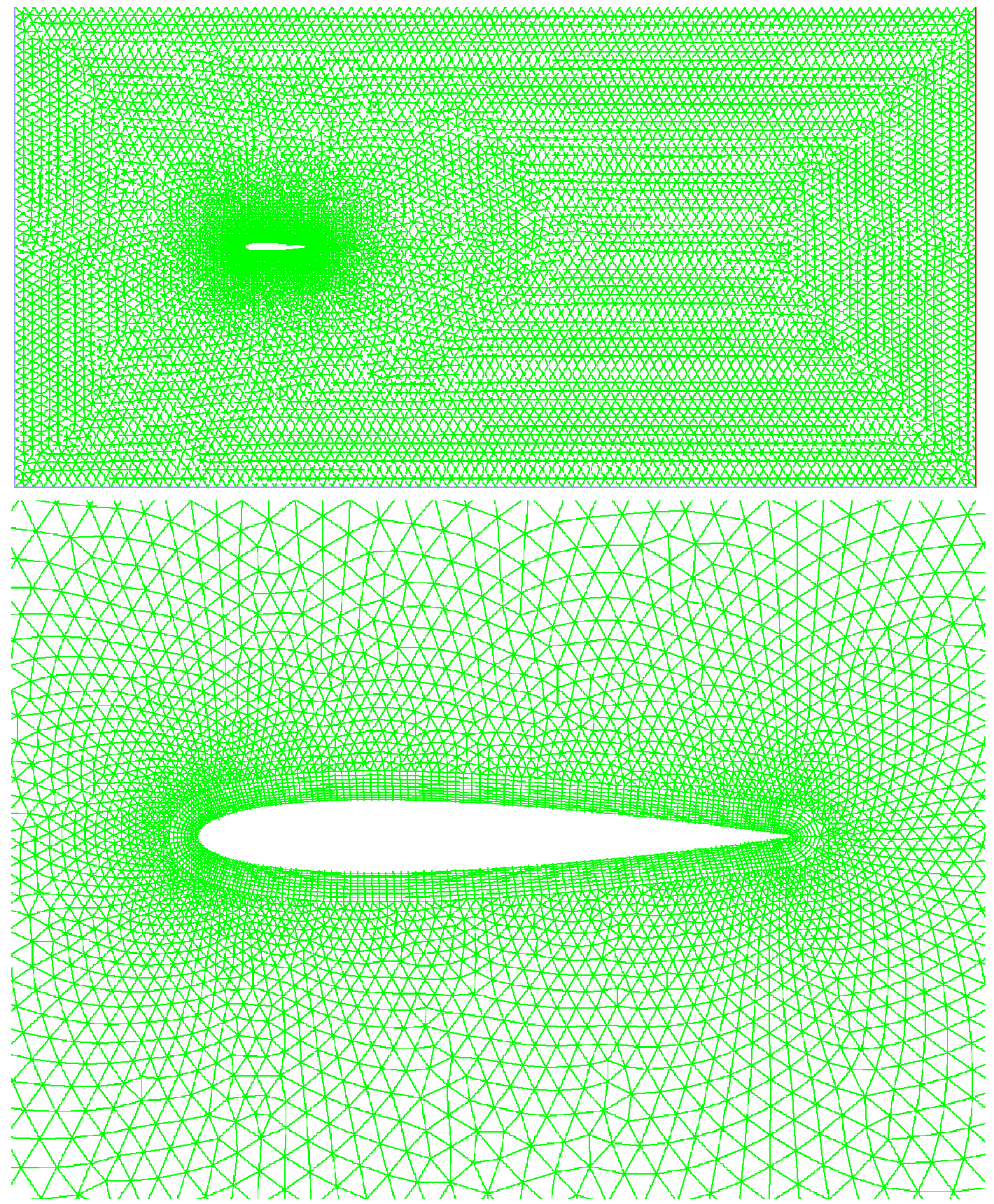

Figure A.25 Visualization of the Mesh for the 2d0012-6 Grid Study Case 

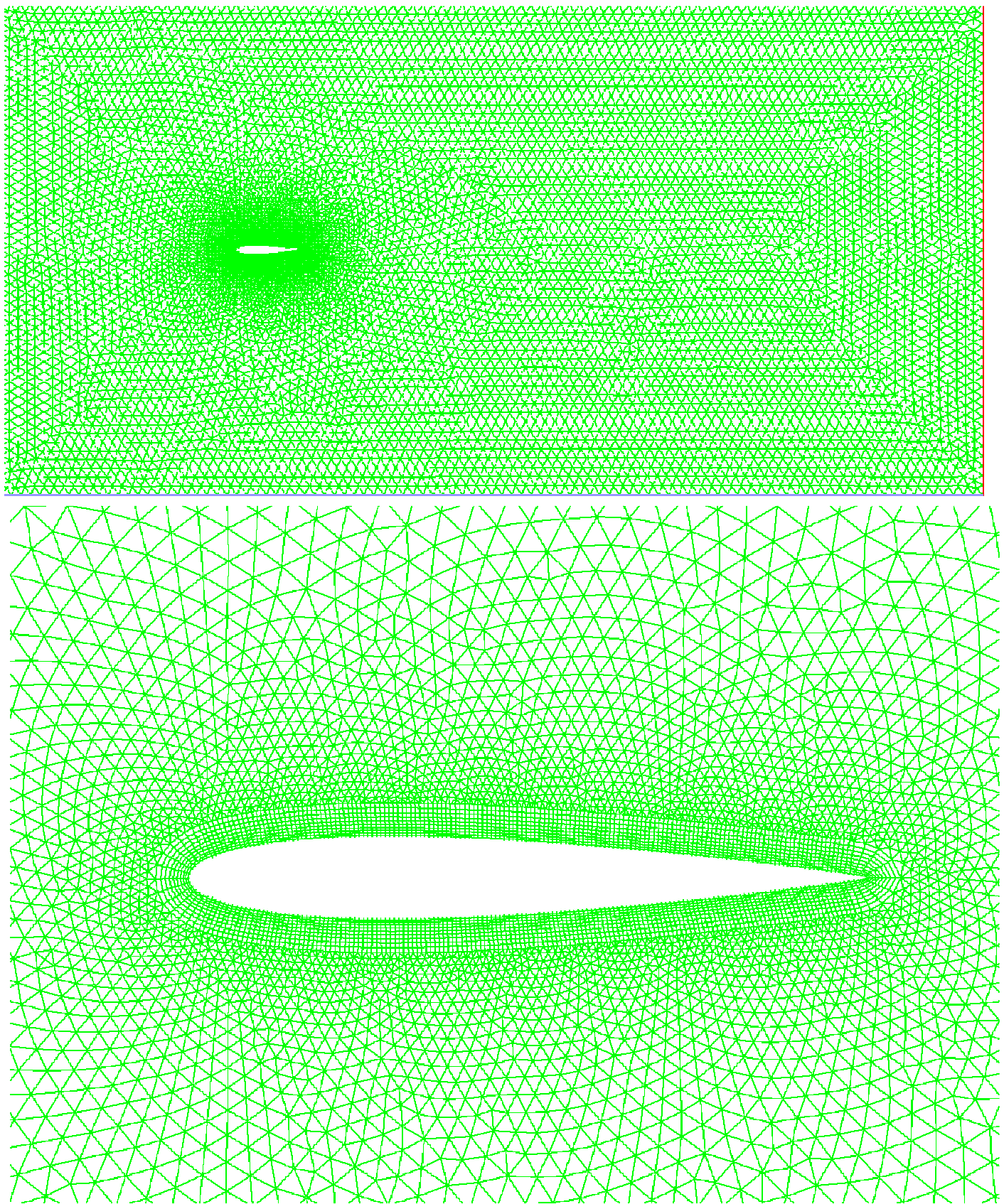

Figure A.26 Visualization of the Mesh for the 2d0012-7 Grid Study Case 

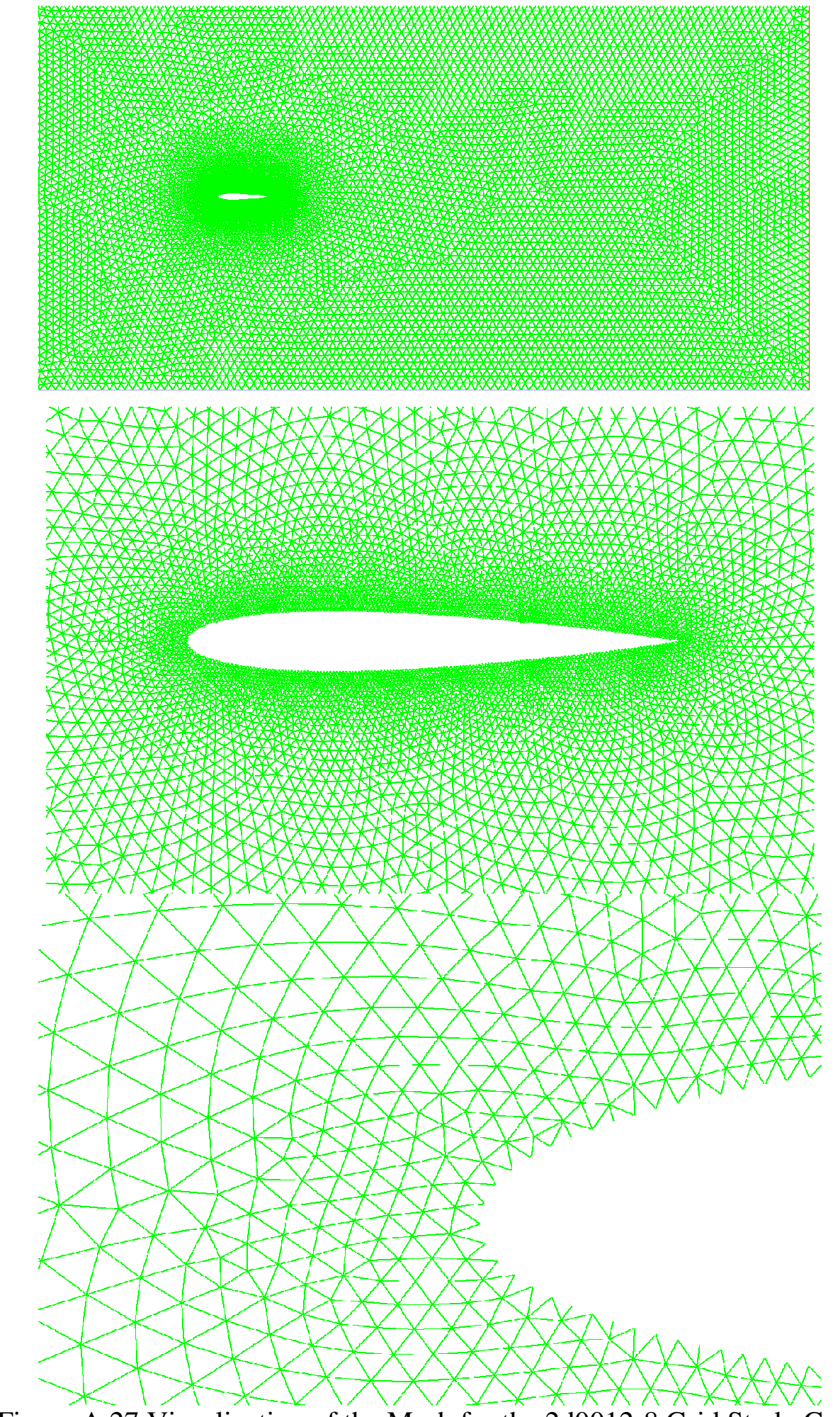

Figure A.27 Visualization of the Mesh for the 2d0012-8 Grid Study Case 

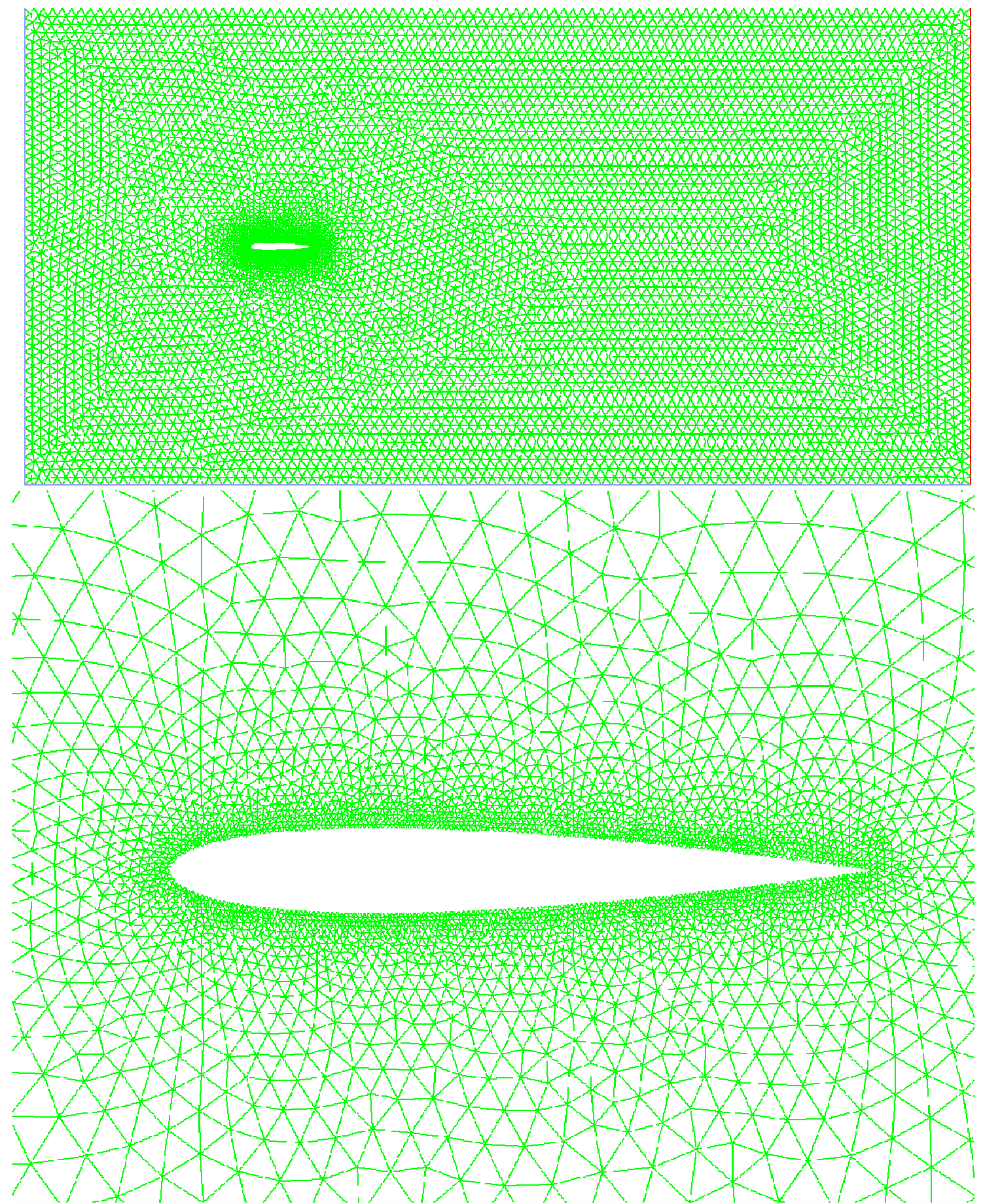

Figure A.28 Visualization of the Mesh for the 2d0012-9 Grid Study Case 

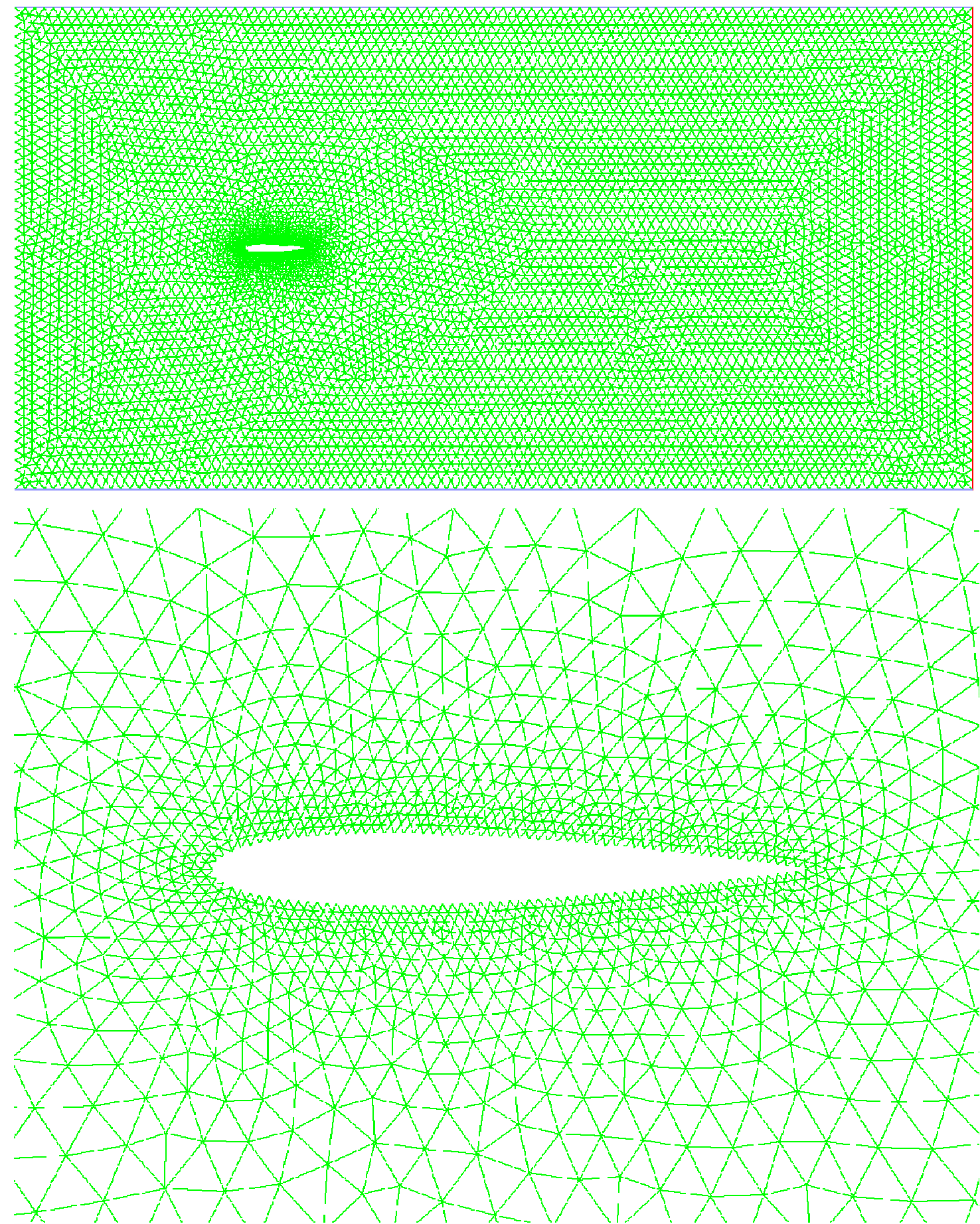

Figure A.29 Visualization of the Mesh for the 2d0012-10 Grid Study Case 

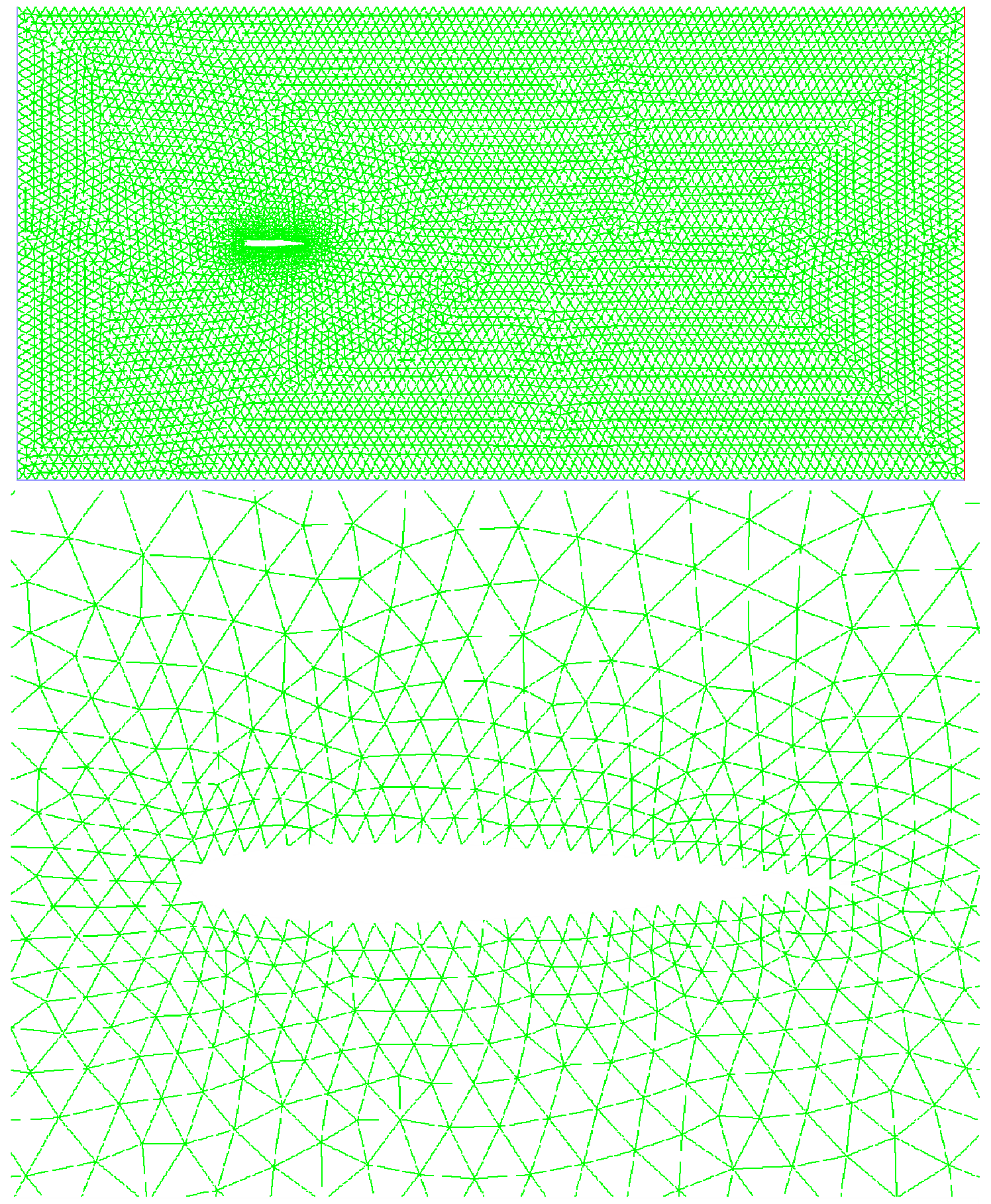

Figure A.30 Visualization of the Mesh for the 2d0012-11 Grid Study Case 


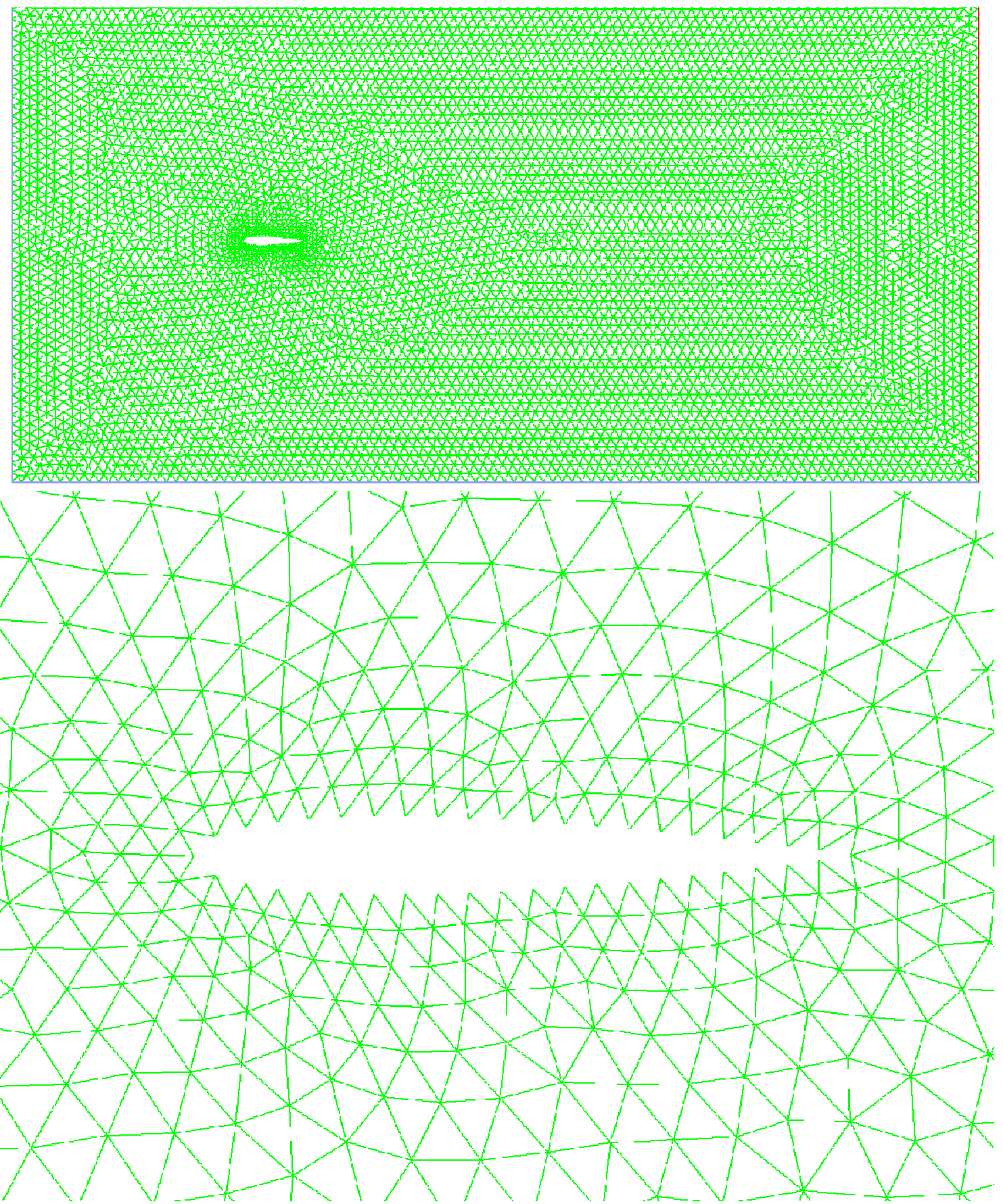

Figure A.31 Visualization of the Mesh for the 2d0012-12 Grid Study Case 


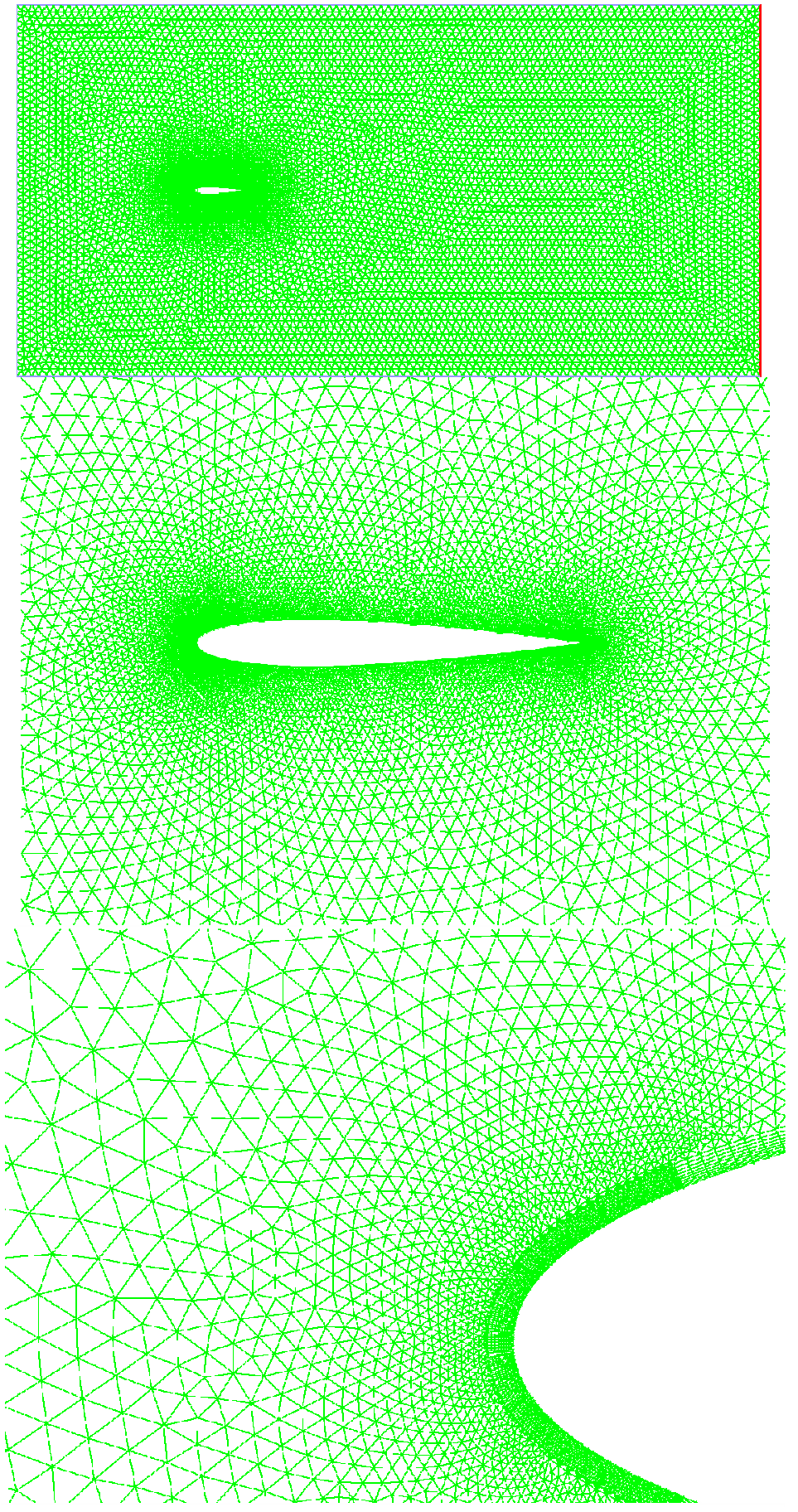

Figure A.32 Visualization of the Mesh for the 2d0012-s1 Grid Study Case 

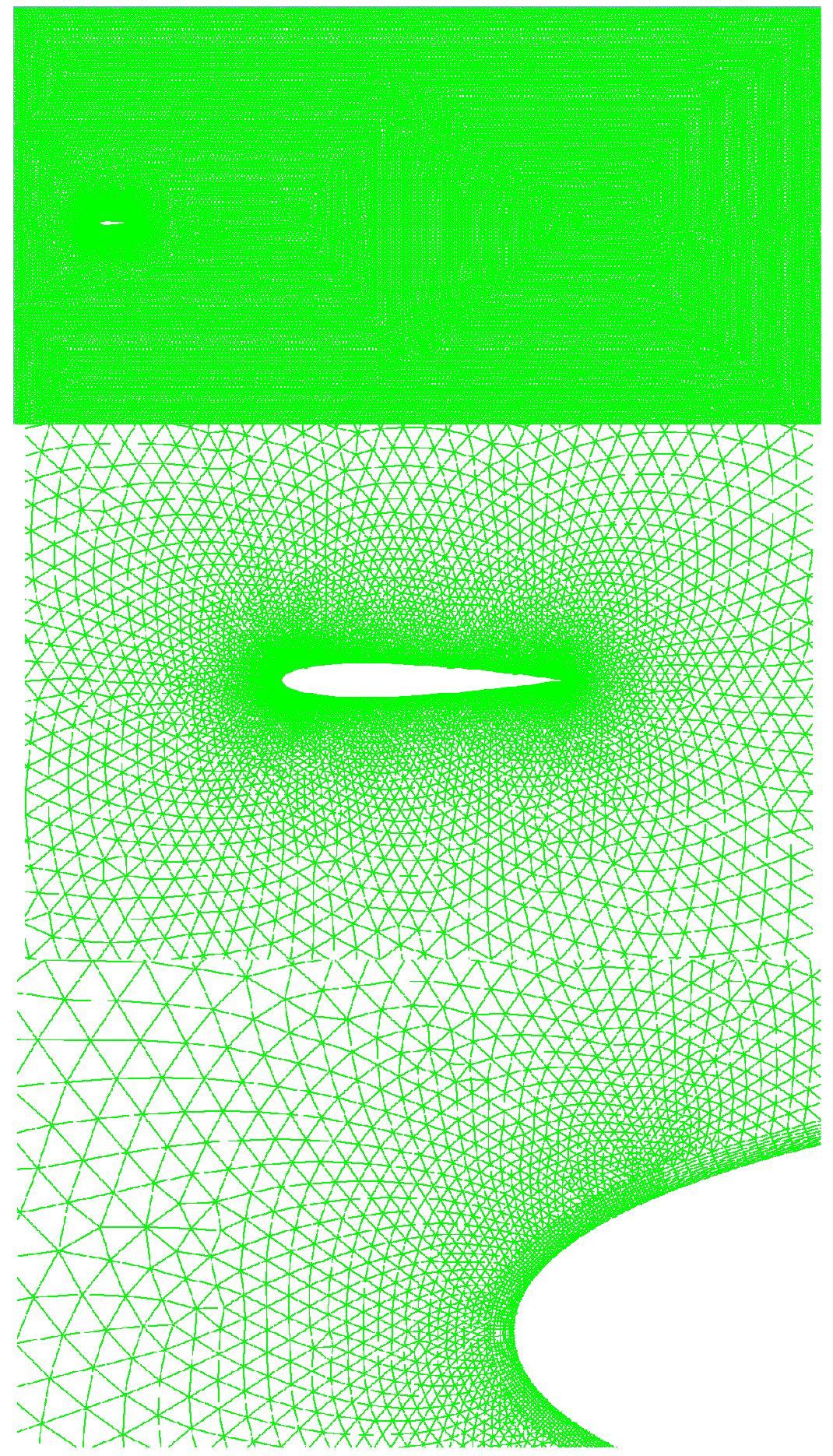

Figure A.33 Visualization of the Mesh for the 2d0012-s2 Grid Study Case 


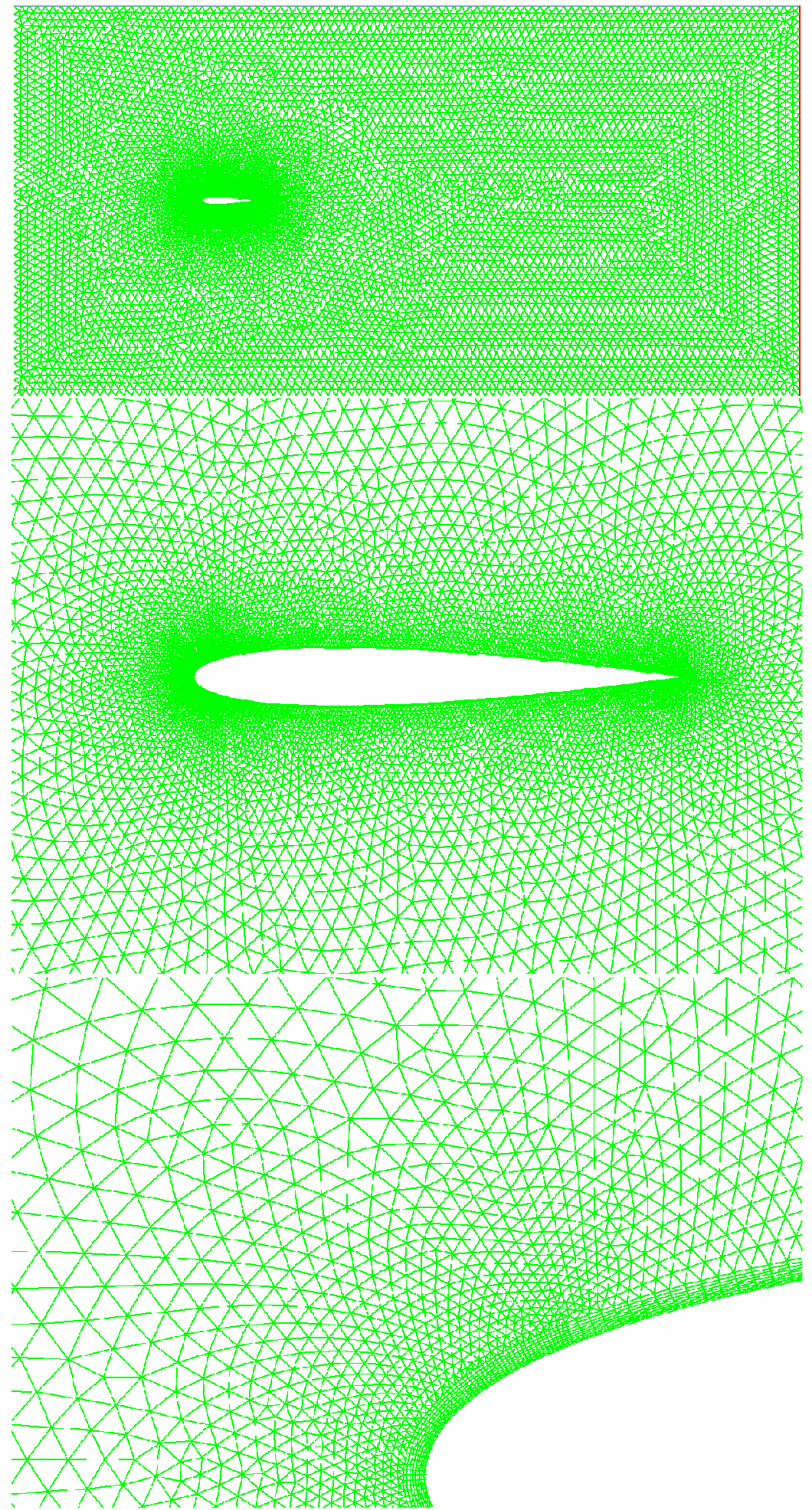

Figure A.34 Visualization of the Mesh for the 2d0012-s3 Grid Study Case 

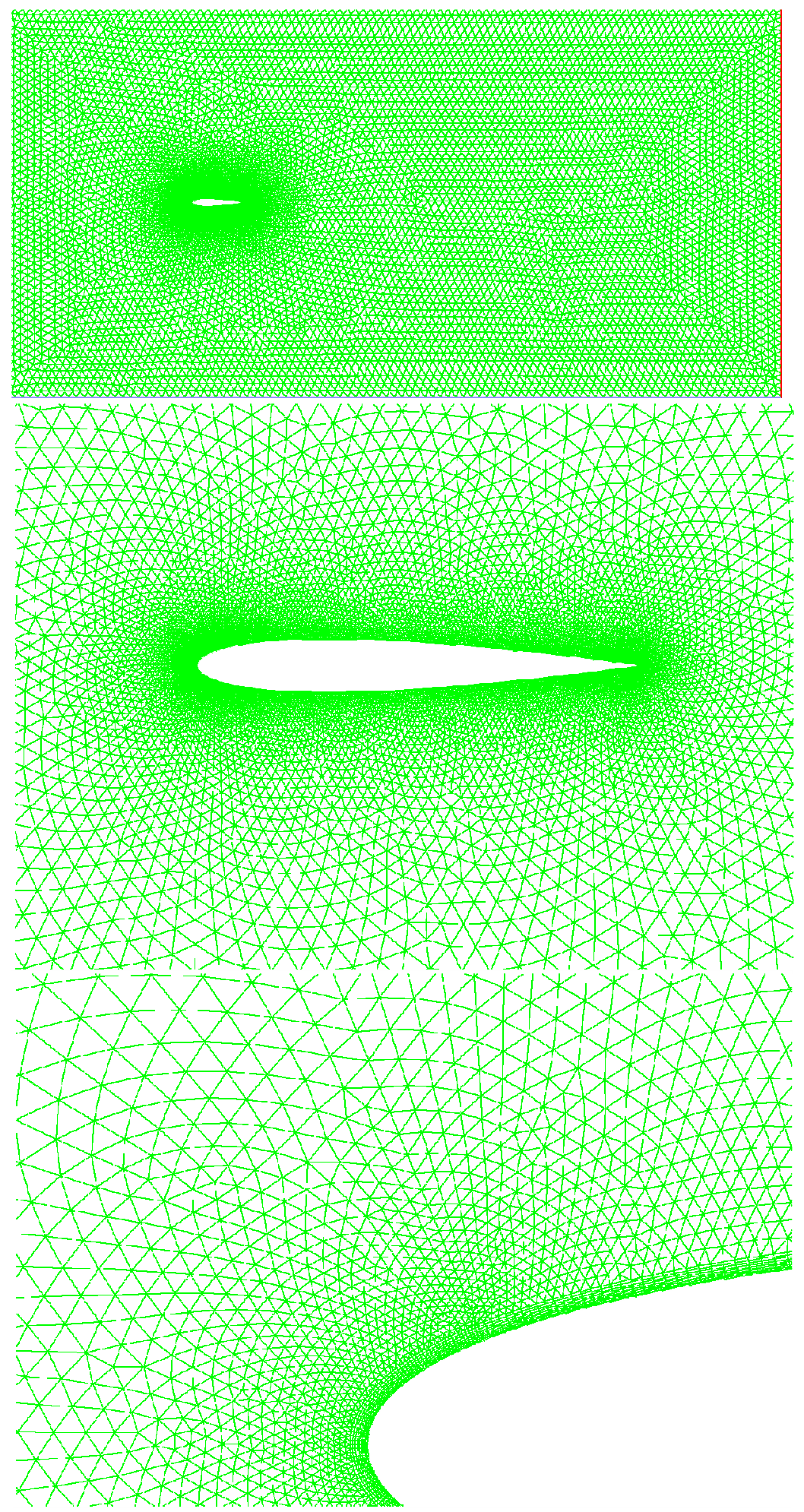

Figure A.35 Visualization of the Mesh for the 2d0012-s4 Grid Study Case 

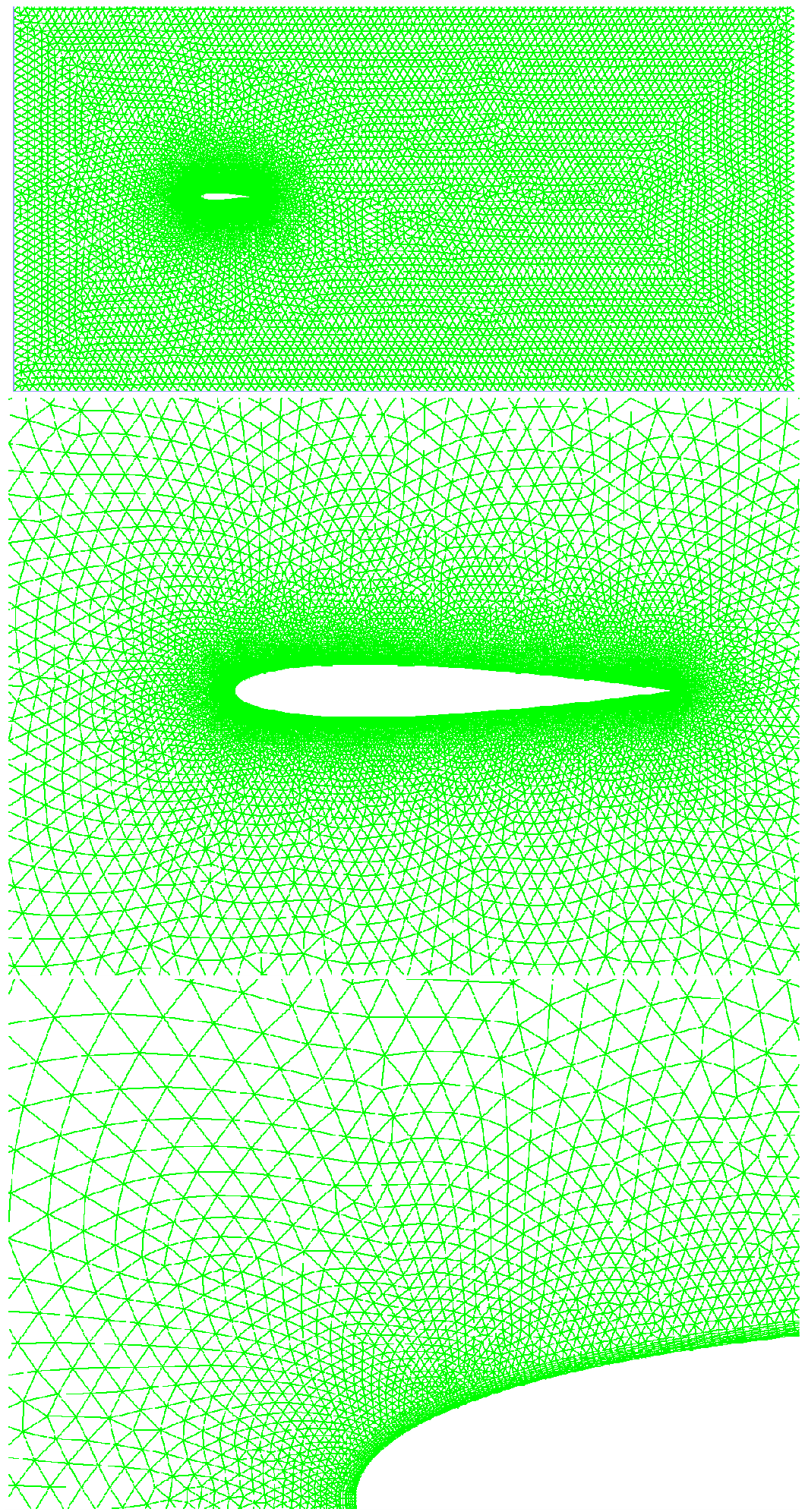

Figure A.36 Visualization of the Mesh for the 2d0012-s5 Grid Study Case 

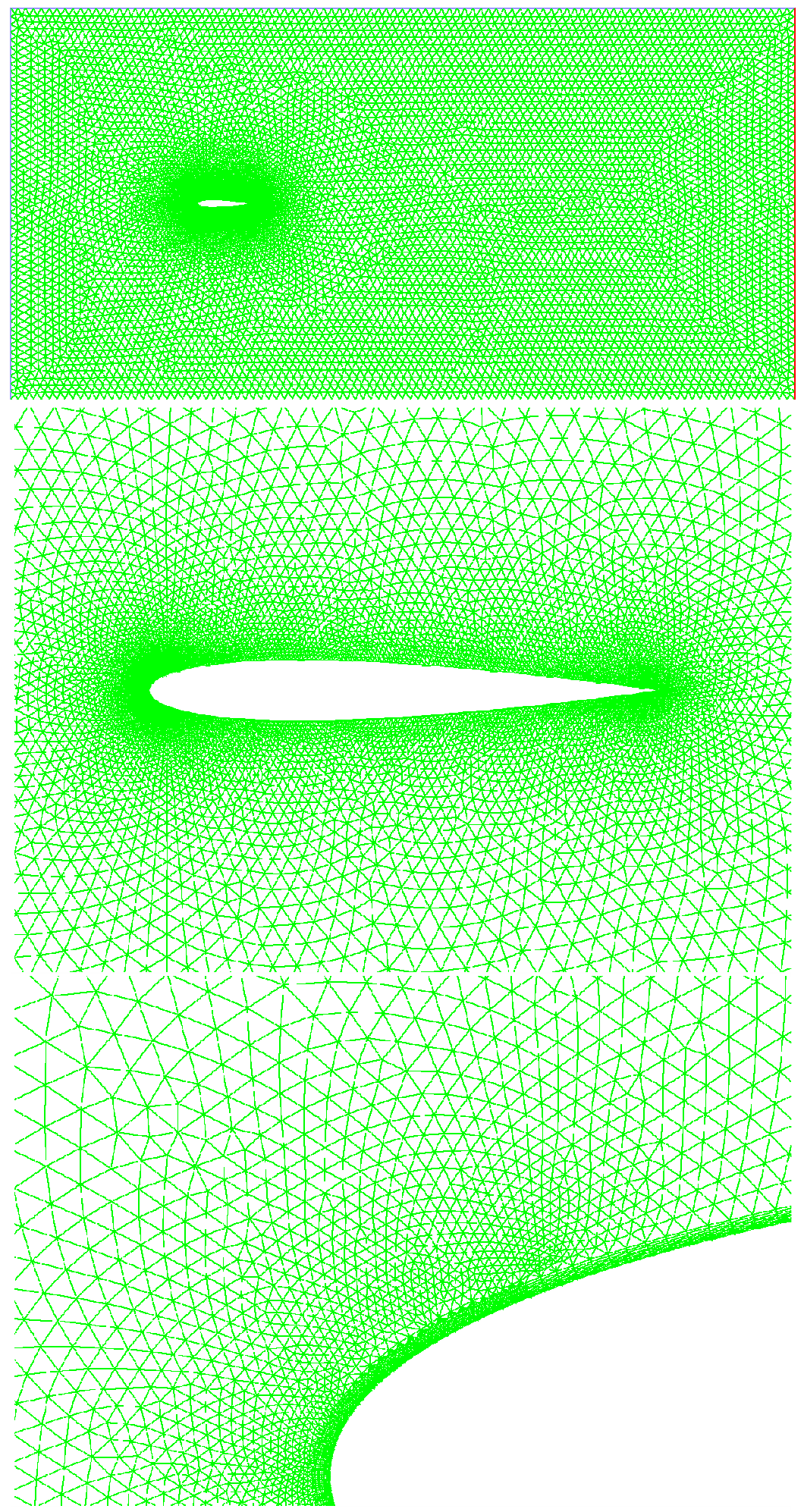

Figure A.37 Visualization of the Mesh for the 2d0012-s6 Grid Study Case 


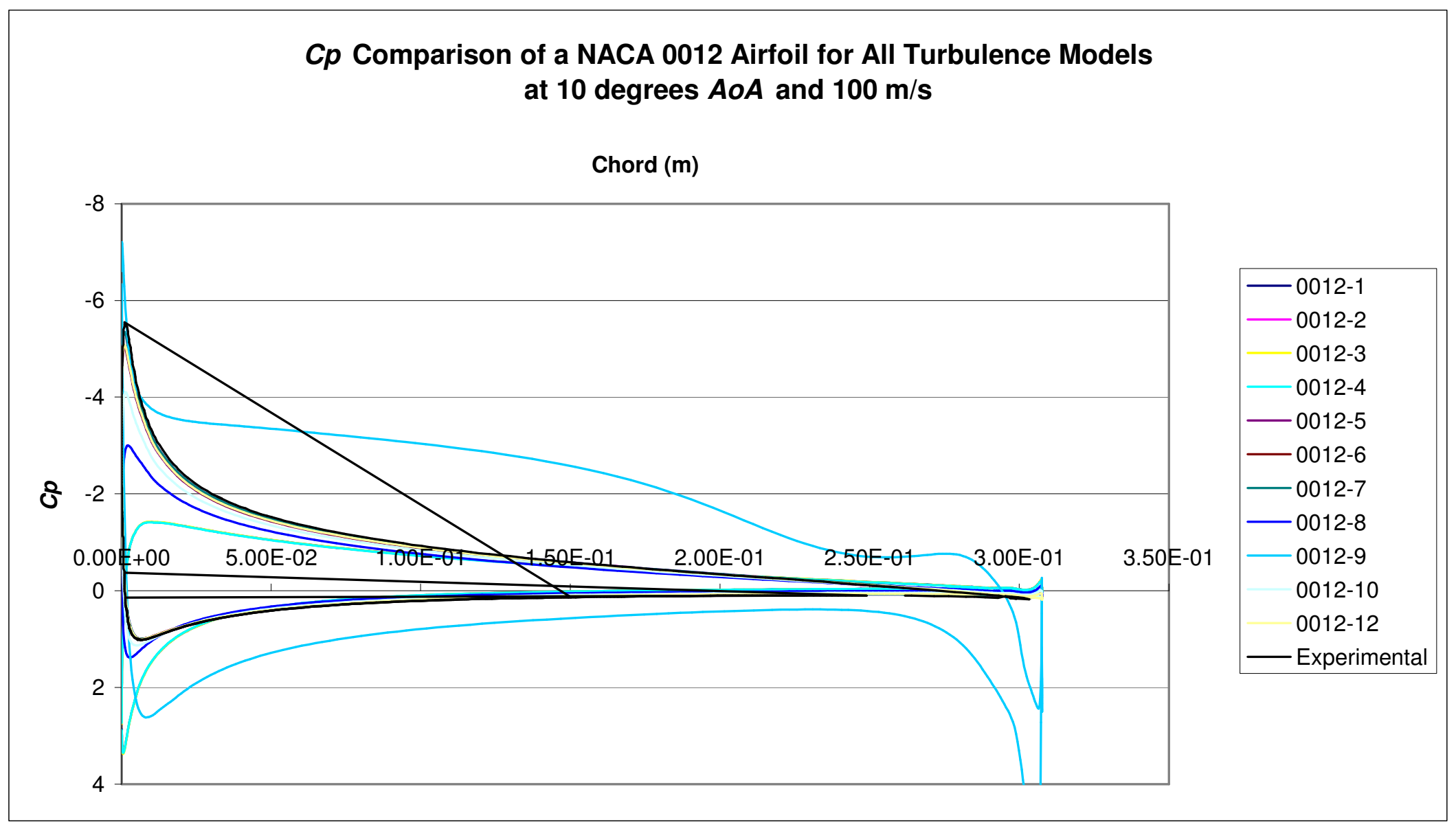

Figure A.38 Cp Plots of the Twelve Different Turbulence Models and Model Options on a NACA 0012 Airfoil at $10^{\circ} \mathrm{AoA}, 100 \mathrm{~m} / \mathrm{s}$ 


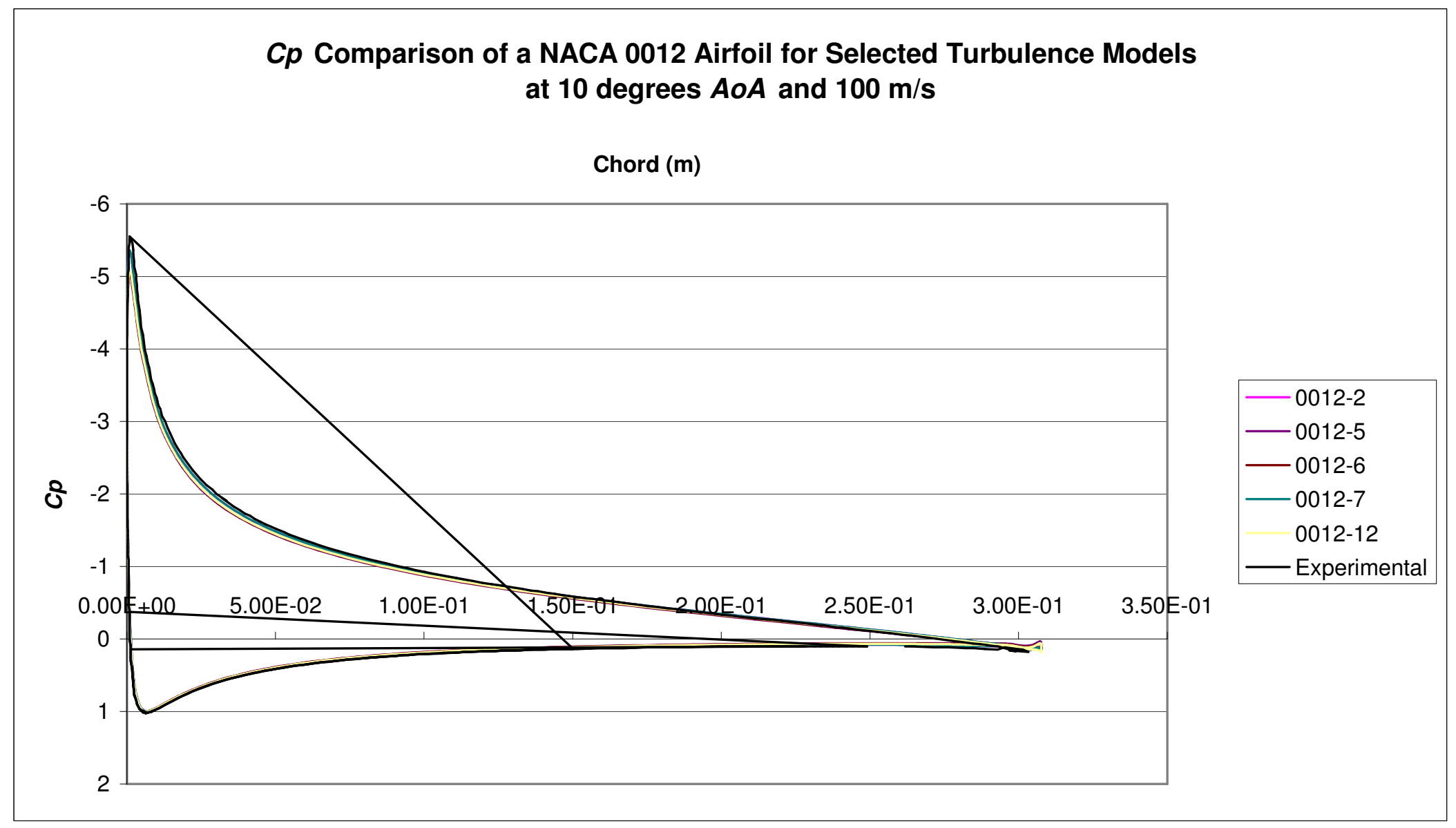

Figure A.39 $C p$ Plots of the Five Best Turbulence Models on a NACA 0012 Airfoil at $10^{\circ} A o A, 100 \mathrm{~m} / \mathrm{s}$ 


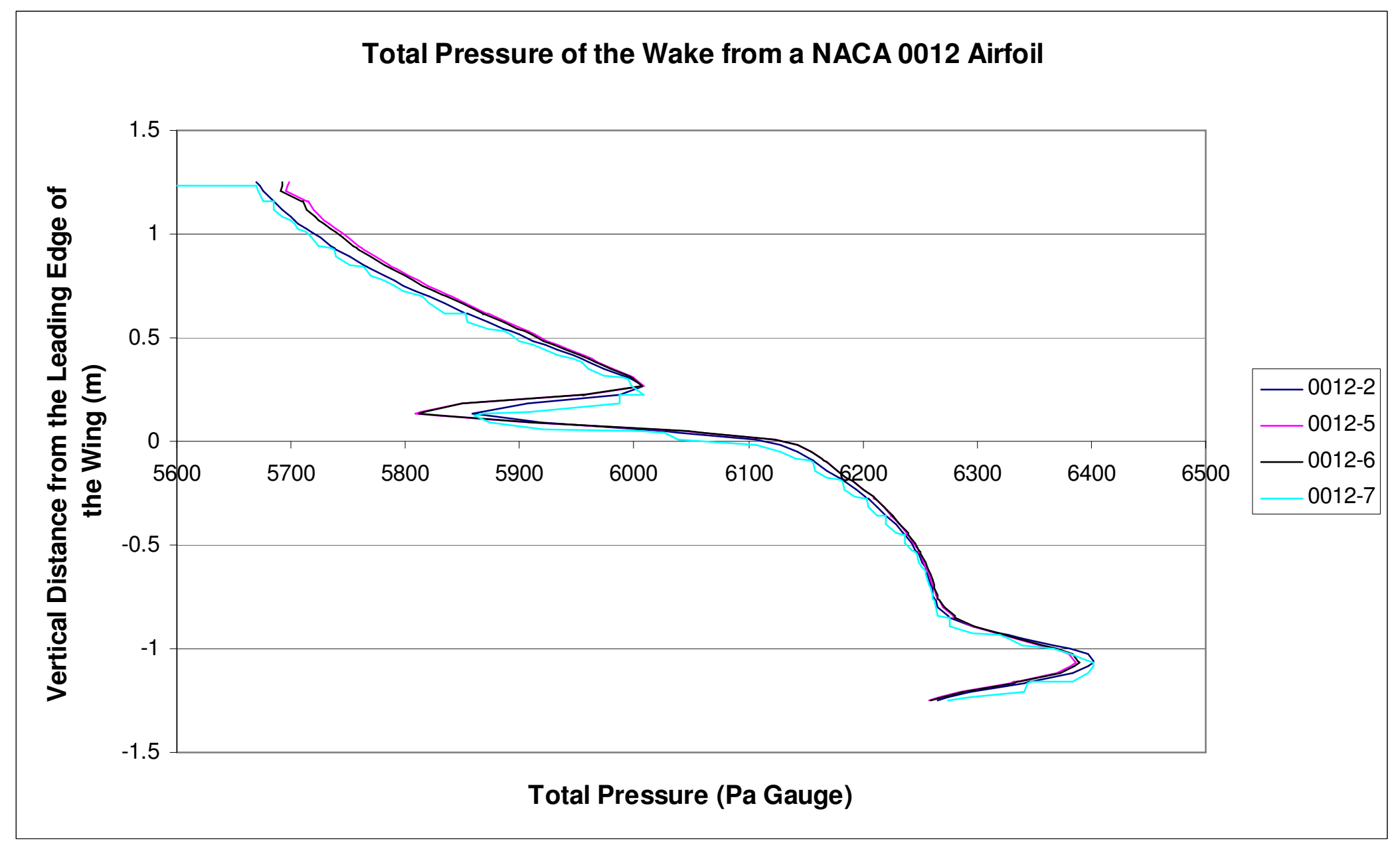

Figure A.40 Total Pressure Measurements with Different Turbulence Models of the Wake of a NACA 0012 Airfoil at $10^{\circ} \mathrm{AoA}, 100 \mathrm{~m} / \mathrm{s}$ 


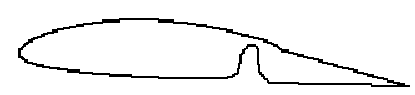

Jun 24,2007

Grid

FLUENT 6.3 [2d. dp. pbns. 5-A)

Figure A.41 Cross-Section View of the Canard on the Velocity 


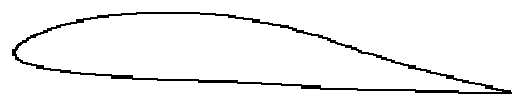

Jun 24,2007

Grid

FLUENT 6.3 [2d, dp, pbns, S-A]

Figure A.42 Cross-Section View of the Proposed Simplified Canard on the Velocity 

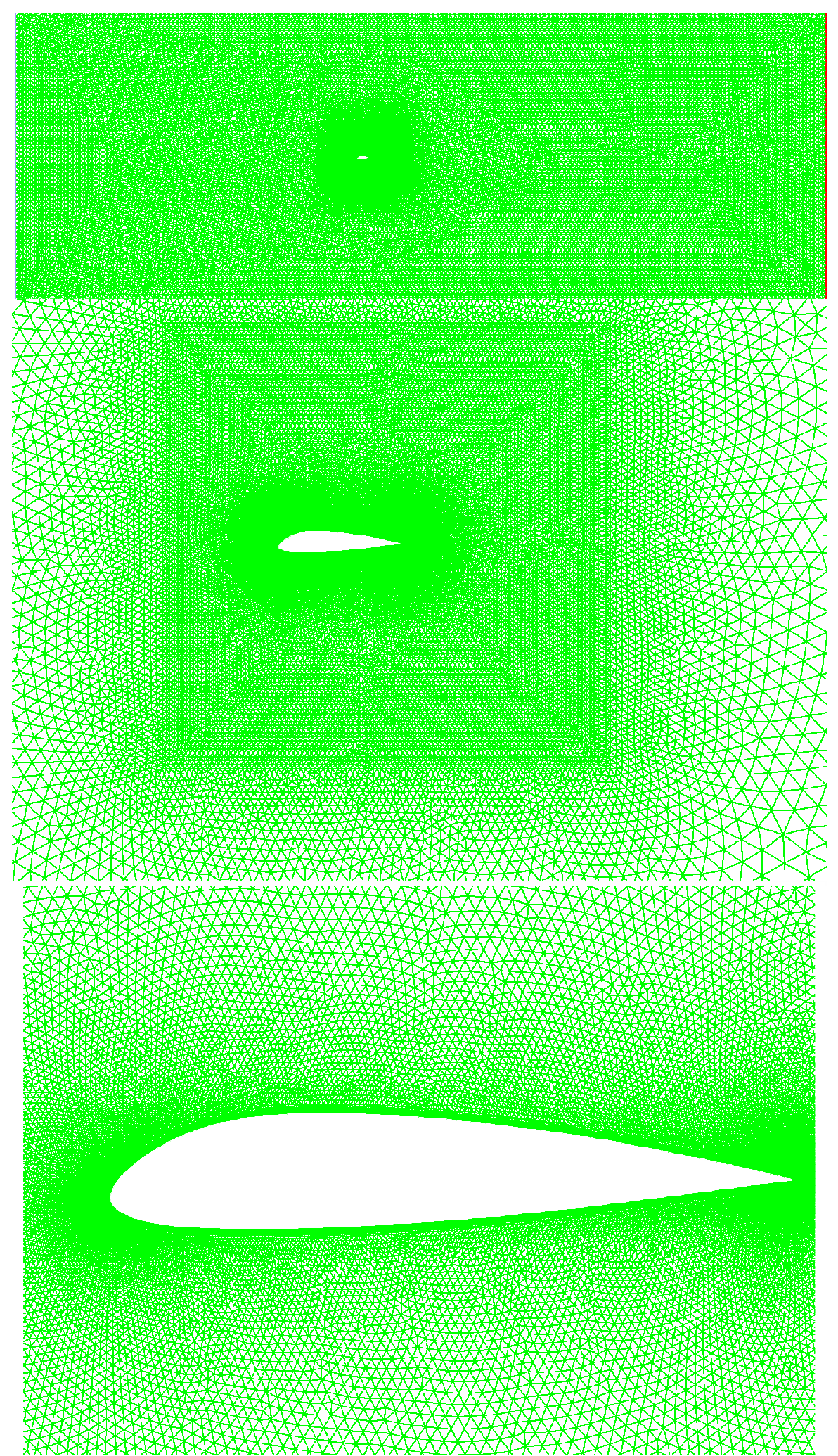

Figure A.43 Hybrid Mesh around the Wing of the Velocity 


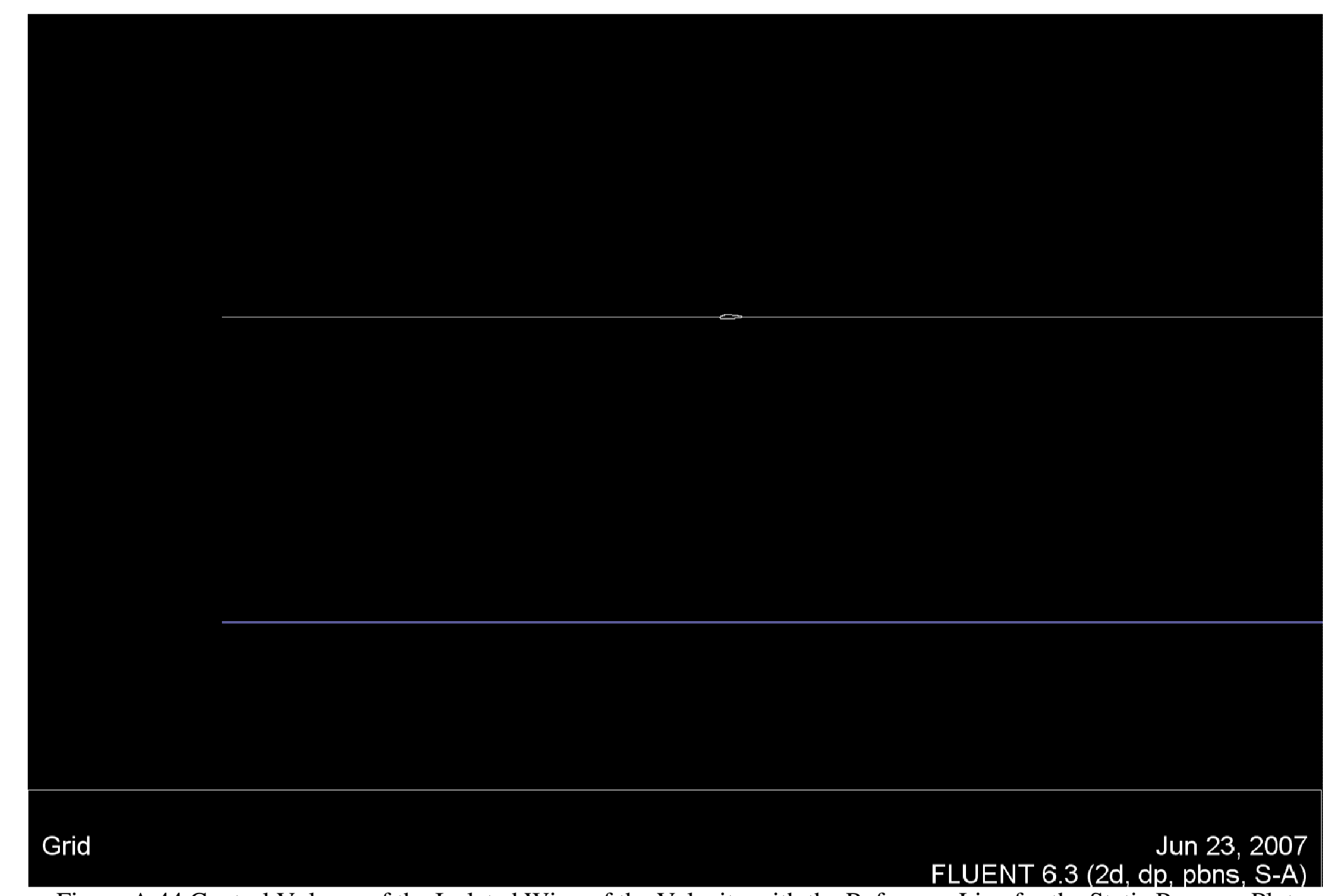

Figure A.44 Control Volume of the Isolated Wing of the Velocity with the Reference Line for the Static Pressure Plot 


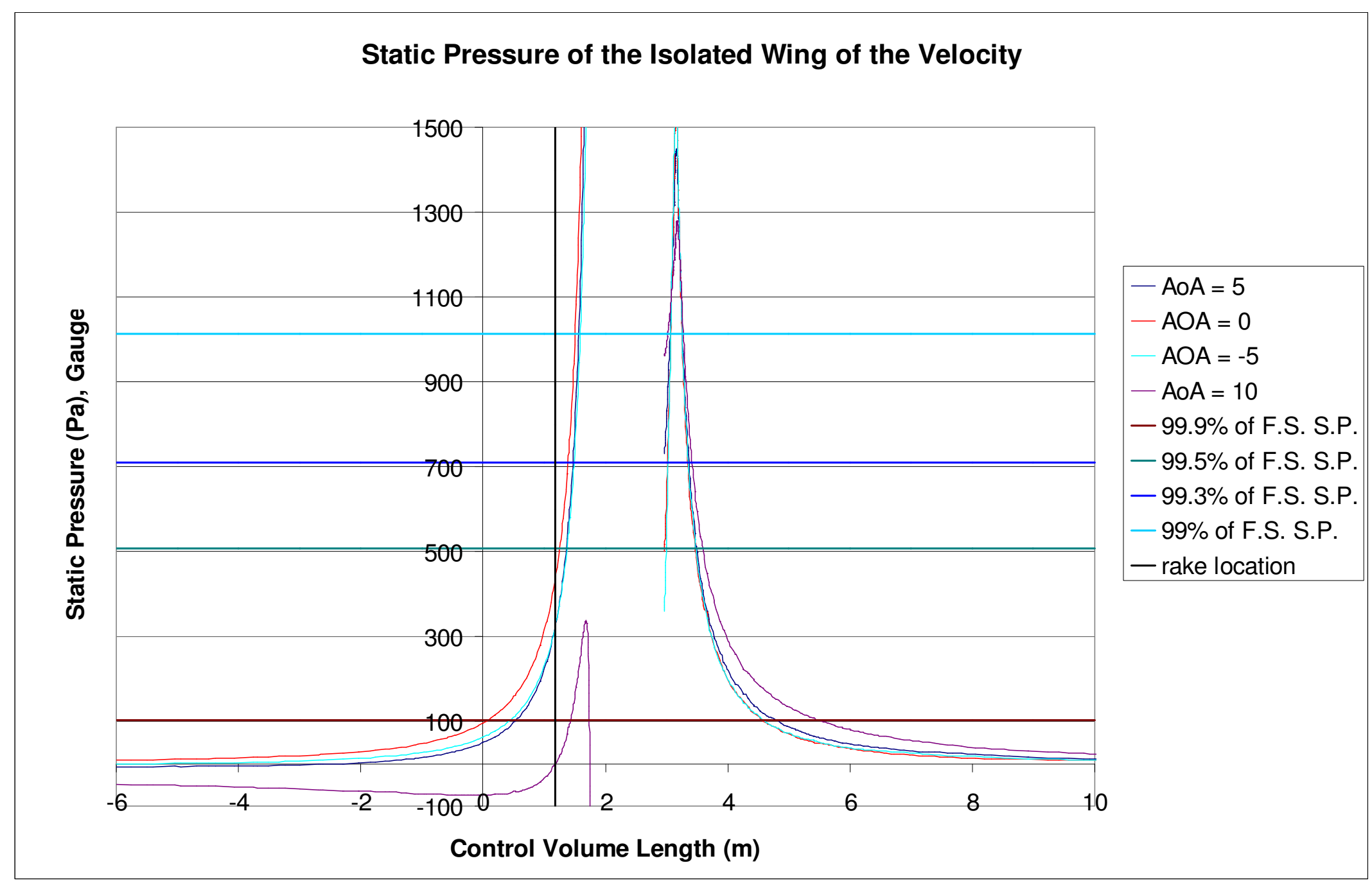

Figure A.45 Static Pressure of the Isolated Wing of the Velocity at Four Different AoAs at $100 \mathrm{~m} / \mathrm{s}$ 

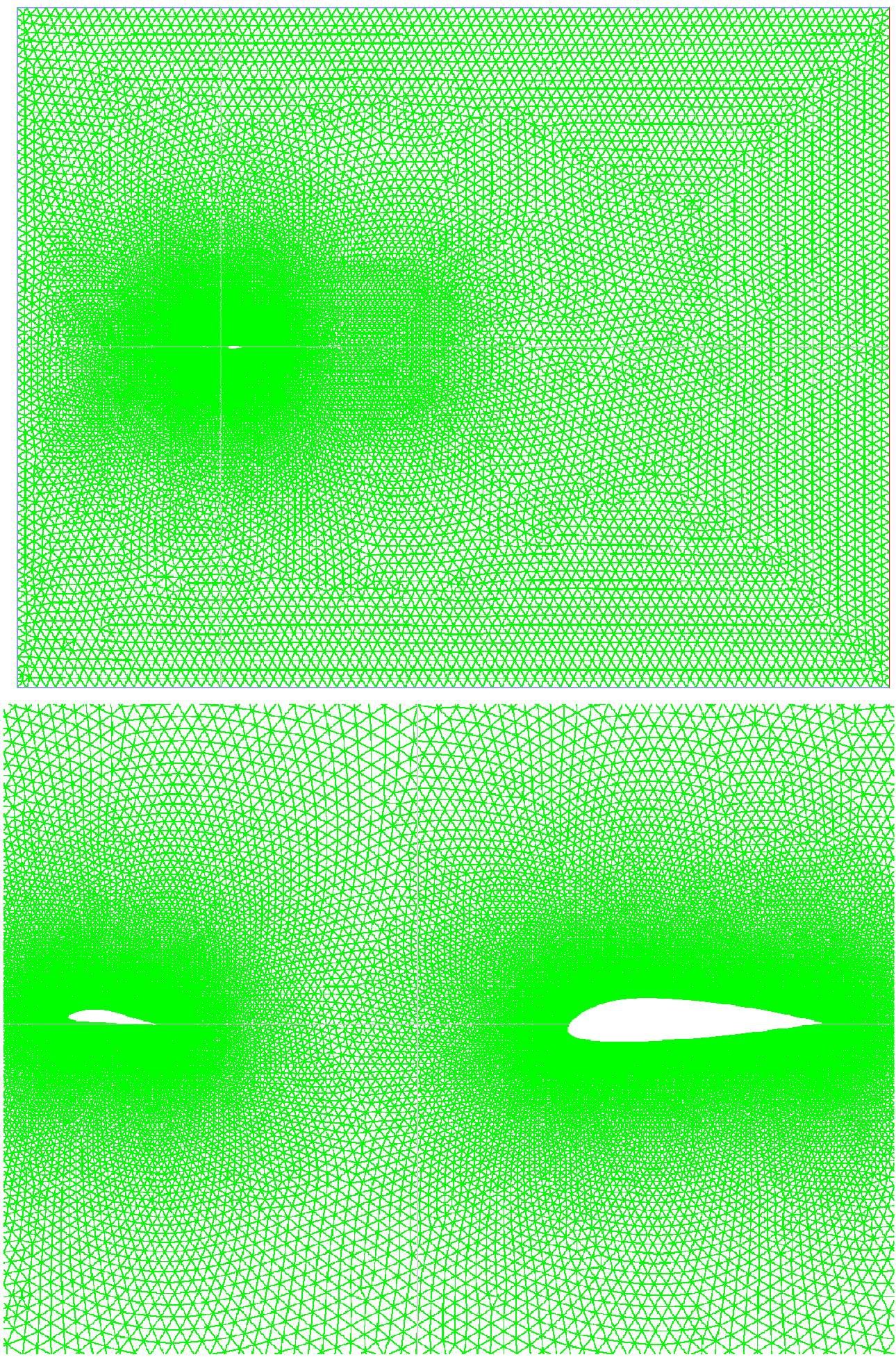

Figure A.46 Mesh between the Canard and Wing Used for the 2-D Study of the Interaction of the Canard Wake on the Wing of the Velocity 


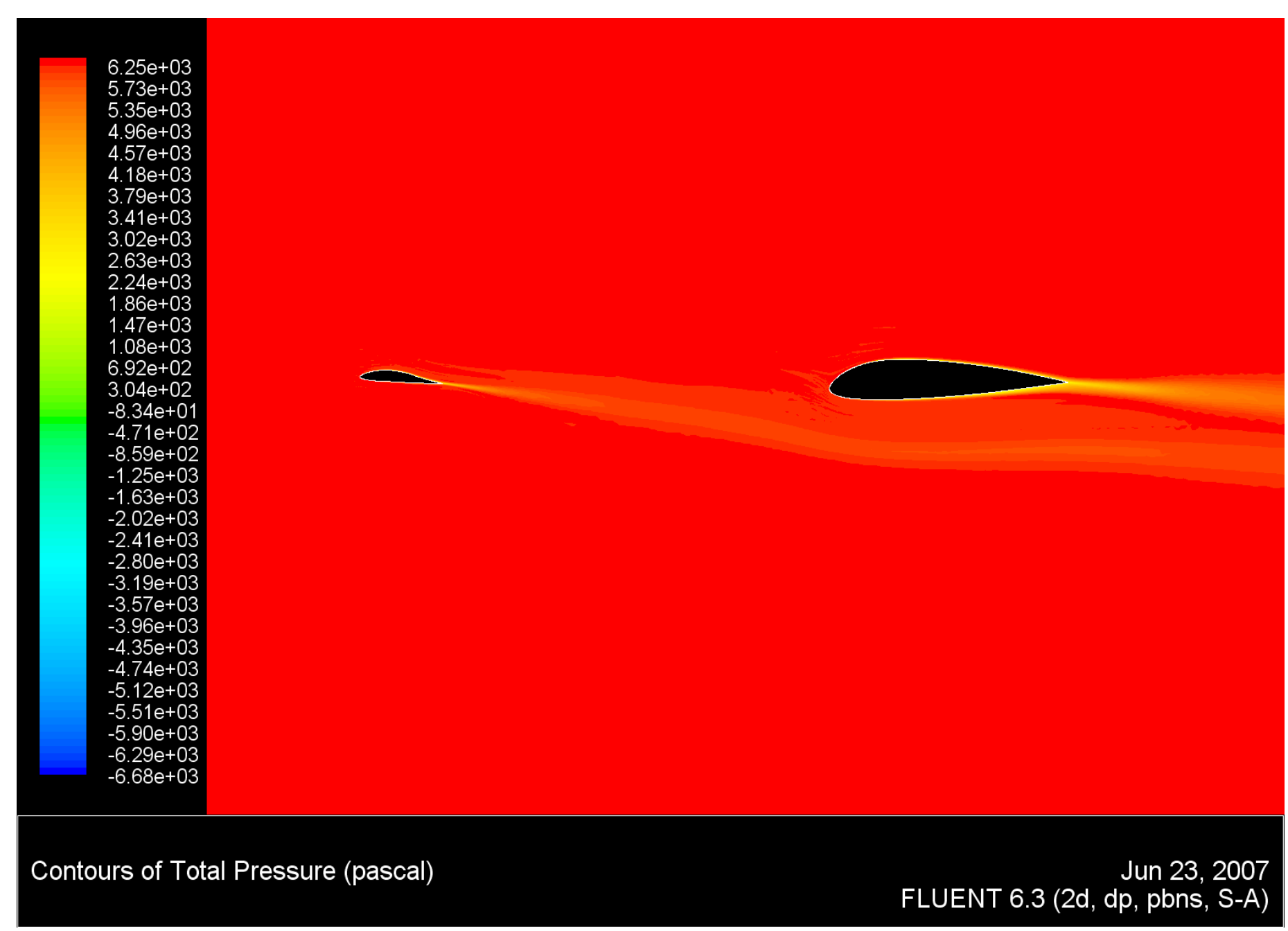

Figure A.47 Gauge Total Pressure Plot of the Velocity Canard and Wing Using the Spalart-Allmaras Turbulence Model at $-5^{\circ} \mathrm{AoA}, 100 \mathrm{~m} / \mathrm{s}$ 


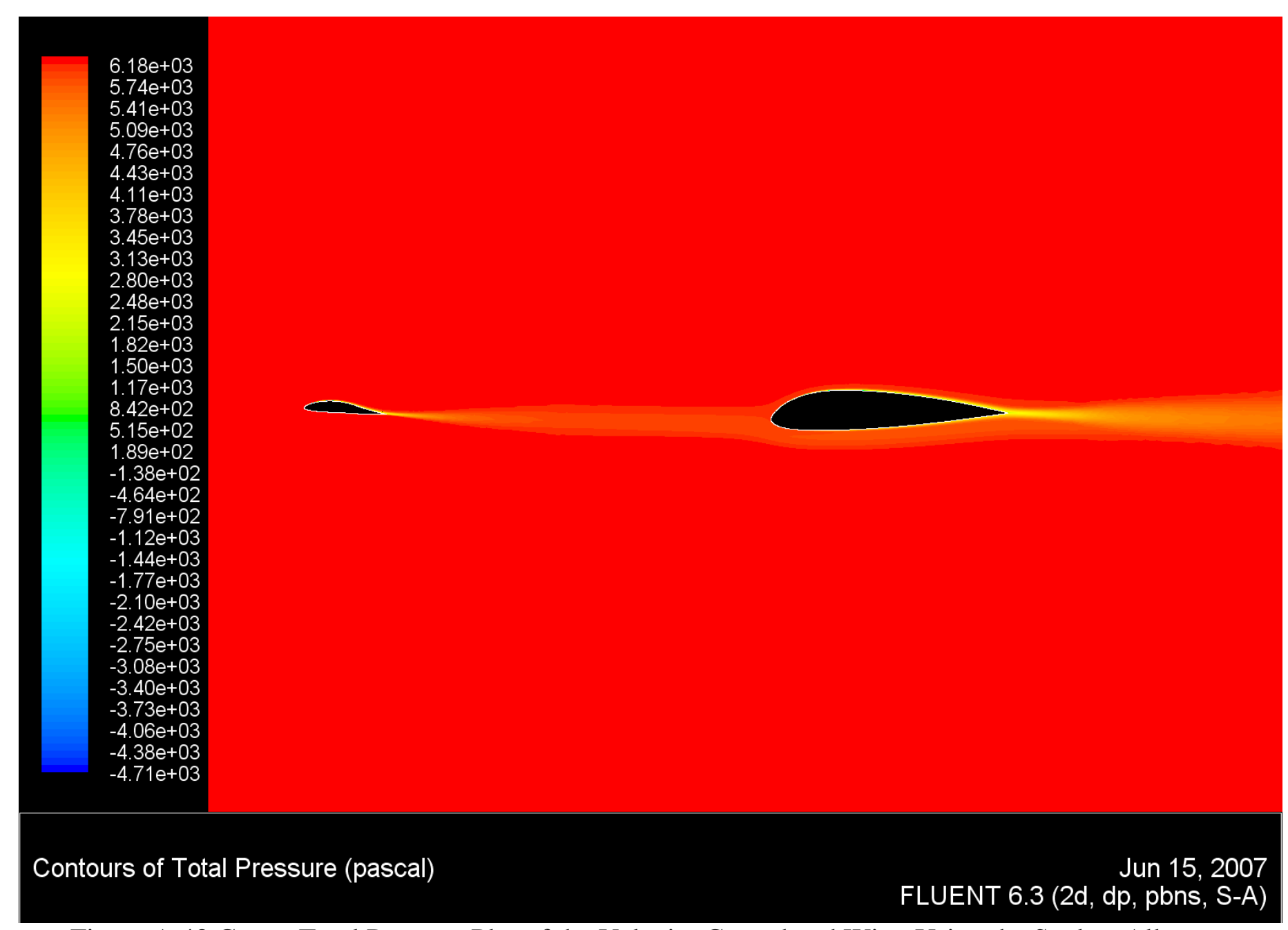

Figure A.48 Gauge Total Pressure Plot of the Velocity Canard and Wing Using the Spalart-Allmaras Turbulence Model at $0^{\circ} \mathrm{AoA}, 100 \mathrm{~m} / \mathrm{s}$ 


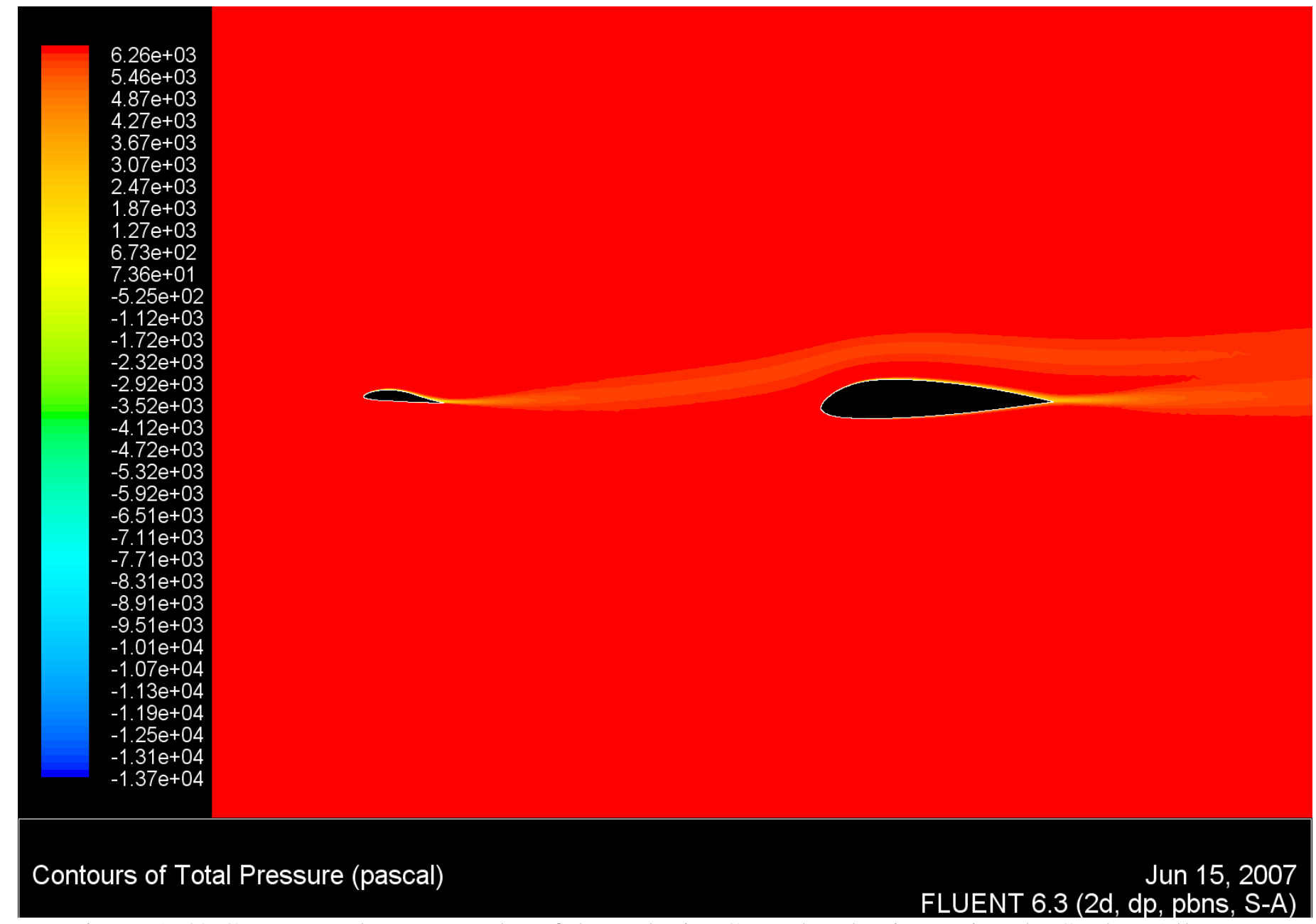

Figure A.49 Gauge Total Pressure Plot of the Velocity Canard and Wing Using the Spalart-Allmaras Turbulence Model at $5^{\circ} A o A, 100 \mathrm{~m} / \mathrm{s}$ 


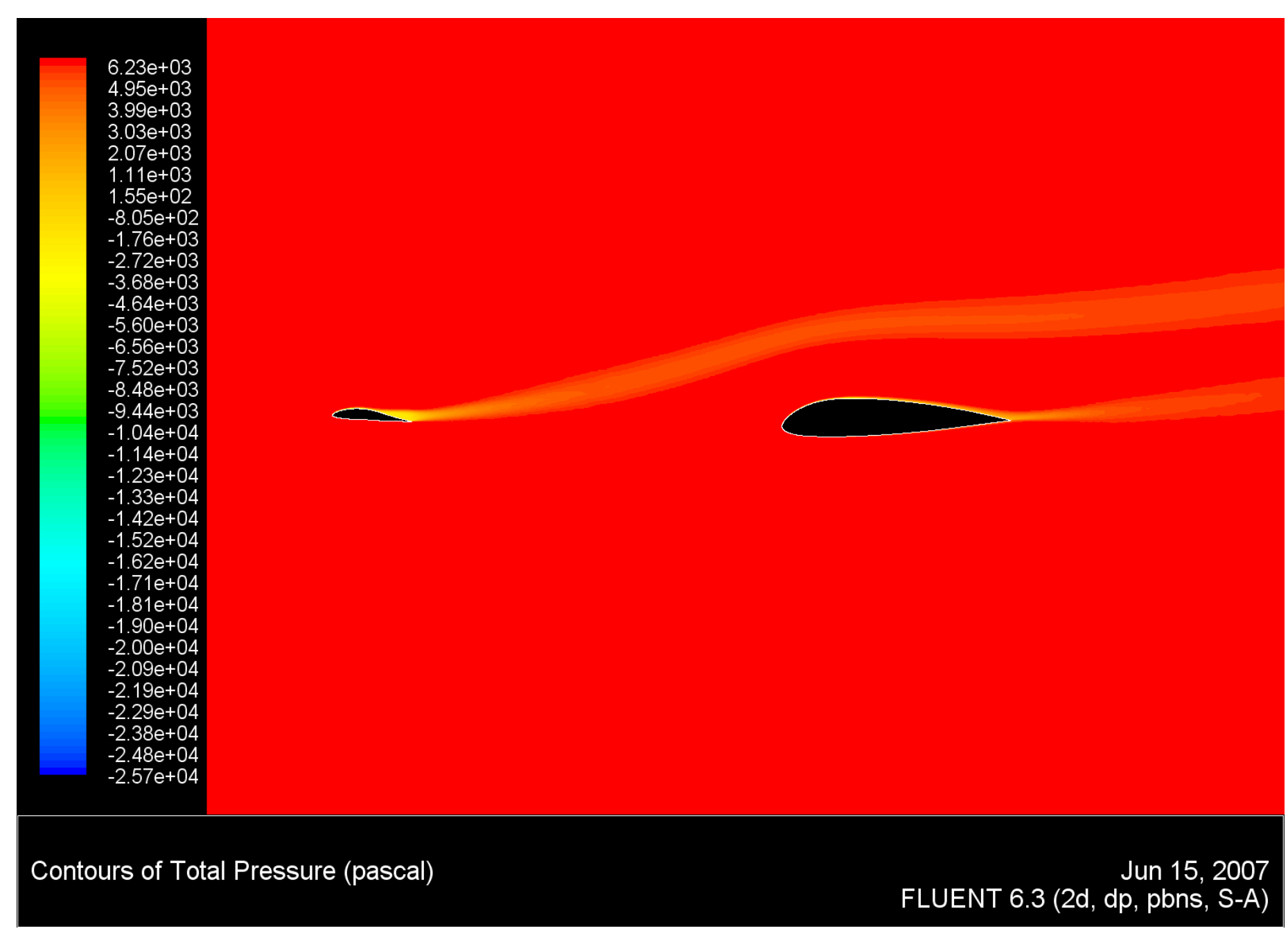

Figure A.50 Gauge Total Pressure Plot of the Velocity Canard and Wing Using the Spalart-Allmaras Turbulence Model at $10^{\circ} \mathrm{AoA}, 100 \mathrm{~m} / \mathrm{s}$ 


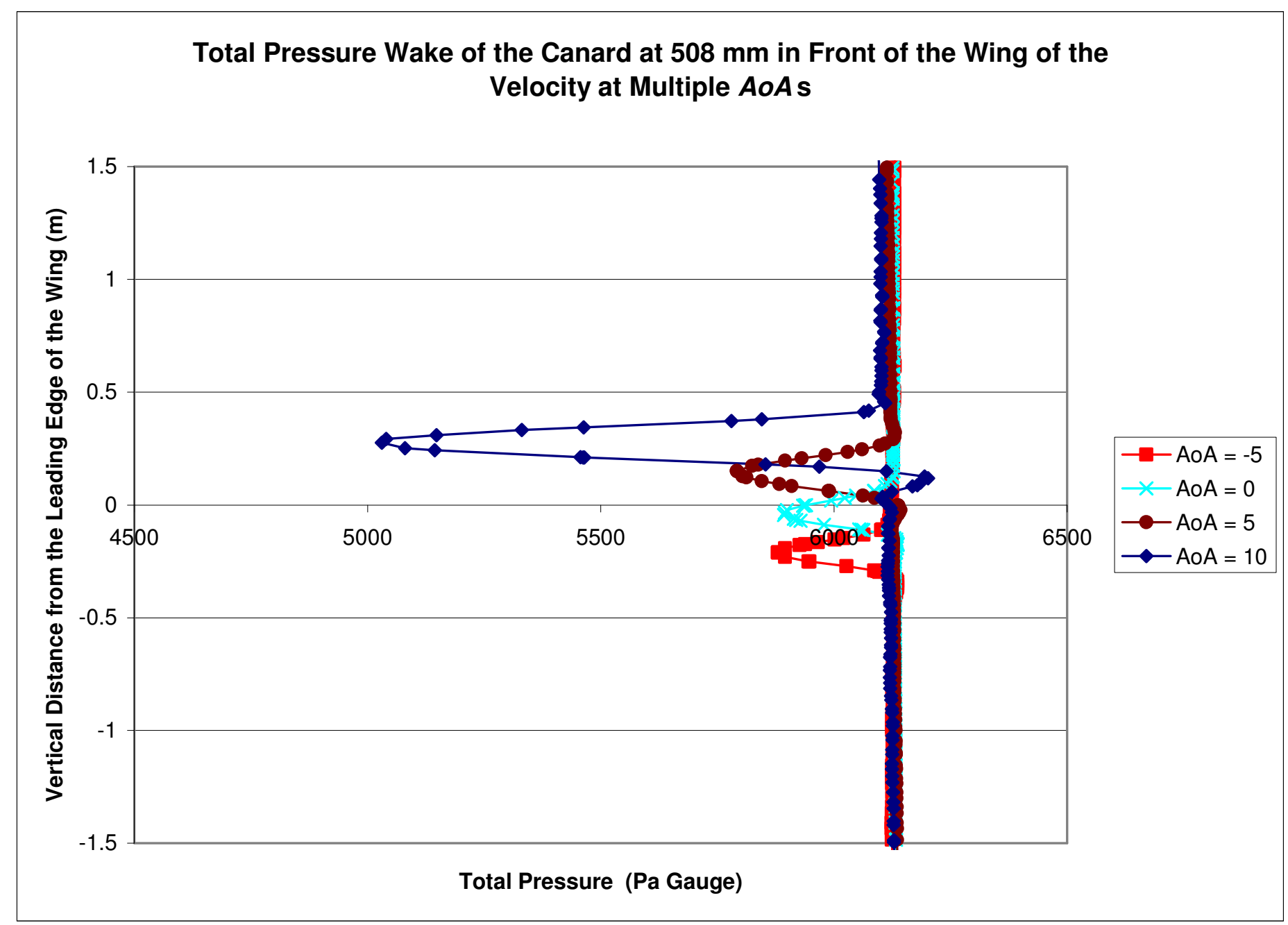

Figure A.51 Gauge Total Pressure of the Canard Wake at $508 \mathrm{~mm}$ in Front of the Leading Edge of the Wing of the Velocity over a Range of $A o A$ s 


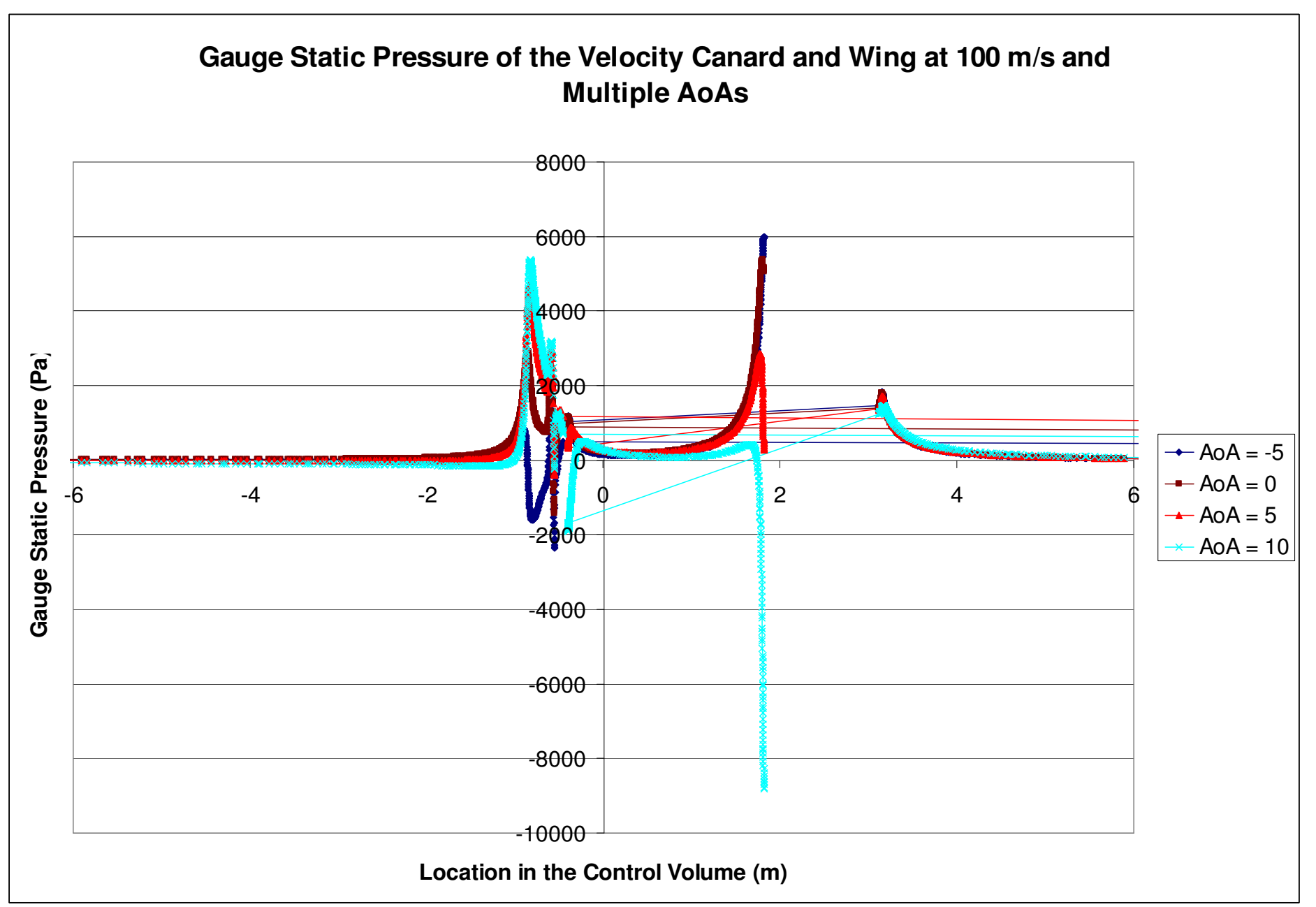

Figure A.52 Gauge Static Pressure along the Reference Line Running the Length of the Control Volume over a Range of $A o A s$ 

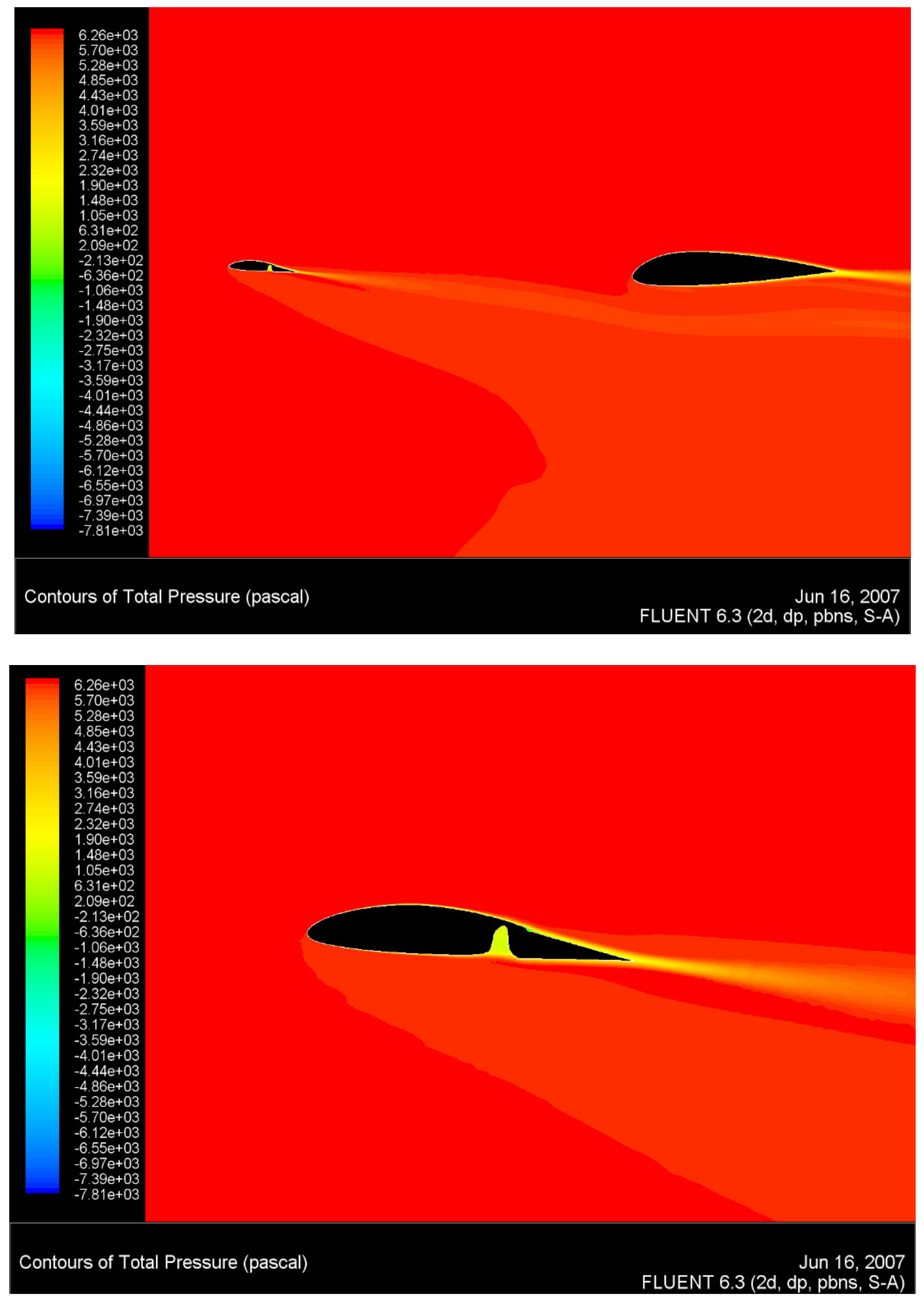

Figure A.53 Gauge Total Pressure Plot of the Velocity Canard and Wing Using the Spalart-Allmaras Turbulence Model at $-5^{\circ} A o A, 100 \mathrm{~m} / \mathrm{s}$ 

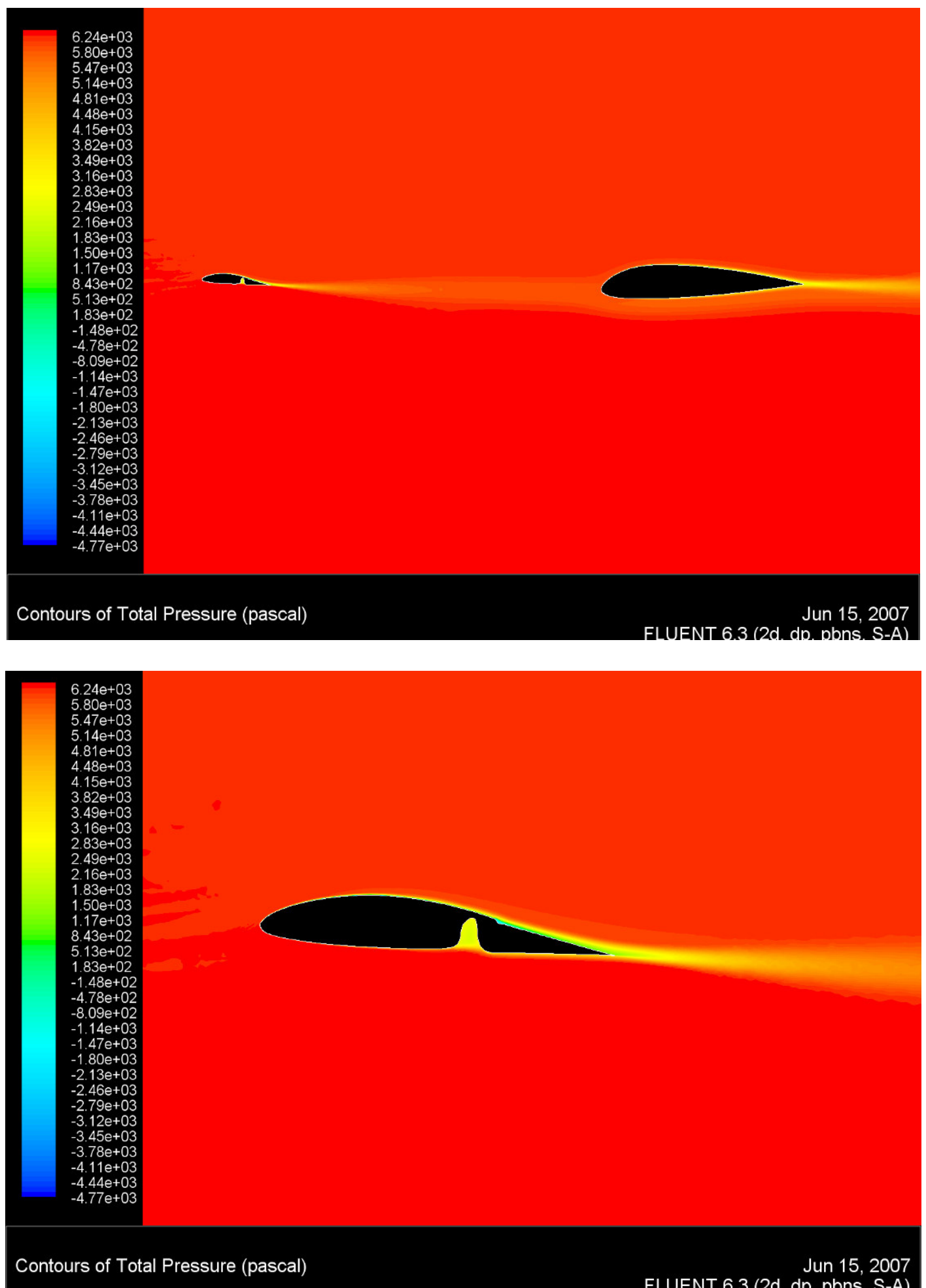

Figure A.54 Gauge Total Pressure Plot of the Velocity Canard and Wing Using the Spalart-Allmaras Turbulence Model at $0^{\circ} A o A, 100 \mathrm{~m} / \mathrm{s}$ 

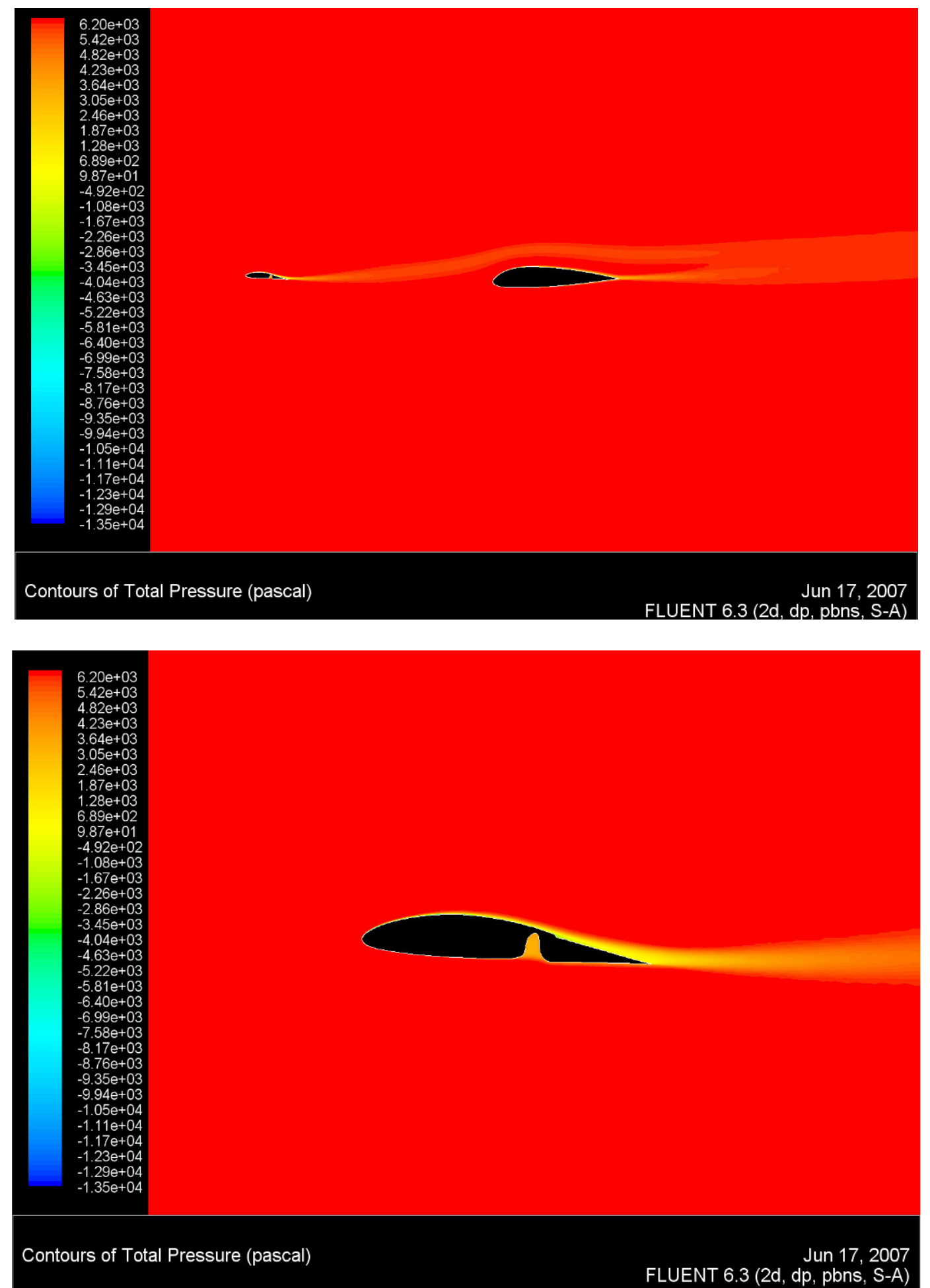

Figure A.55 Gauge Total Pressure Plot of the Velocity Canard and Wing Using the Spalart-Allmaras Turbulence Model at $5^{\circ} A o A, 100 \mathrm{~m} / \mathrm{s}$ 

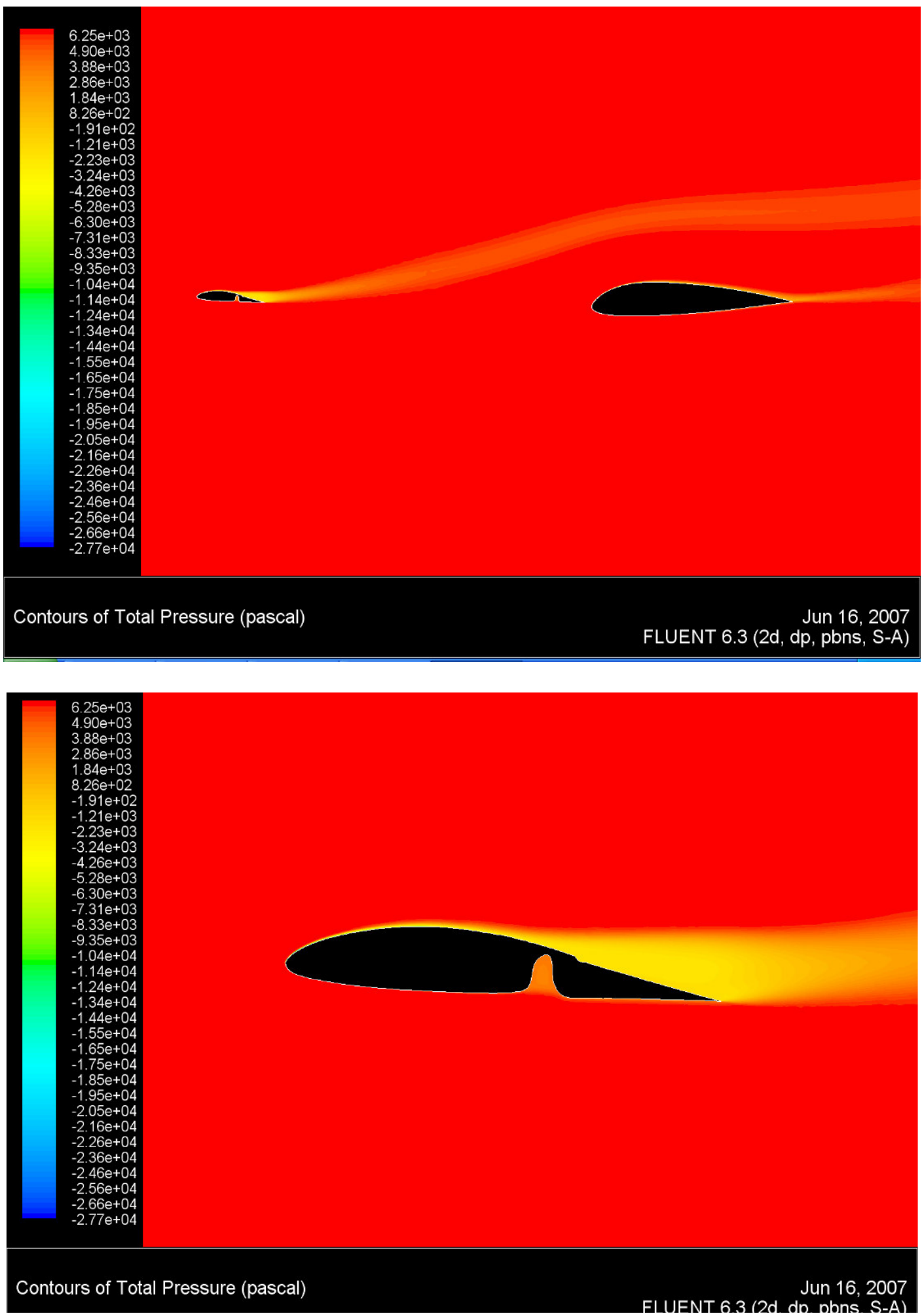

Figure A.56 Gauge Total Pressure Plot of the Velocity Canard and Wing Using the Spalart-Allmaras Turbulence Model at $10^{\circ} \mathrm{AoA}, 100 \mathrm{~m} / \mathrm{s}$ 


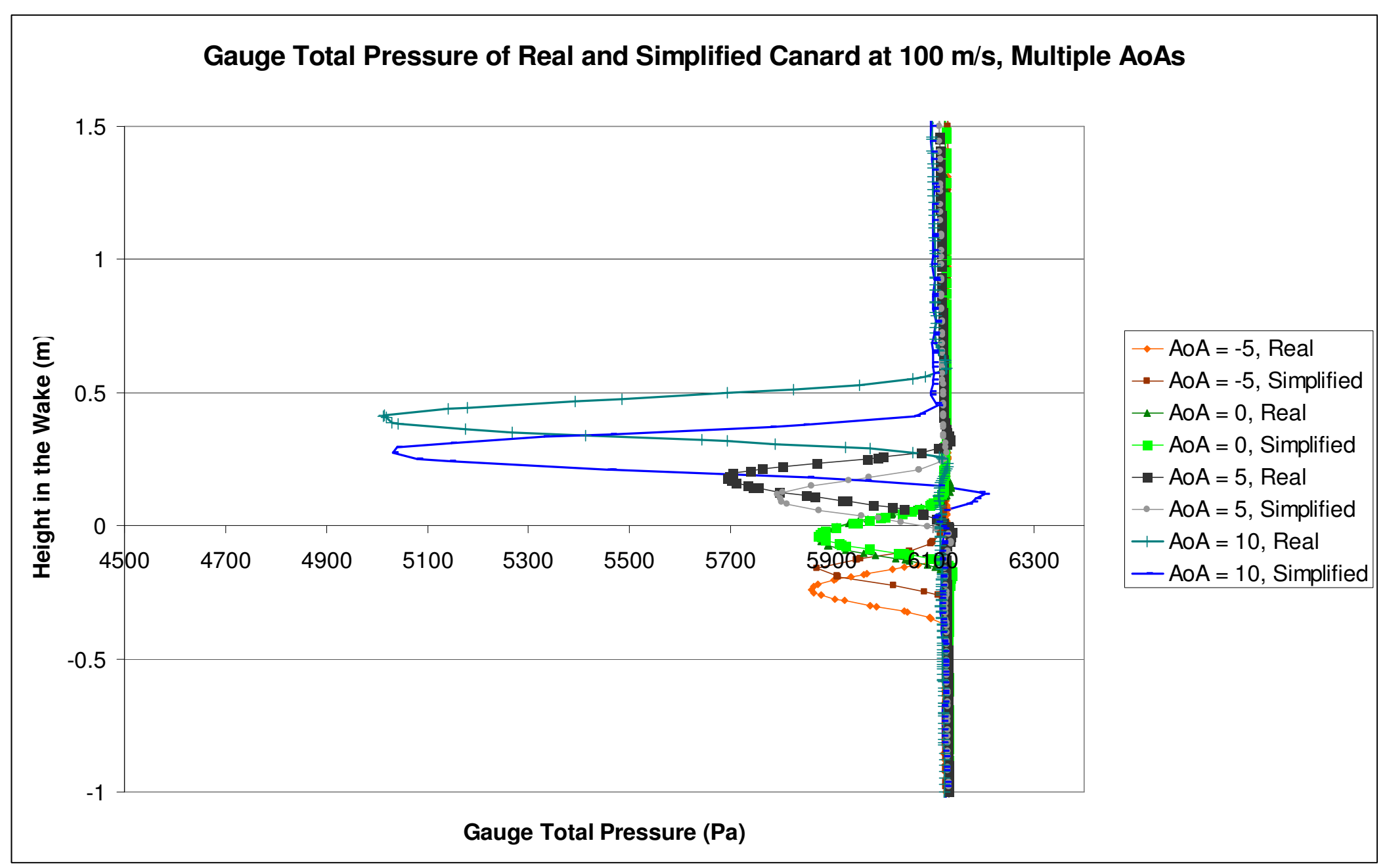

Figure A.57 Comparison of Real and Simplified Canard Total Pressure Wakes at $100 \mathrm{~m} / \mathrm{s}$ for the Four Different AoAs 


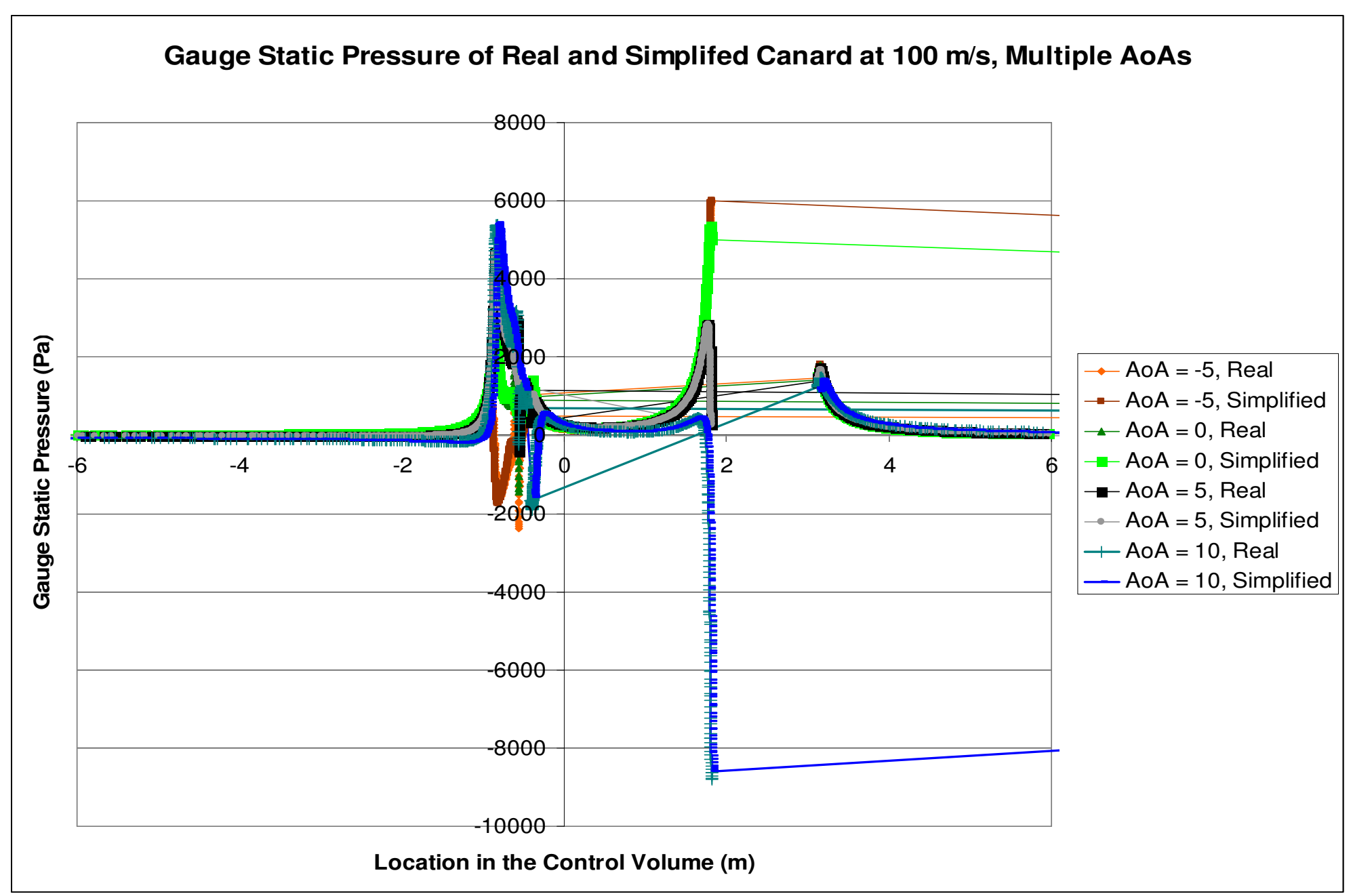

Figure A.58 Comparison of Real and Simplified Canard Static Pressure at $100 \mathrm{~m} / \mathrm{s}$ for the Four Different AoAs 

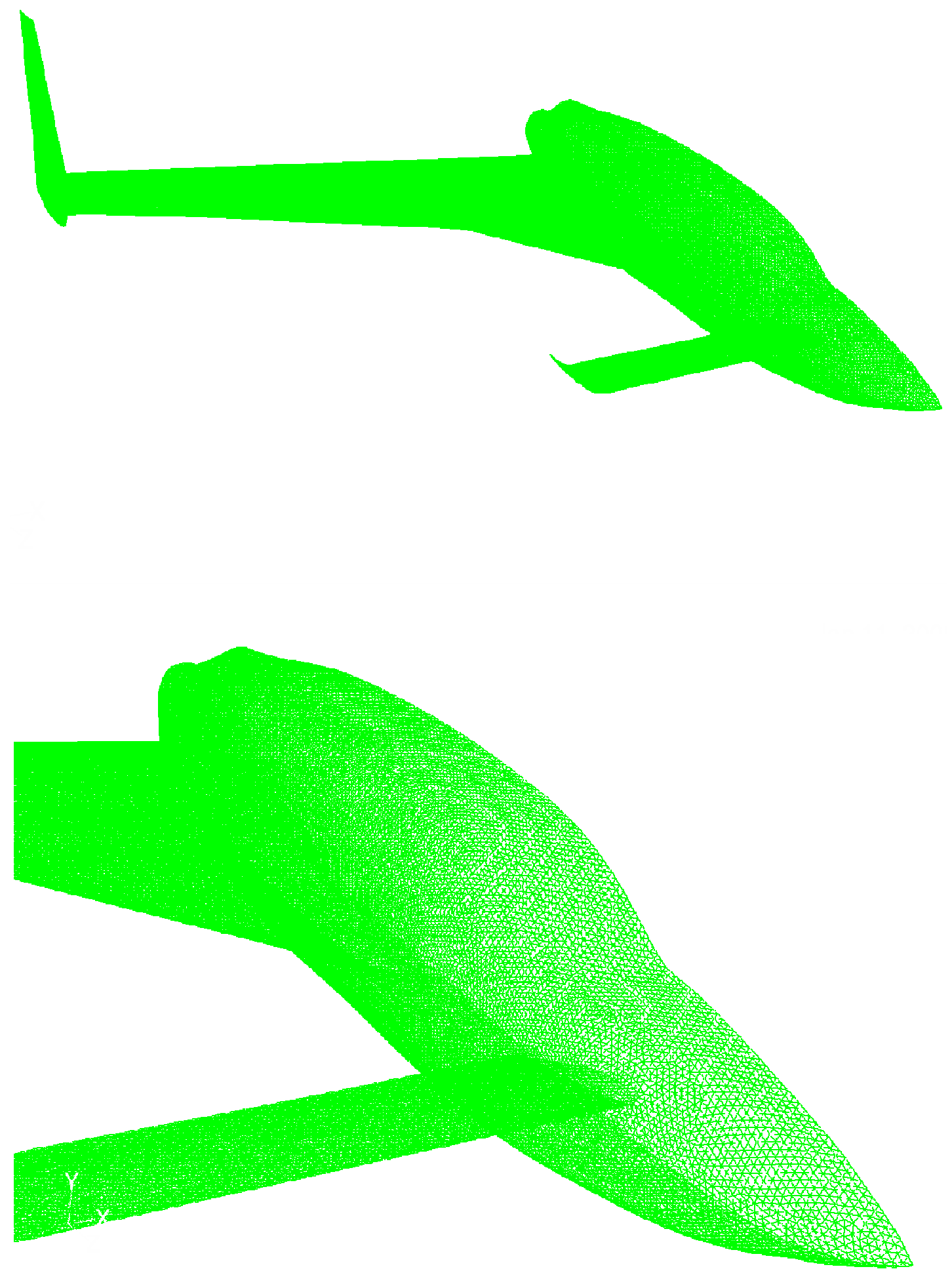

Figure A.59 View of the 3-D Model of the Velocity Used for the Initial Simulations and Control Volume Sizing Study 

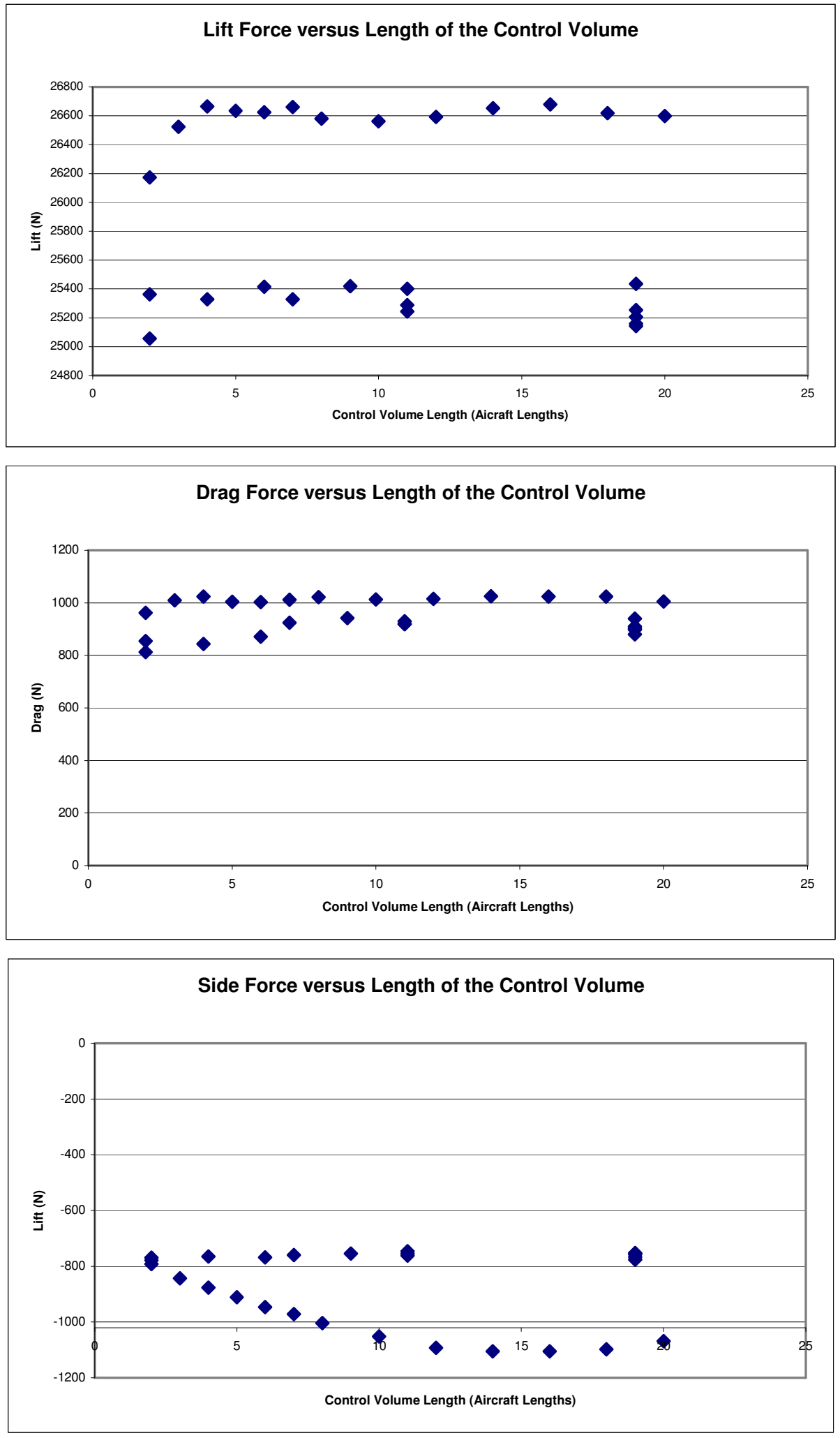

Figure A.60 Body Forces Versus Control Volume Length 

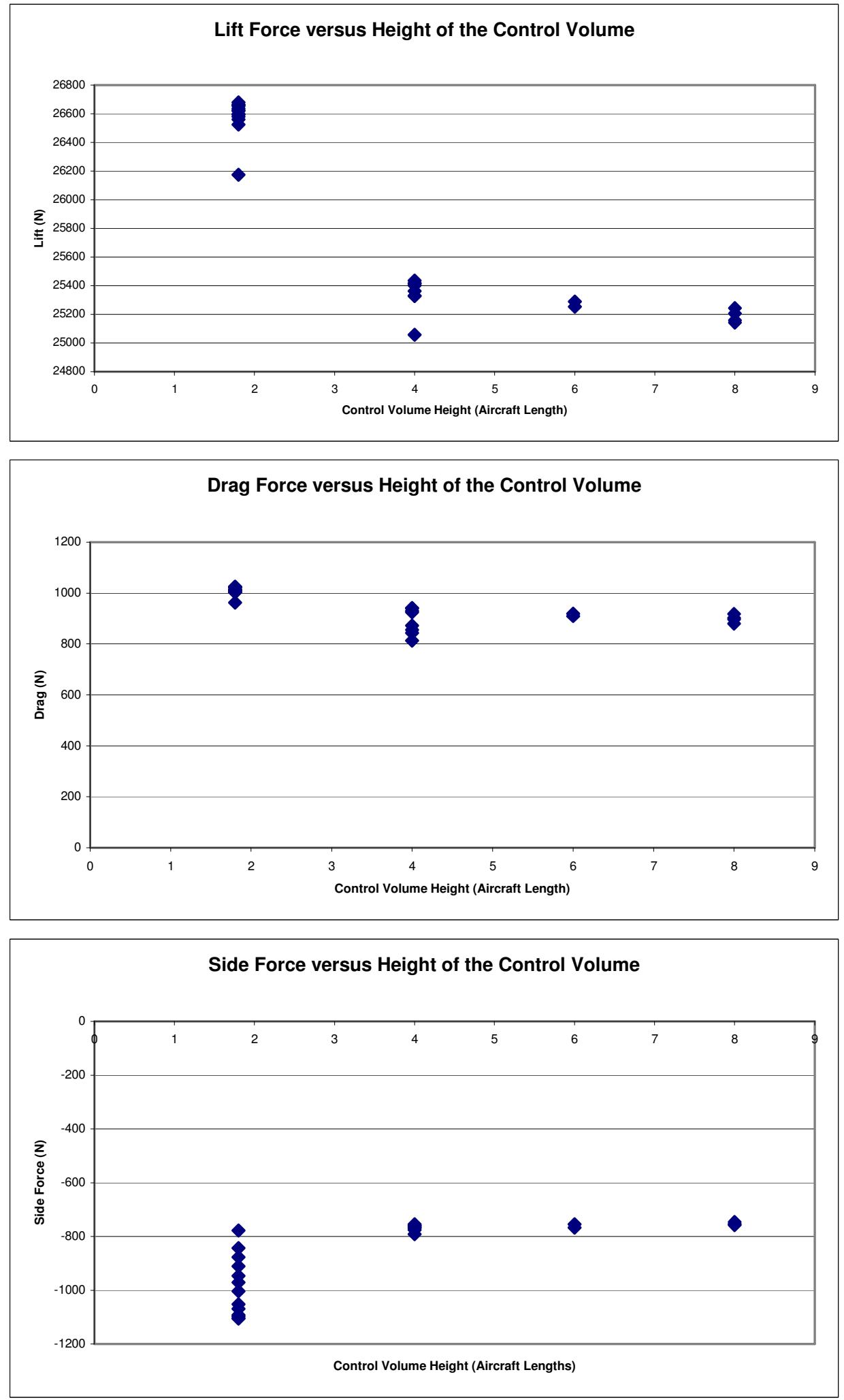

Figure A.61 Body Forces Versus Control Volume Height 

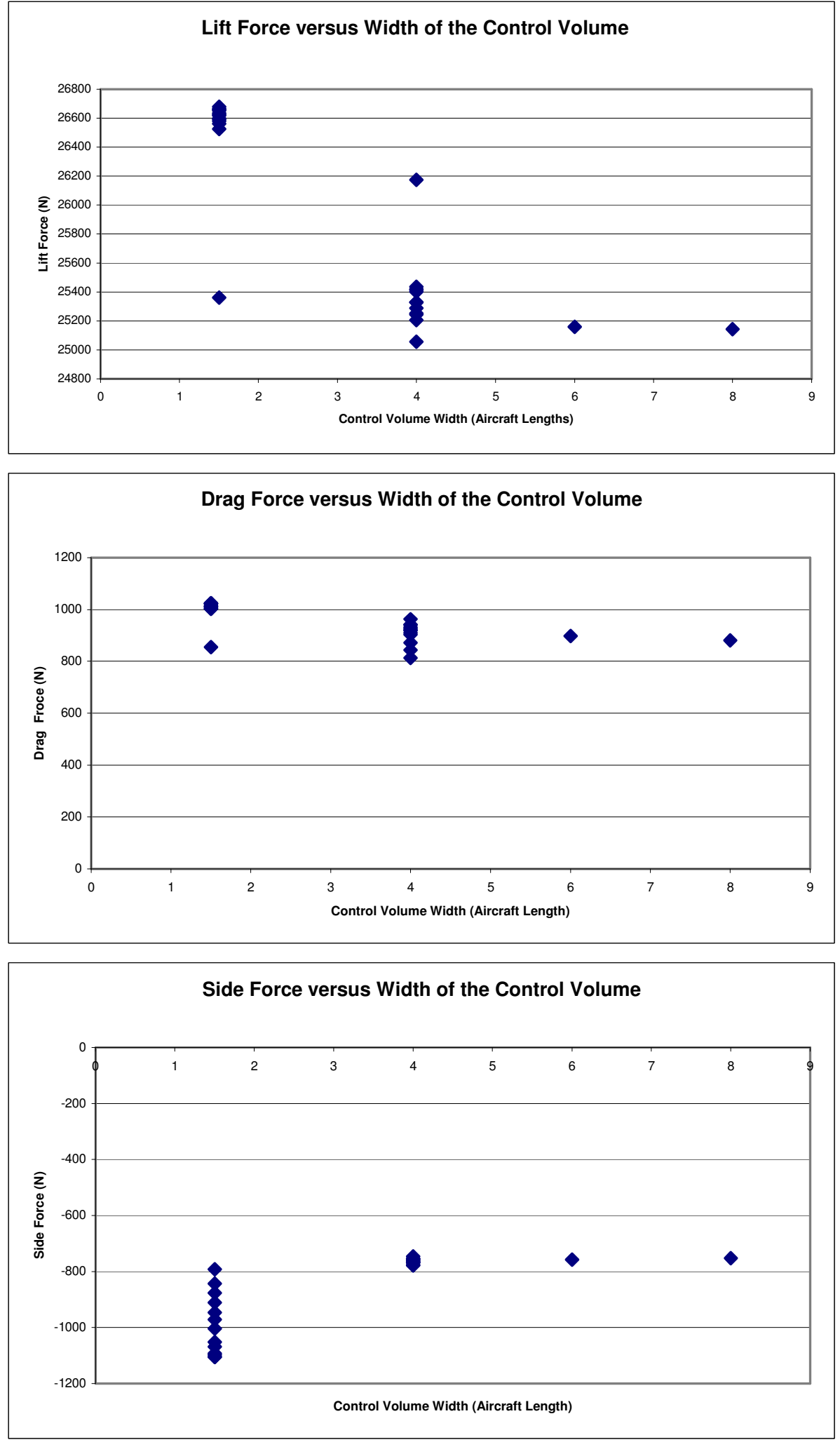

Figure A.62 Body Forces Versus Control Volume Width 

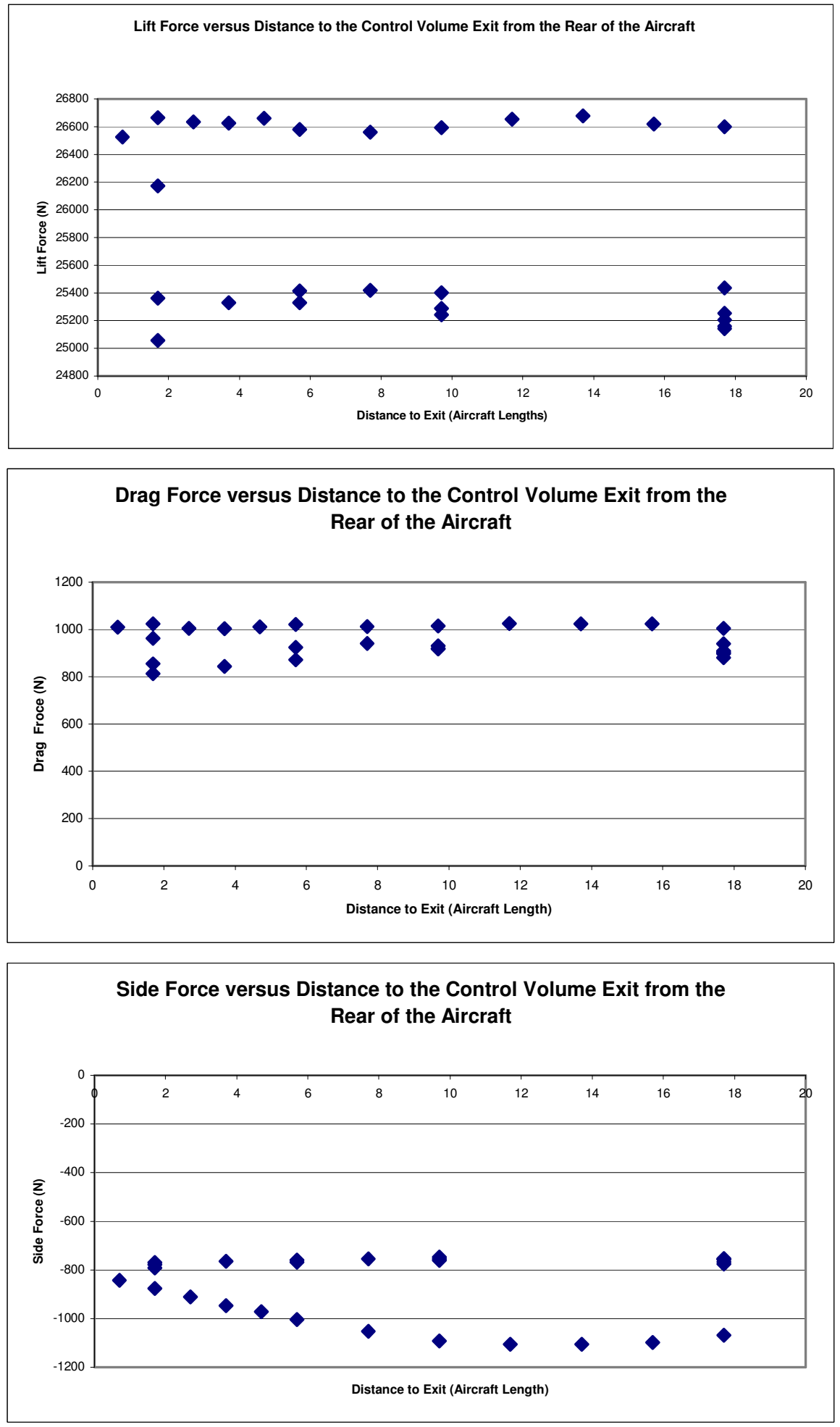

Figure A.63 Body Forces Versus Distance from the Rear of the Aircraft to the Control Volume Exit 

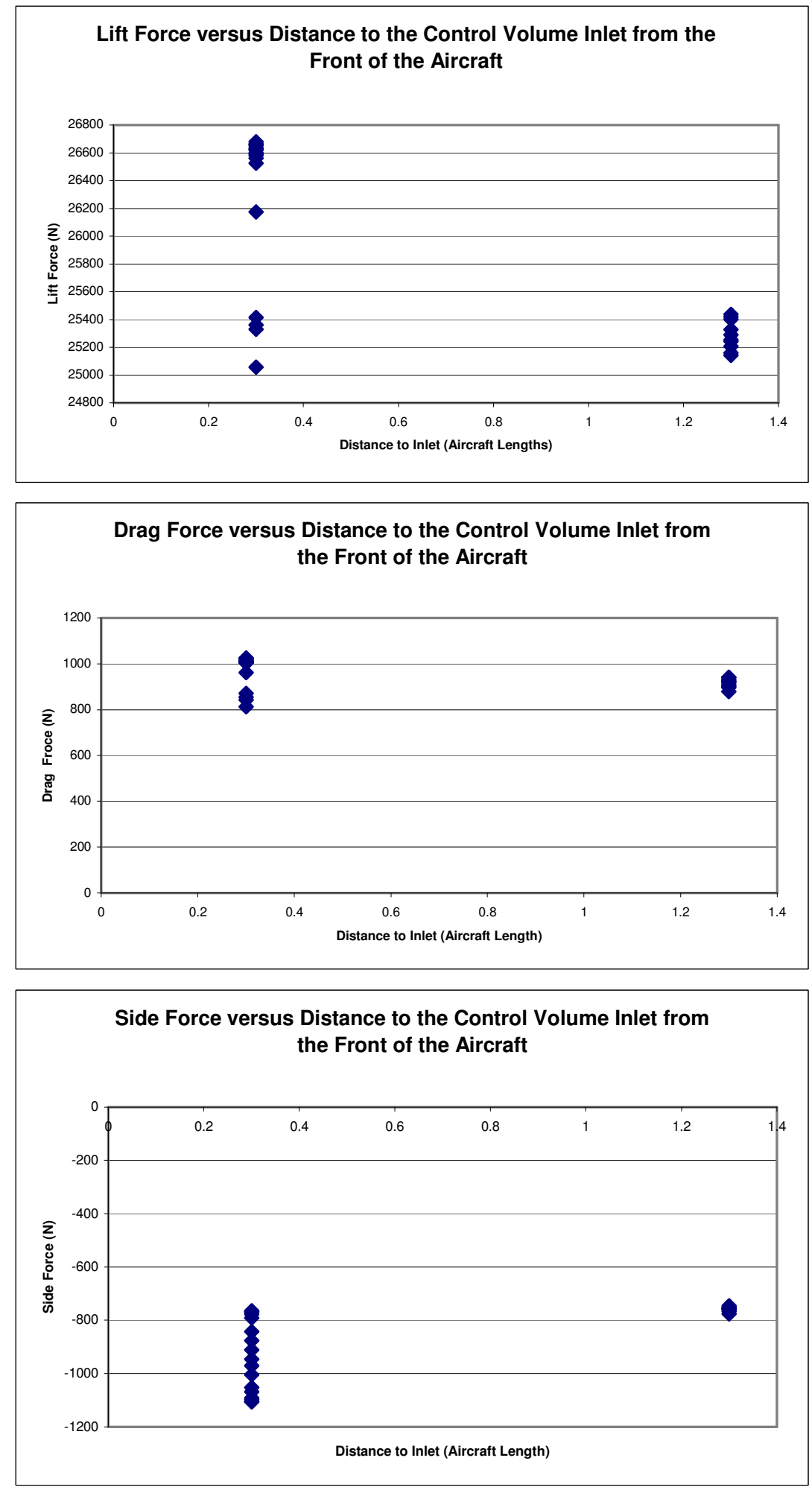

Figure A.64 Body Forces versus Distance from the Front of the Aircraft to the Control Volume Inlet 


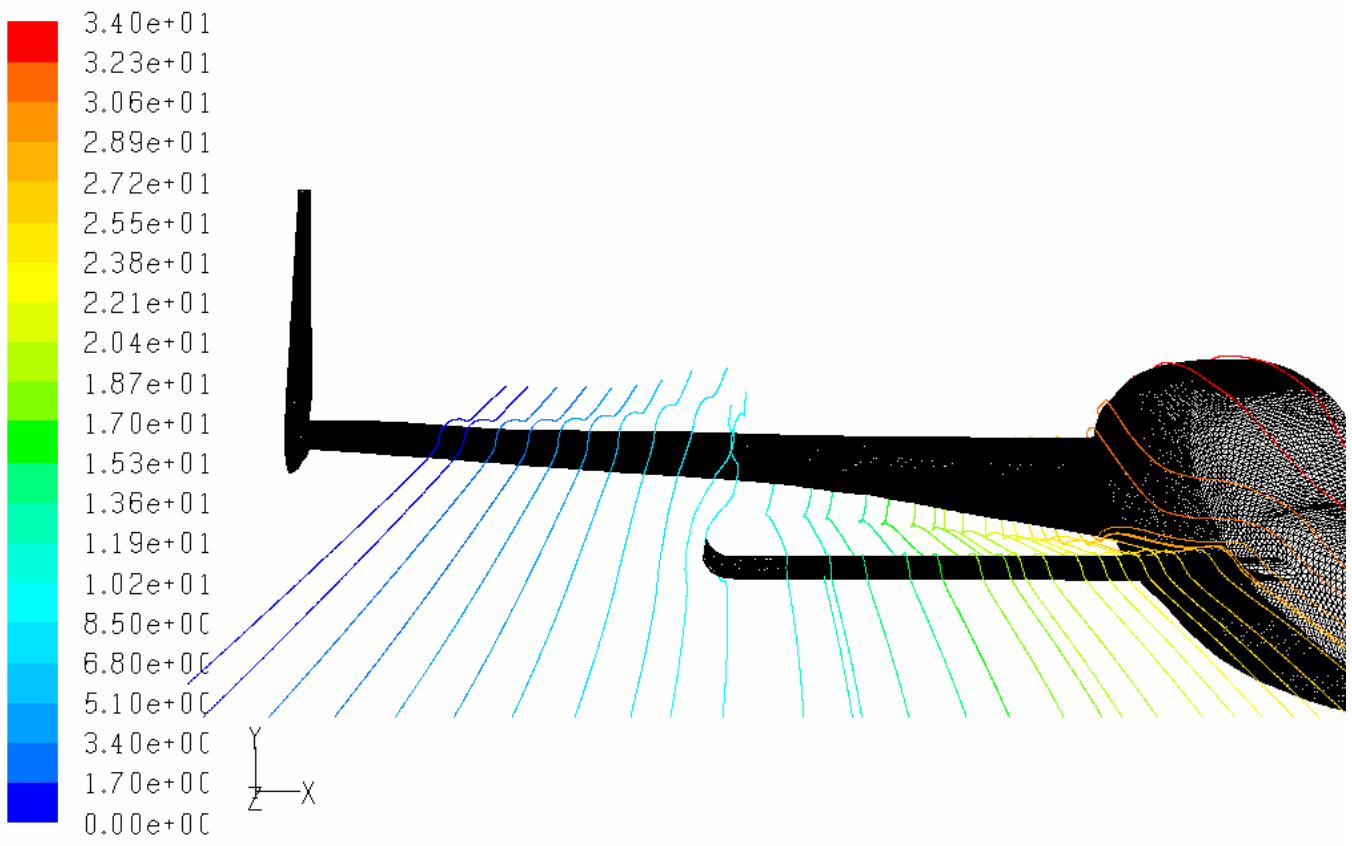

Pathlines Colored by Particle ID

FLUENT 6.3 ( $3 \mathrm{~d}$, dp, pbns)

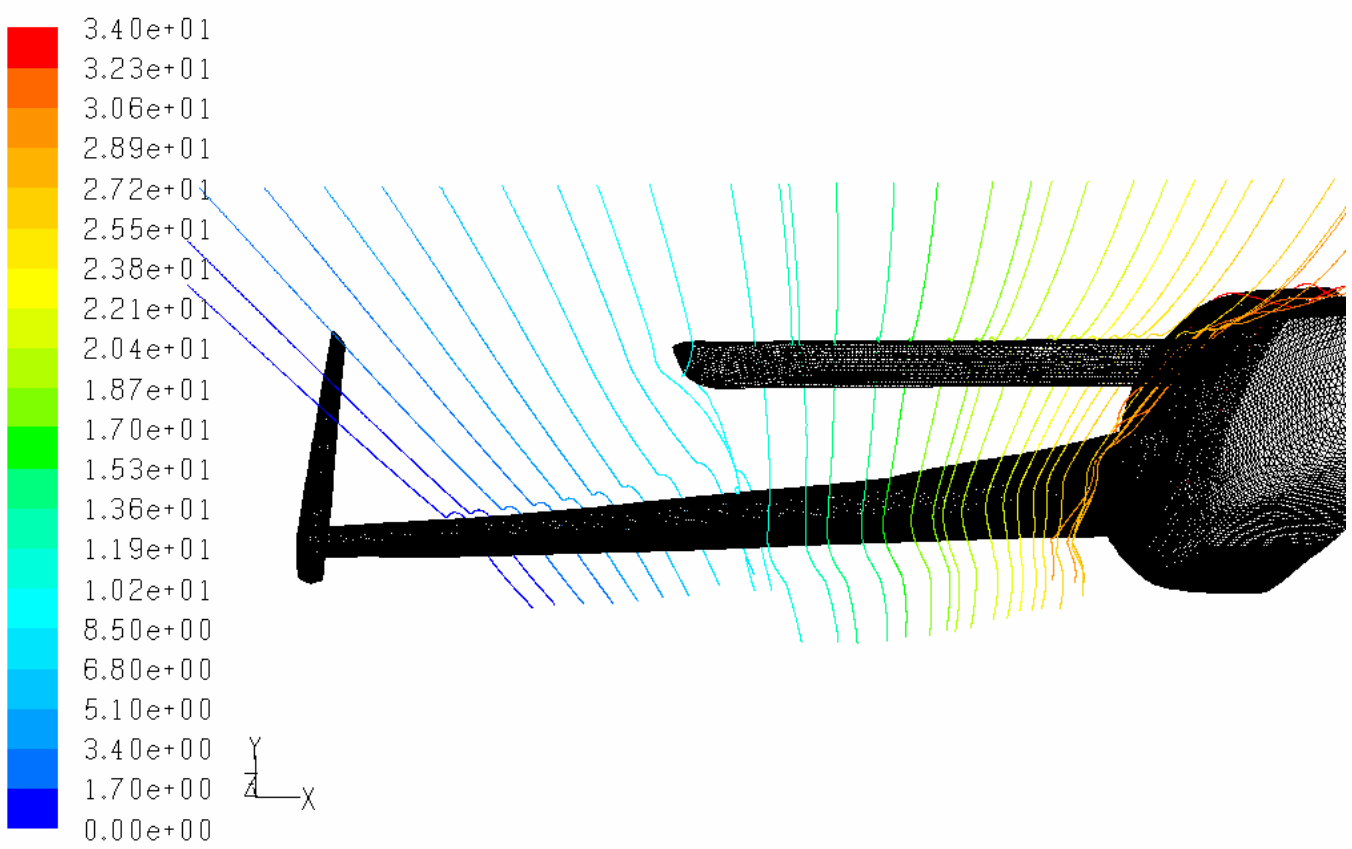

Pathlines Colored by Particle ID

Jun 24, 2007

FLUENT 6.3 (3d, dp, pbns)

Figure A.65 Pathlines around the Canard of the Velocity at $0^{\circ} A o A, 100 \mathrm{~m} / \mathrm{s}$ 

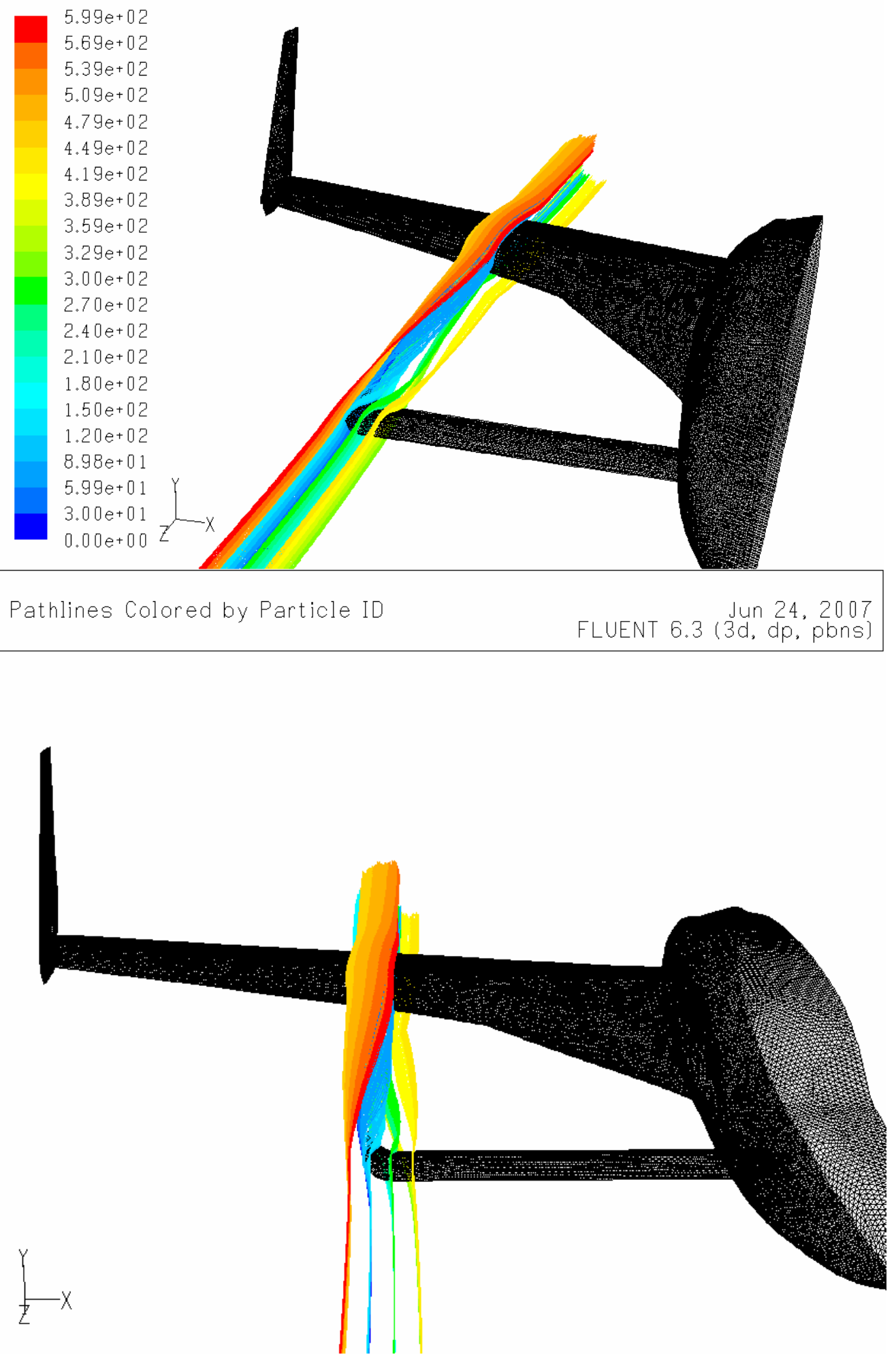

Figure A.66 Pathlines Clustered around the Canard Tip Vortex to Visualize the Size and Range of Influence of the Tip Vortex at $0^{\circ} A o A, 100 \mathrm{~m} / \mathrm{s}$ 


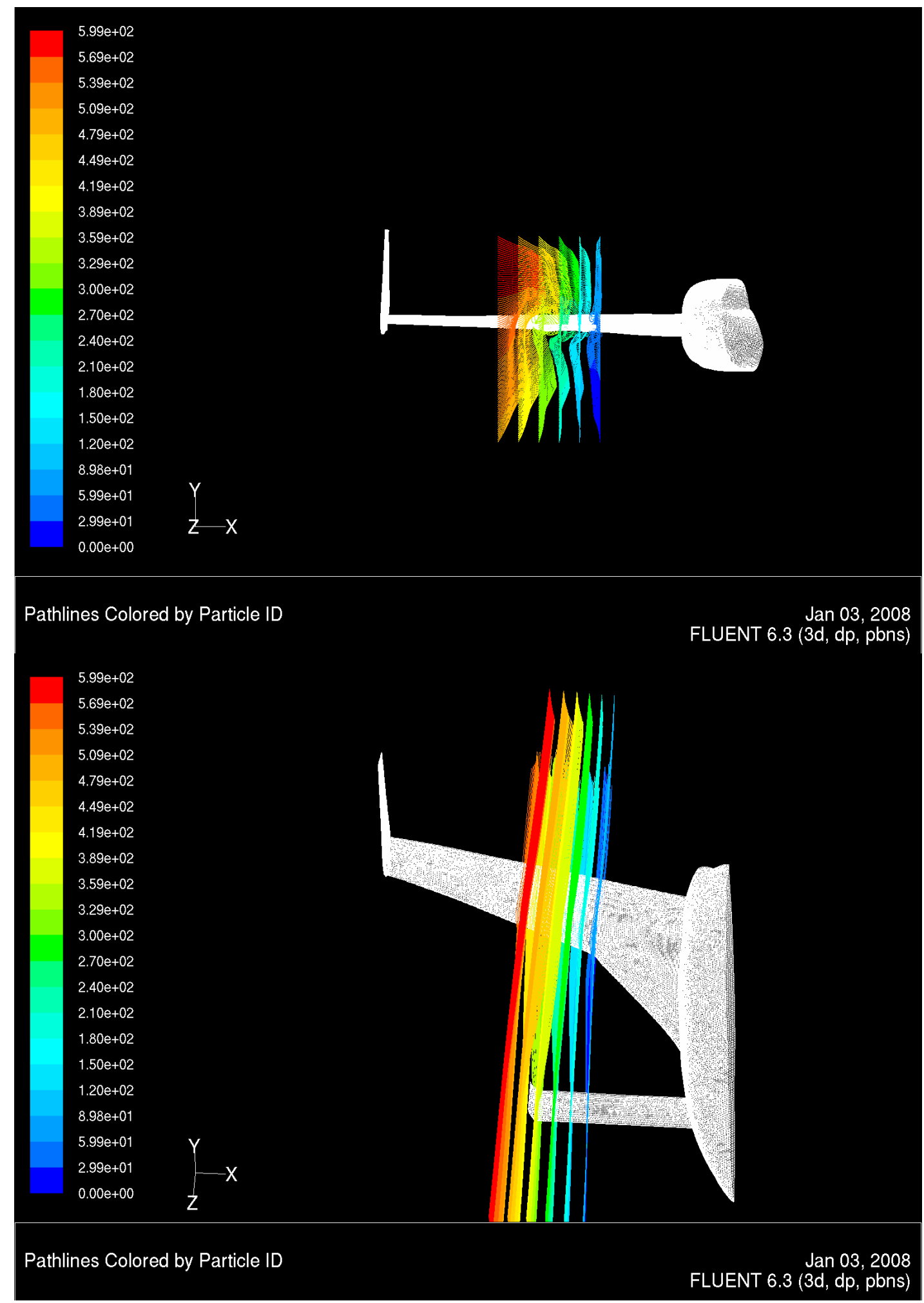

Figure A.67 Pathlines Exploring the Spanwise Range of Influence of the Tip Vortex at $0^{\circ} A o A, 100 \mathrm{~m} / \mathrm{s}$ 

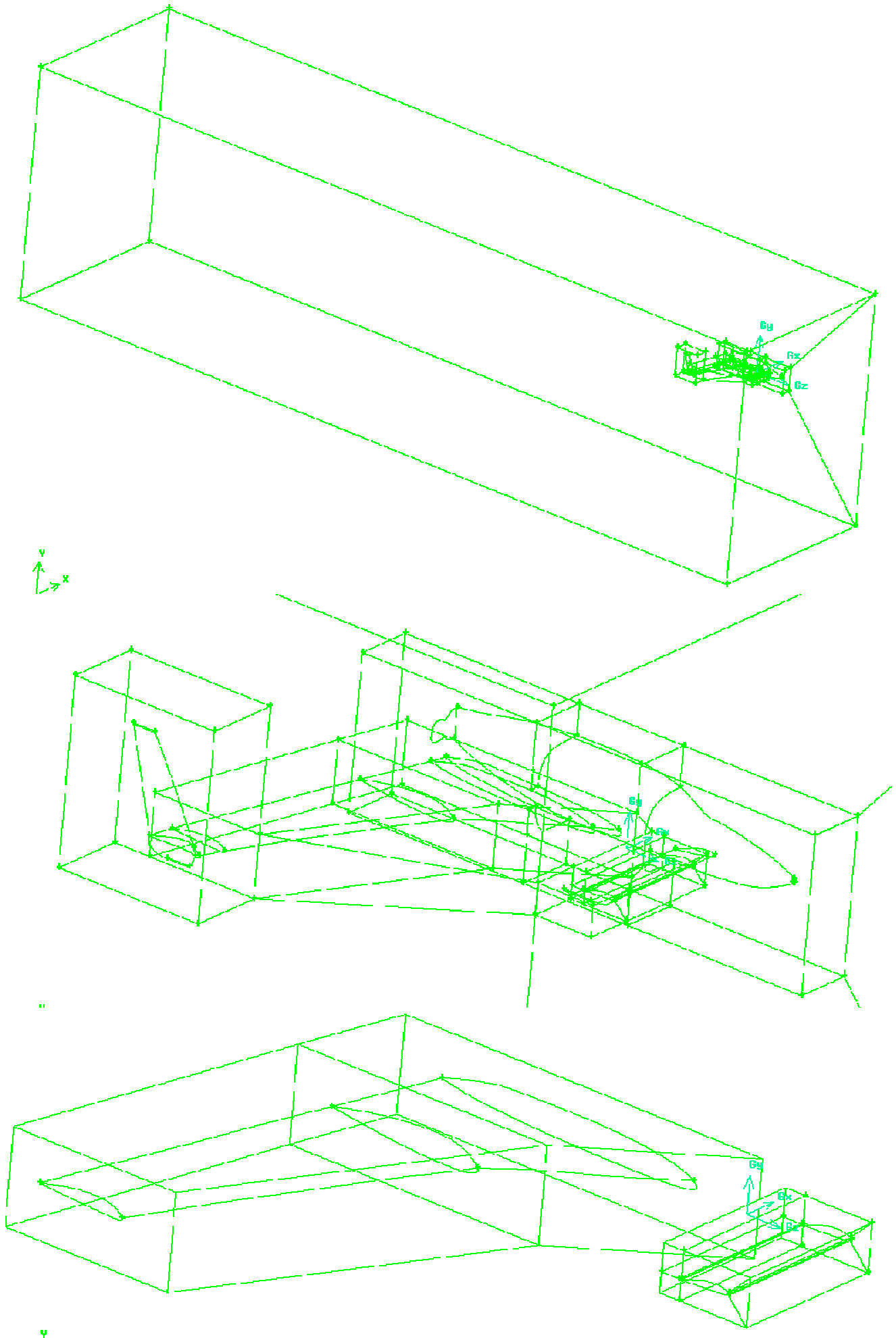

Figure A.68 Control Volume and Sub-Volumes Used to Create a Structured Mesh around the Canard and Boundary-Layer of the Wing 

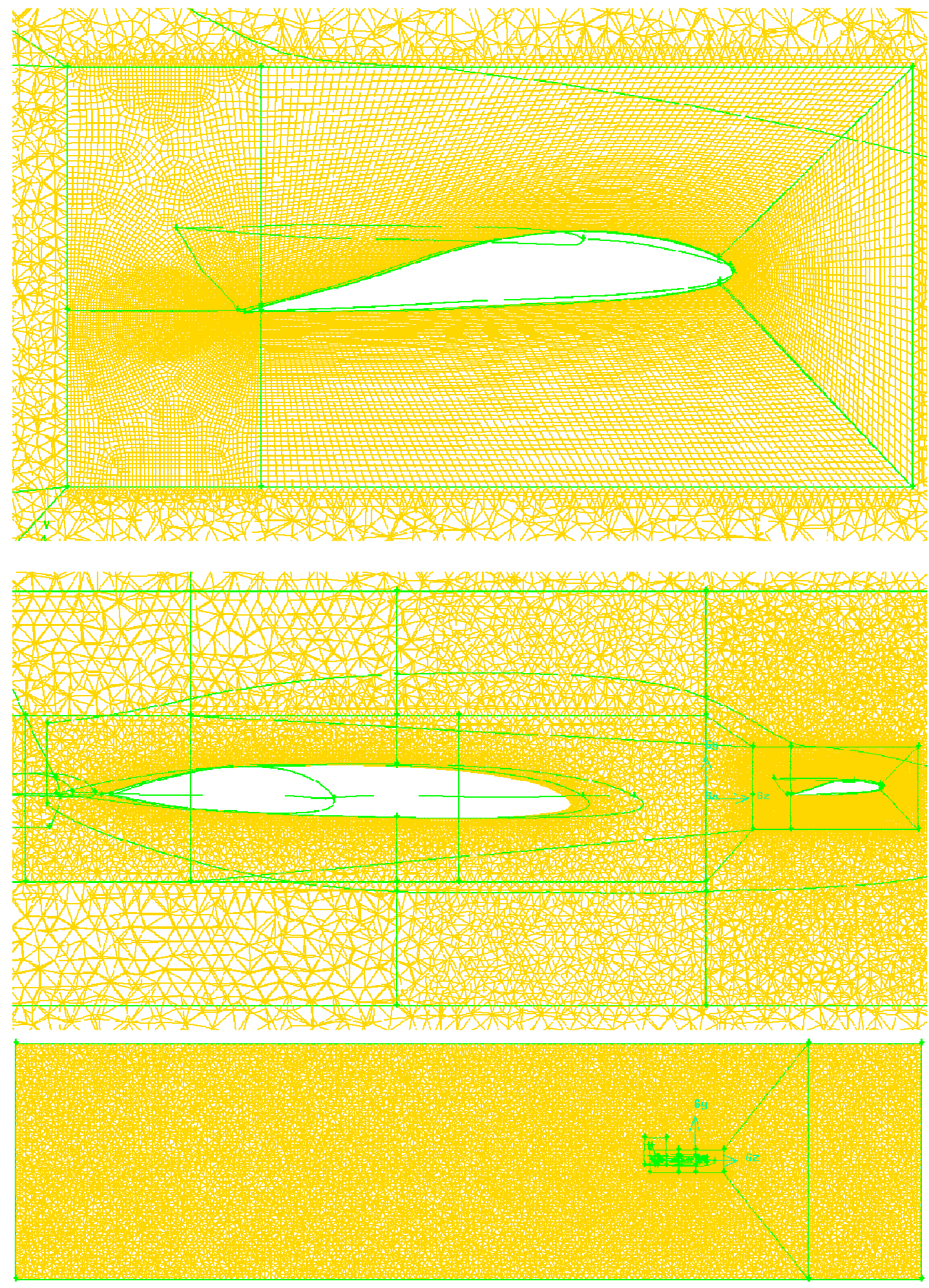

Figure A.69 Structured Mesh around the Canard and Boundary Layer of the Wing with a Tetrahedral Mesh in the Remainder of the Control Volume 


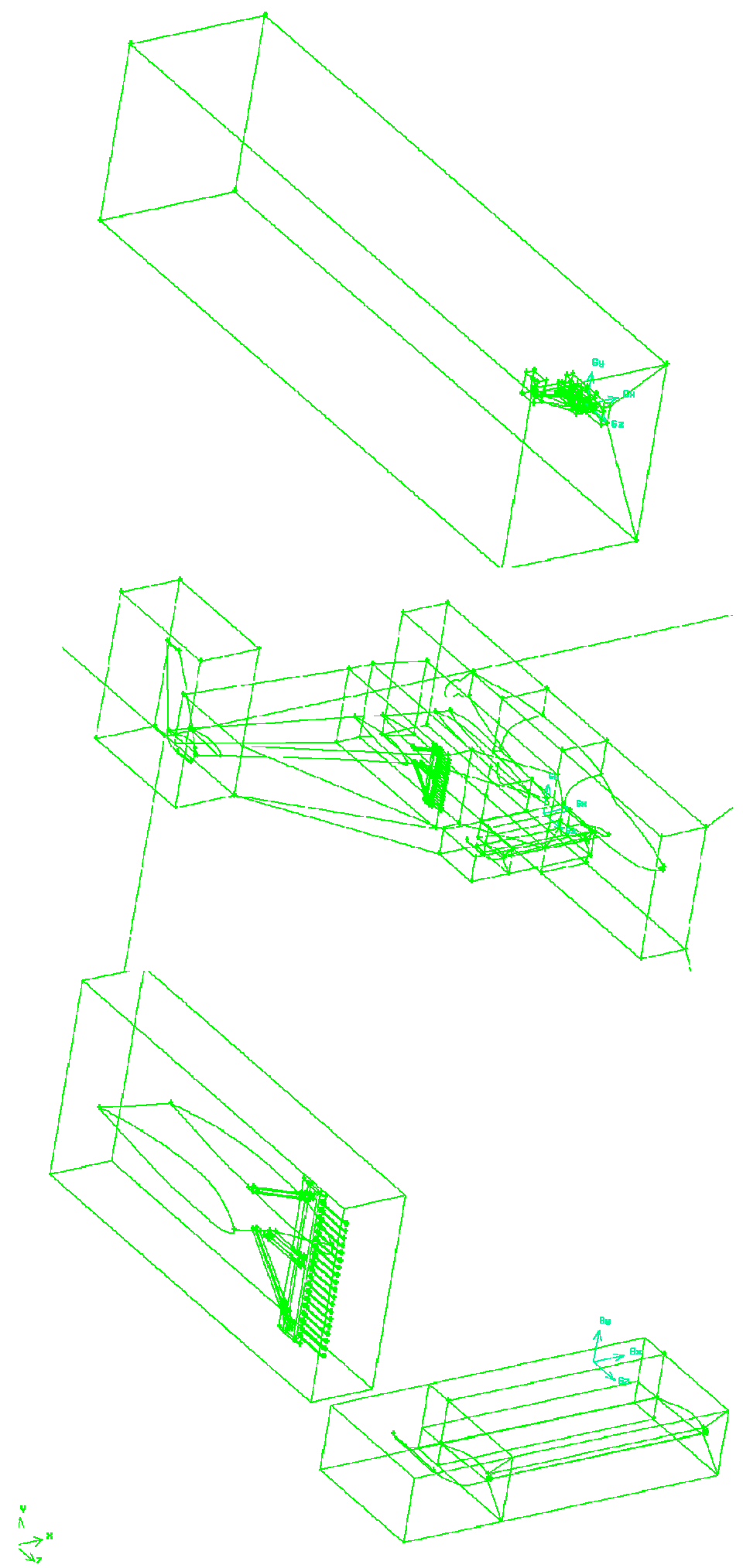

Figure A.70 Control Volume and Sub-Volumes Used to Create an Unstructured Mesh that Includes the Pressure Rake and Maintains Grid Refinement around the Canard 

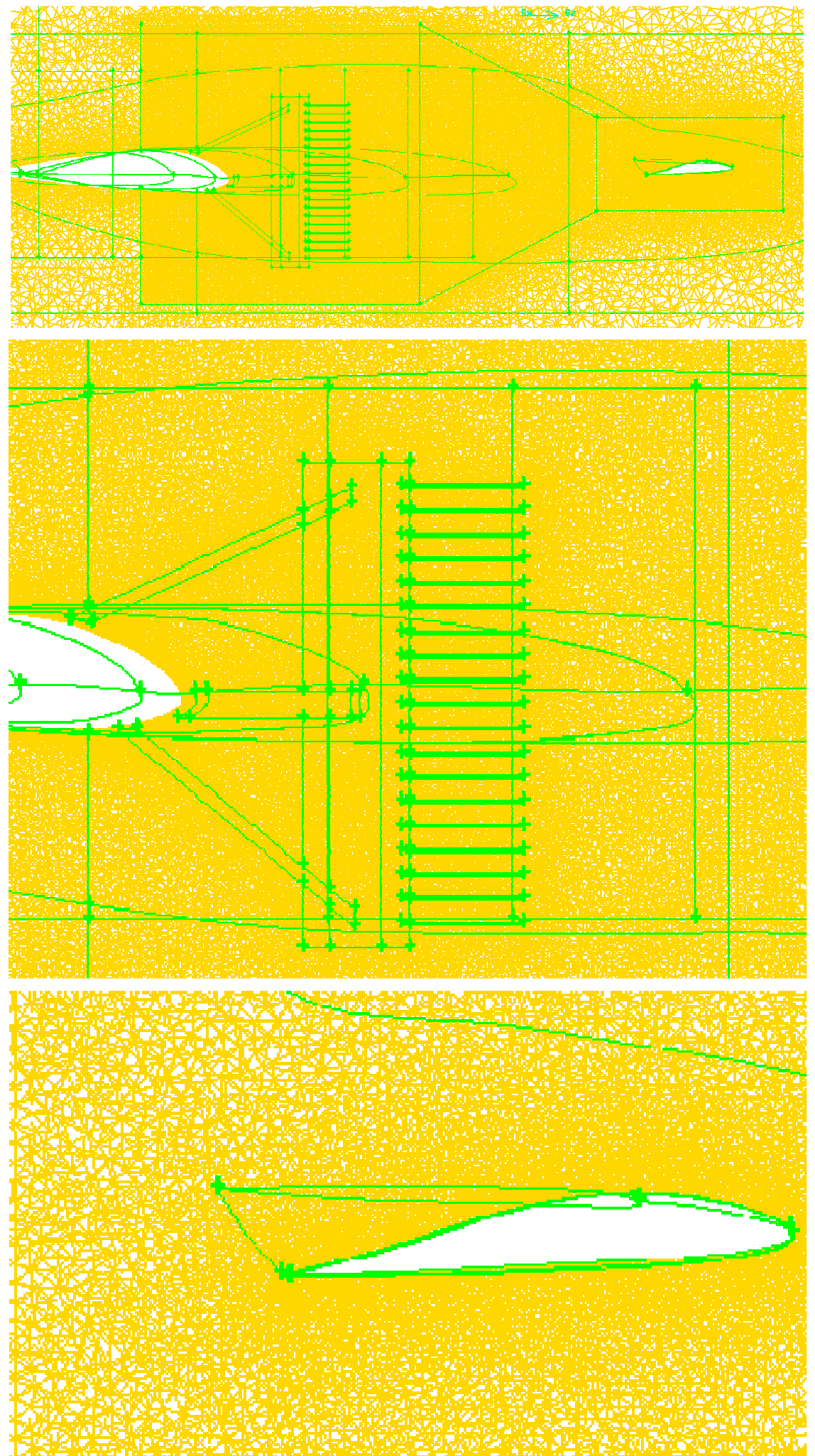

Figure A.71 Unstructured Mesh around the Velocity with the Pressure Rake 

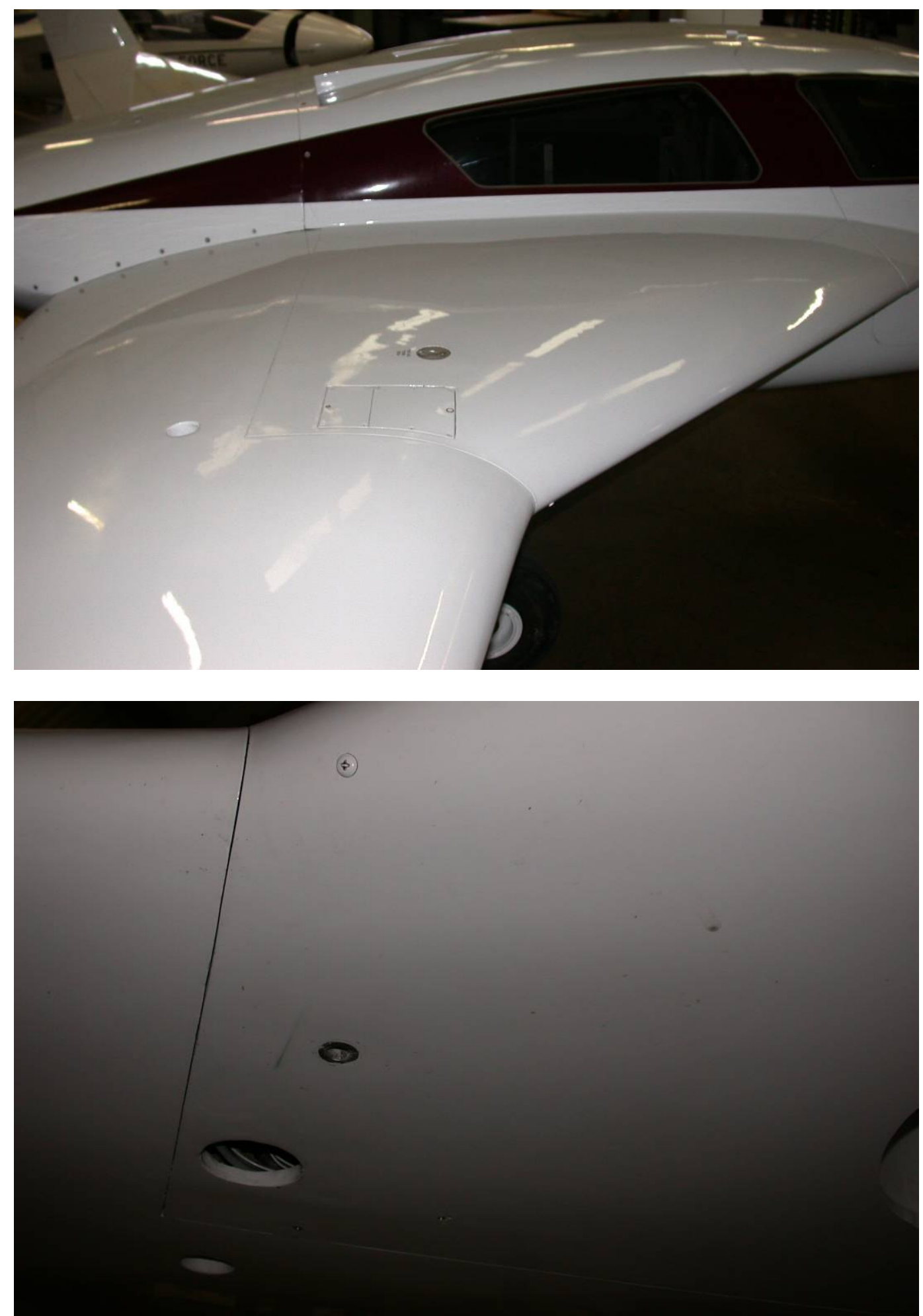

Figure A.72 Available Attachment Points at the Crank Location on the Upper and Lower Surface of the Wing of the Velocity 


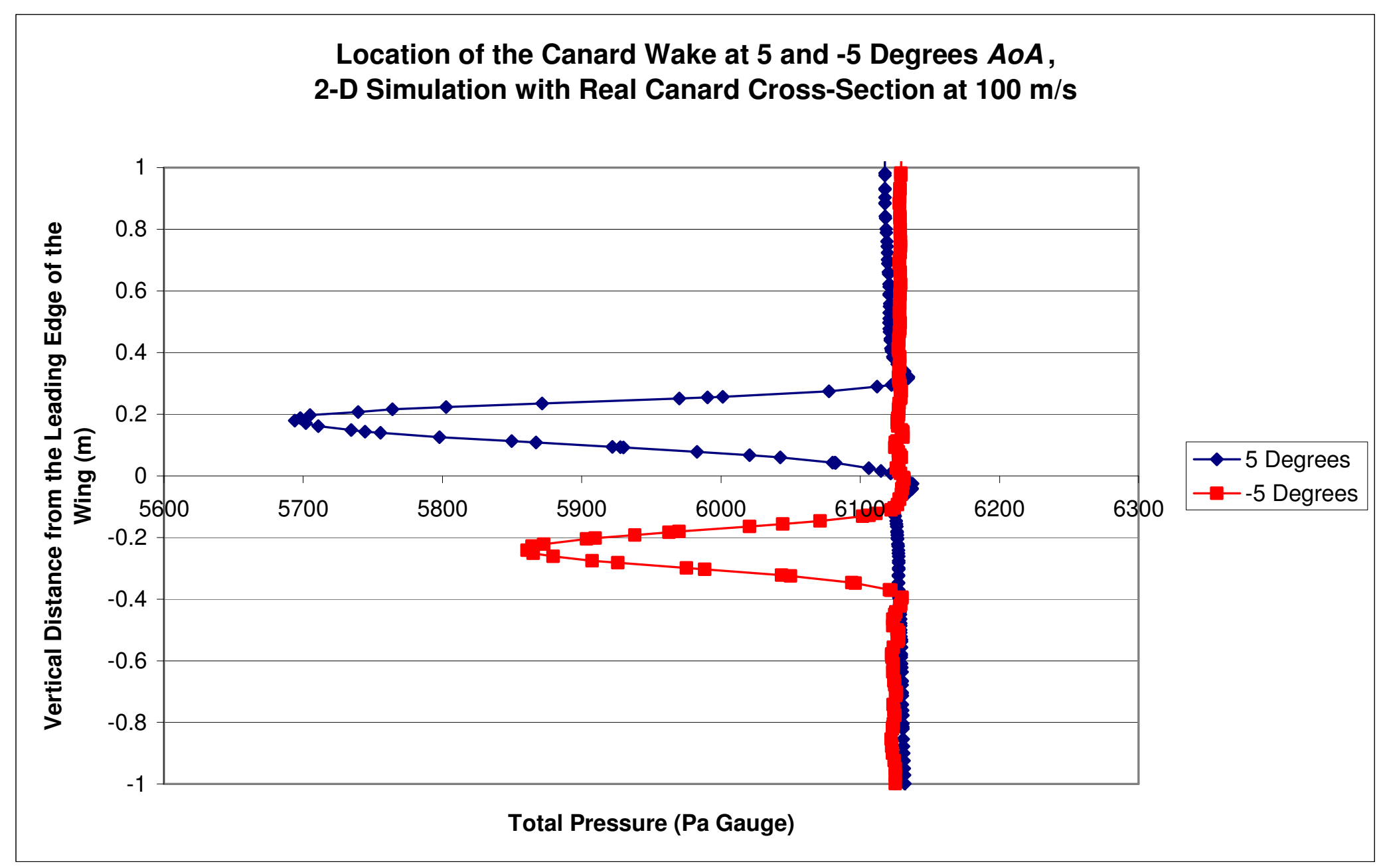

Figure A.73 Predicted Locations of the Wake at $\pm 5^{\circ} \mathrm{AoA}$ 

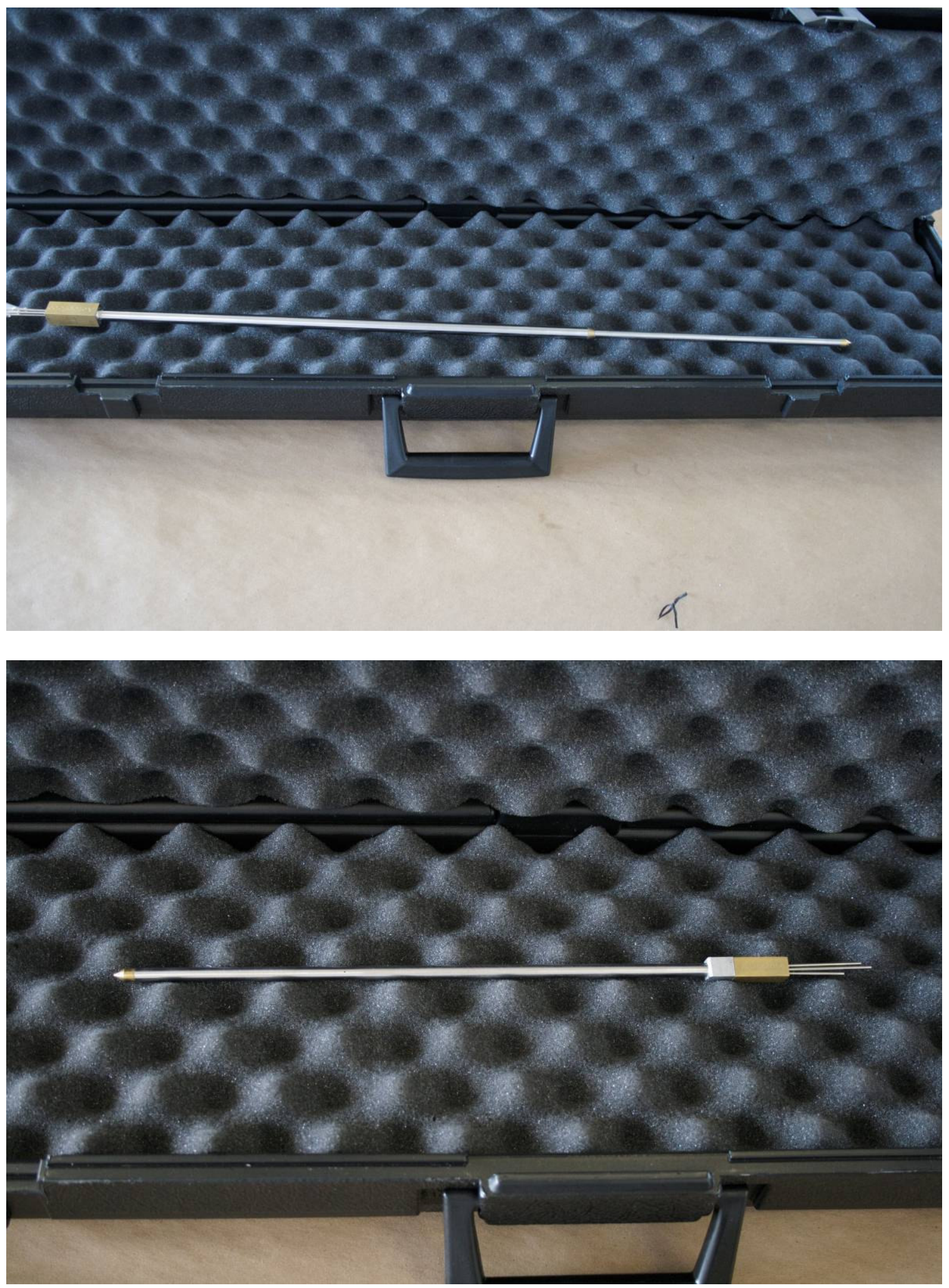

Figure A.74 12-inch and 24-inch 5-hole Probes Produced by Aeroprobe 


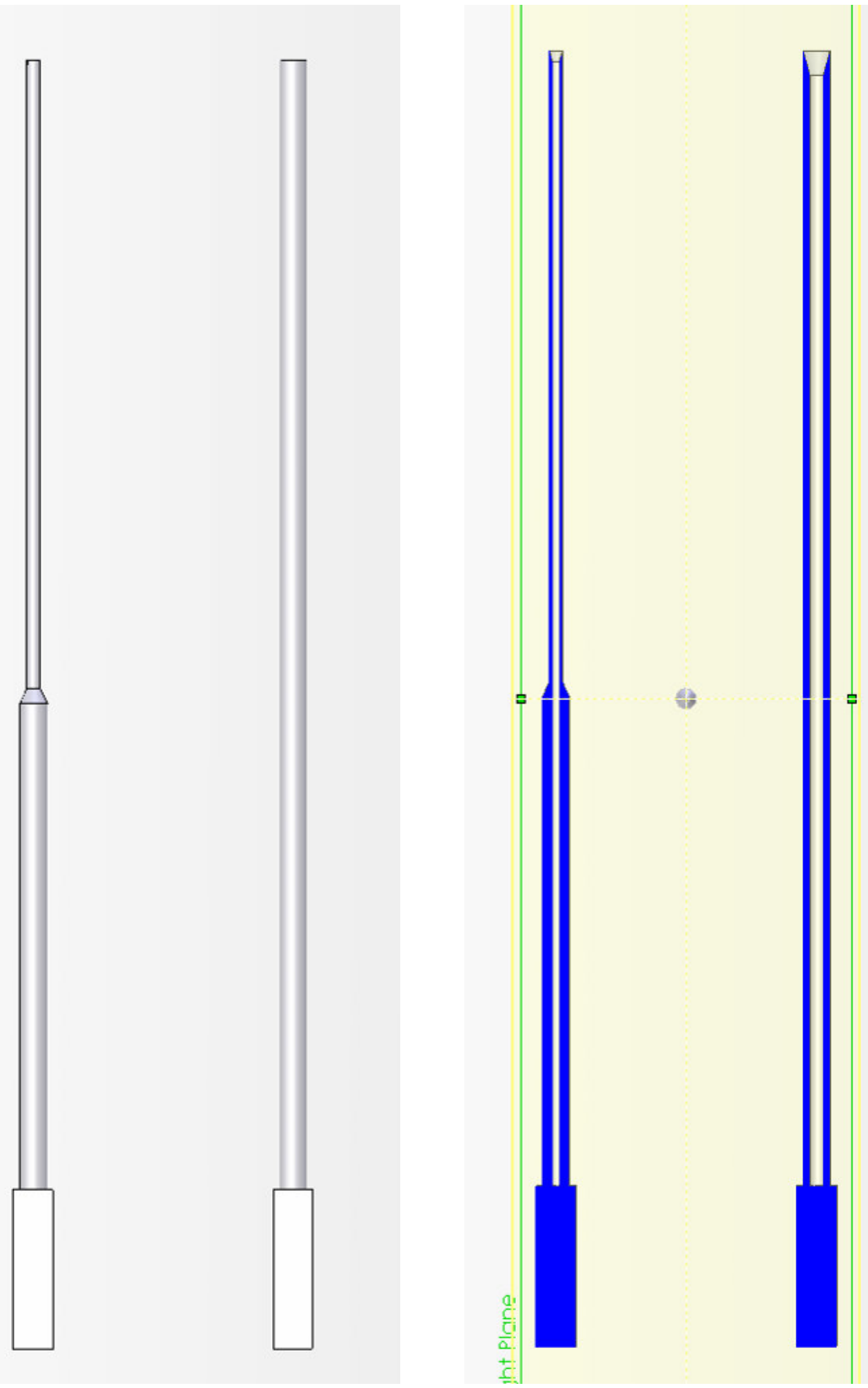

Figure A.75 Standard and Cross-Section Views of Stepped and Straight Designed Pitot Probes 

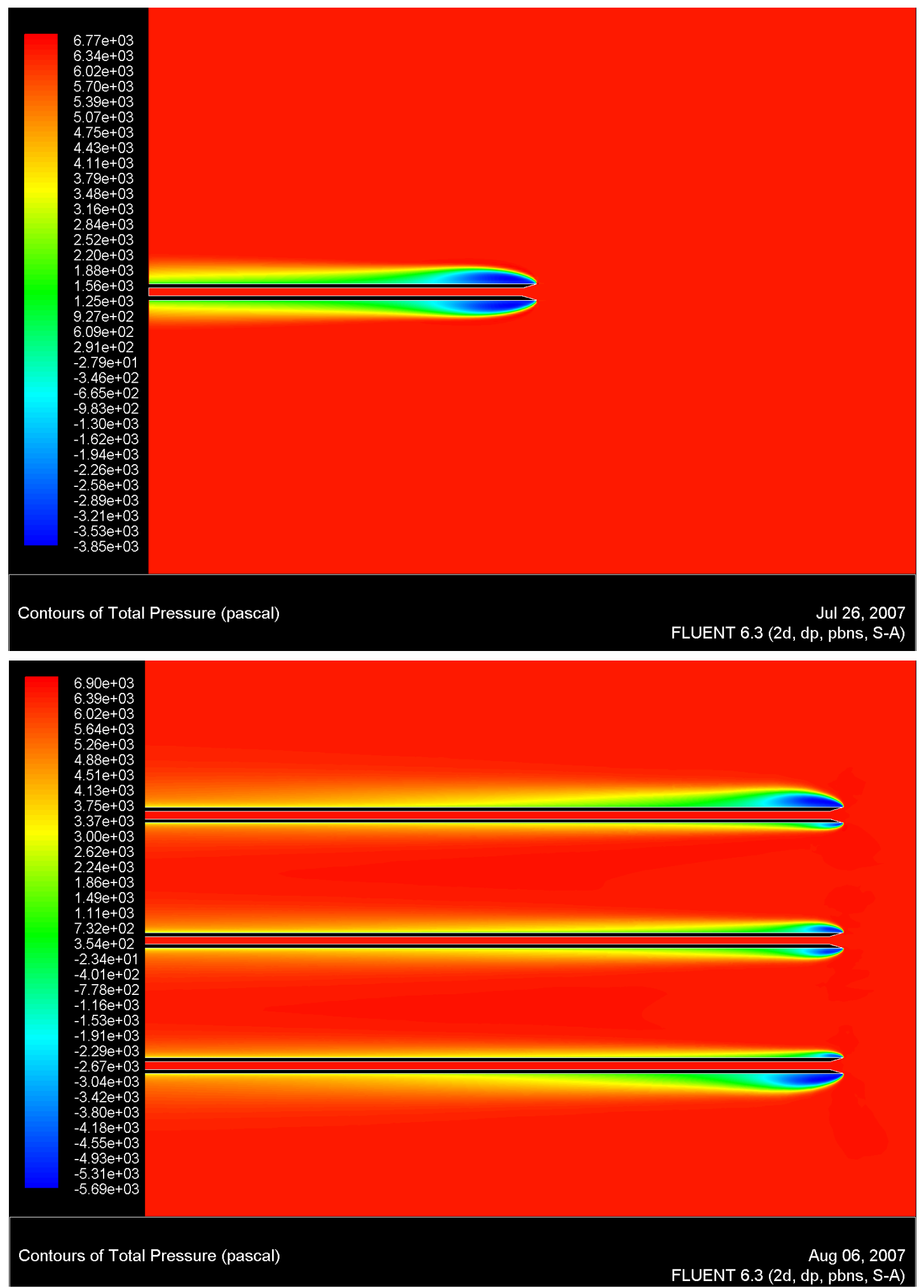

Figure A.76 Mid-plane Total Pressure Plot of Comparison of Isolated Pitot Probe and Multiple Pitot Probes Checking for Interference between Probes 

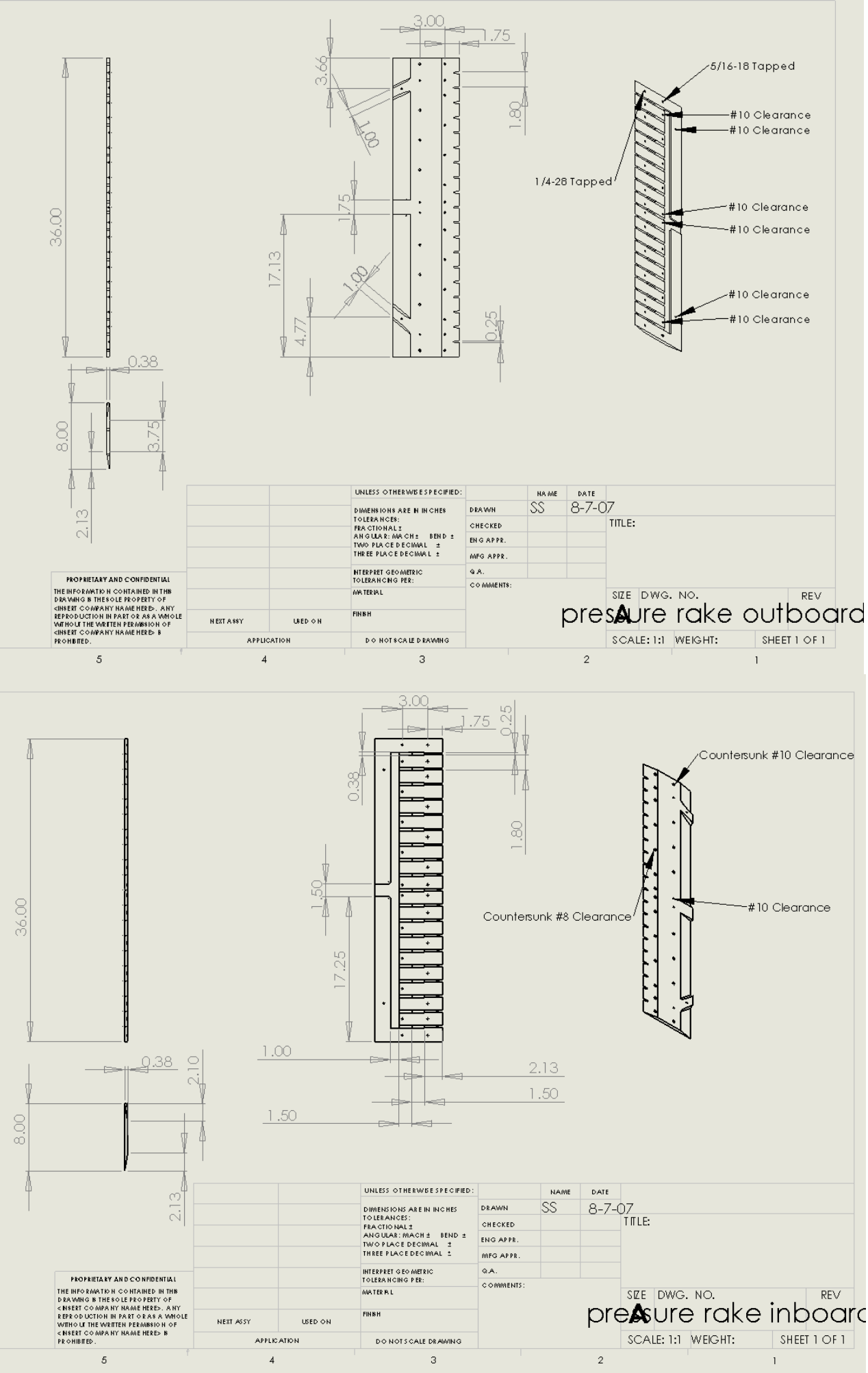

Figure A.77 3-View and Cross-Section of SolidWorks Design of the Pressure Rake 

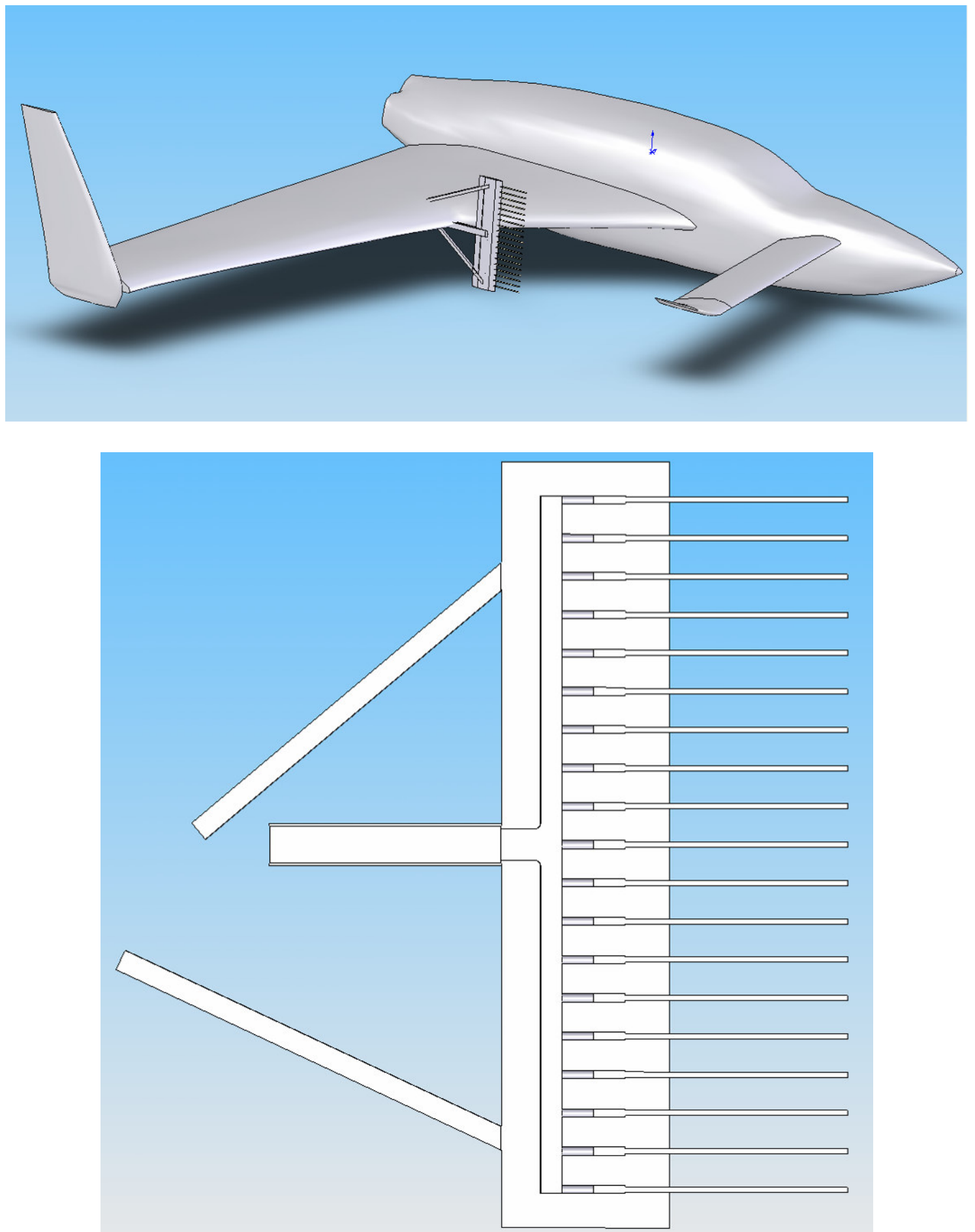

Figure A.78 SolidWorks Drawings of the Pressure Rake Mounting Location and Interior of the Rake 


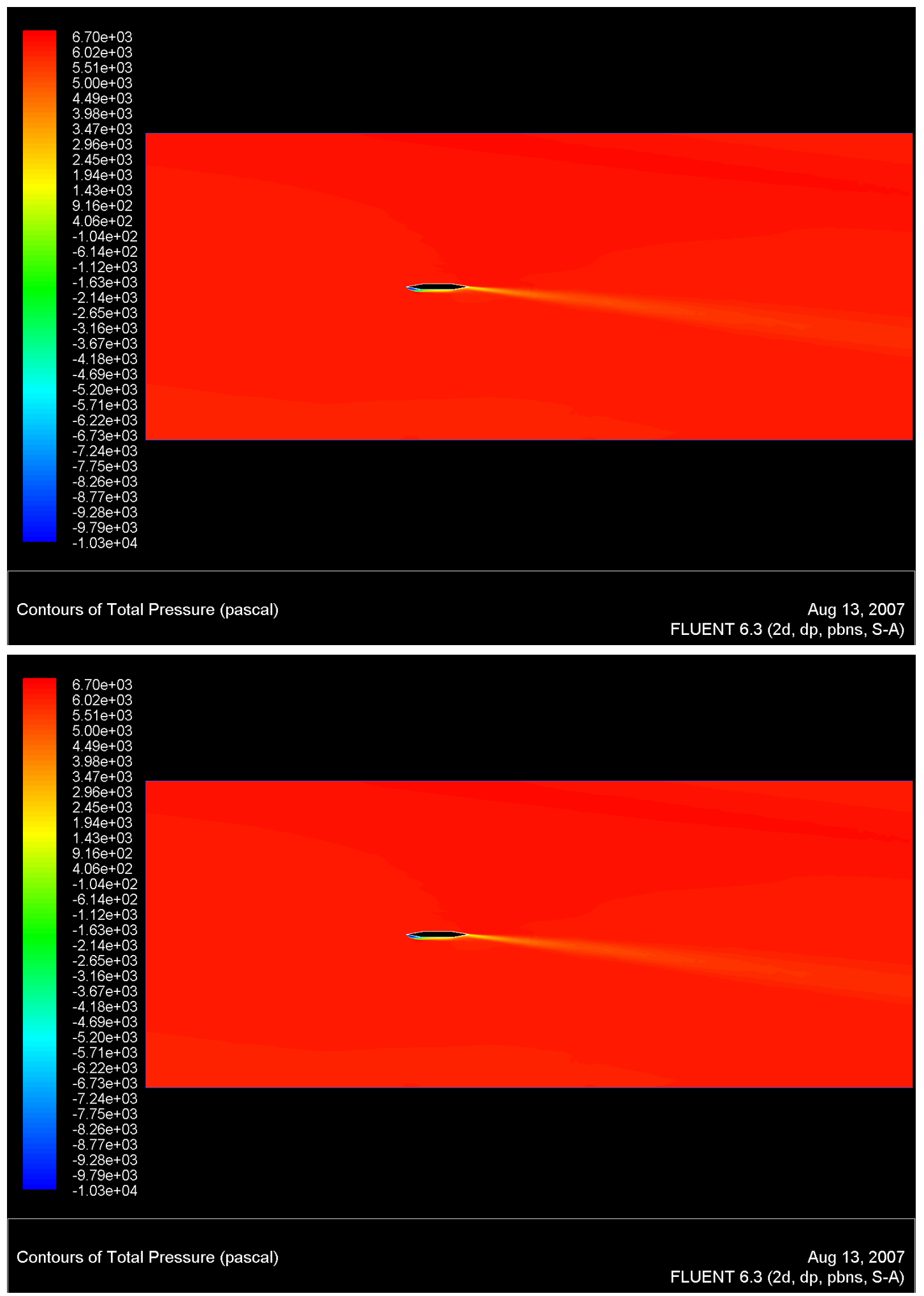

Figure A.79 CFD Plots of the 2-D Simulations of the Pressure Rake Cross-Section 

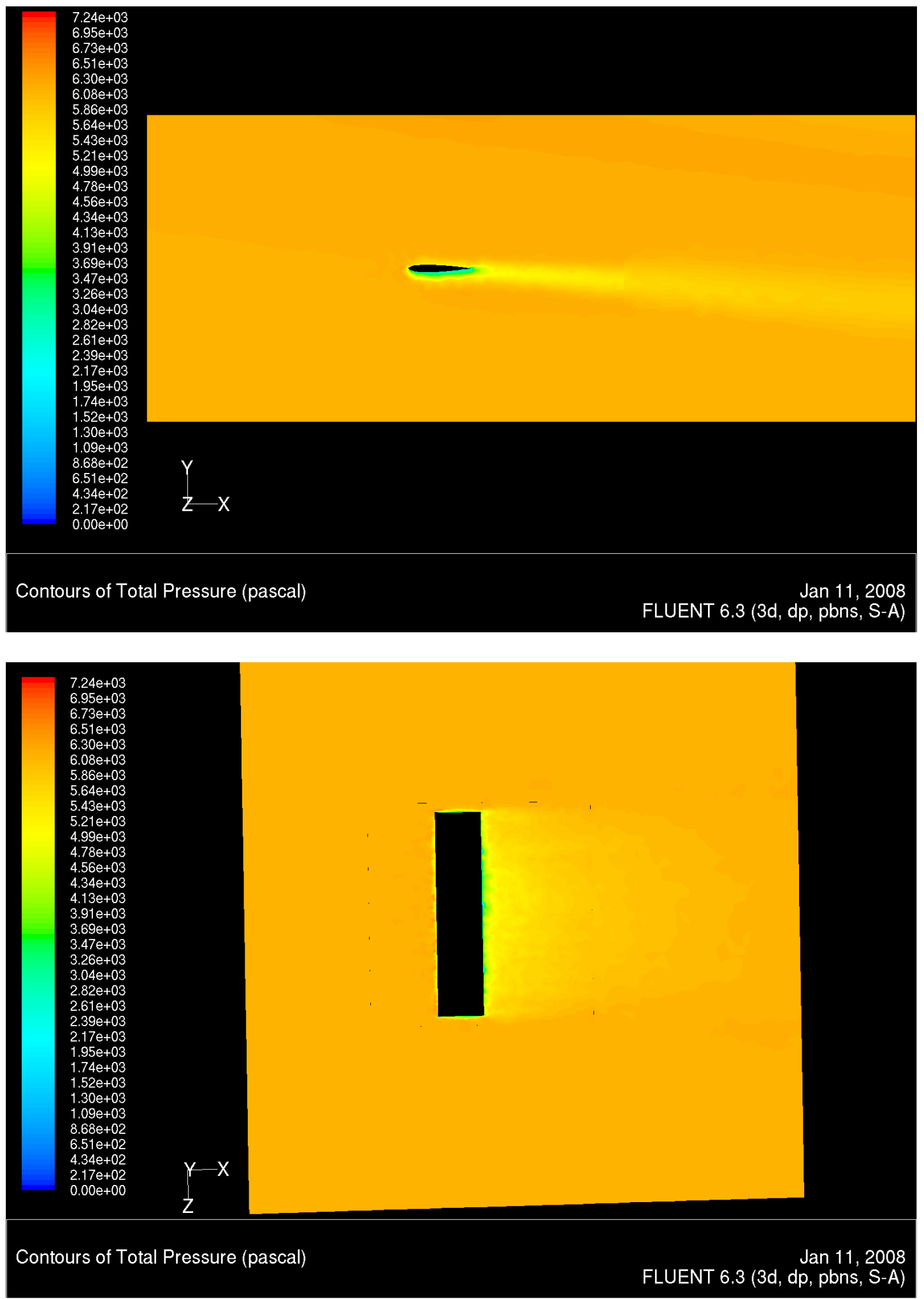

Figure A.80 CFD Plots of the 3-D Simulations of the Pressure Rake with the CrossSection Replaced by the NACA 0012 


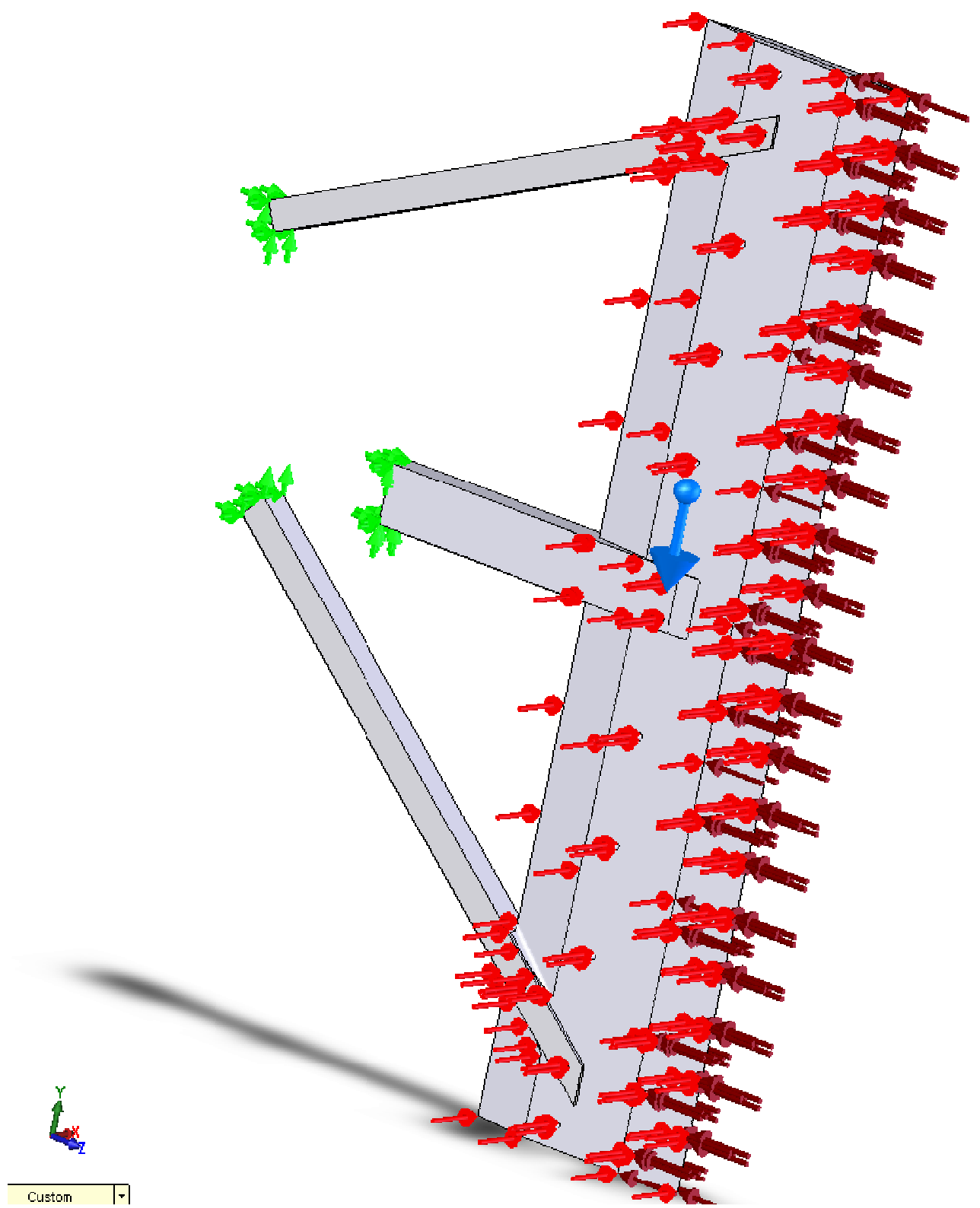

Figure A.81 Loads Applied to Pressure Rake in COSMOSWorks for Stress Analysis 

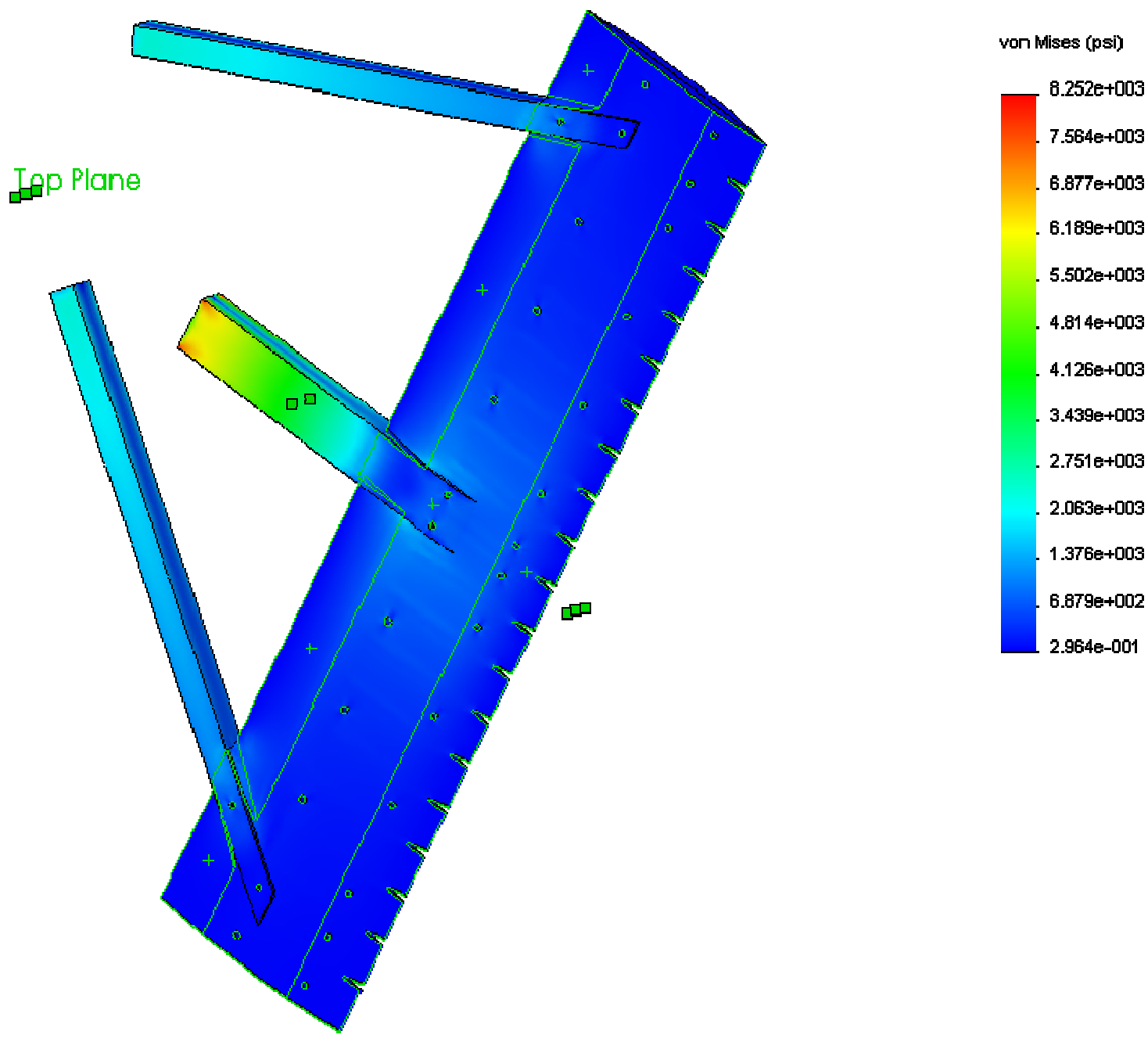

Figure A.82 Maximum Von Mises Stress Concentration from COSMOSWorks for 1.5 Times a Collision Avoidance Maneuver Loading 

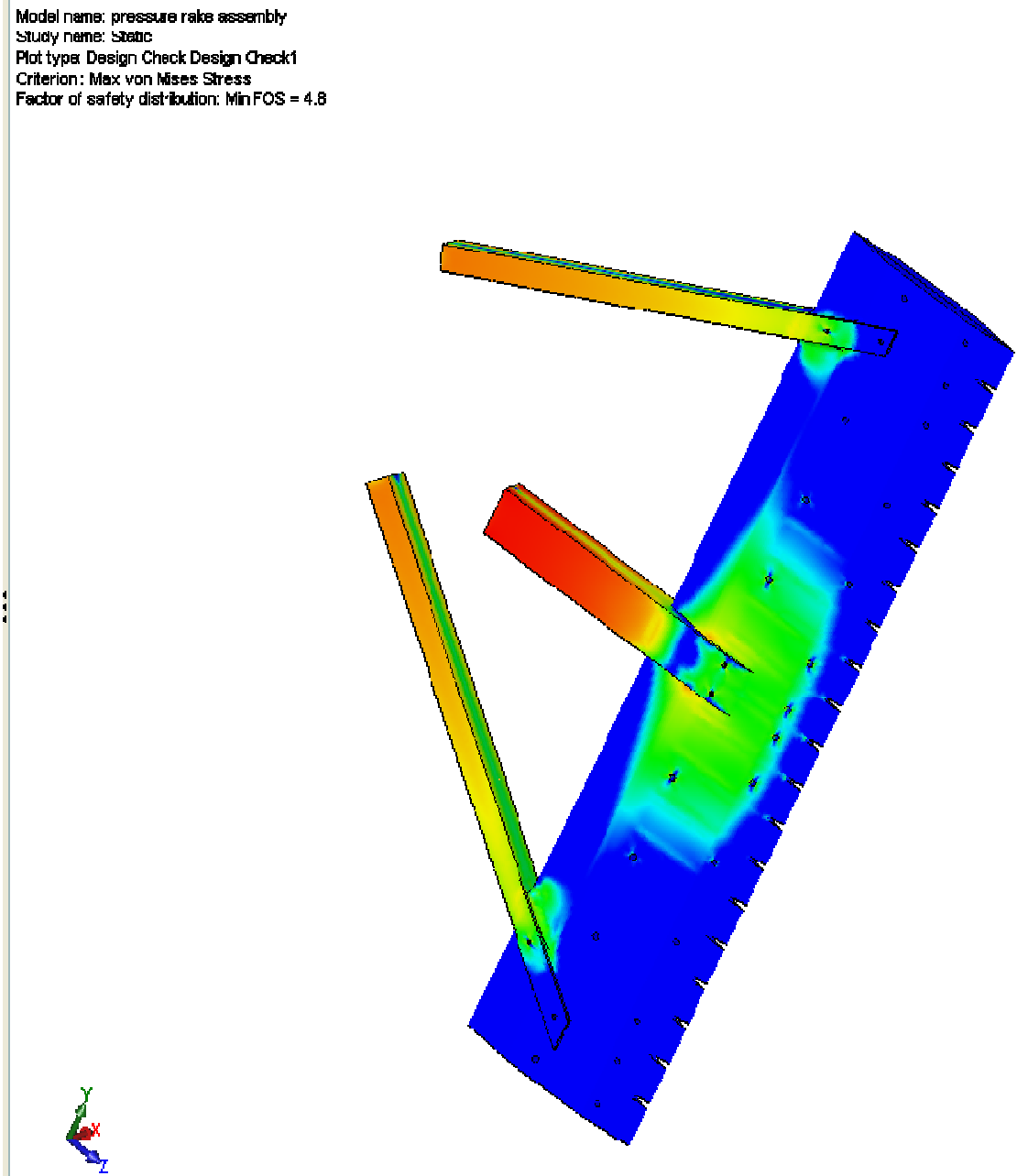

Fos

$1.0006+002$
$9.207 e+001$

$8.4140+001$

7.621e+00

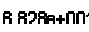

8.035 +001

$5.242 x+00$

$4.4490+001$

3 R.5Fa+กก1

$2.8638+001$

$2.0690+001$

$1.2789+001$

$4.8338+000$

Figure A.83 Factor of Safety Distribution from COSMOSWorks for 1.5 Times a

Collision Avoidance Maneuver Loading 
Model neme: pressure rake assernbly

study neme: stetc

Flot type: Static displacement Displacenent'

Defo'metion socte: 1
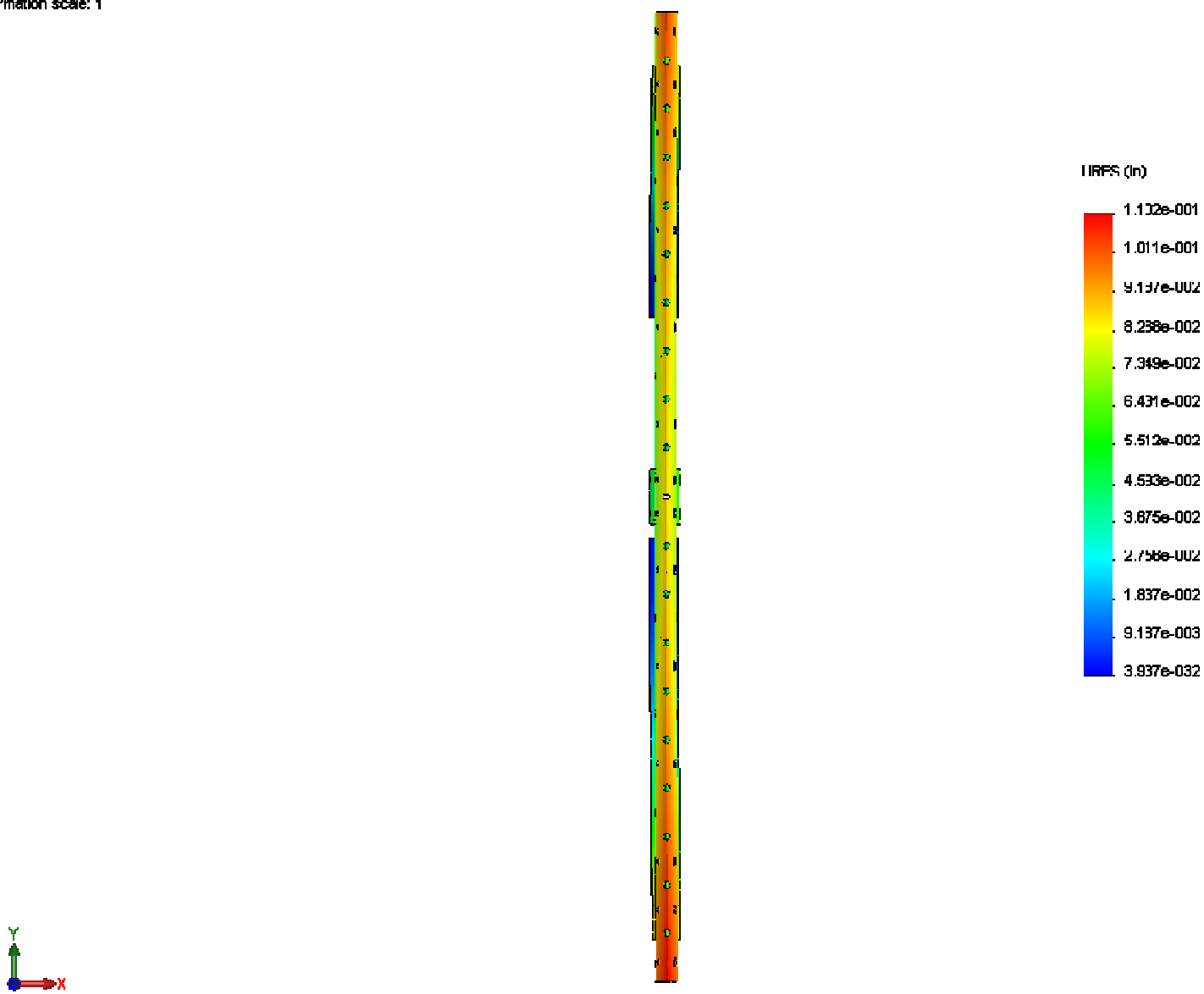

Figure A.84 Maximum Predicted Deflection from COSMOSWorks for 1.5 Times a Collision Avoidance Maneuver Loading 


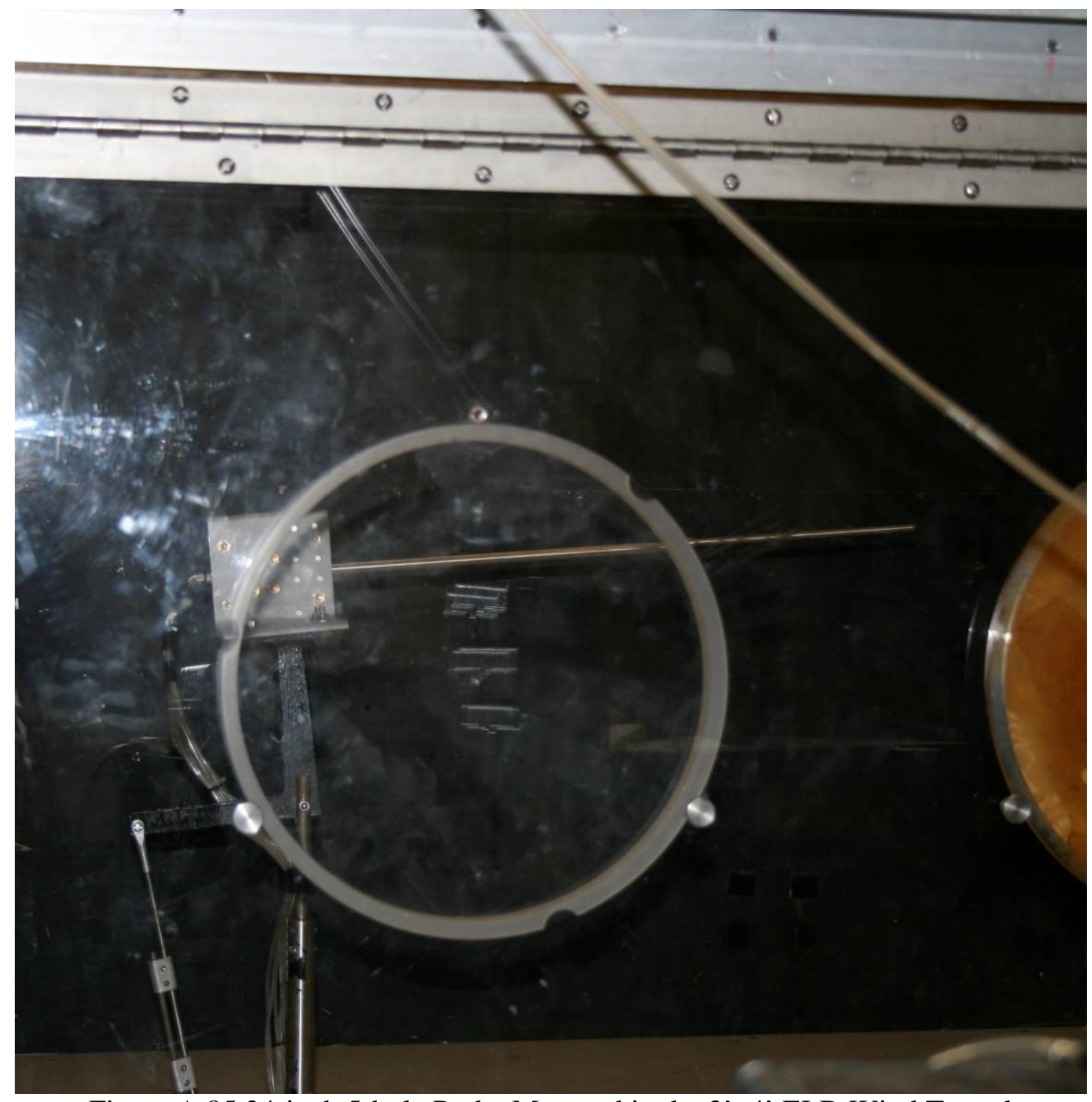

Figure A.85 24-inch 5-hole Probe Mounted in the 3'x4' ELD Wind Tunnel 

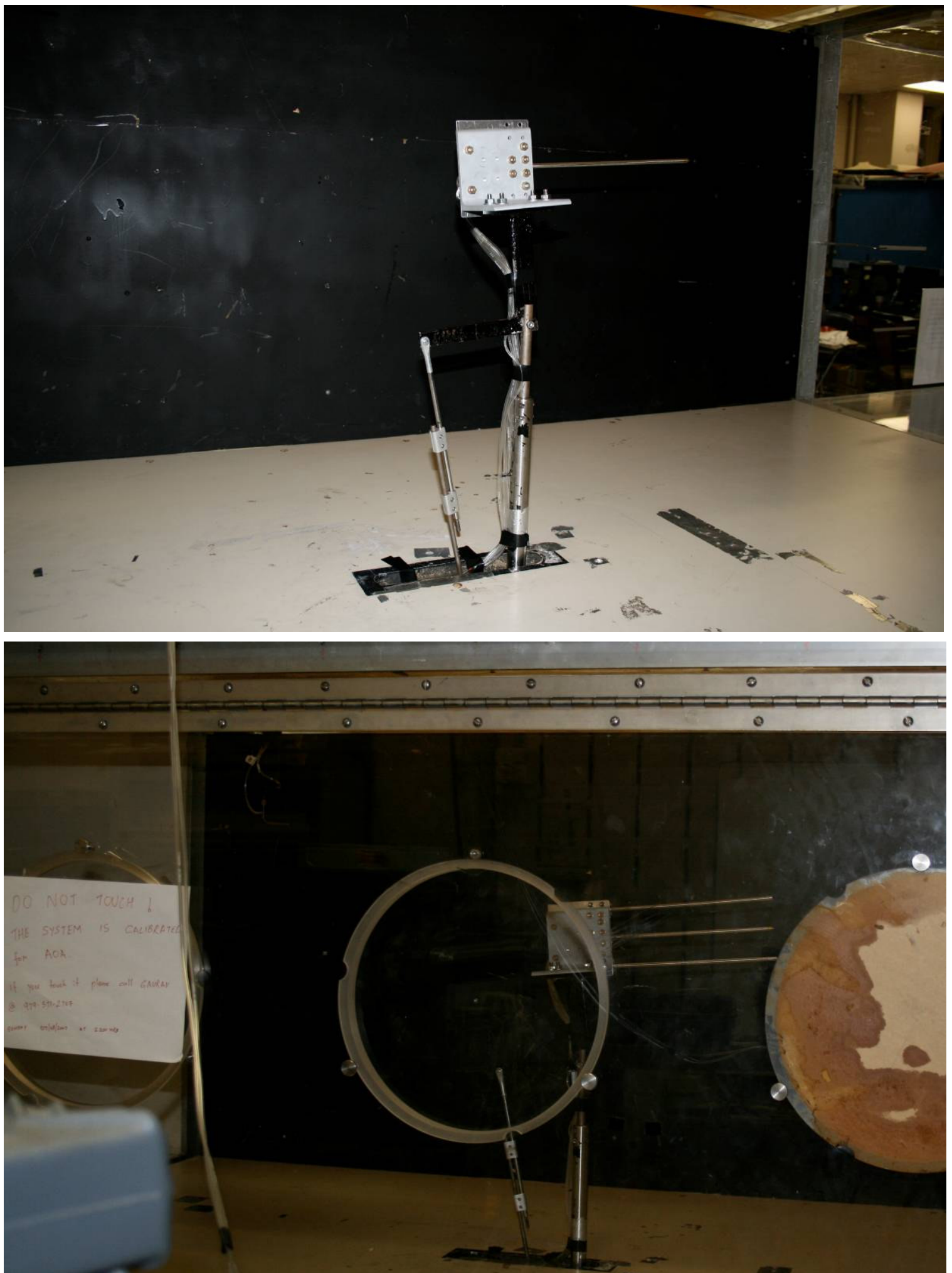

Figure A.86 12-inch 5-hole Probe Mounted in the 3'x4' ELD Wind Tunnel Isolated and with the Pitot Probes on Either Side at the Spacing Used in the Pressure Rake 


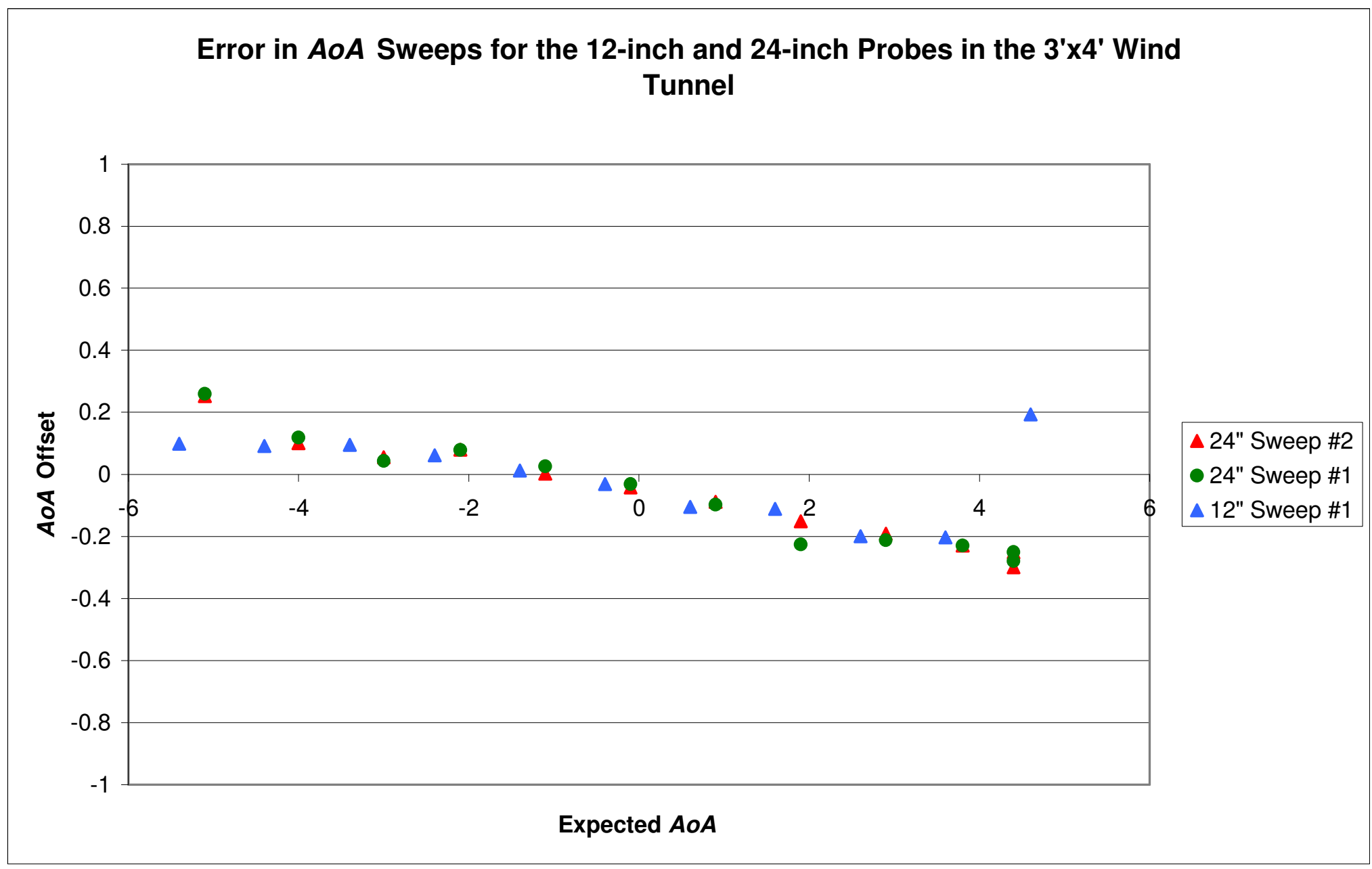

Figure A.87 Angle of Attack Sweep Plots for 12 and 24-inch 5-hole Probes 

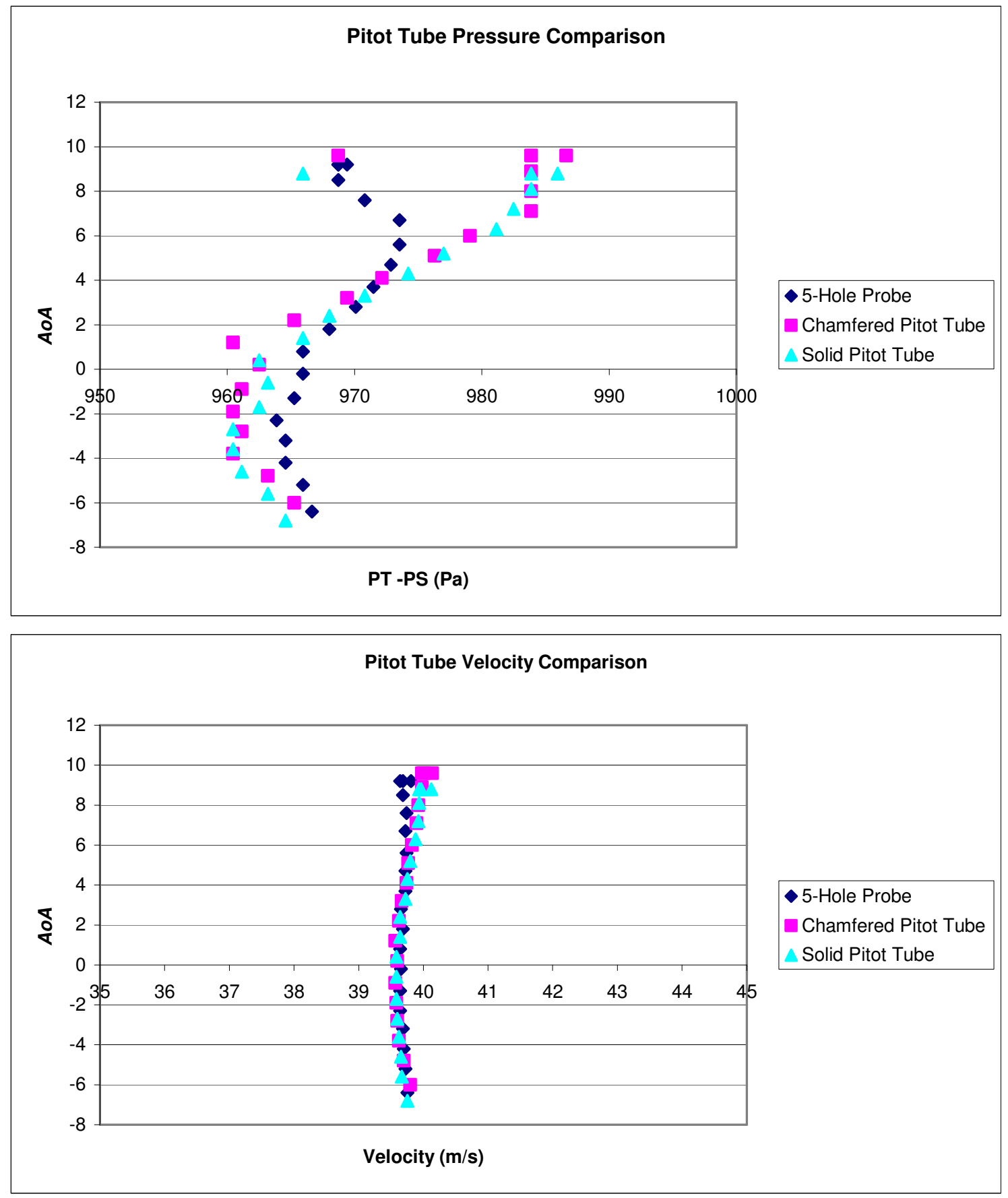

Figure A.88 Wind Tunnel Comparison of 12-inch 5-hole Probe to Pitot Probes 

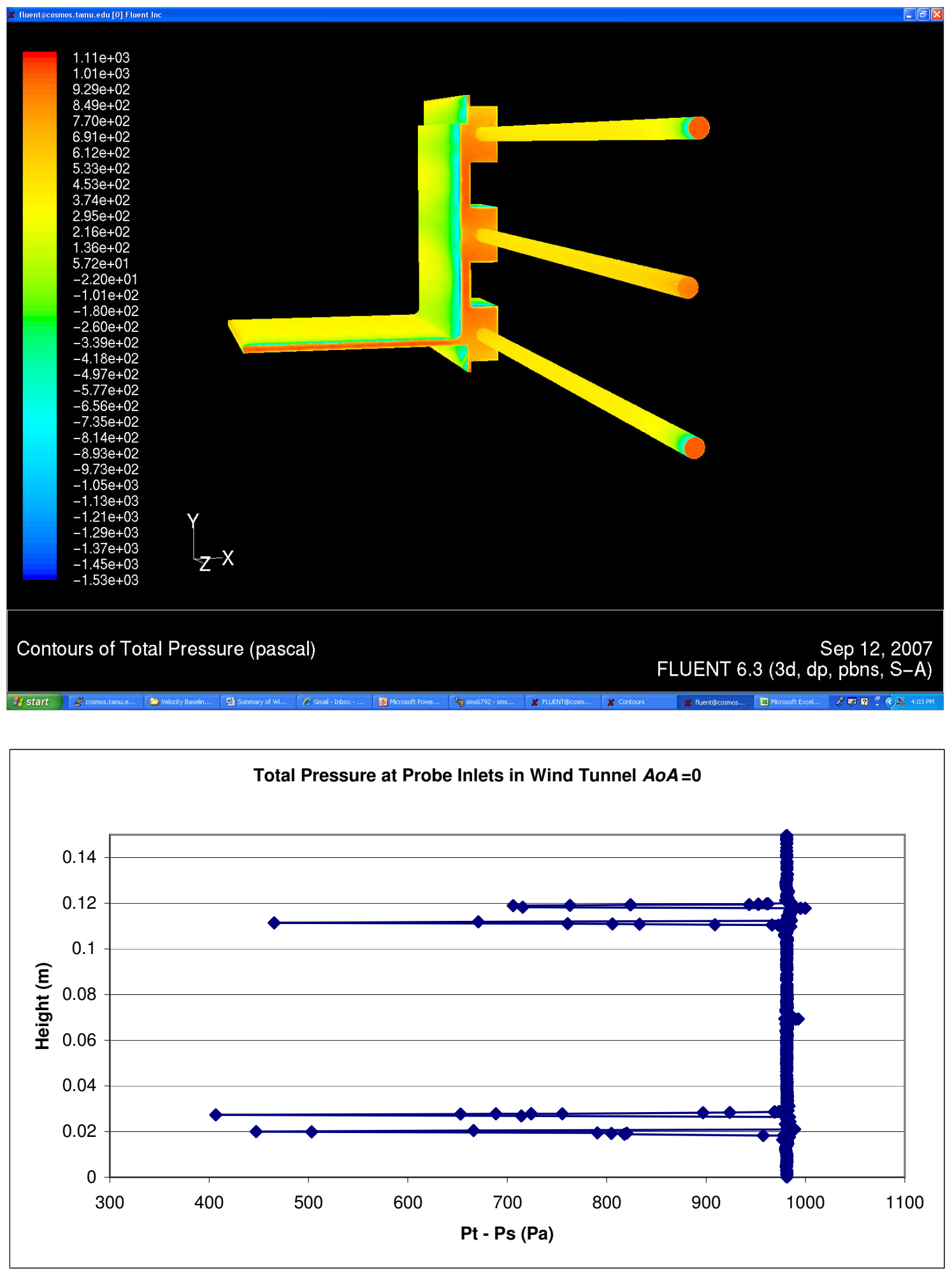

Figure A.89 Computational Results in Support of the Wind Tunnel Experiments 

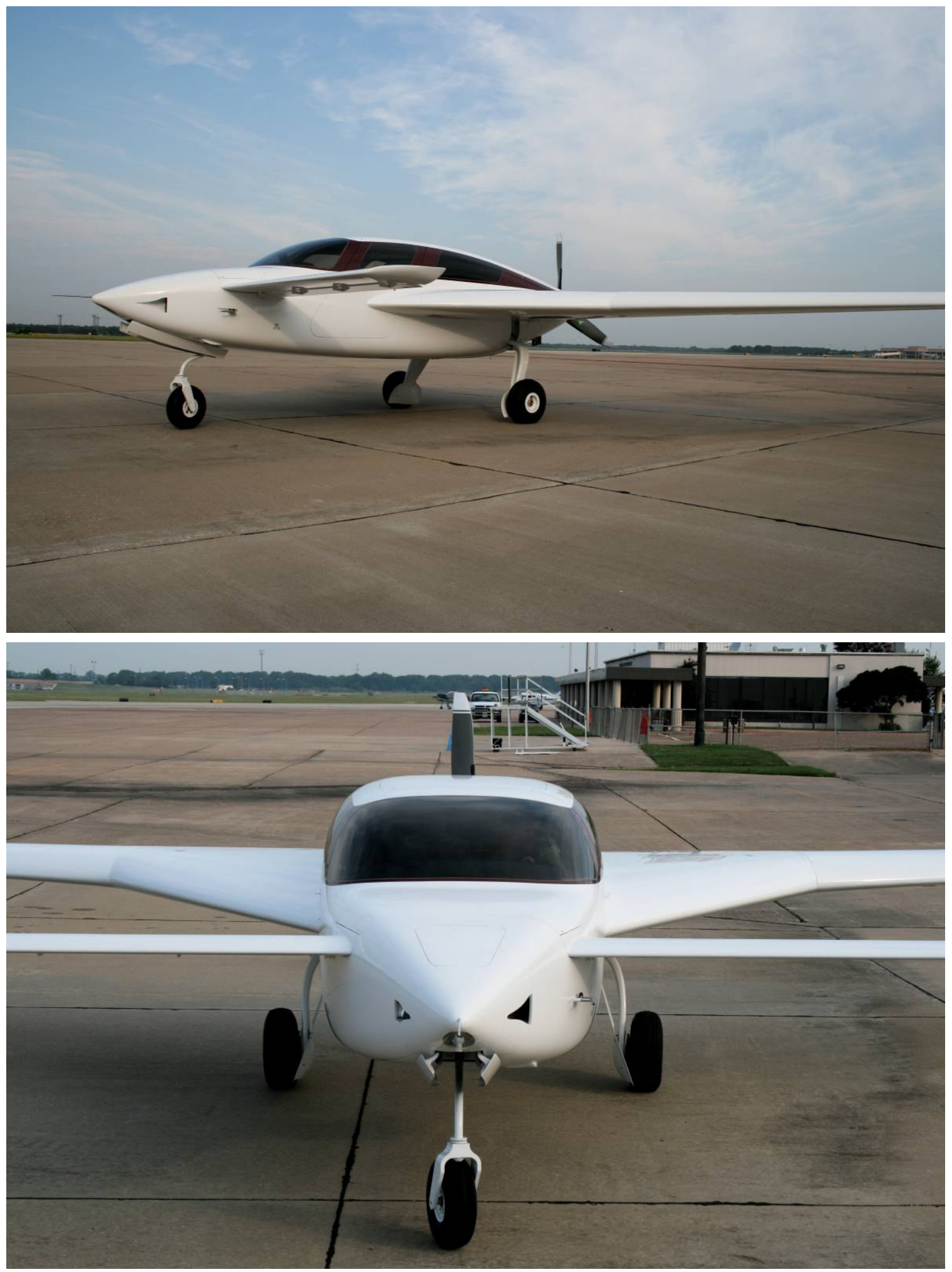

Figure A.90 24-inch 5-hole Probe Extending out the Nose of the Velocity 


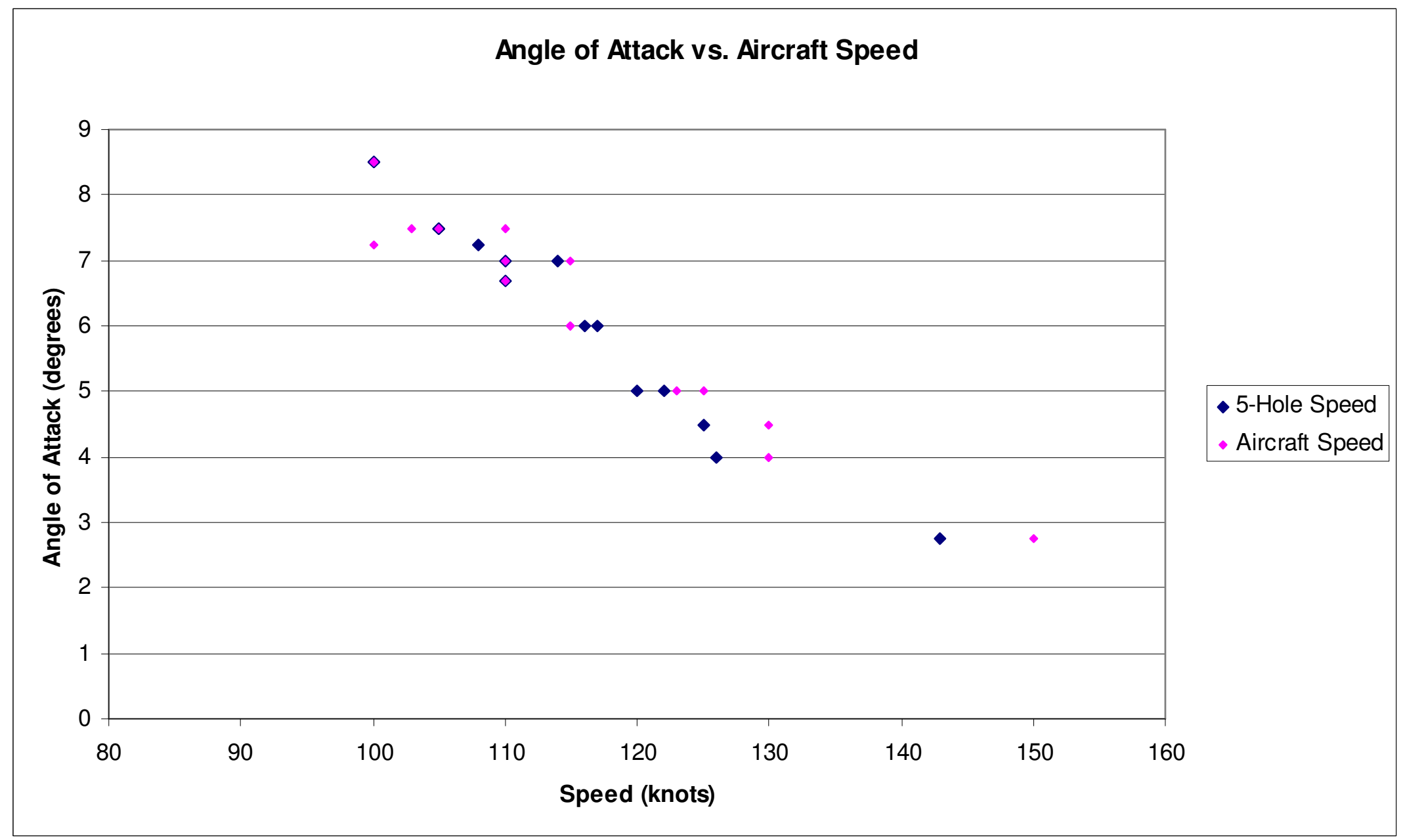

Figure A.91 Aircraft Angle of Attack vs. Airspeed with Zero Elevator Deflection during Baseline Measurements 


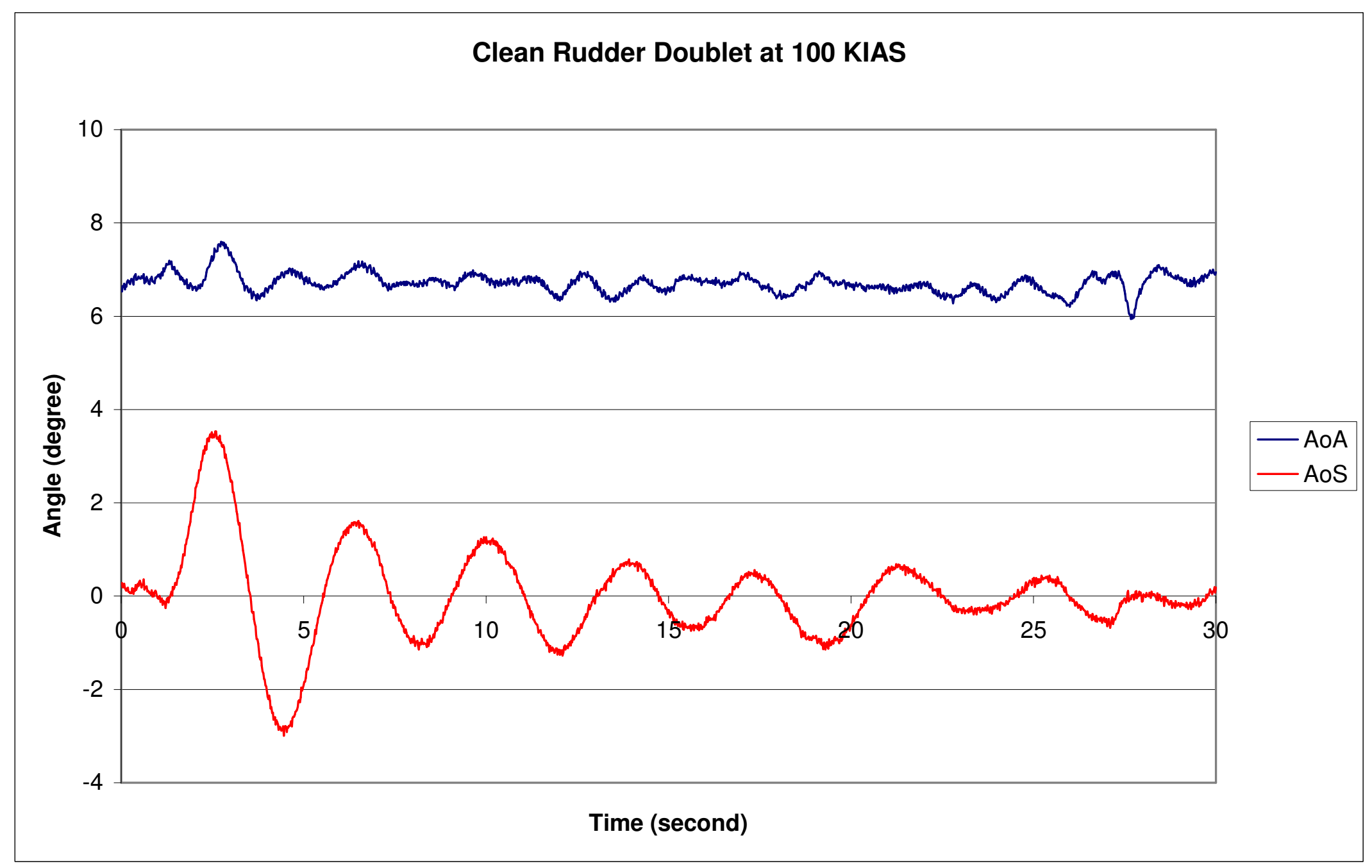

Figure A.92 Rudder Doublet of the Velocity in Clean Configuration at $100 \mathrm{KIAS}(51 \mathrm{~m} / \mathrm{s})$ and 8,500 feet 


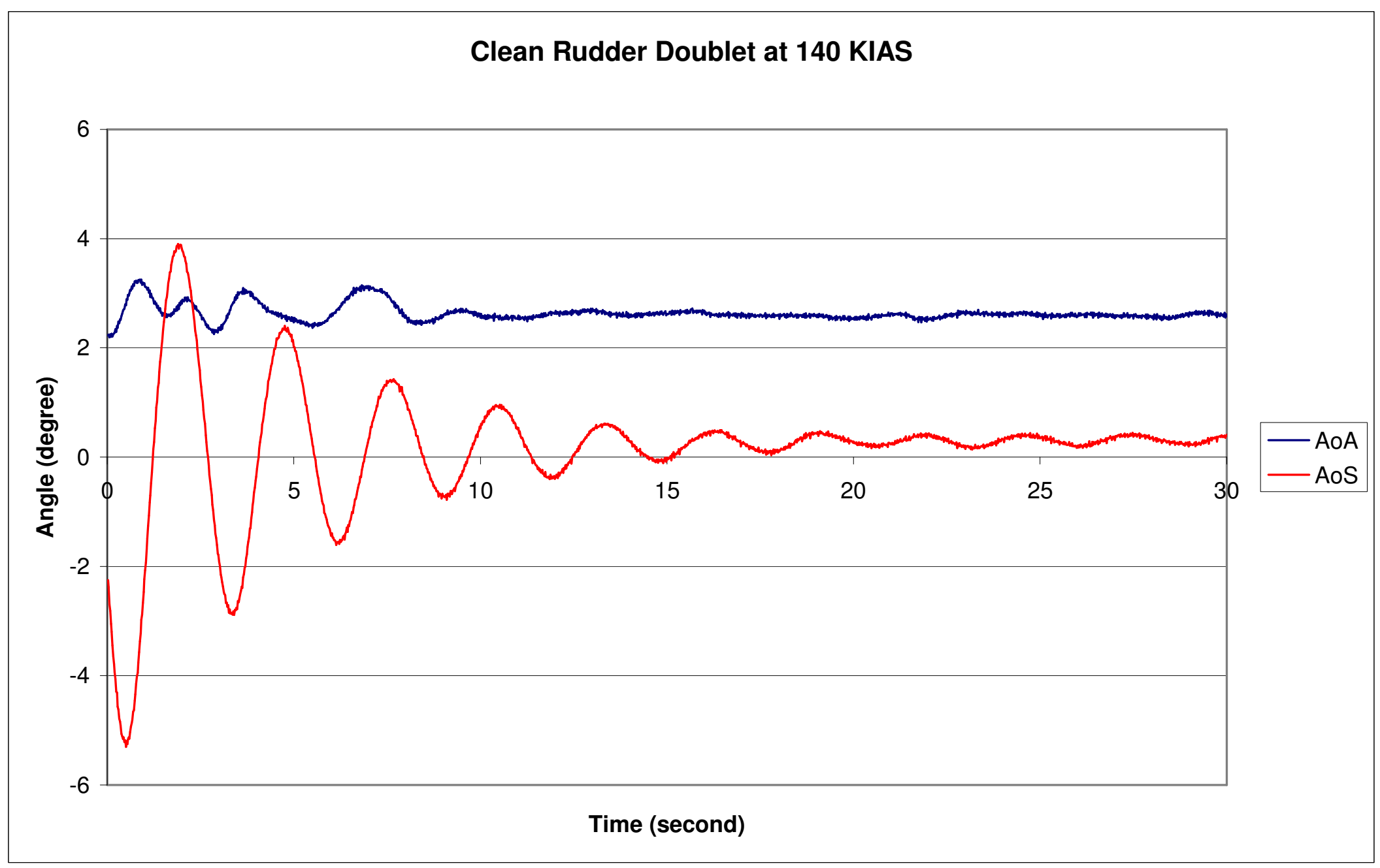

Figure A.93 Rudder Doublet of the Velocity in Clean Configuration at 140 KIAS $(72 \mathrm{~m} / \mathrm{s})$ and 8,500 feet 


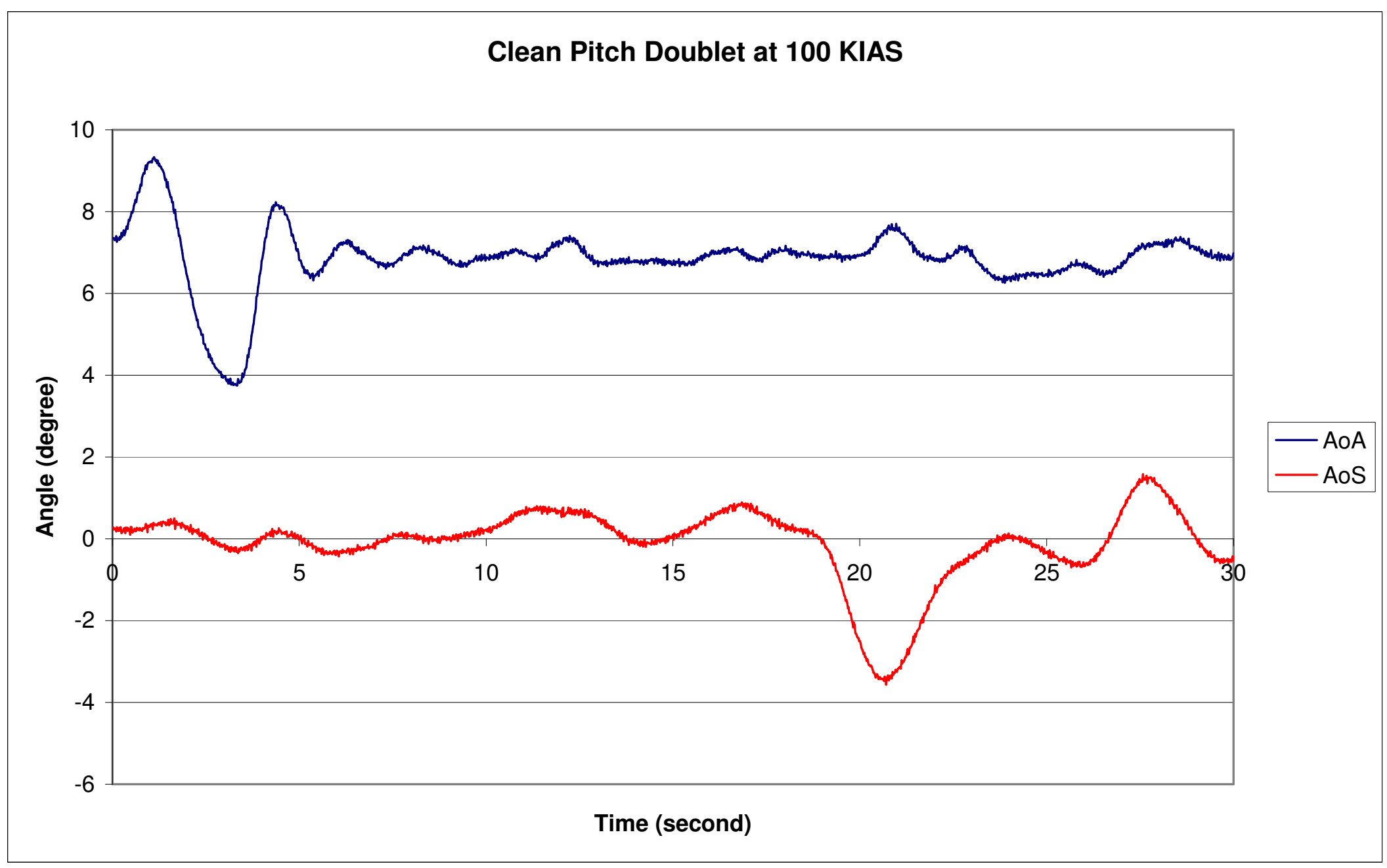

Figure A.94 Pitch Doublet of the Velocity in Clean Configuration at $100 \mathrm{KIAS}(51 \mathrm{~m} / \mathrm{s})$ and 8,500 feet 


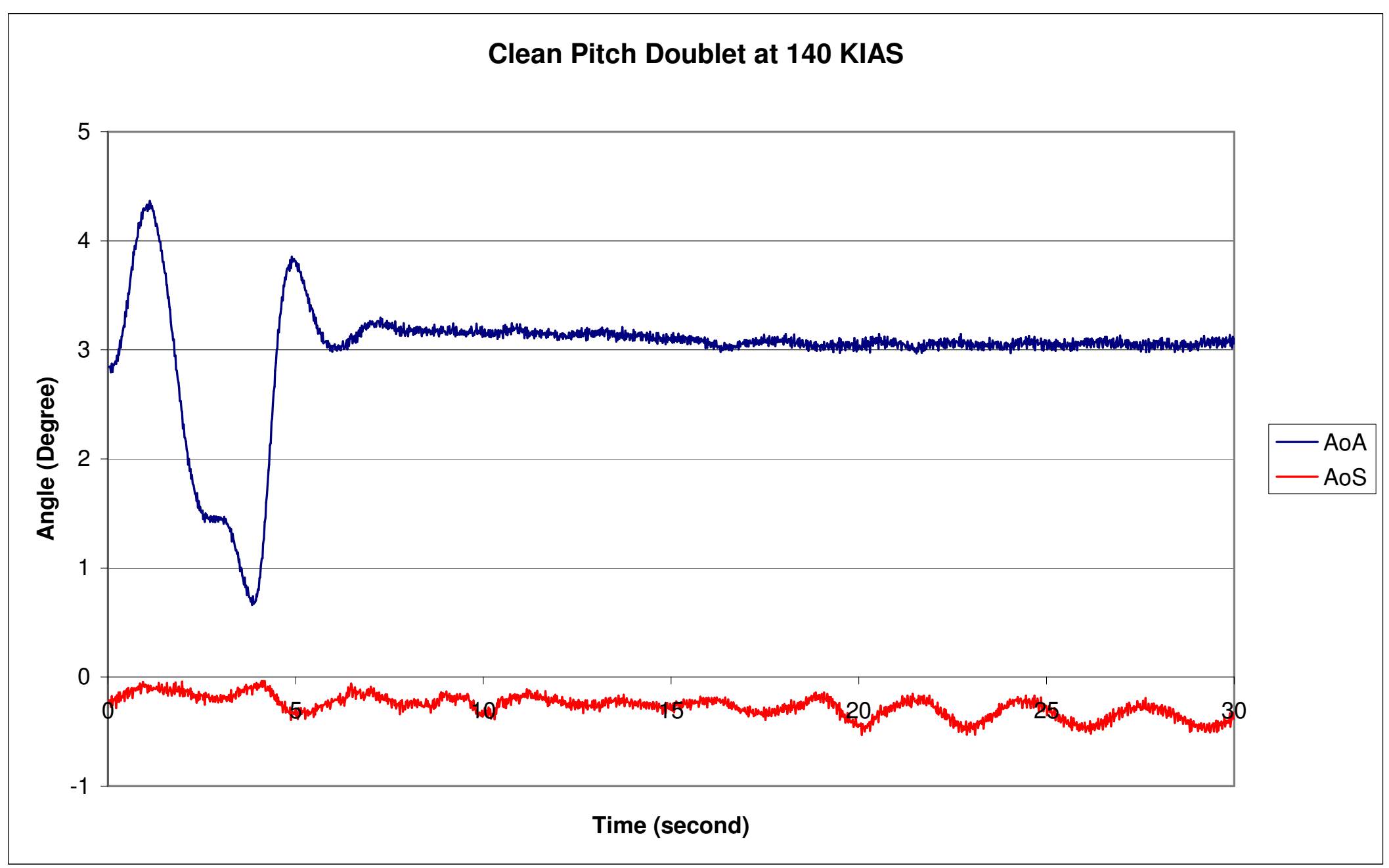

Figure A.95 Pitch Doublet of the Velocity in Clean Configuration at $140 \mathrm{KIAS}(72 \mathrm{~m} / \mathrm{s})$ and 8,500 feet 


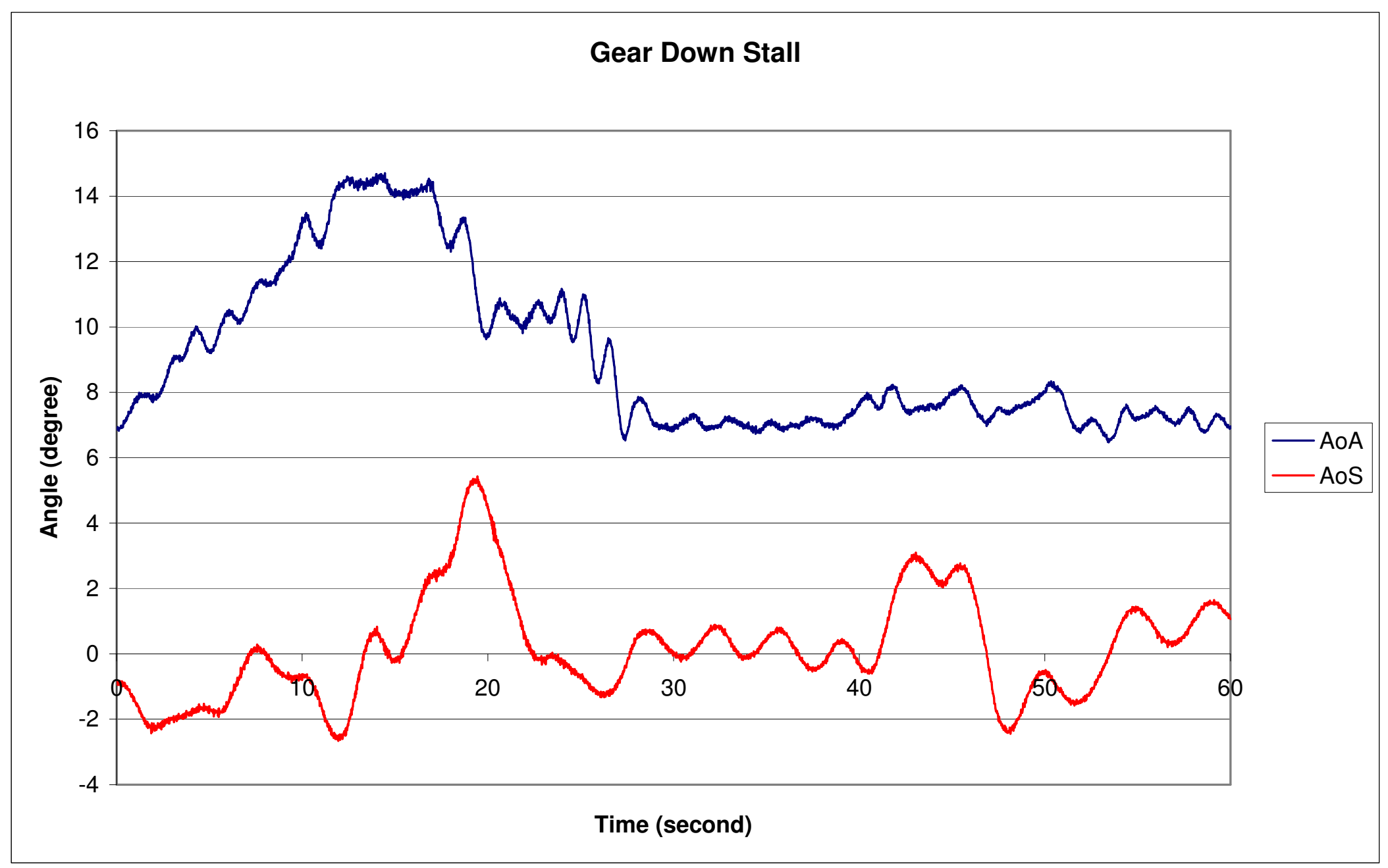

Figure A.96 Clean Flying Qualities in the Velocity - Gear Down, Power Off Stall at 8,000 feet 


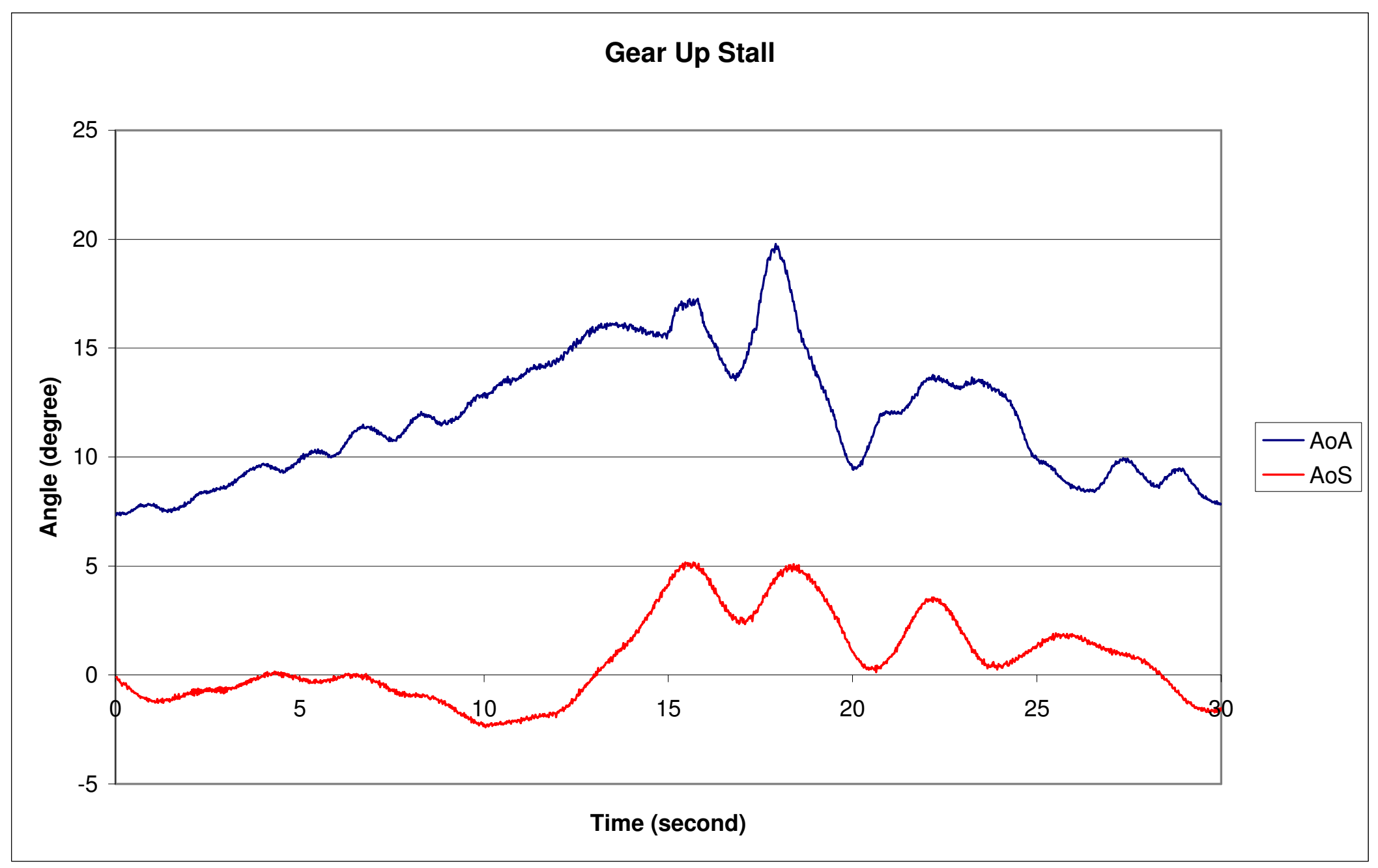

Figure A.97 Clean Flying Qualities in the Velocity - Gear Up, Power Off Stall at 8,000 feet 

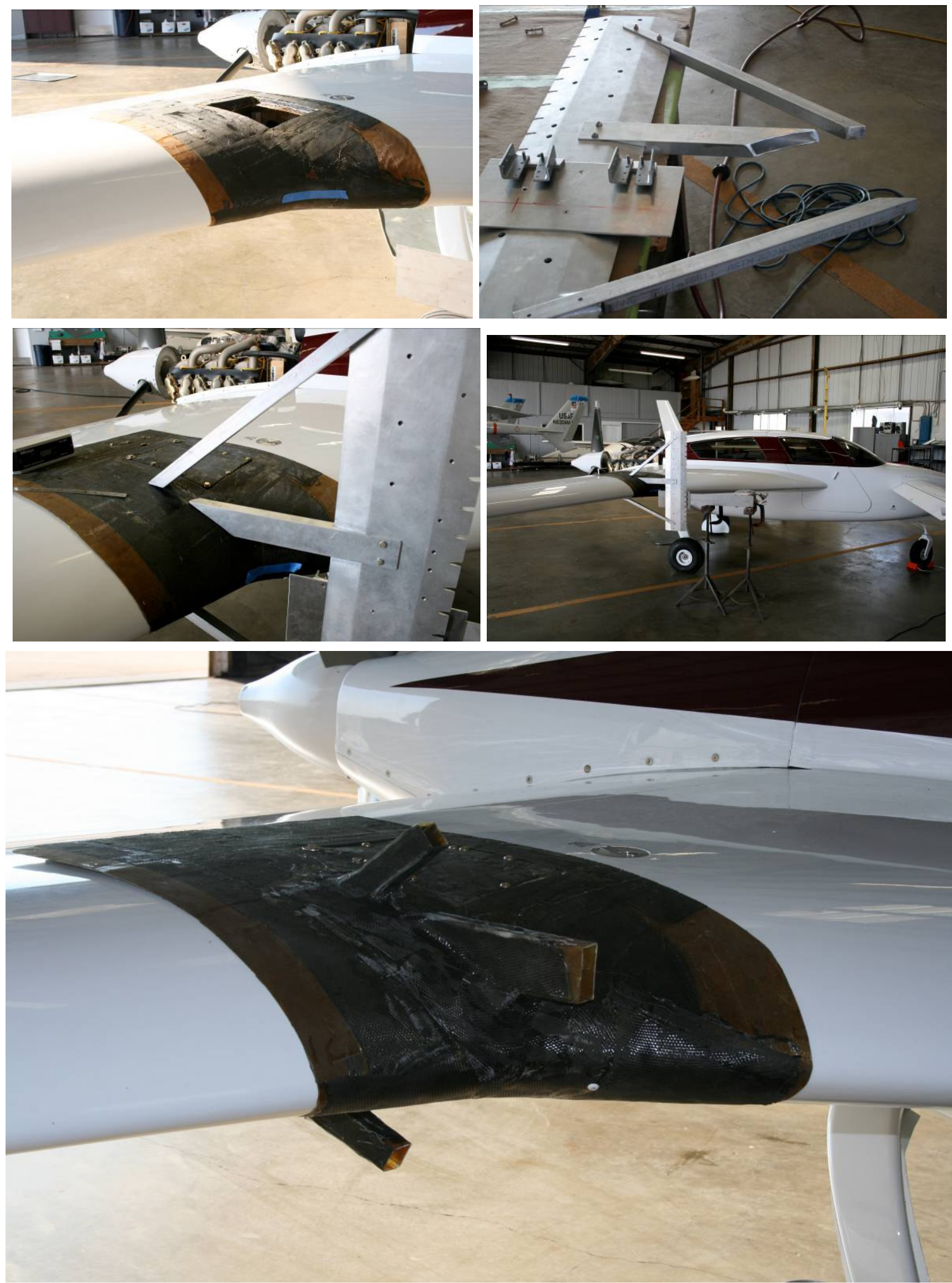

Figure A.98 Stages of Construction on the Wing Glove and Attachment to the Pressure Rake 

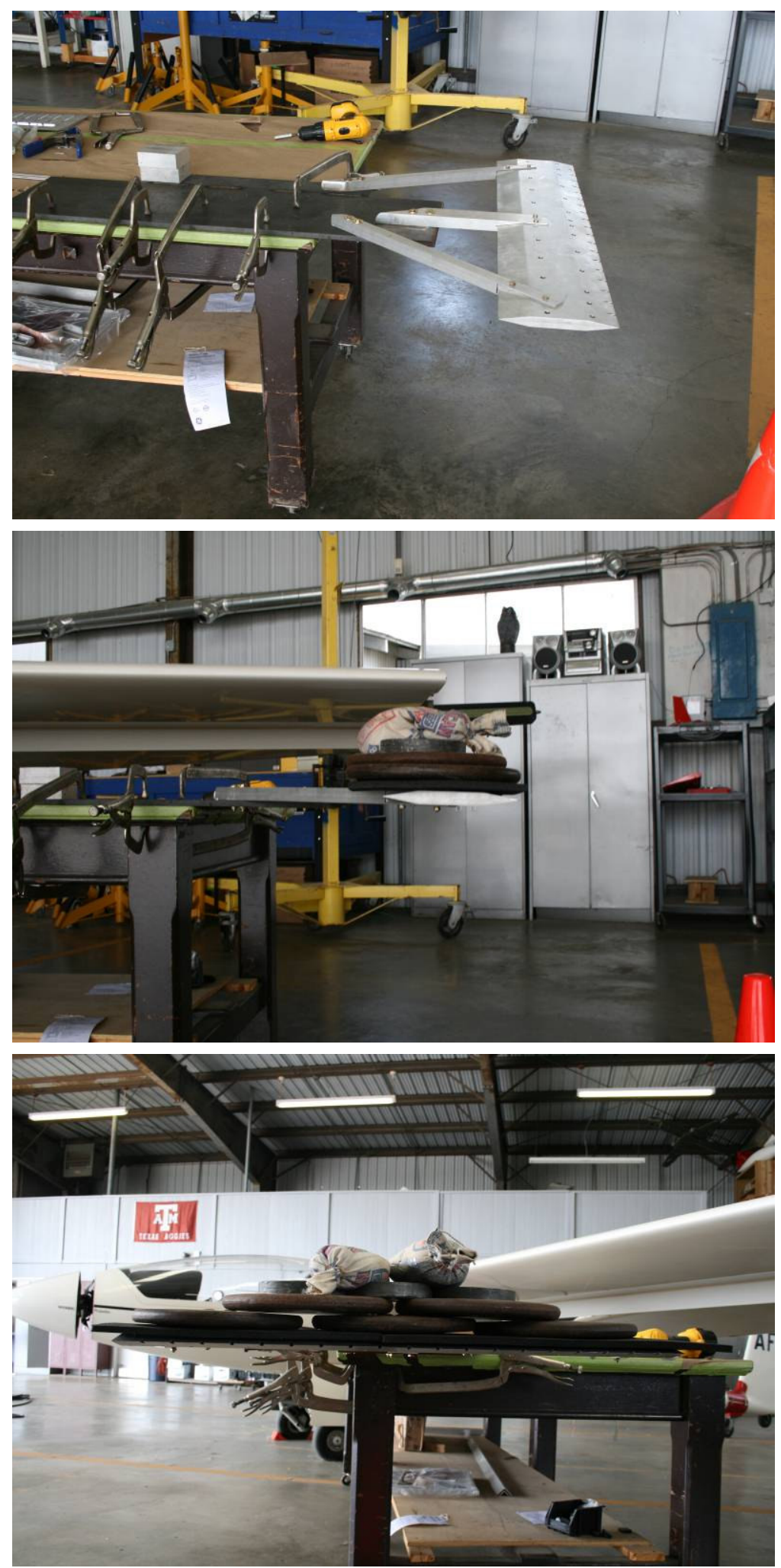

Figure A.99 Static Load Testing of the Pressure Rake and Struts with 86 kg (190 lbs) 

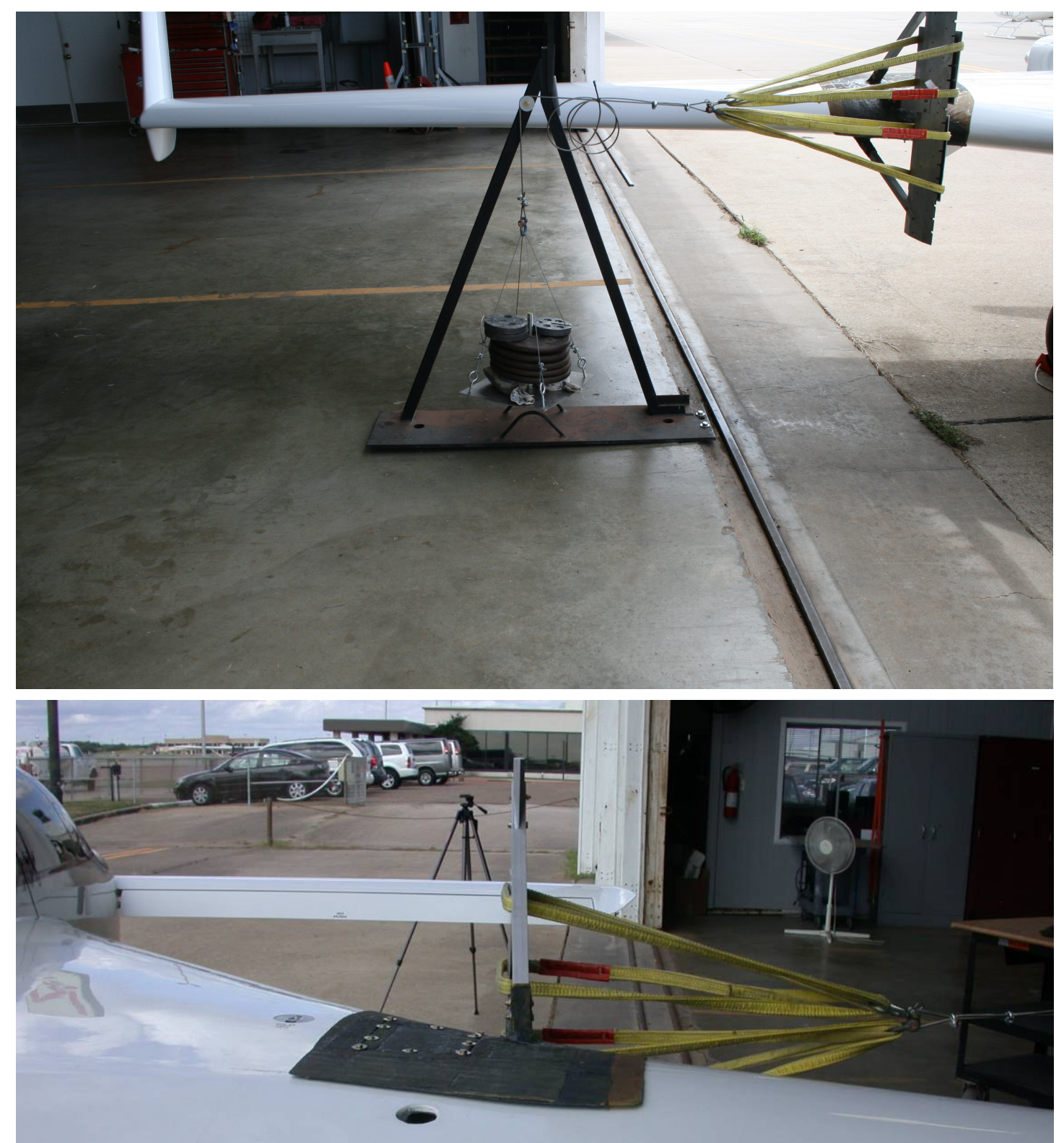

Figure A.100 Side Load of $86 \mathrm{~kg}$ Applied to the Pressure Rake While Mounted to the Aircraft 

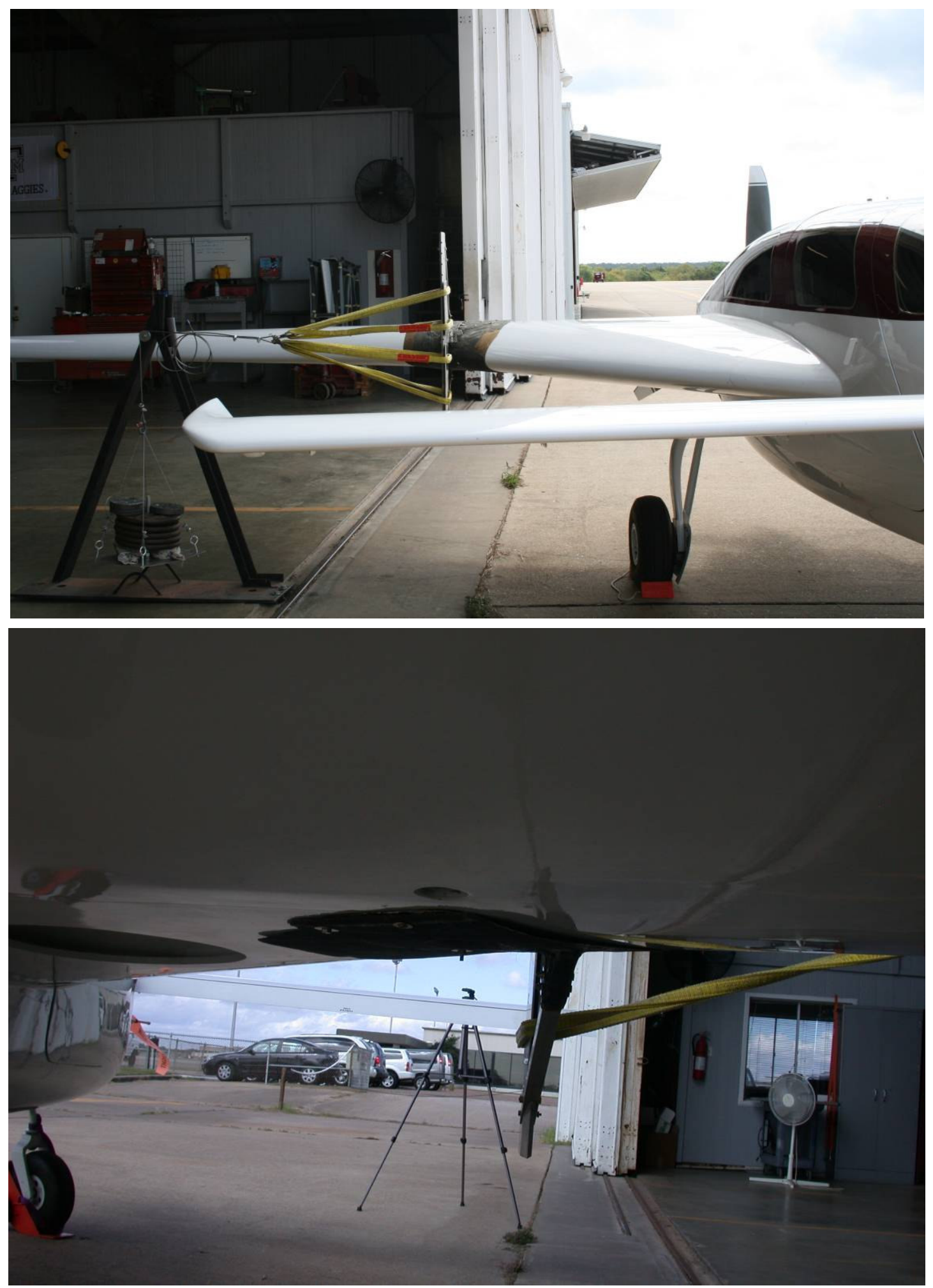

Figure A.101 Monitoring for Deflections or Yielding in the Pressure Rake during Static Load Test 


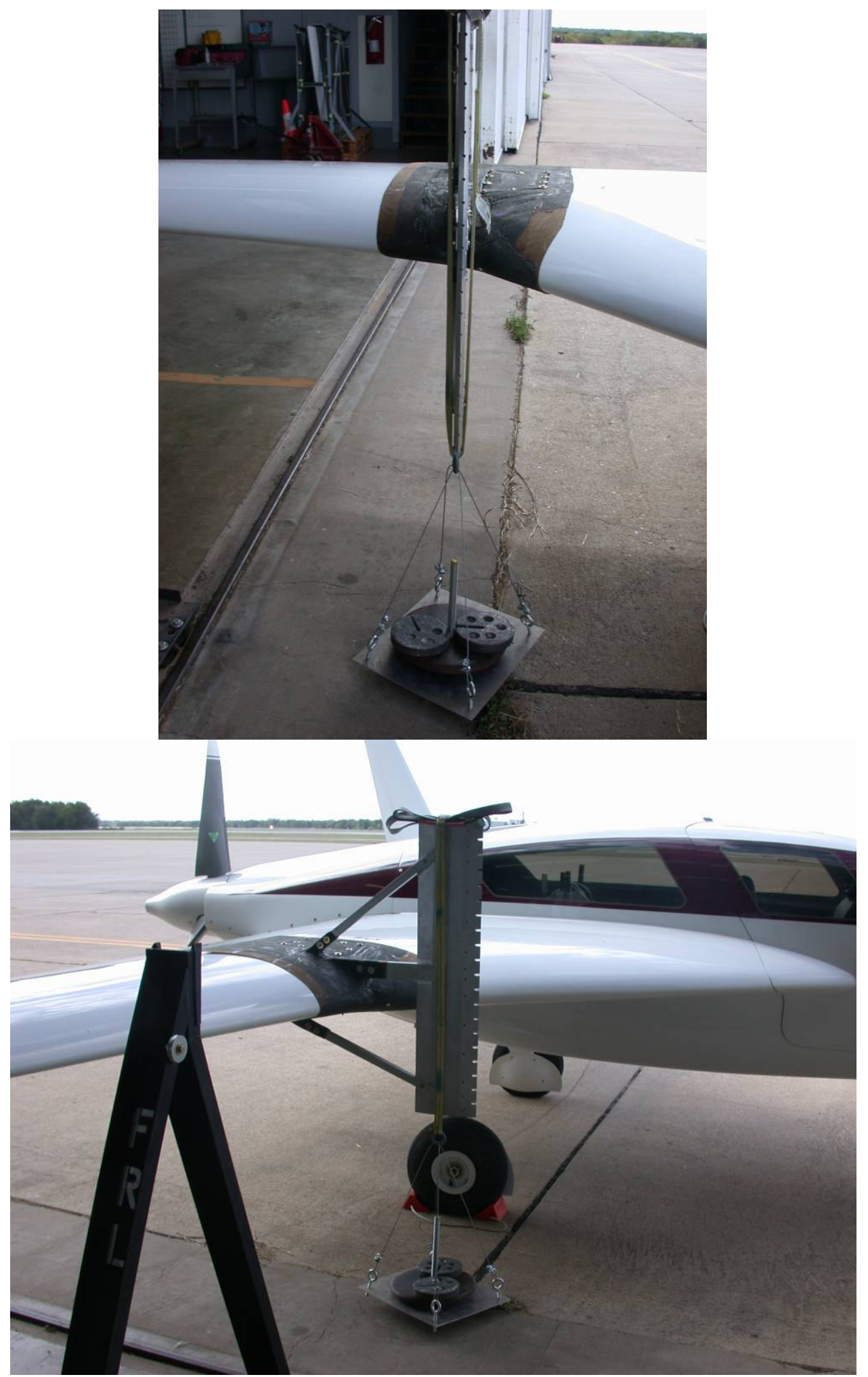

Figure A.102 Hanging 20 kg (45 lbs) From the Pressure Rake to Simulate a 2-G Pull-up 

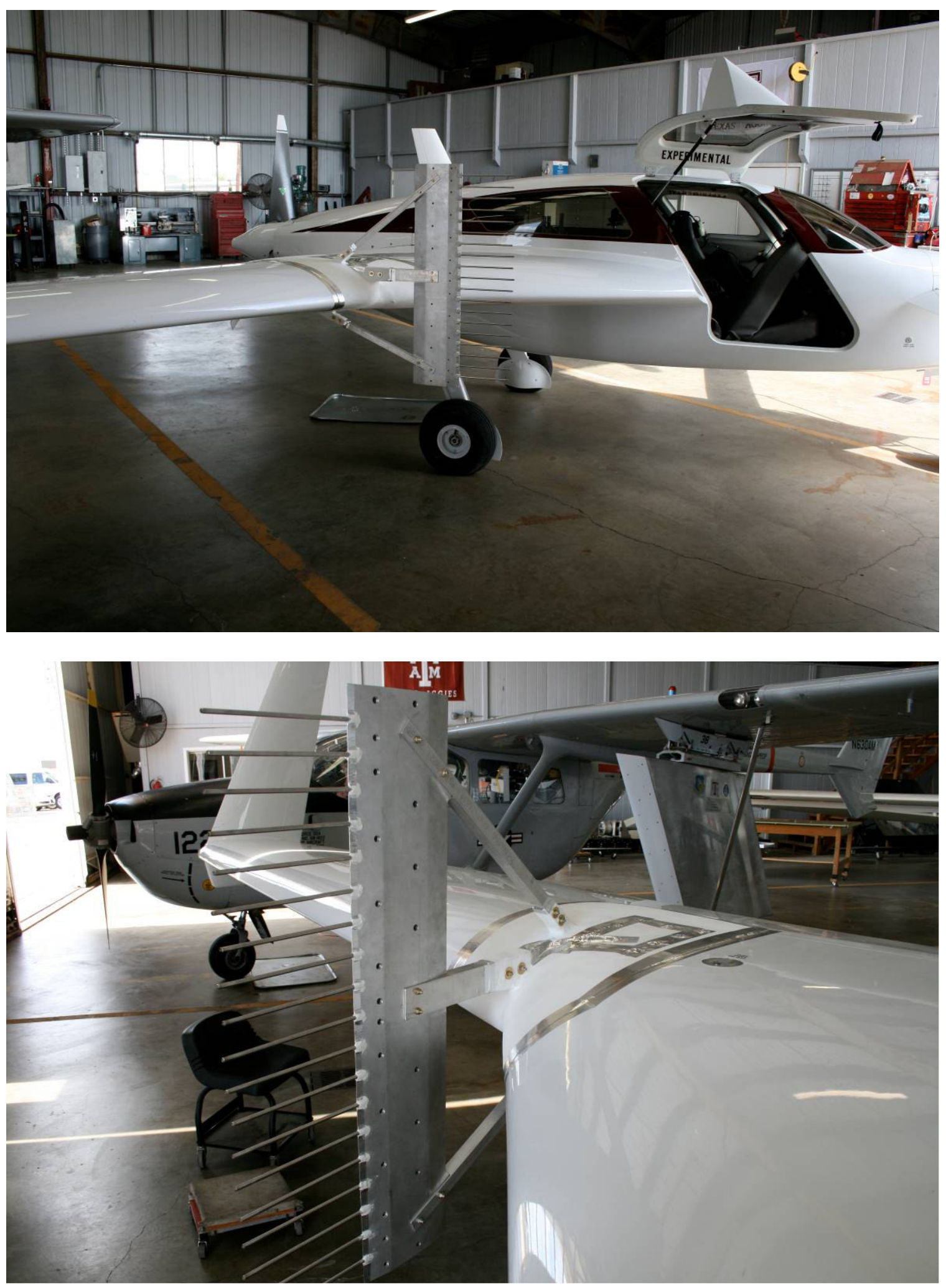

Figure A.103 Wing Glove and Pressure Rake Completed and Ready for Flight 

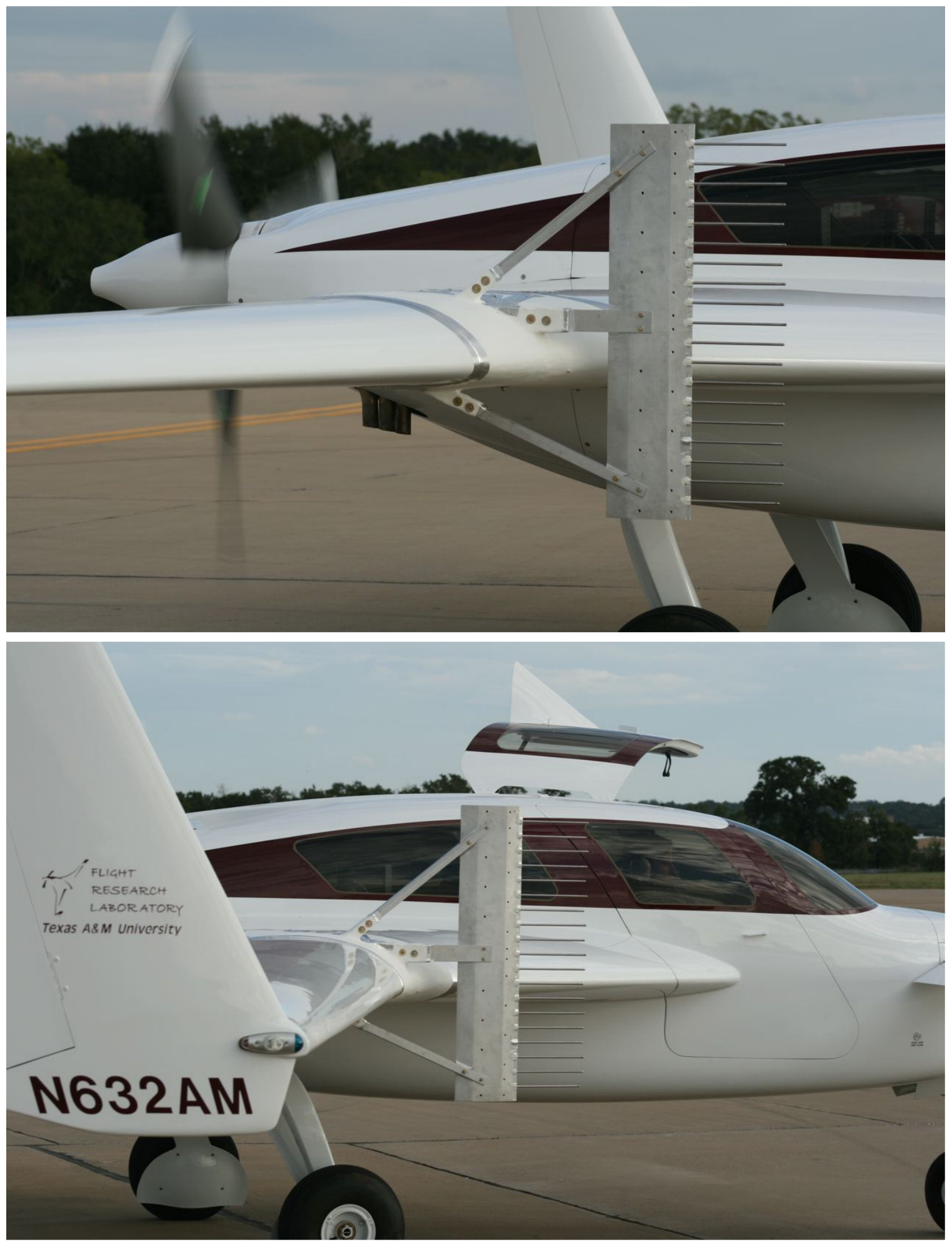

Figure A.104 Engine Run-up Test with the Pressure Rake 

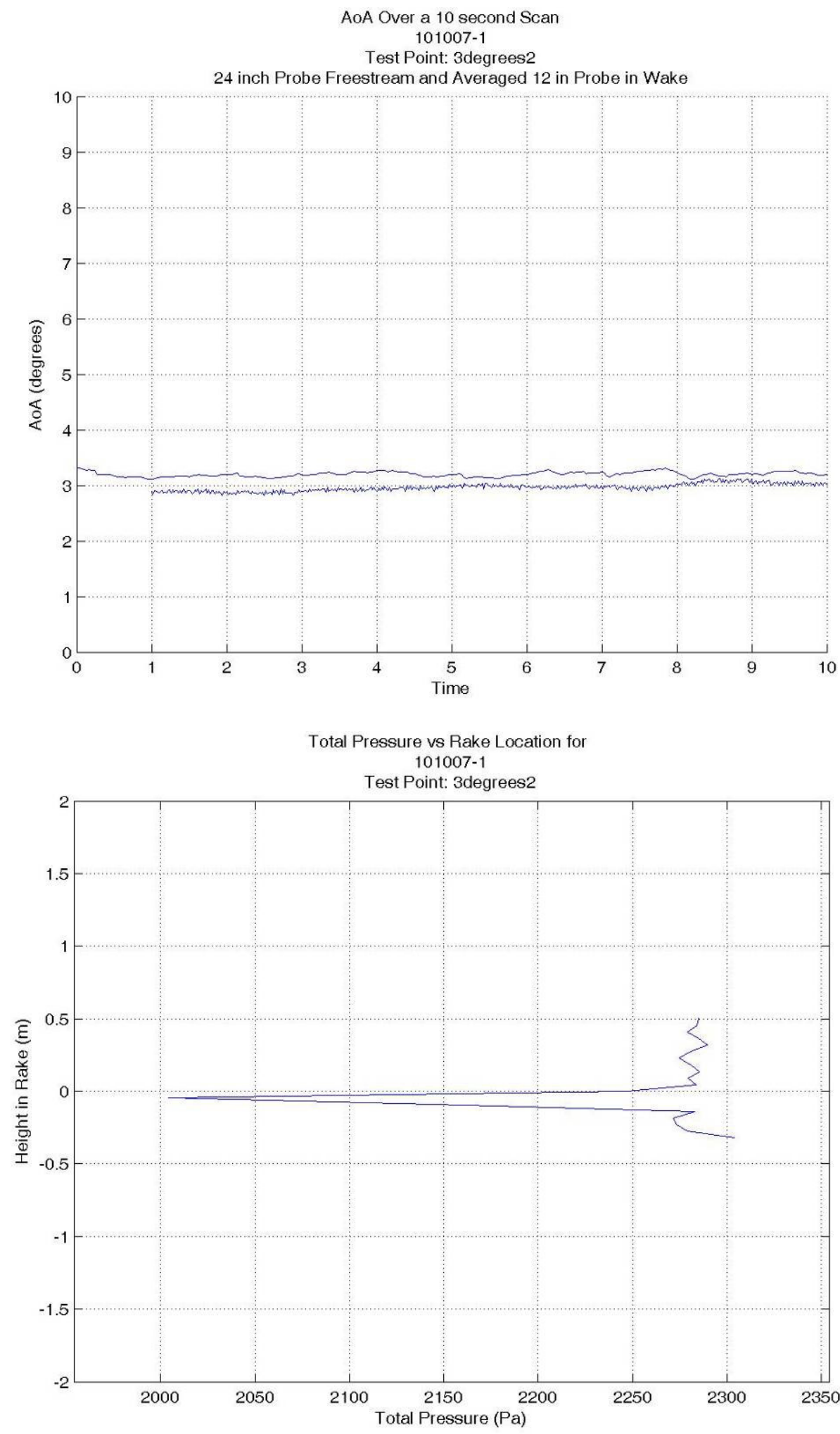

Figure A.105 Flight $101007-1$ at $3^{\circ} A o A, 143$ KIAS at 8,500 feet 

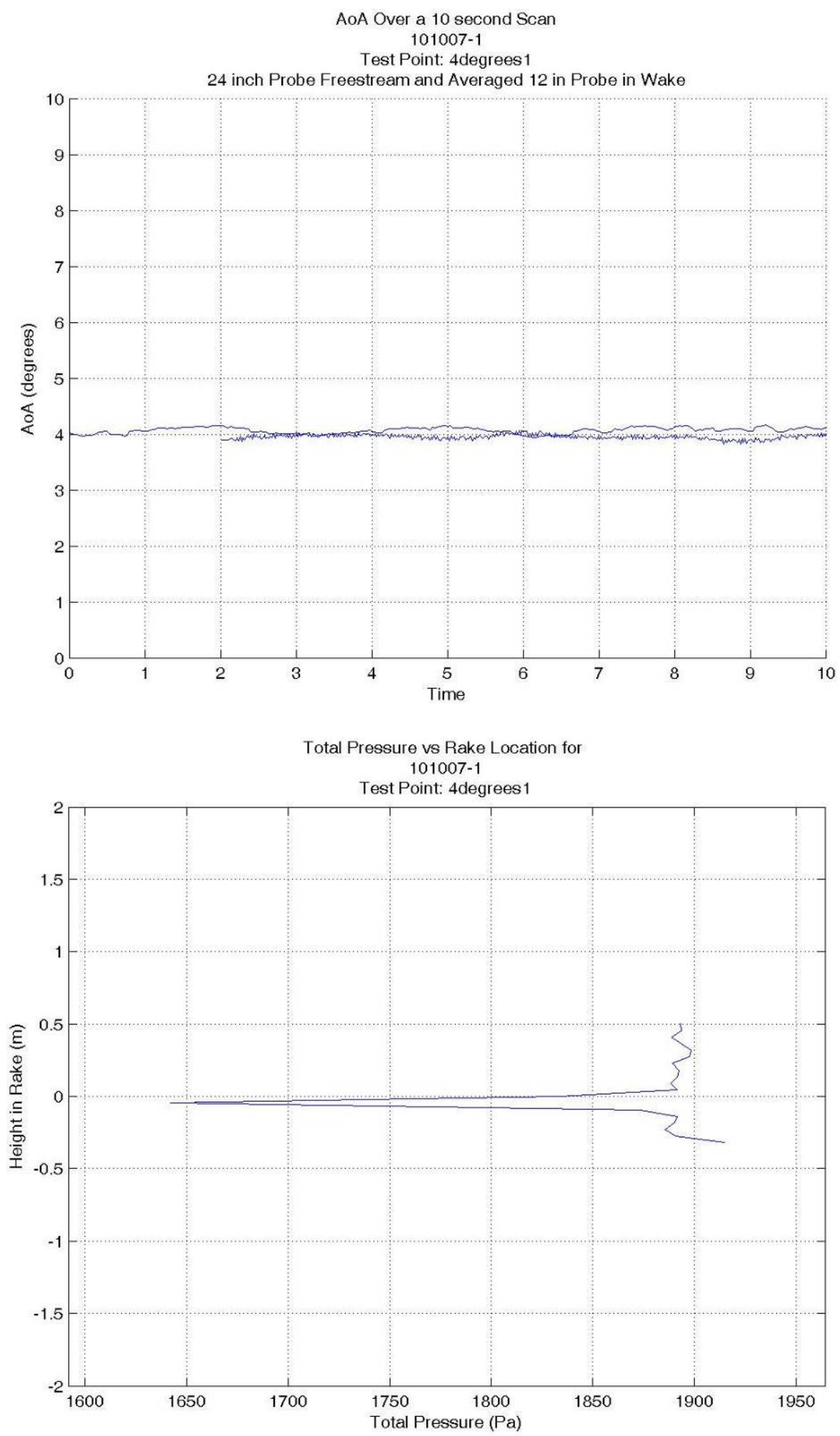

Figure A.106 Flight $101007-1$ at $4^{\circ} A o A, 128$ KIAS at 8,500 feet 

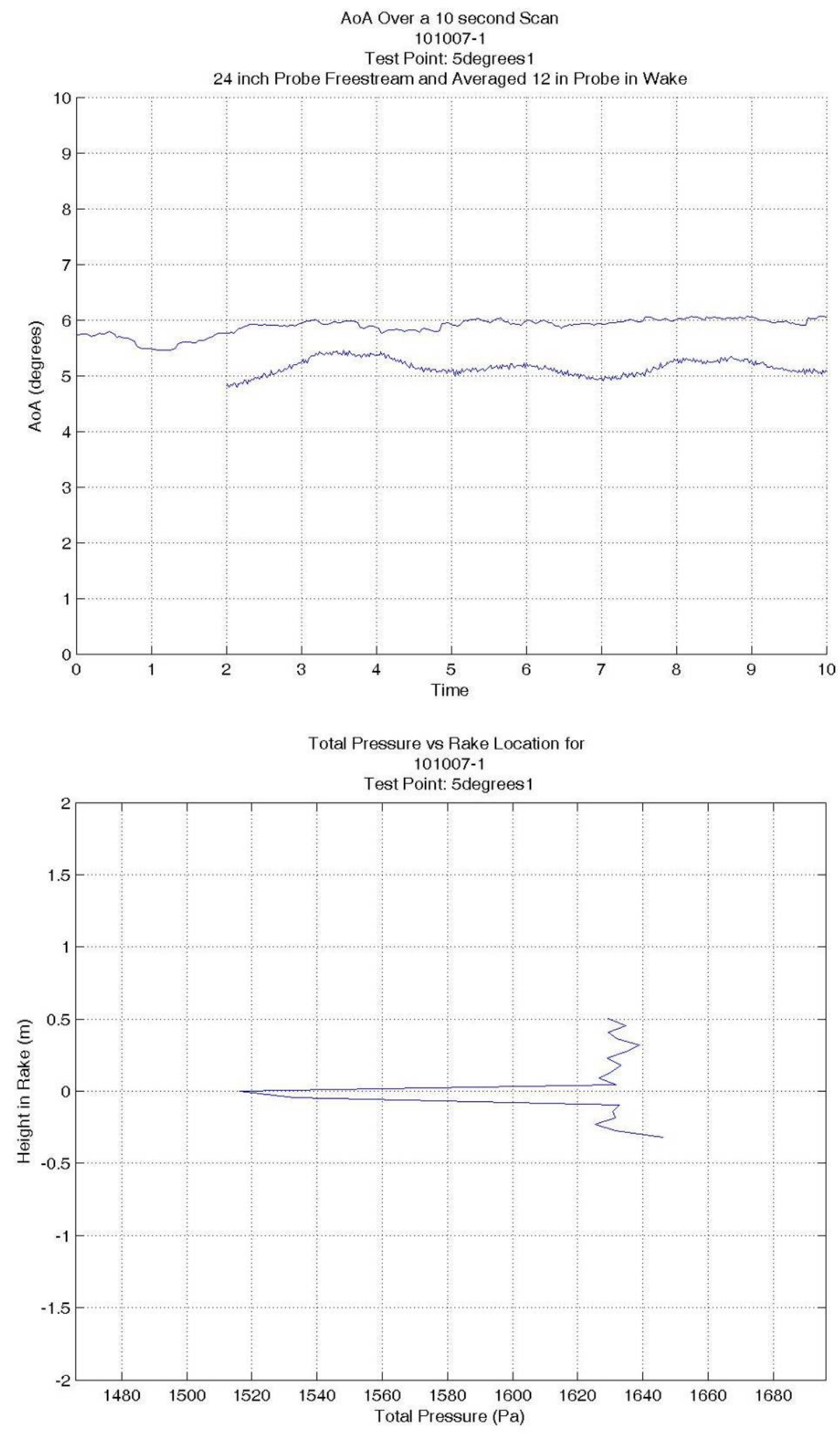

Figure A.107 Flight $101007-1$ at $5^{\circ} A o A, 120$ KIAS at 8,500 feet 


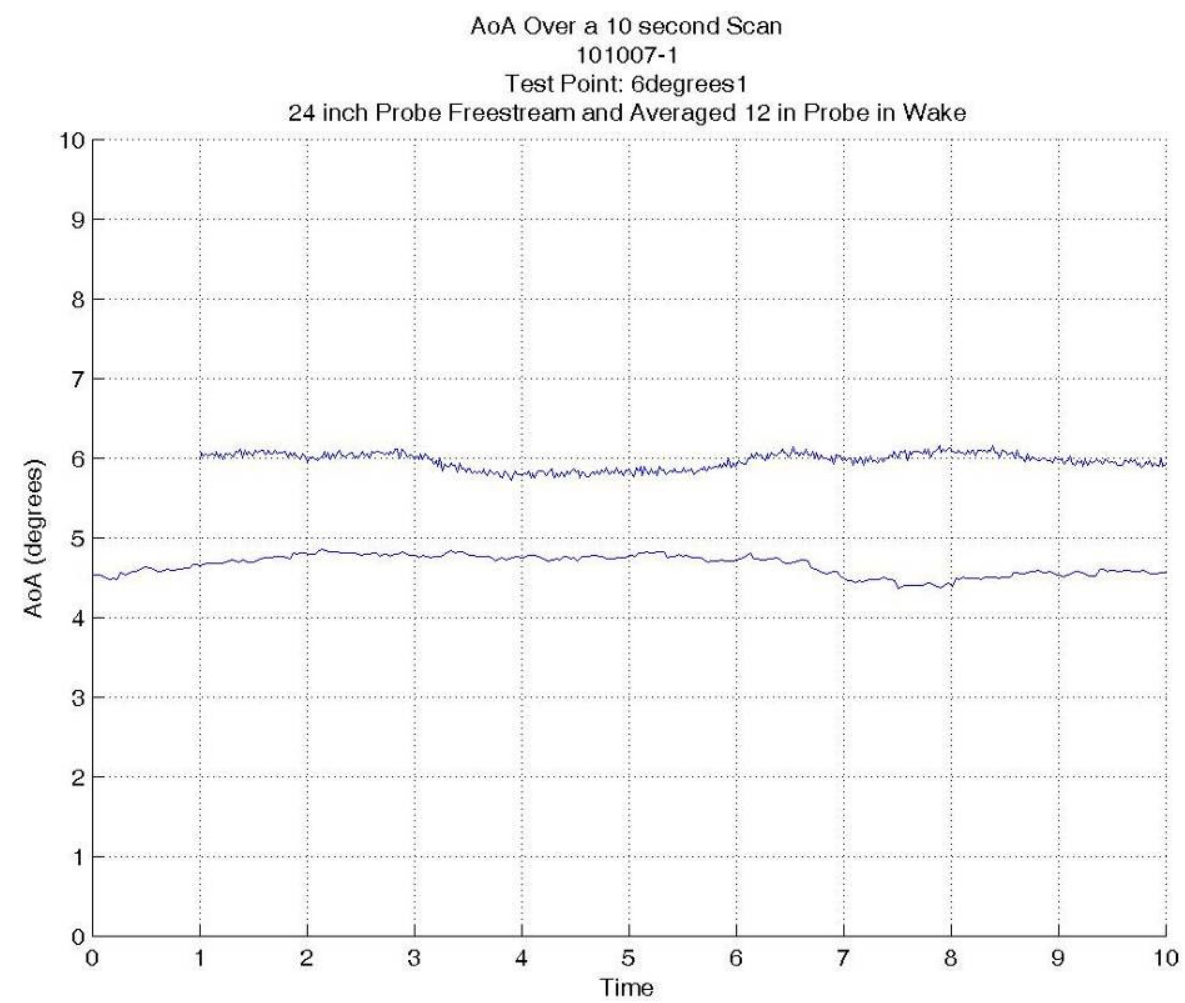

Total Pressure vs Rake Location for 101007-1

Test Point: 6degrees 1

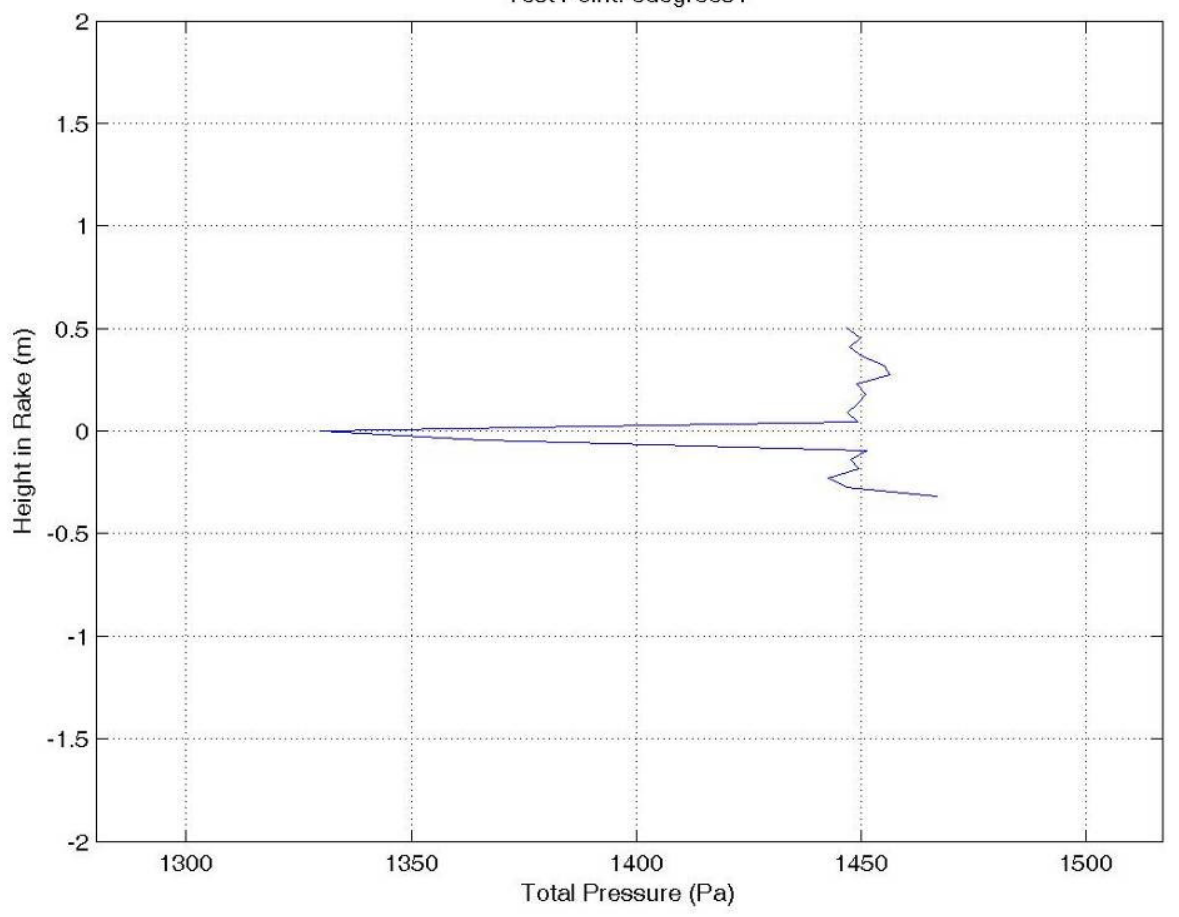

Figure A.108 Flight $101007-1$ at $6^{\circ} A o A, 112$ KIAS at 8,500 feet 


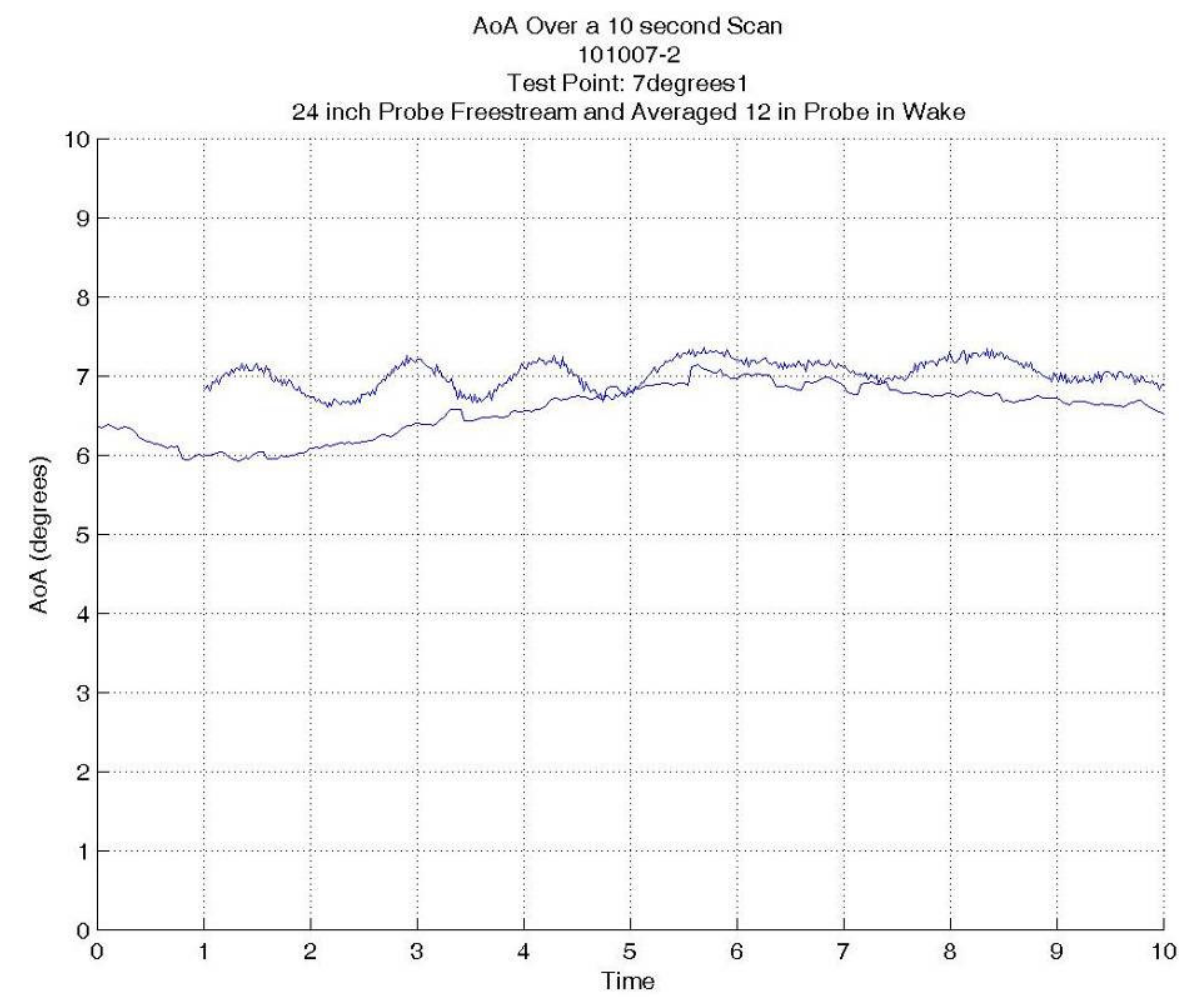

Total Pressure vs Rake Location for 101007-2

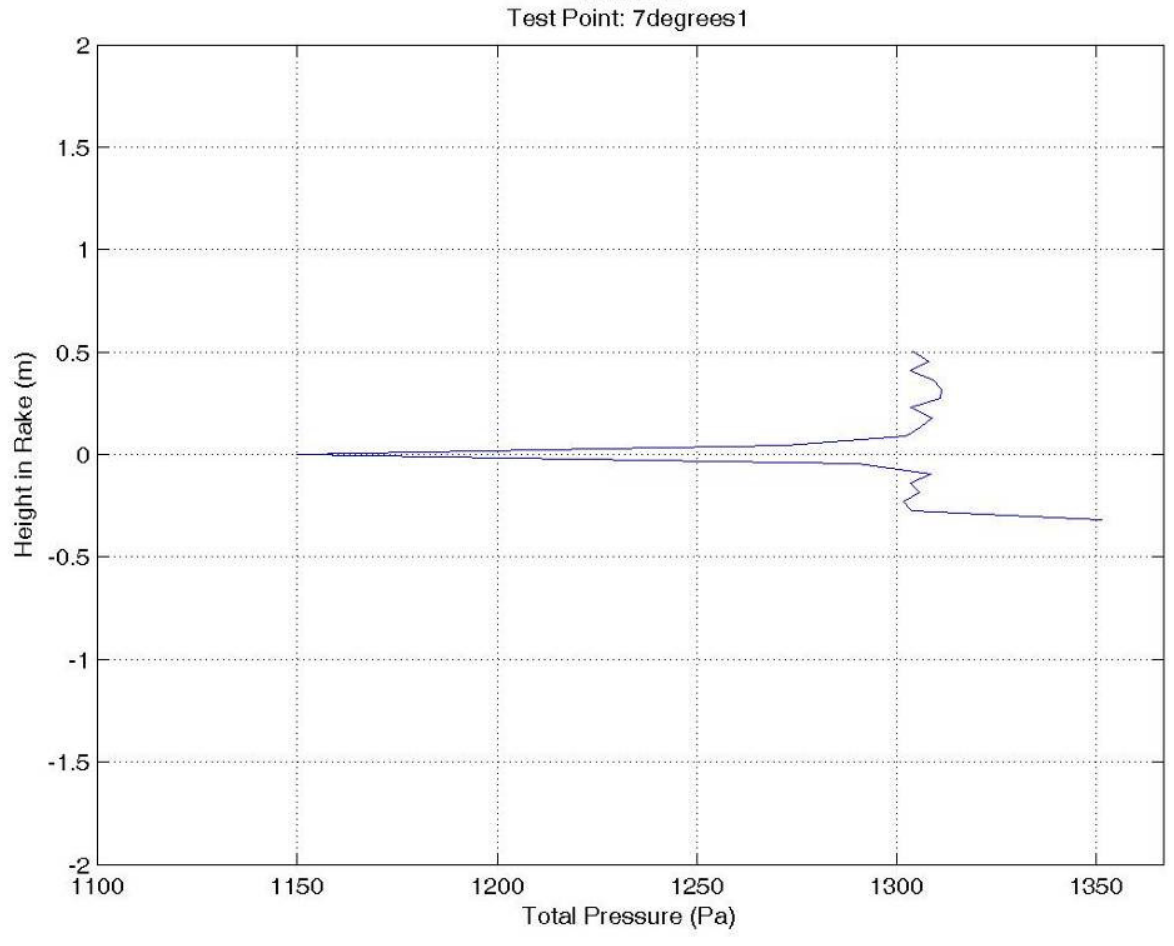

Figure A.109 Flight $101007-1$ at $7^{\circ} A o A, 105$ KIAS at 8,500 feet 


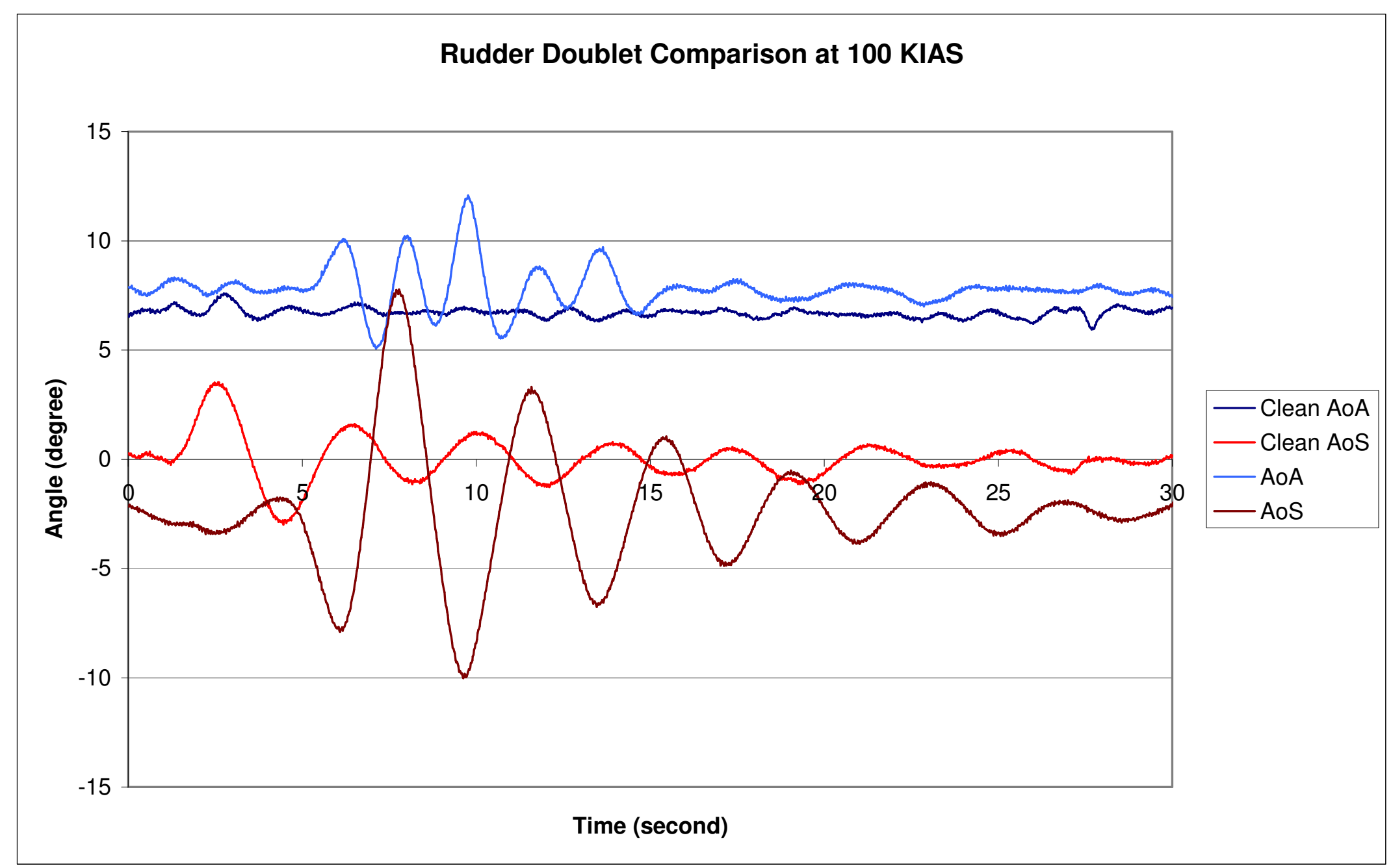

Figure A.110 Rudder Doublet of the Velocity with the Pressure Rake at 100 KIAS $(51 \mathrm{~m} / \mathrm{s})$ and 8,500 feet 


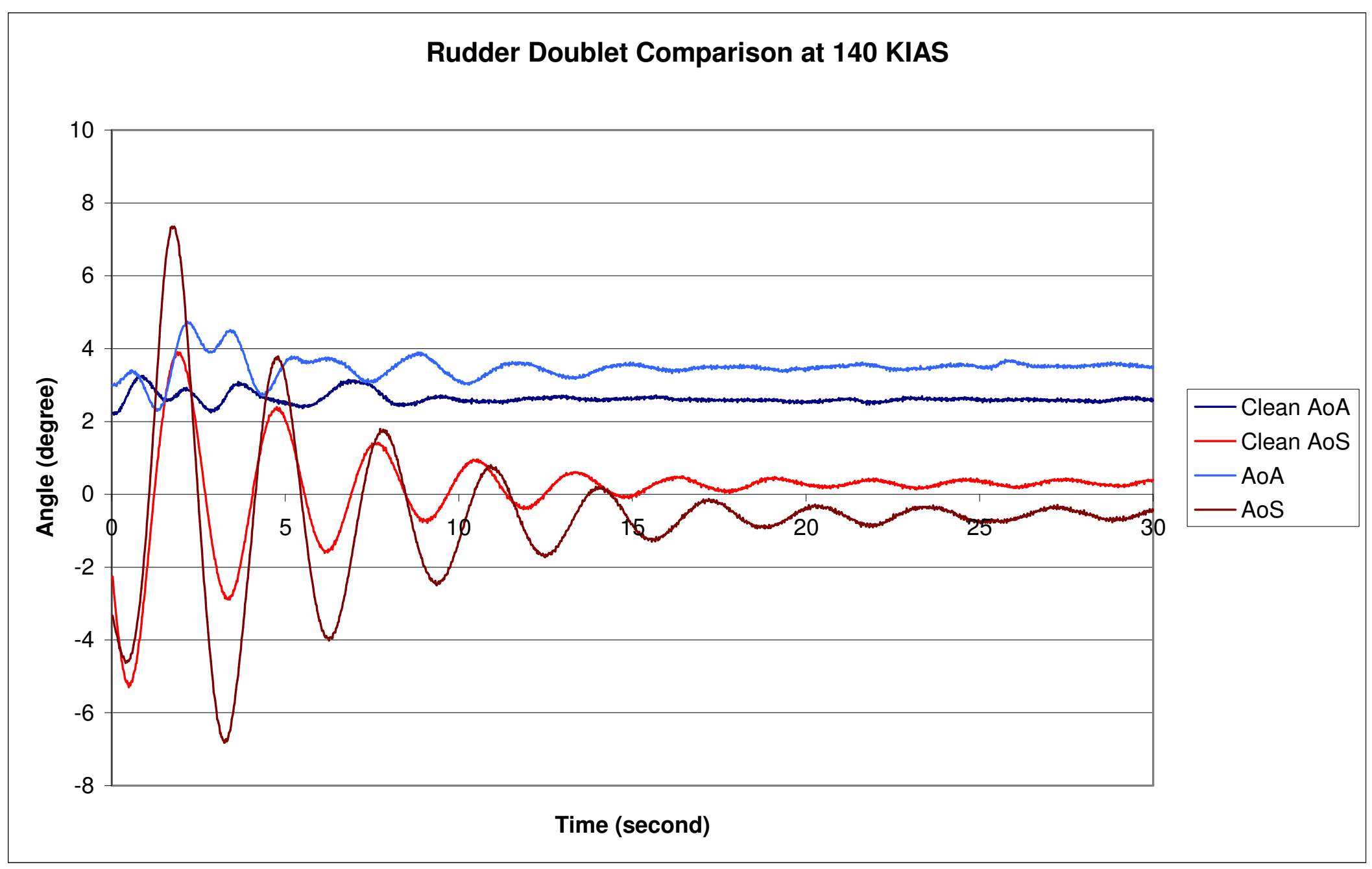

Figure A.111 Rudder Doublet of the Velocity with the Pressure Rake at 140 KIAS (72 m/s) and 8,500 feet 


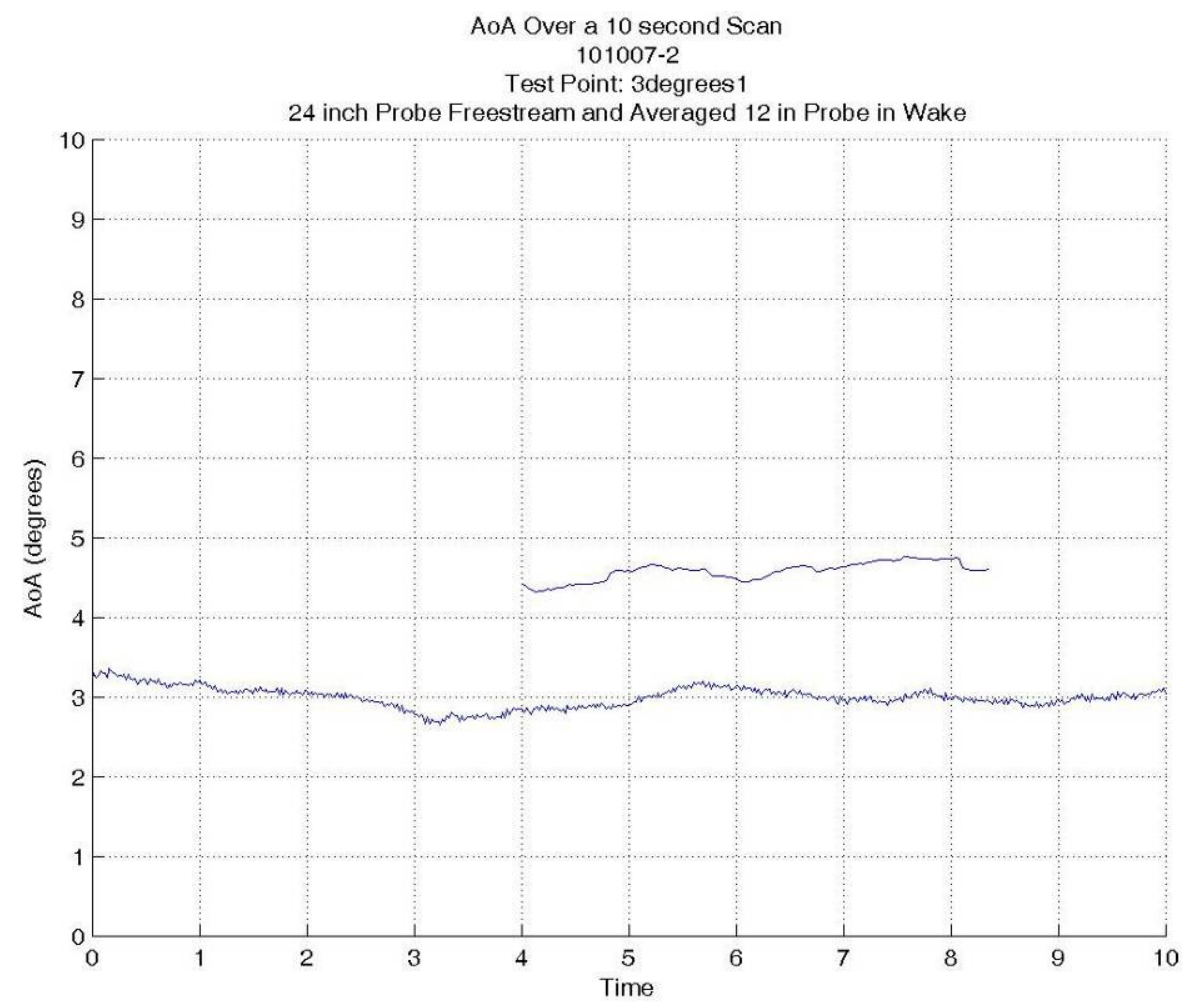

Total Pressure vs Rake Location for 101007-2

Test Point: 3degrees 1

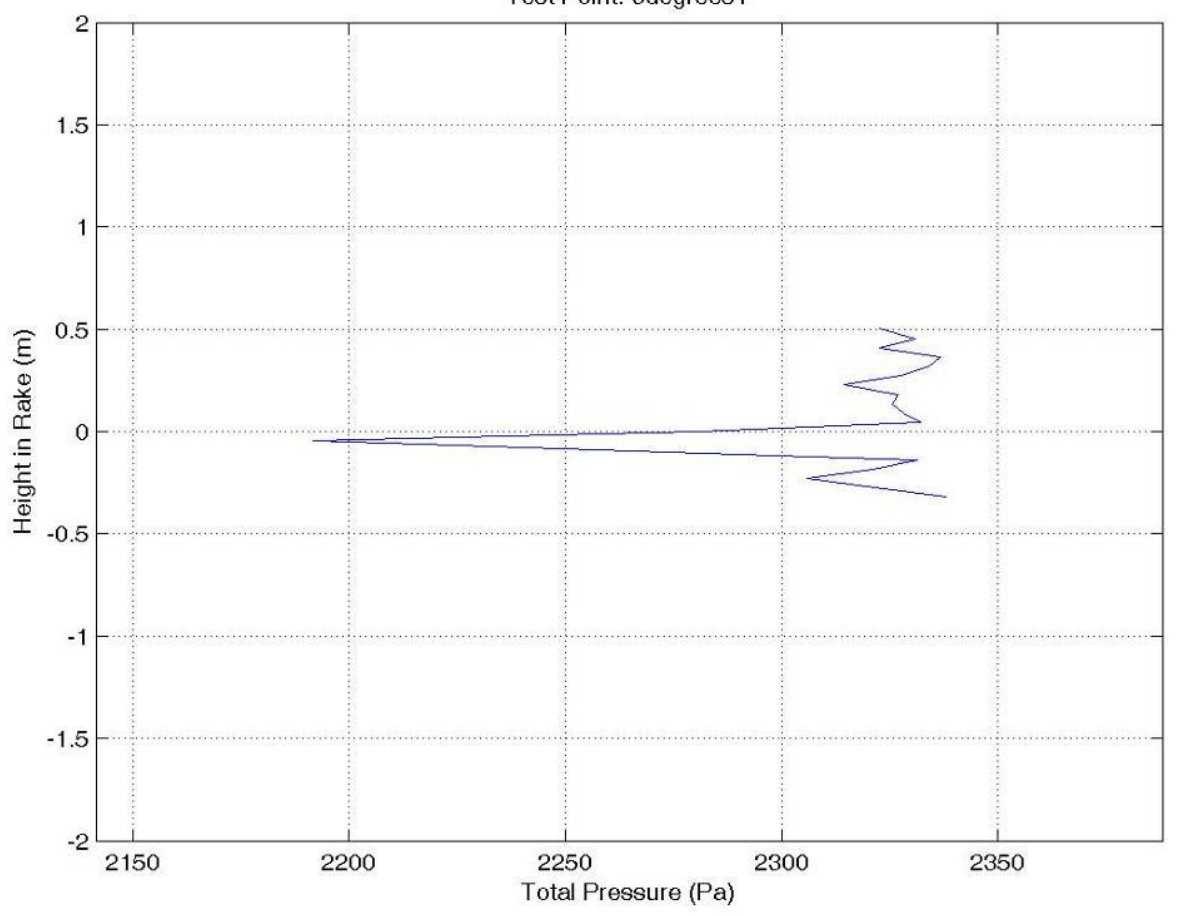

Figure A.112 Flight $101007-2$ at $3^{\circ} \mathrm{AoA}, 147 \mathrm{KIAS}(76 \mathrm{~m} / \mathrm{s})$ at 8,500 feet 

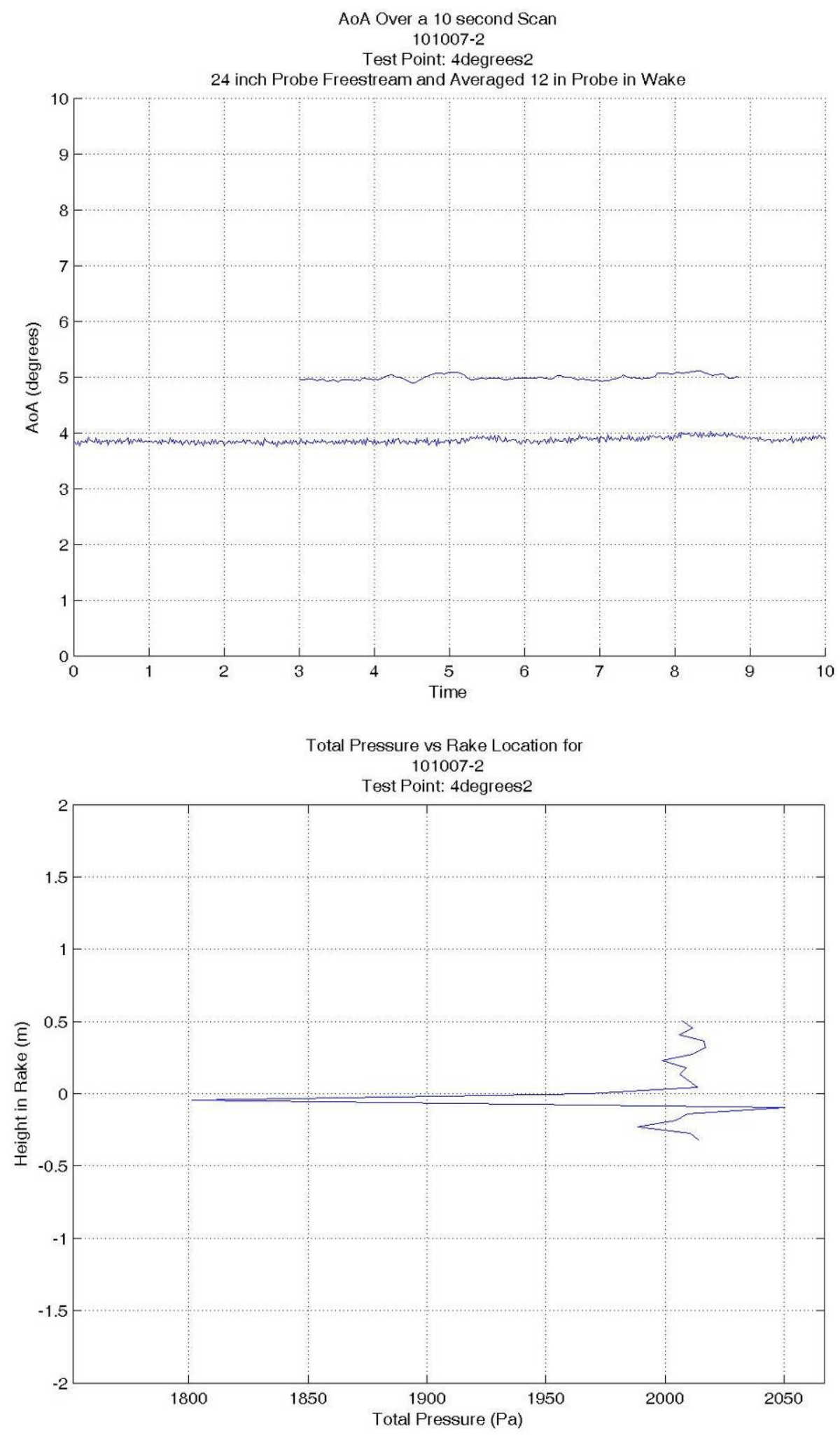

Figure A.113 Flight $101007-2$ at $4^{\circ} A o A, 130 \mathrm{KIAS}(67 \mathrm{~m} / \mathrm{s})$ at 8,500 feet 


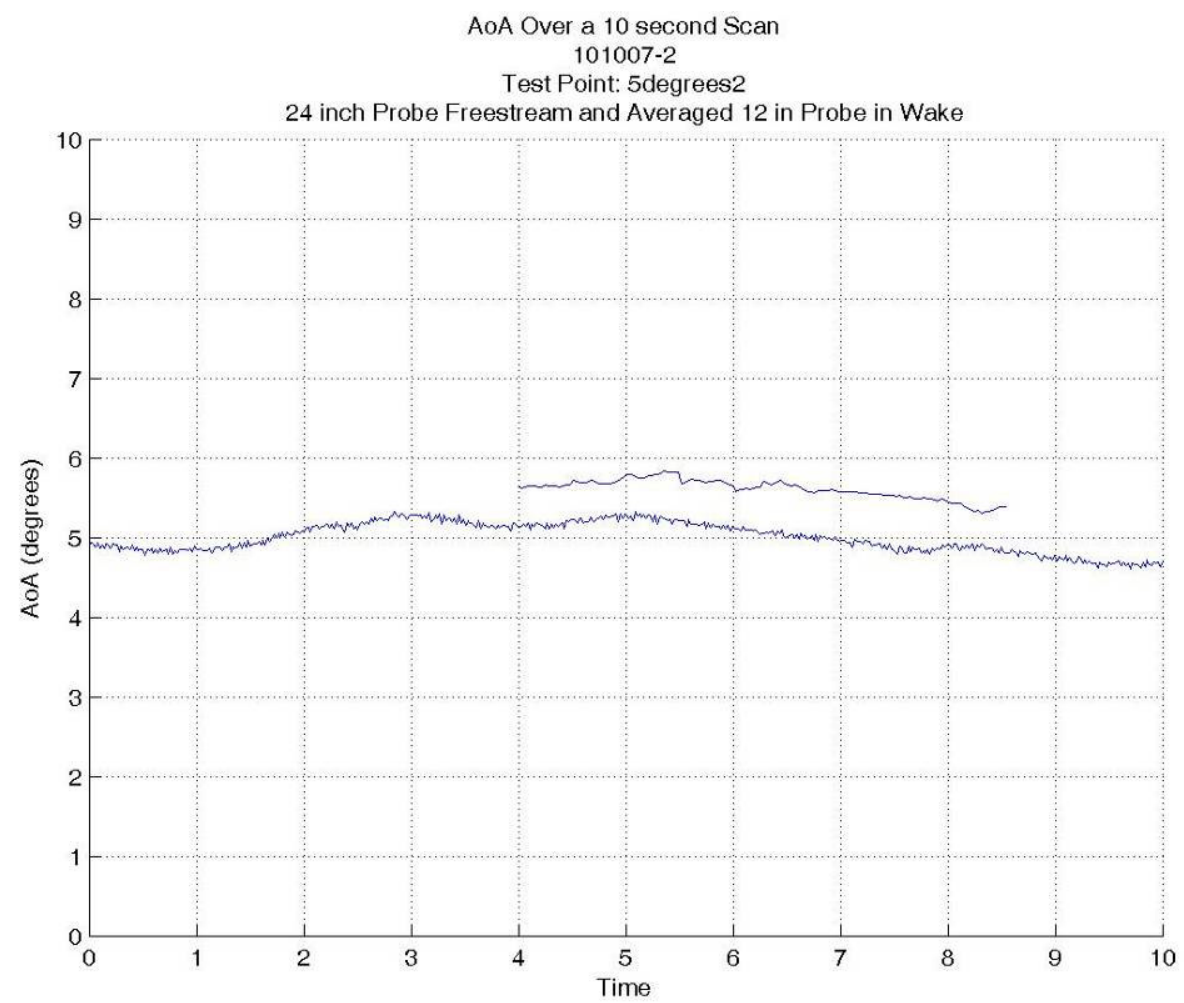

Total Pressure vs Rake Location for 101007-2

Test Point: 5degrees2

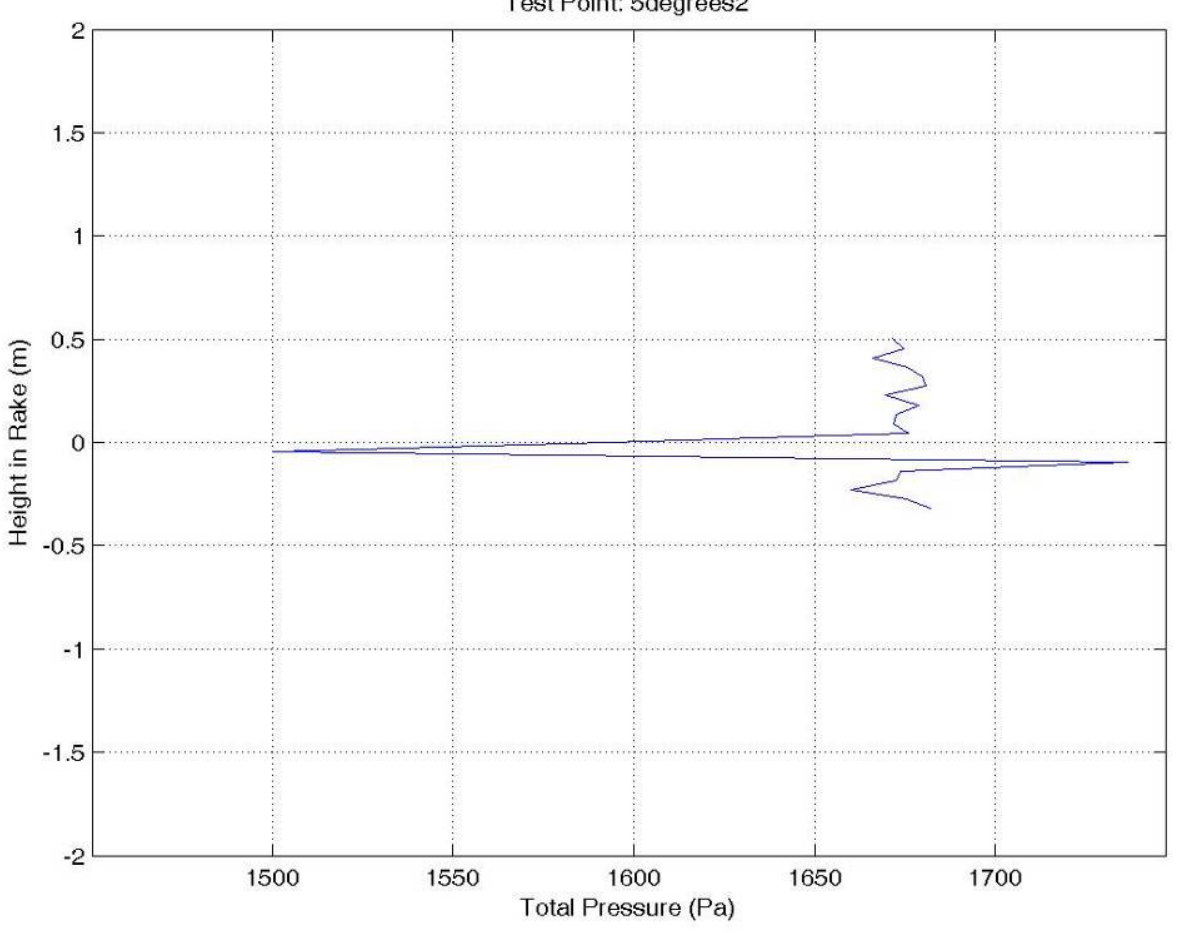

Figure A.114 Flight $101007-2$ at $5^{\circ} A o A, 120 \mathrm{KIAS}(62 \mathrm{~m} / \mathrm{s})$ at 8,500 feet 


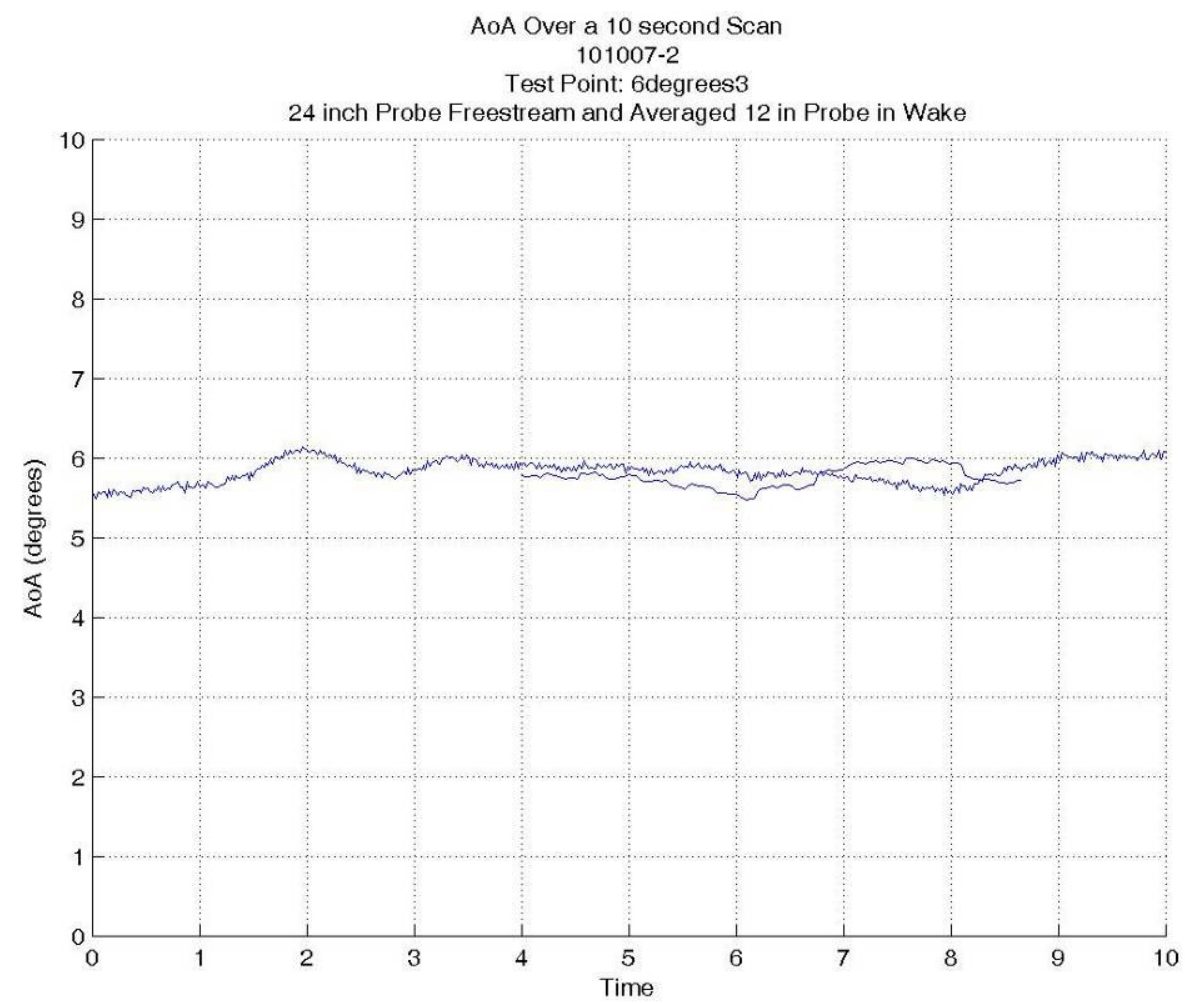

Total Pressure vs Rake Location for 101007-2

Test Point: 6degrees3

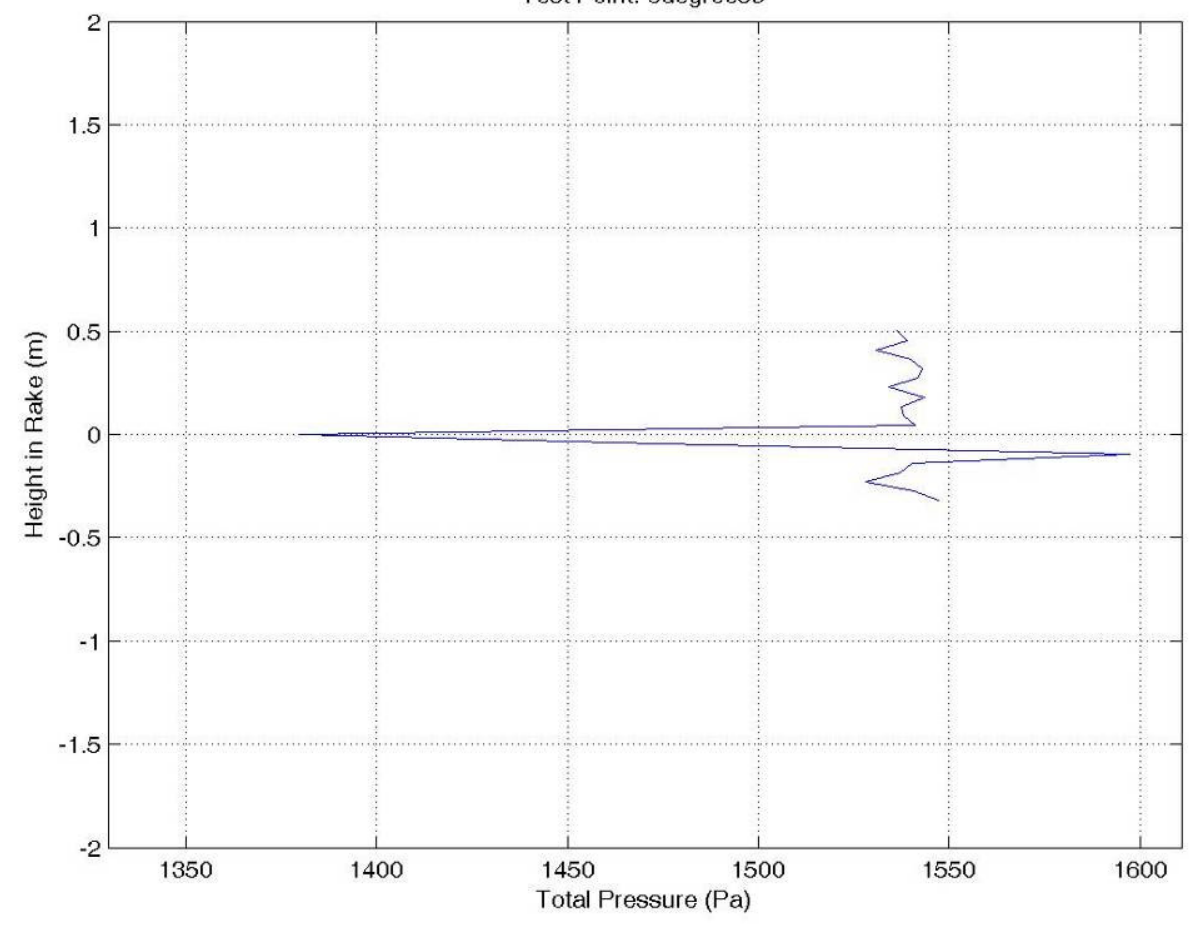

Figure A.115 Flight $101007-2$ at $6^{\circ} A o A, 106 \operatorname{KIAS}(54 \mathrm{~m} / \mathrm{s})$ at 8,500 feet 


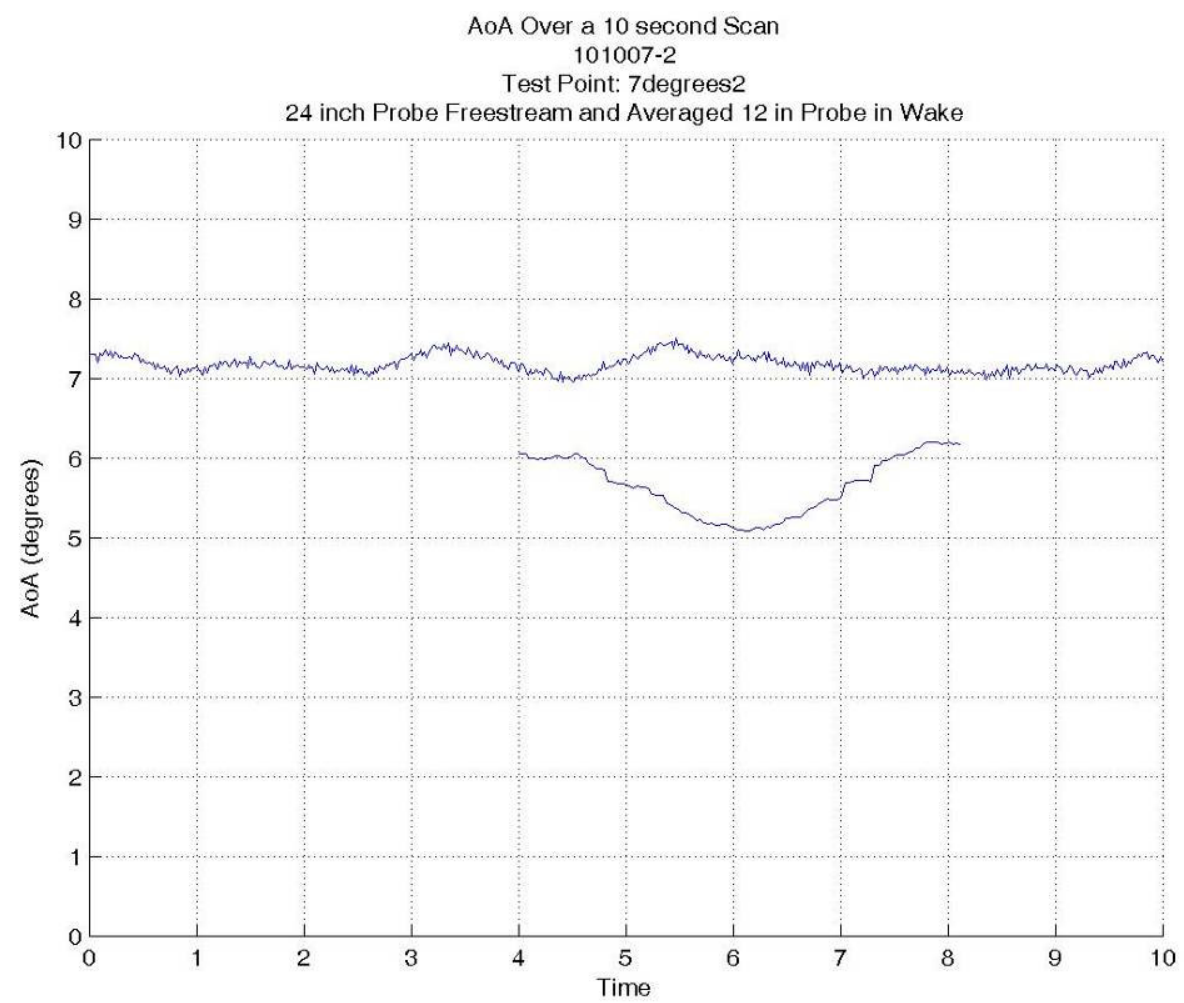

Total Pressure vs Rake Location for 101007-2

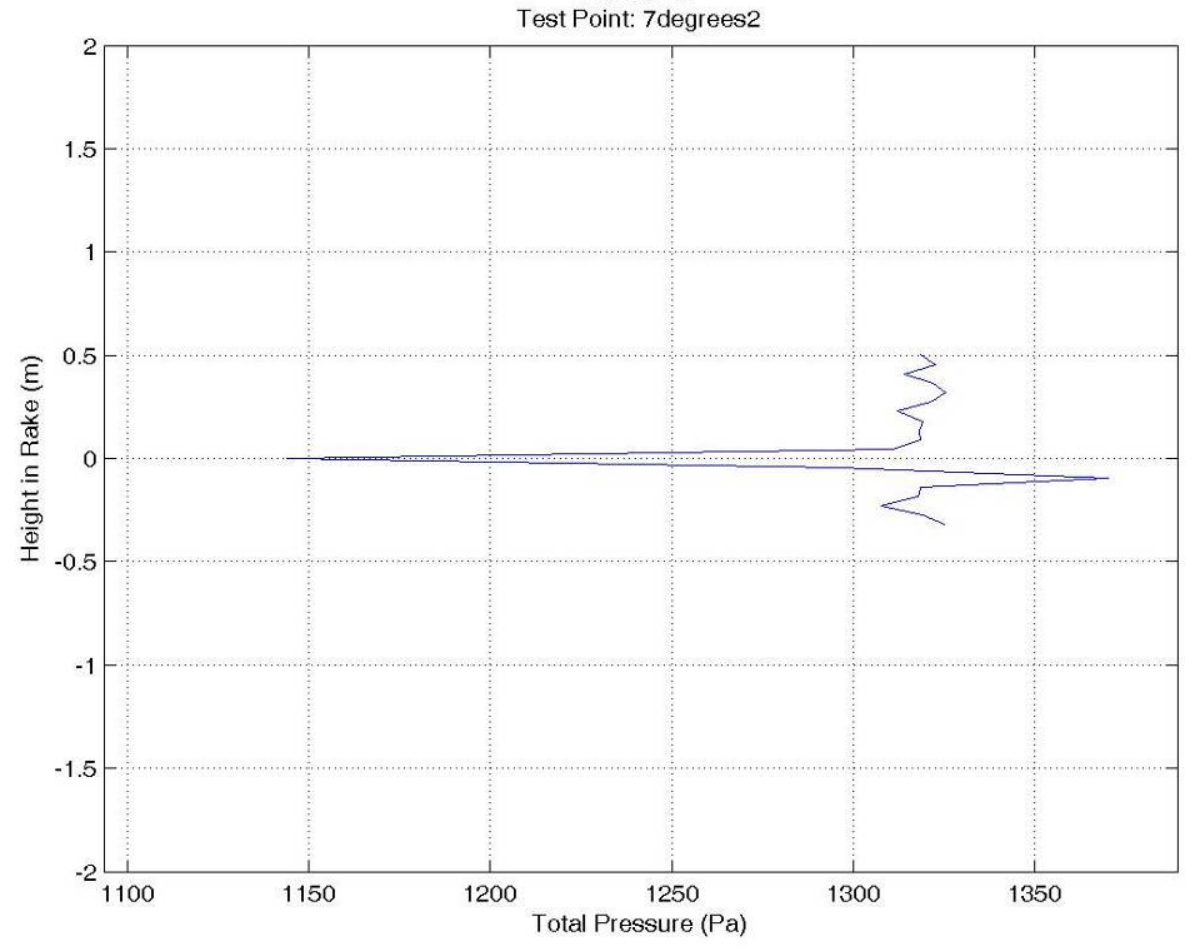

Figure A.116 Flight $101007-2$ at $7^{\circ} A o A, 105 \operatorname{KIAS}(54 \mathrm{~m} / \mathrm{s})$ at 8,500 feet 


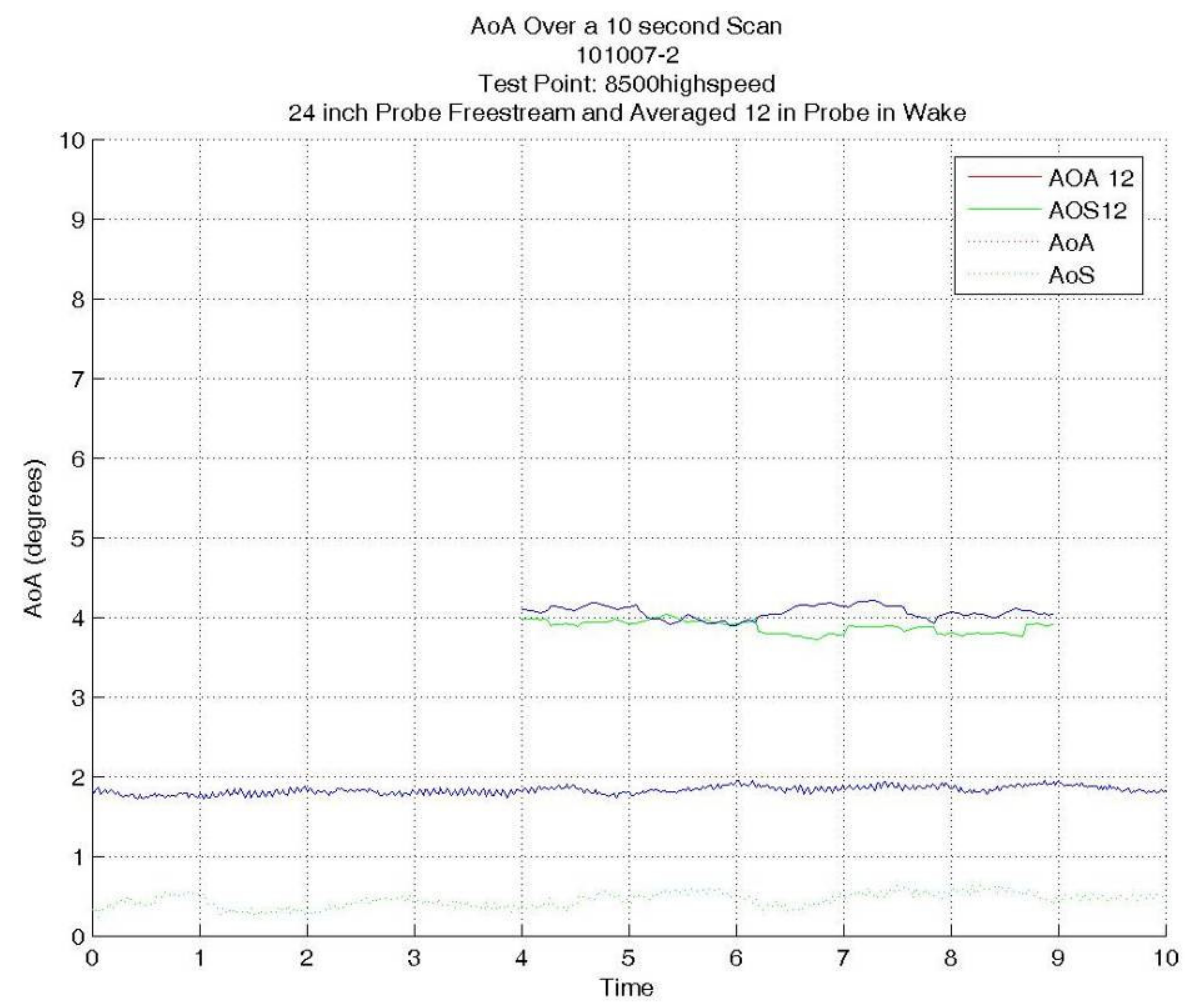

Total Pressure vs Rake Location for 101007-2

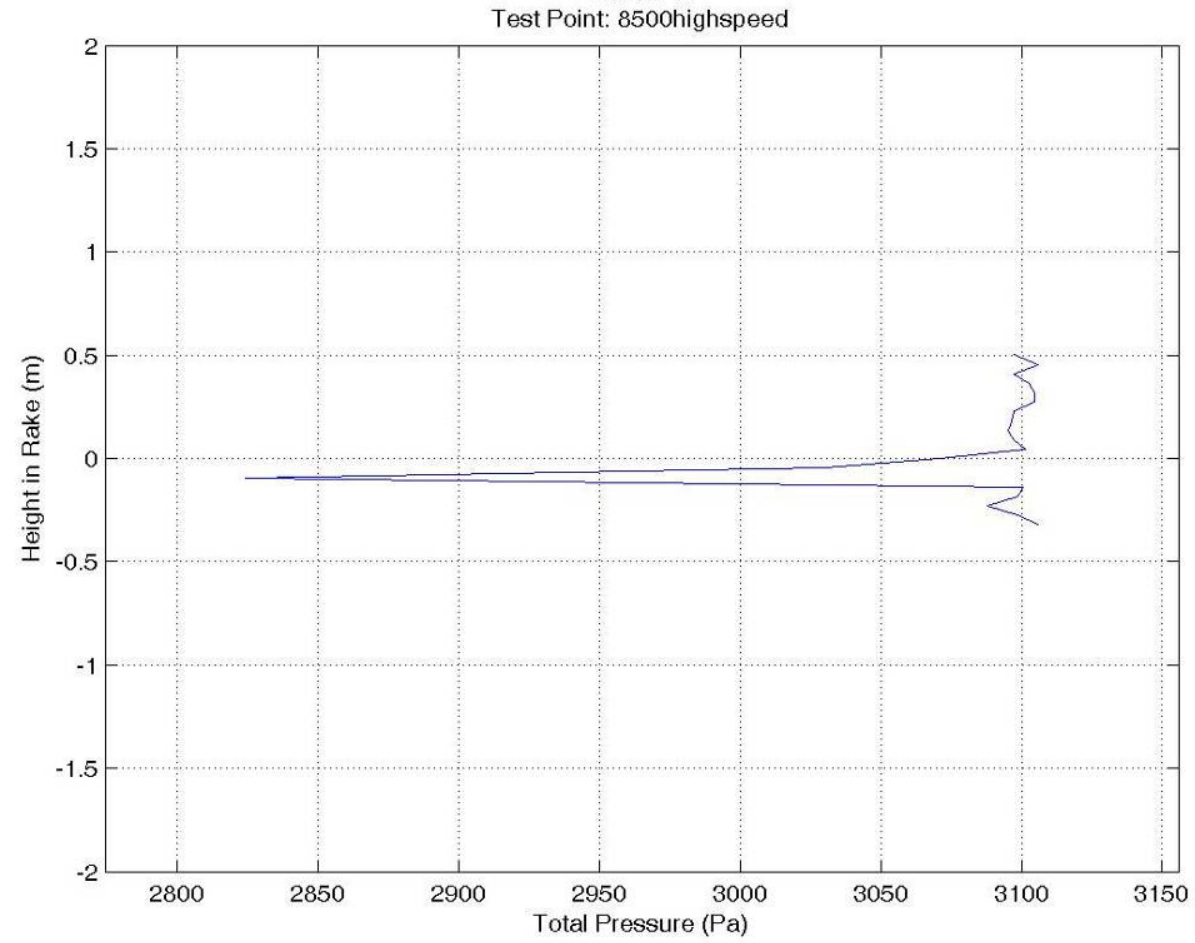

Figure A.117 Flight 101007-2 High-Speed Pass of 170 KIAS (87 m/s) at 8,500 feet 


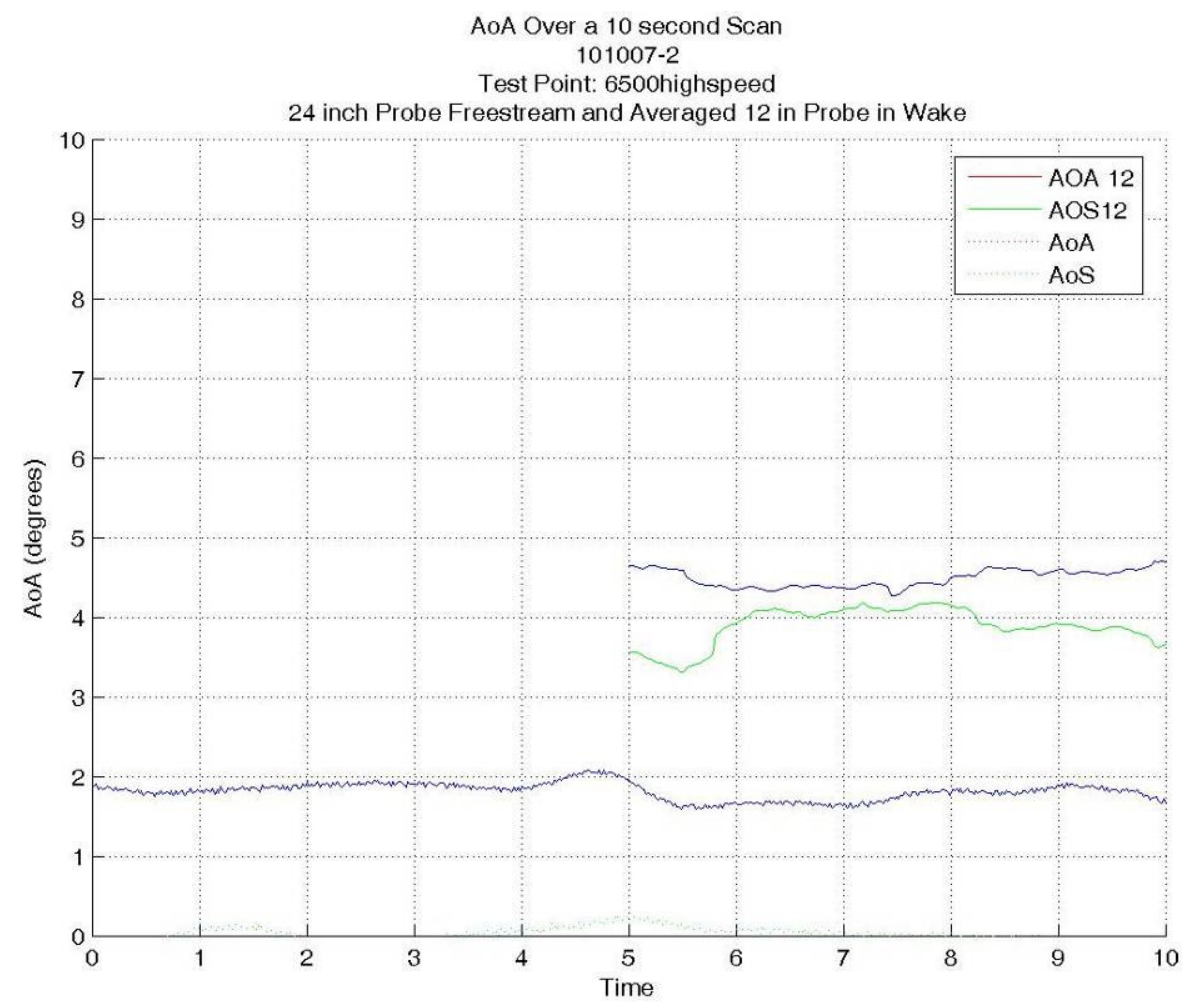

Total Pressure vs Rake Location for 101007-2

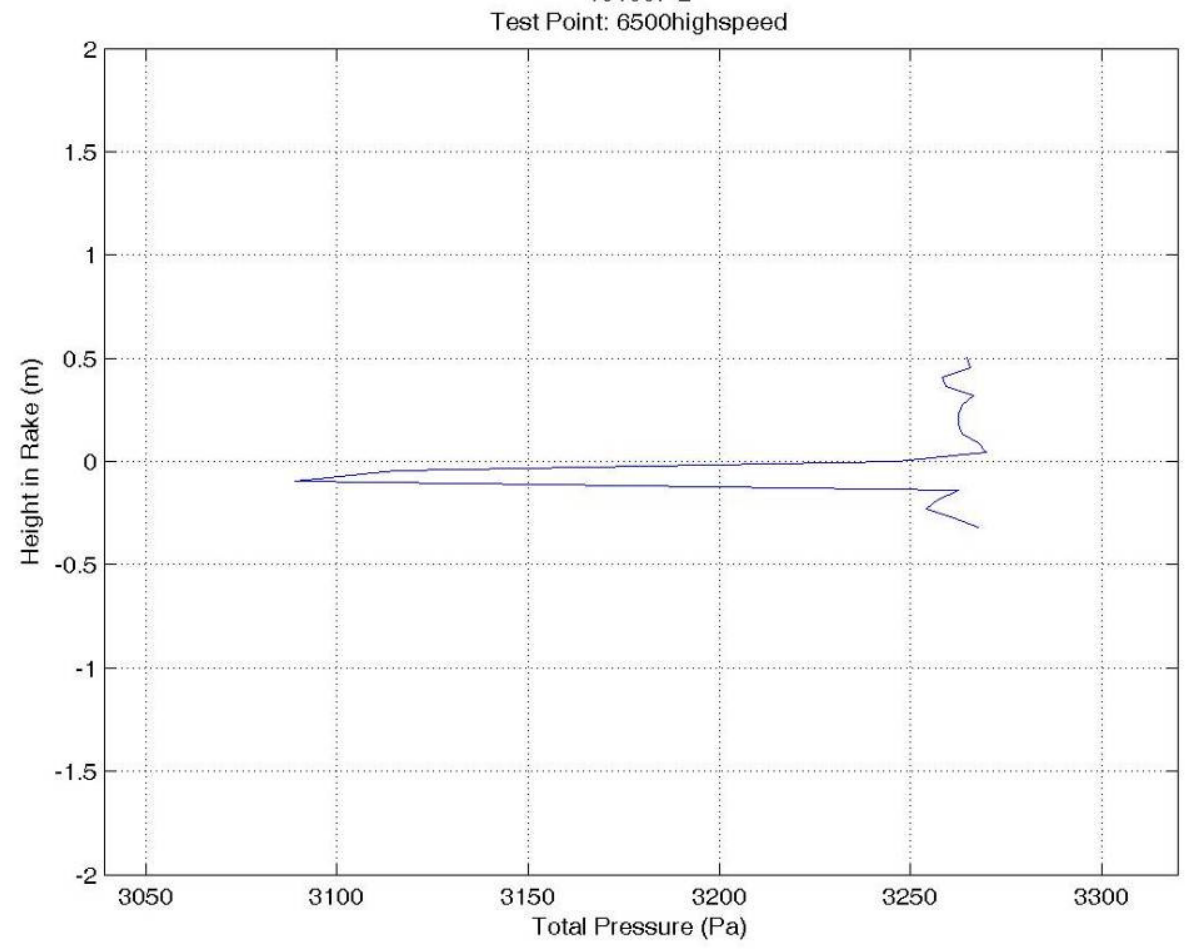

Figure A.118 Flight 101007-2 High-Speed Pass of 170 KIAS ( $87 \mathrm{~m} / \mathrm{s}$ ) at 6,500 feet 


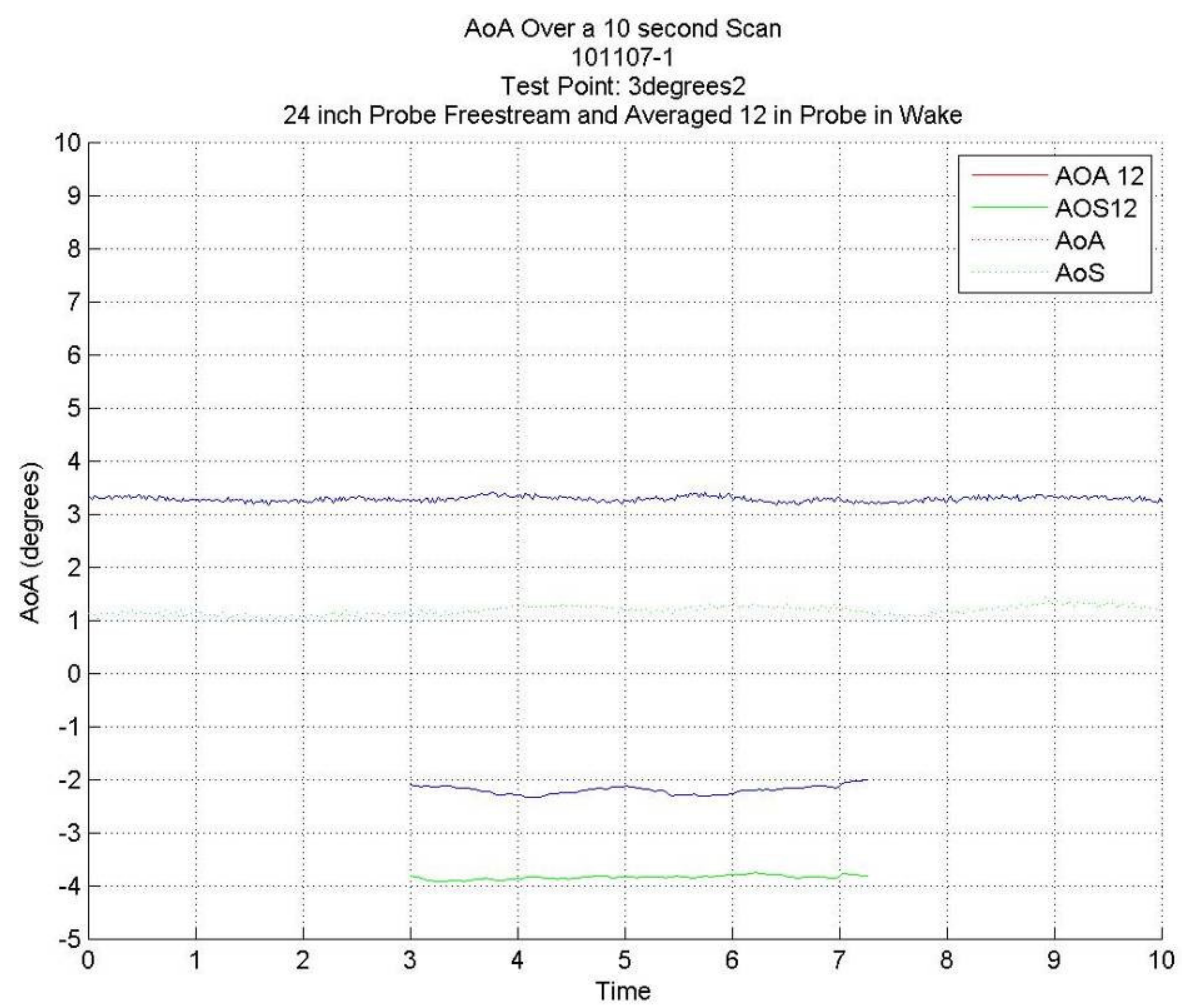

Total Pressure vs Rake Location for 101107-1

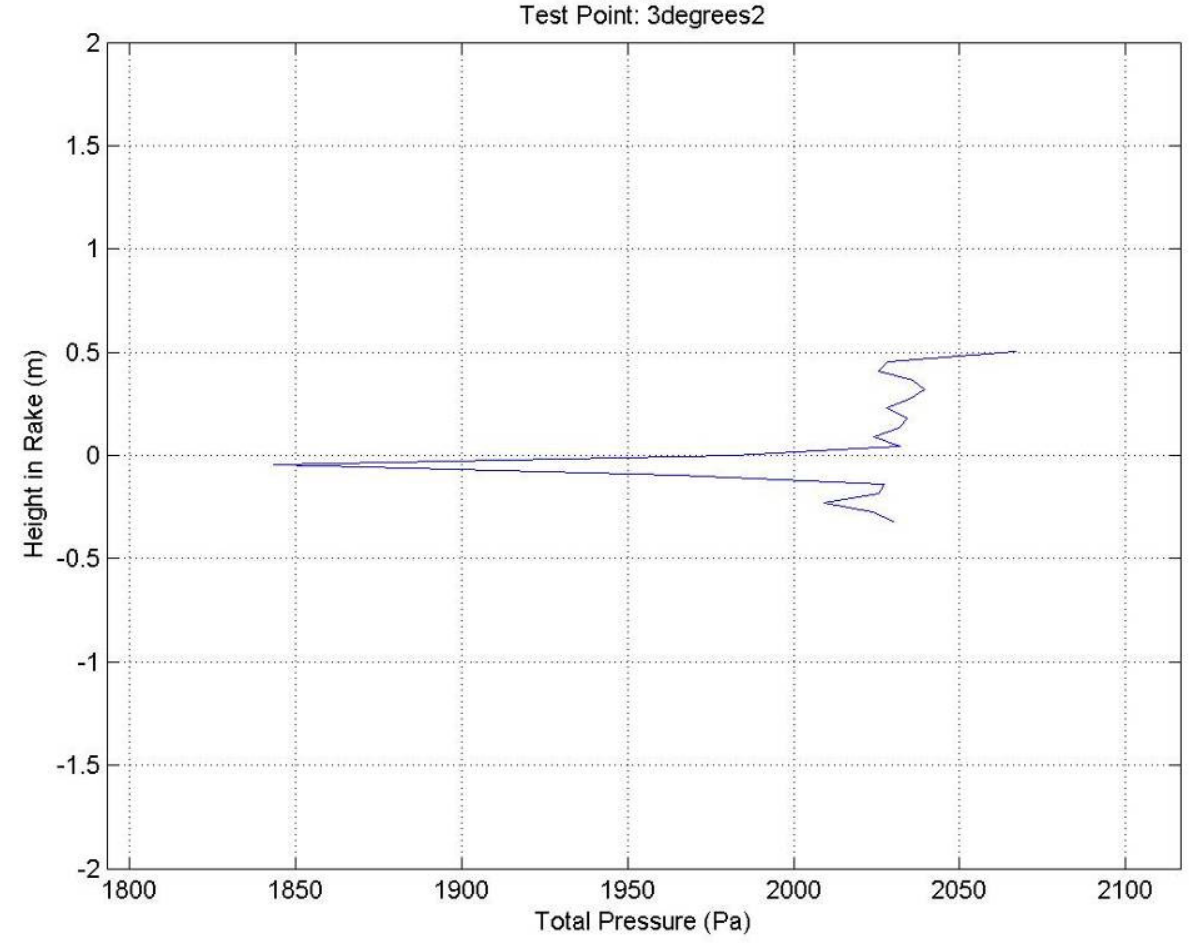

Figure A.119 Flight $101107-1$ at $3^{\circ} \mathrm{AoA}, 138 \mathrm{KIAS}(71 \mathrm{~m} / \mathrm{s})$ at 8,500 feet 

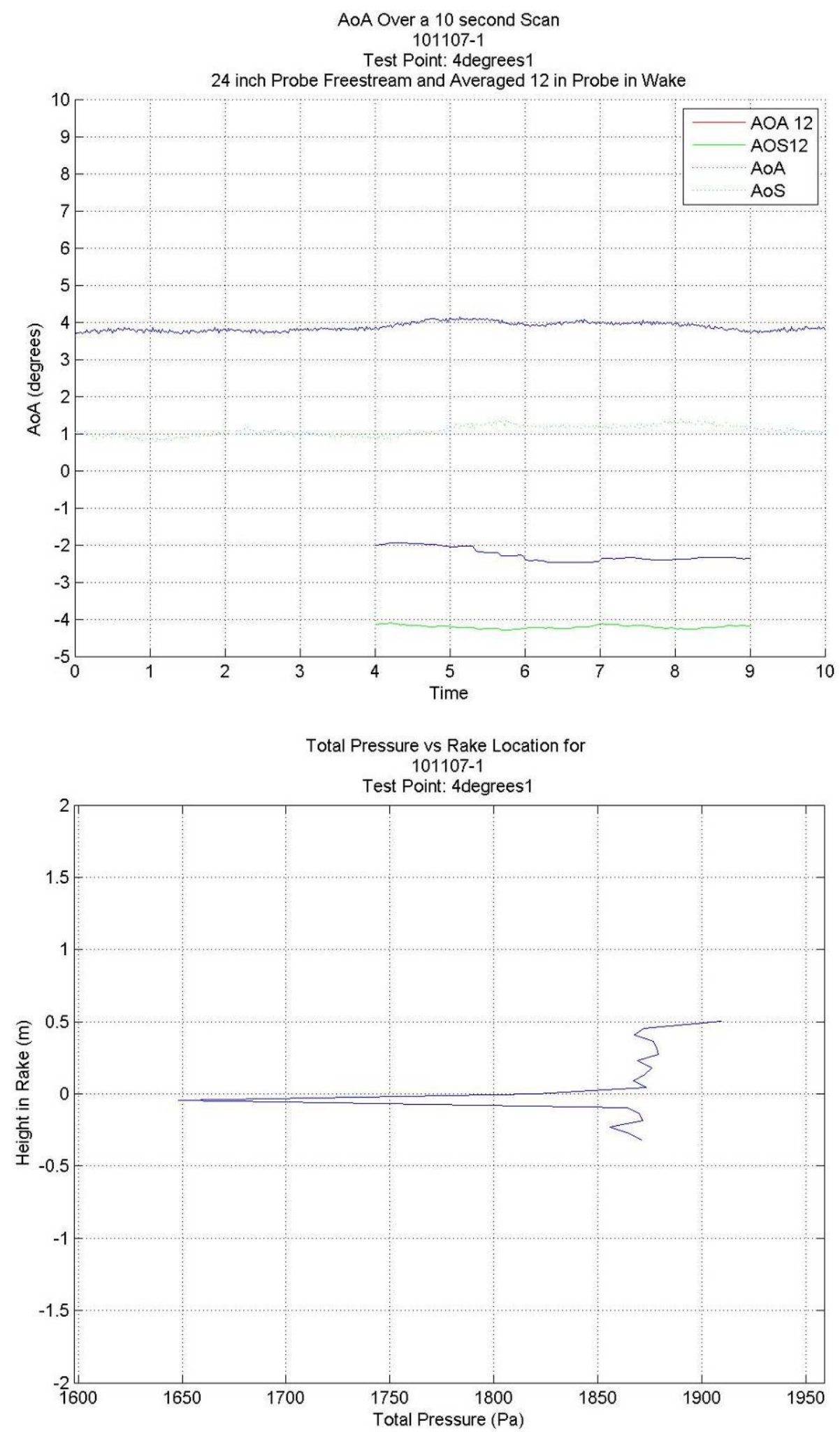

Figure A.120 Flight $101107-1$ at $4^{\circ} A o A, 128 \mathrm{KIAS}(66 \mathrm{~m} / \mathrm{s})$ at 8,500 feet 

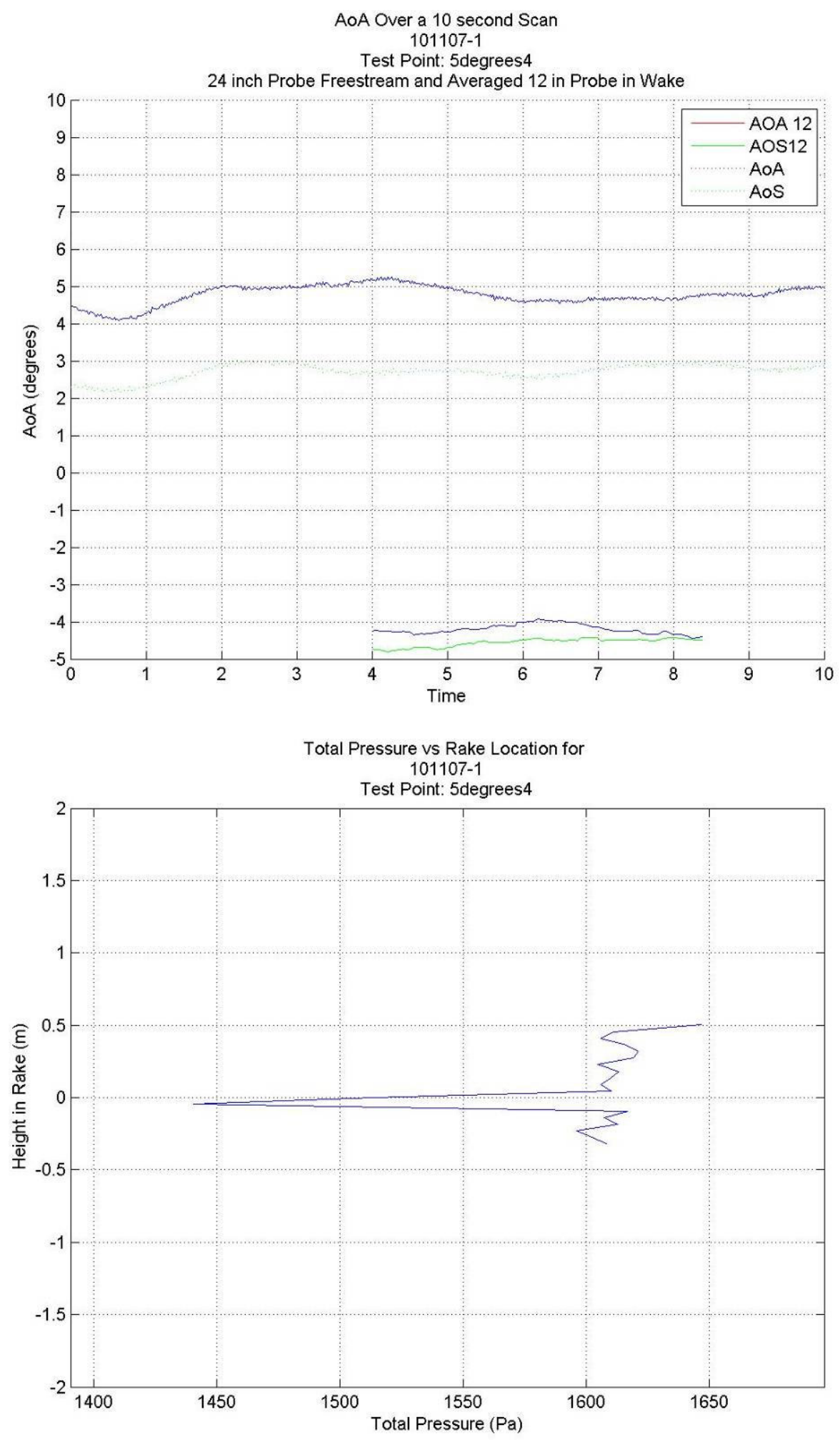

Figure A.121 Flight $101107-1$ at $5^{\circ} A o A, 123 \mathrm{KIAS}(63 \mathrm{~m} / \mathrm{s})$ at 8,500 feet 


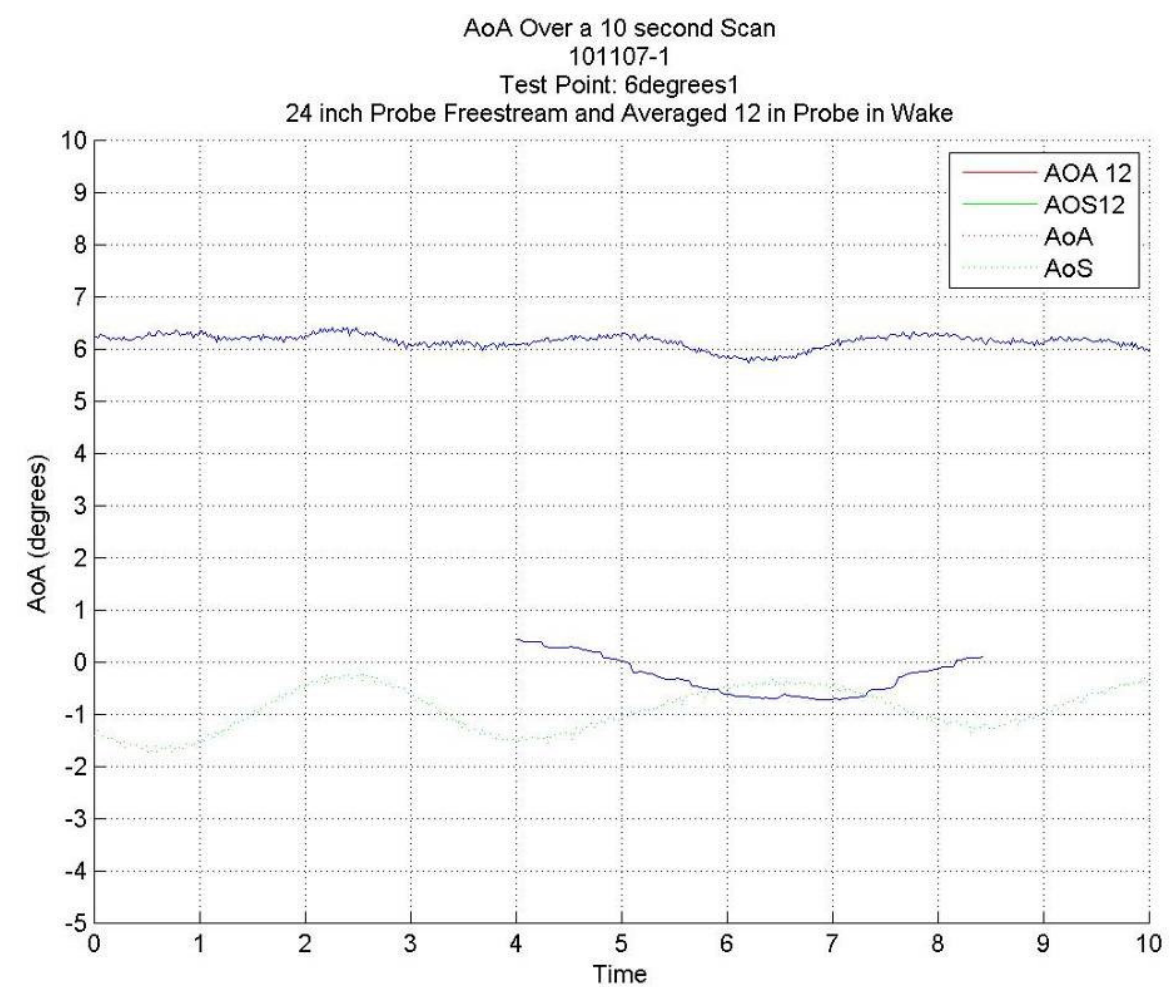

Total Pressure vs Rake Location for 101107-1

Test Point: 6degrees1

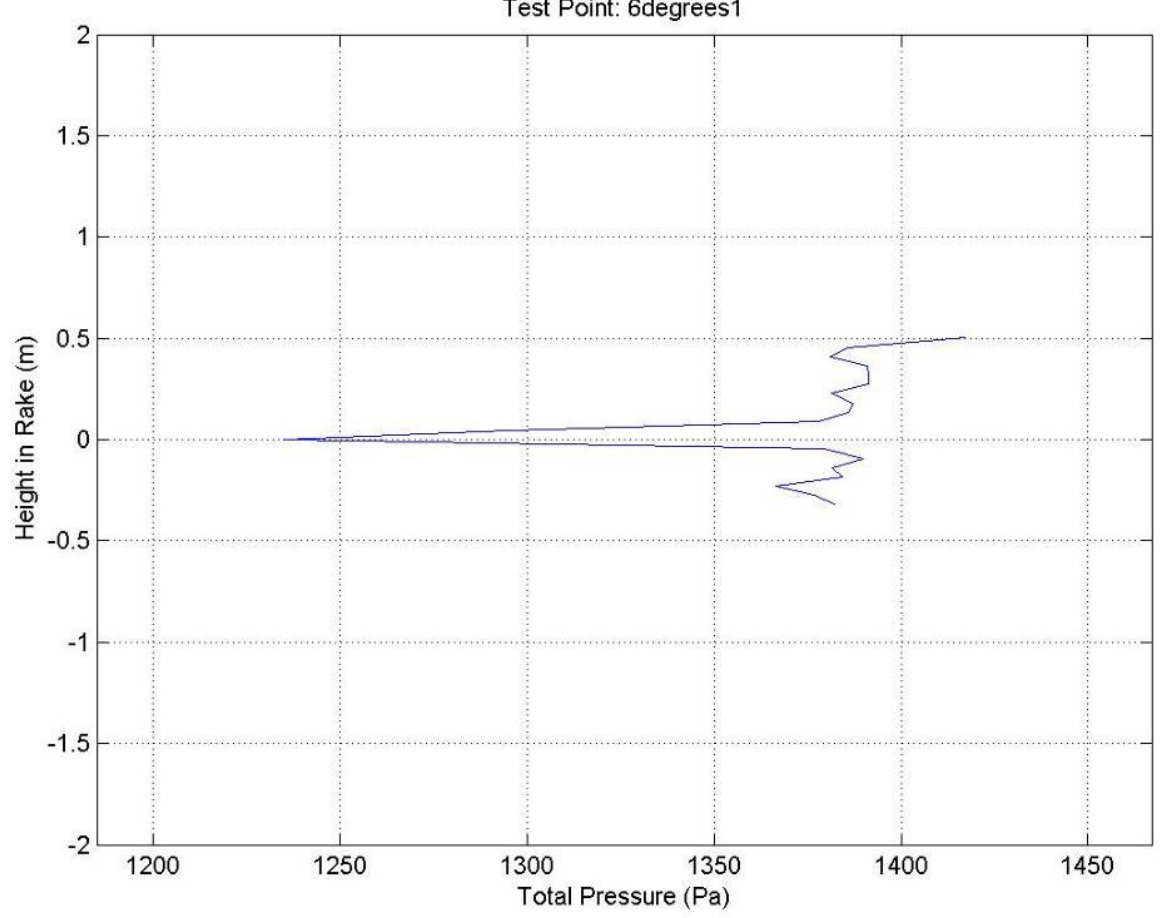

Figure A.122 Flight $101107-1$ at $6^{\circ} \mathrm{AoA}, 110 \mathrm{KIAS}(57 \mathrm{~m} / \mathrm{s})$ at 8,500 feet 


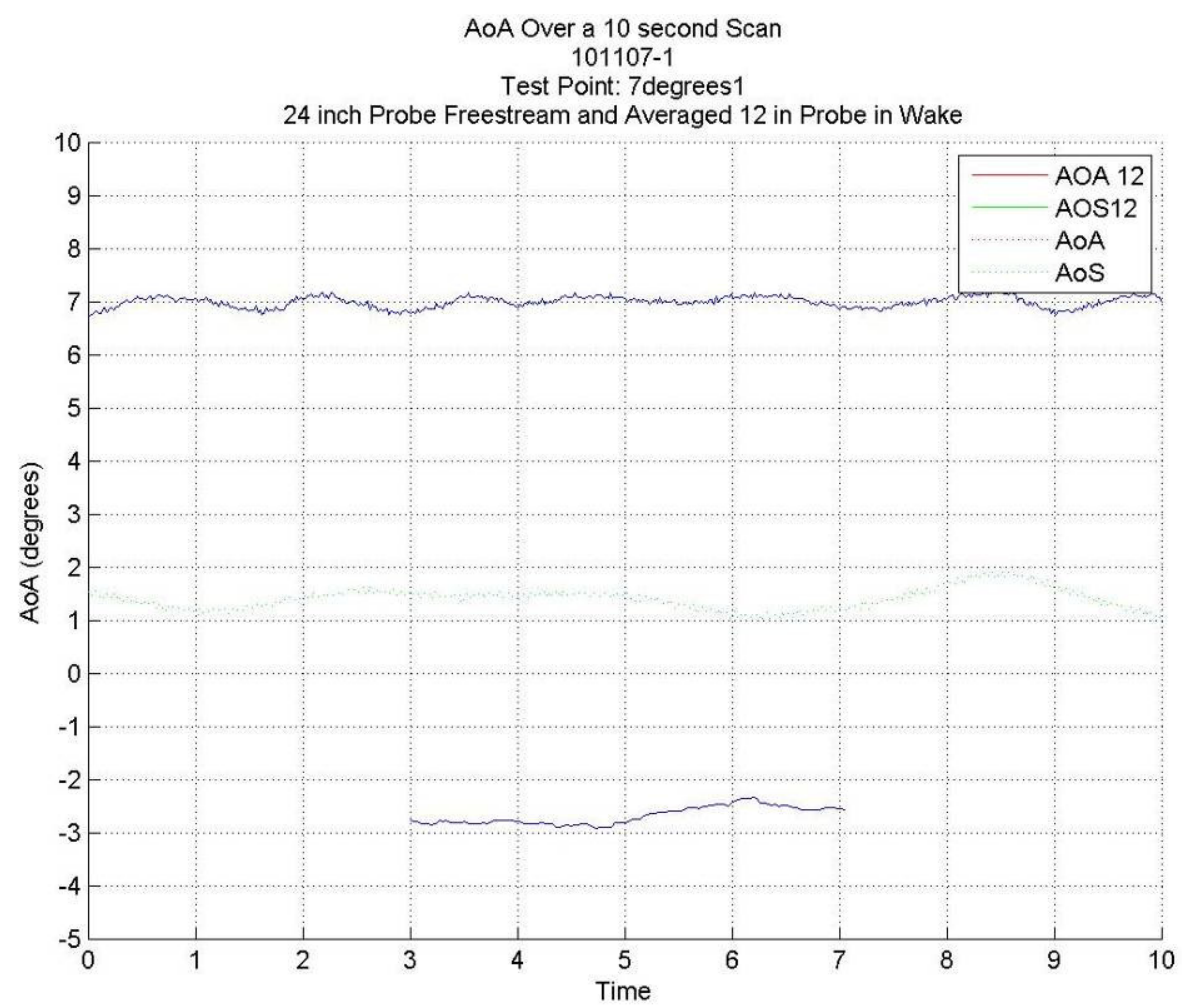

Total Pressure vs Rake Location for 101107-1

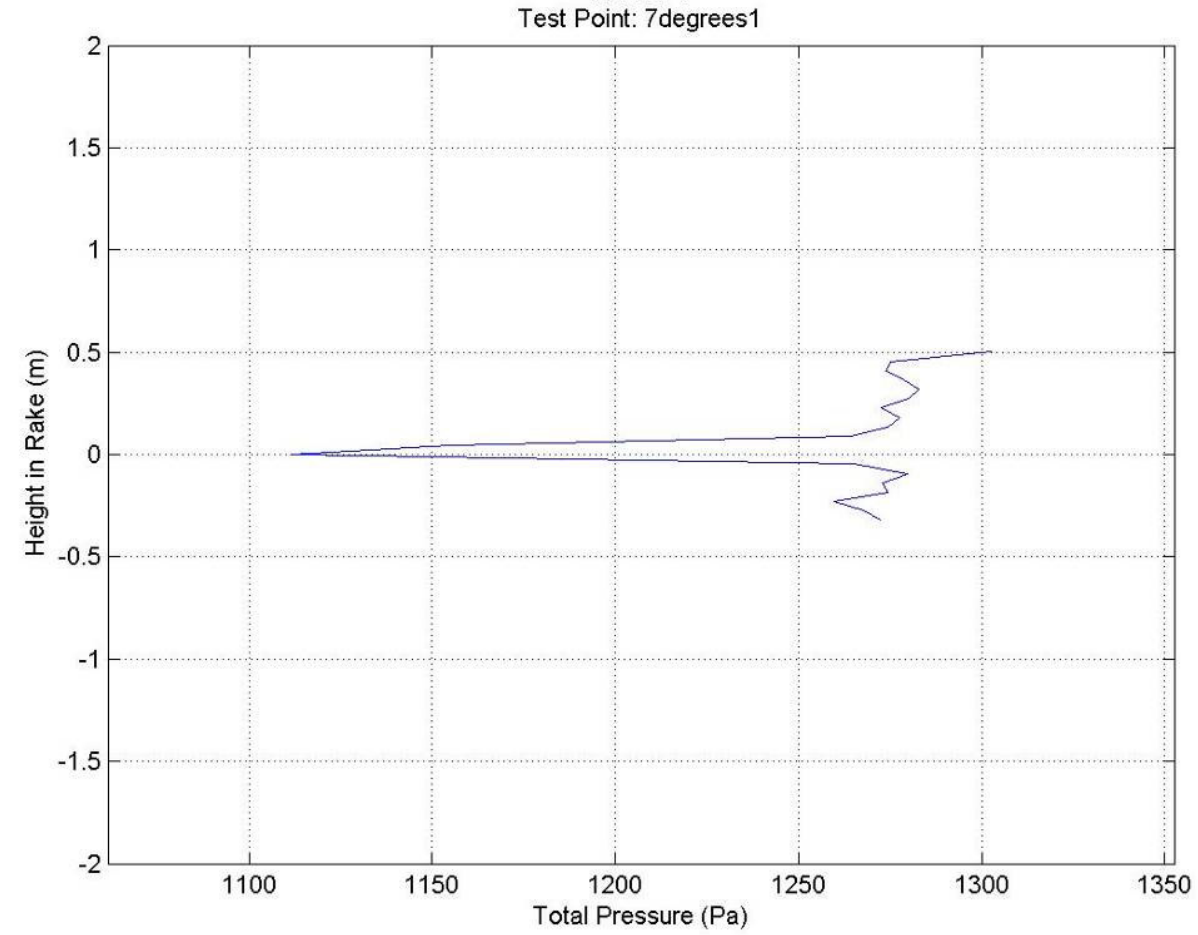

Figure A.123 Flight $101107-1$ at $7^{\circ} A o A, 105 \operatorname{KIAS}(54 \mathrm{~m} / \mathrm{s})$ at 8,500 feet 

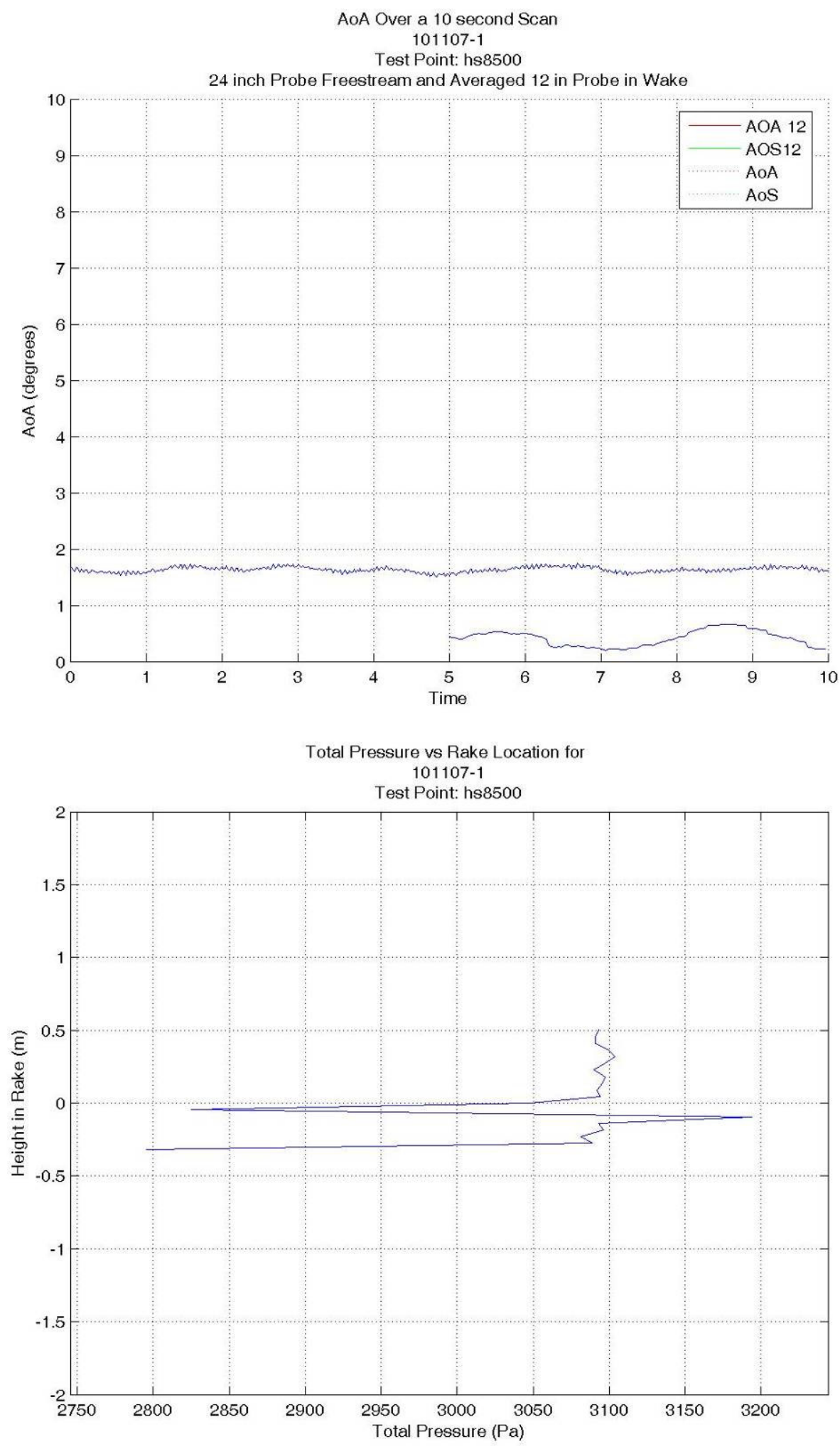

Figure A.124 Flight 101107-1 High-Speed Pass of 170 KIAS (87 m/s) at 8,500 feet 


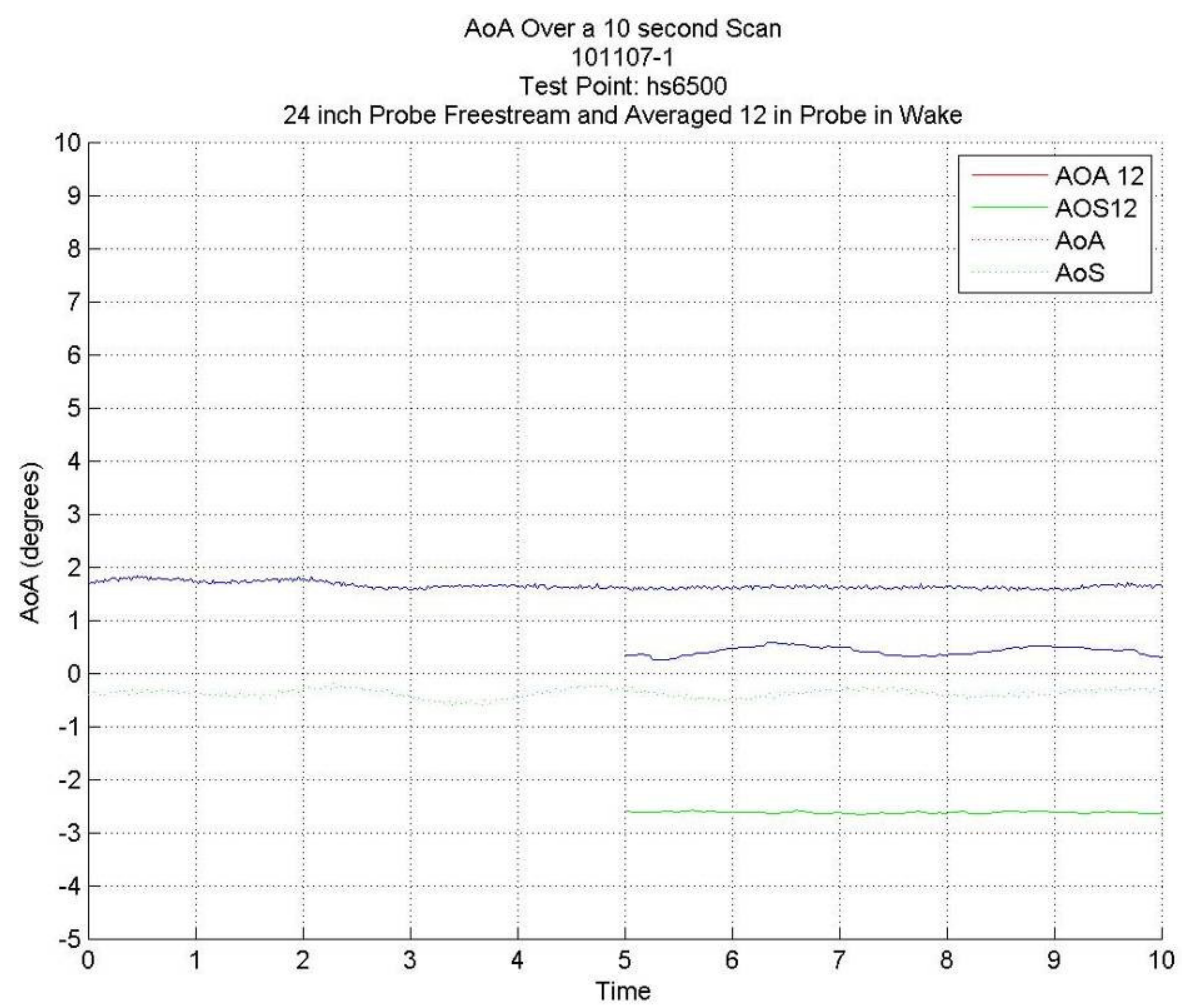

Total Pressure vs Rake Location for 101107-1

Test Point: hs6500

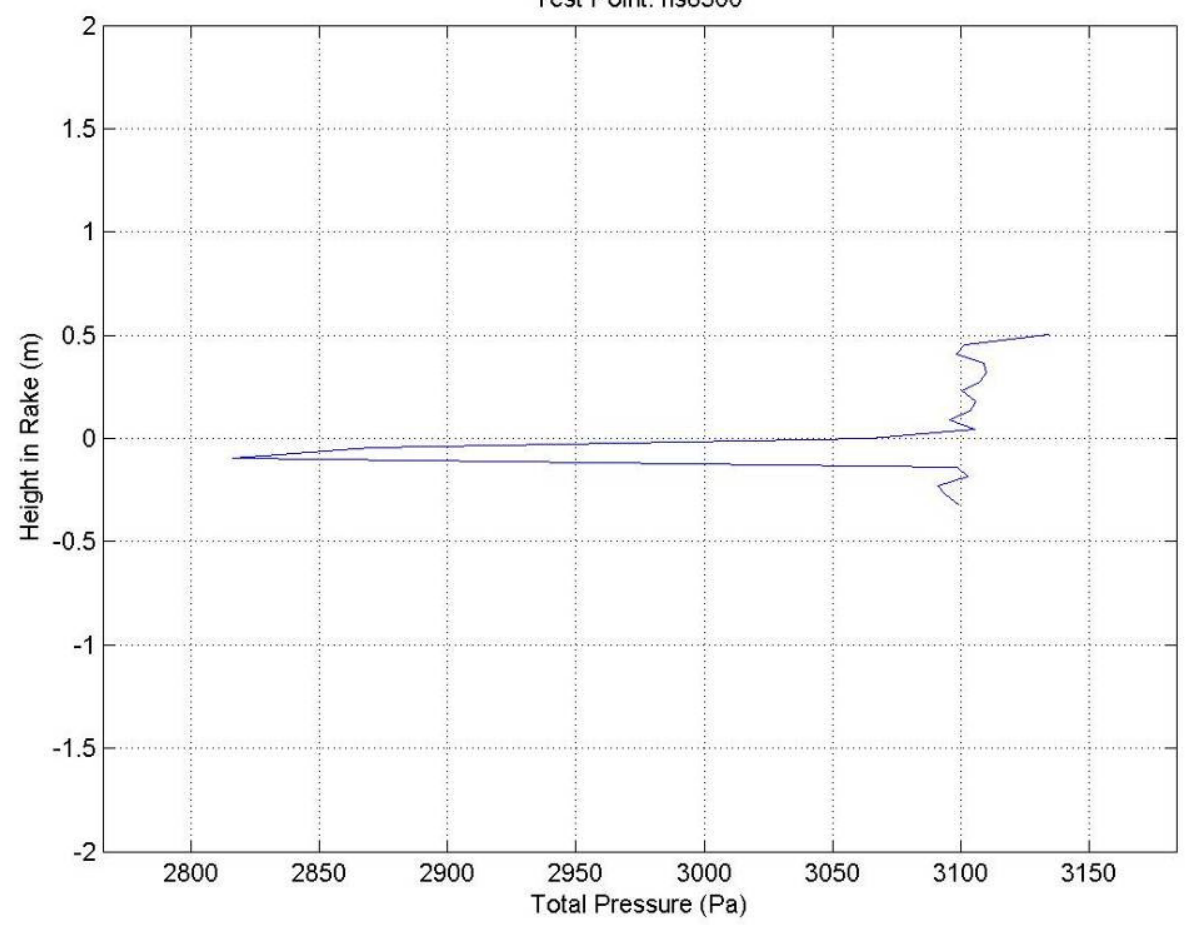

Figure A.125 Flight 101107-1 High-Speed Pass of 170 KIAS (87 m/s) at 6,500 feet 


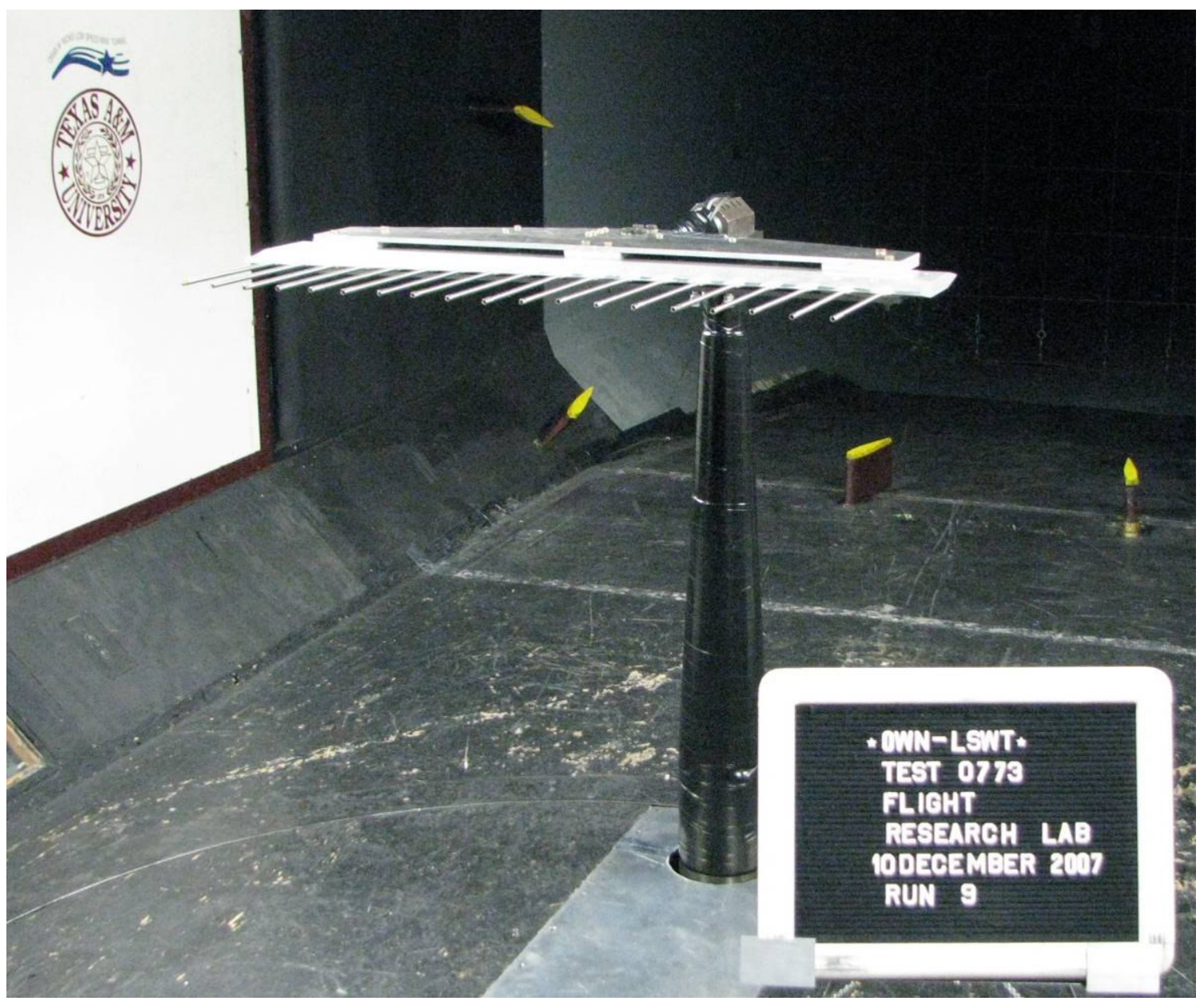

Figure A.126 Pressure Rake Mounted in the Oran W. Nicks Low Speed Wind Tunnel at $0^{\circ} A o A$ and $0^{\circ} A o S$ (Courtesy of Oran W. Nicks Low Speed Wind Tunnel) 


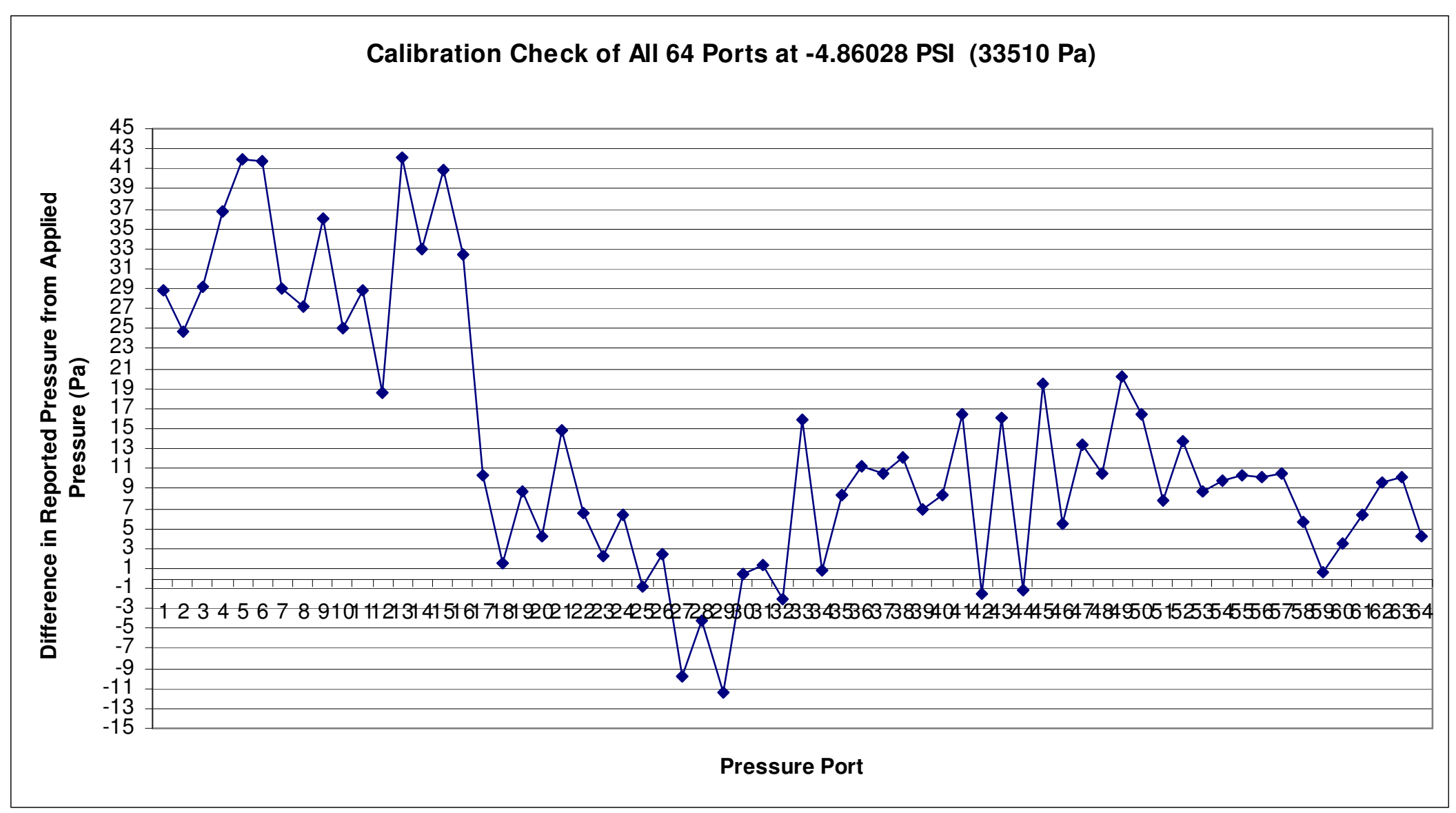

Figure A.127 Error during Calibration Check at $-34 \mathrm{kPa}$ (-5 PSI) Prior to Wind Tunnel Tests 


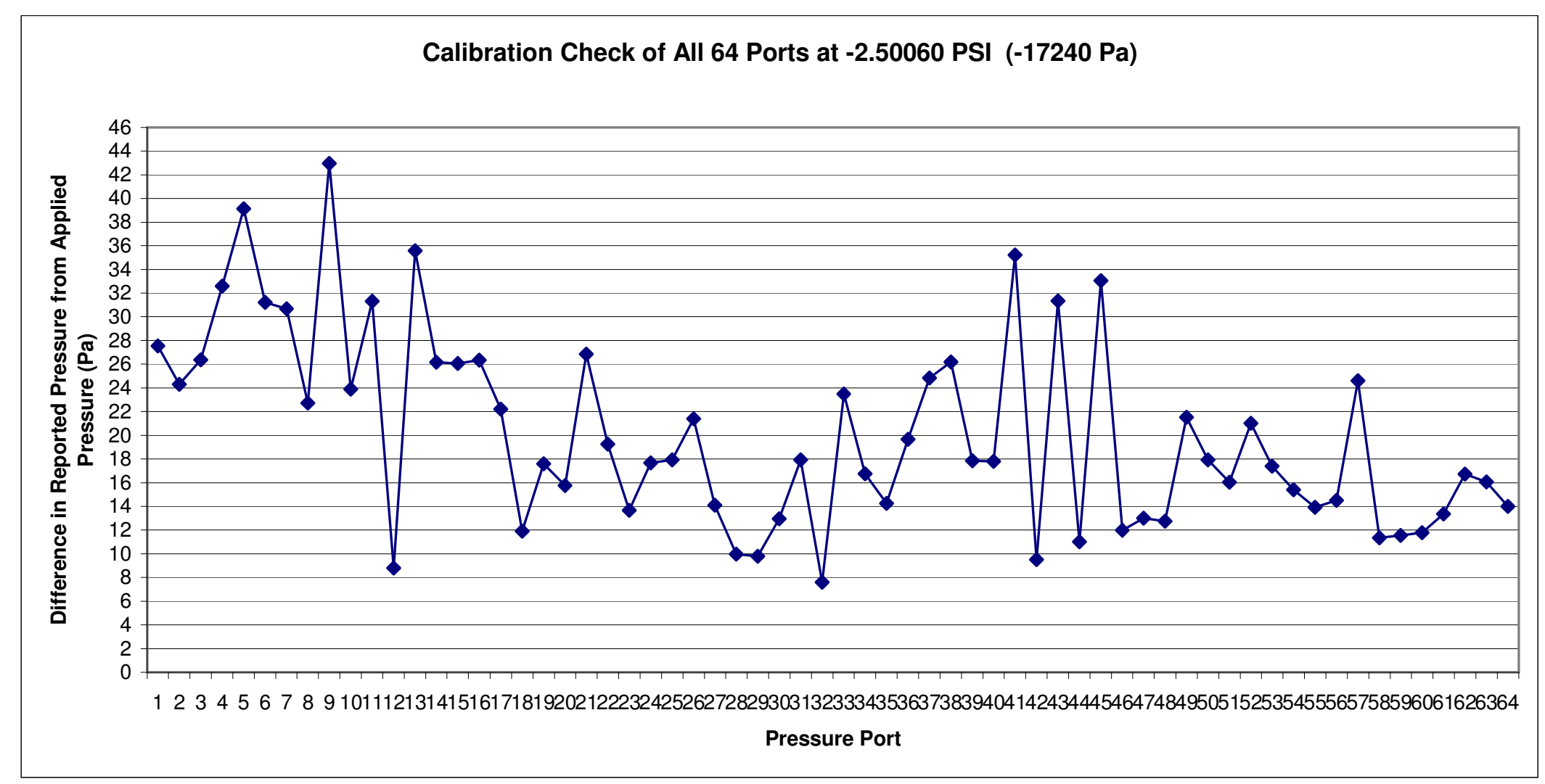

Figure A.128 Error during Calibration Check at $-17 \mathrm{kPa}$ (-2.5 PSI) Prior to Wind Tunnel Tests 


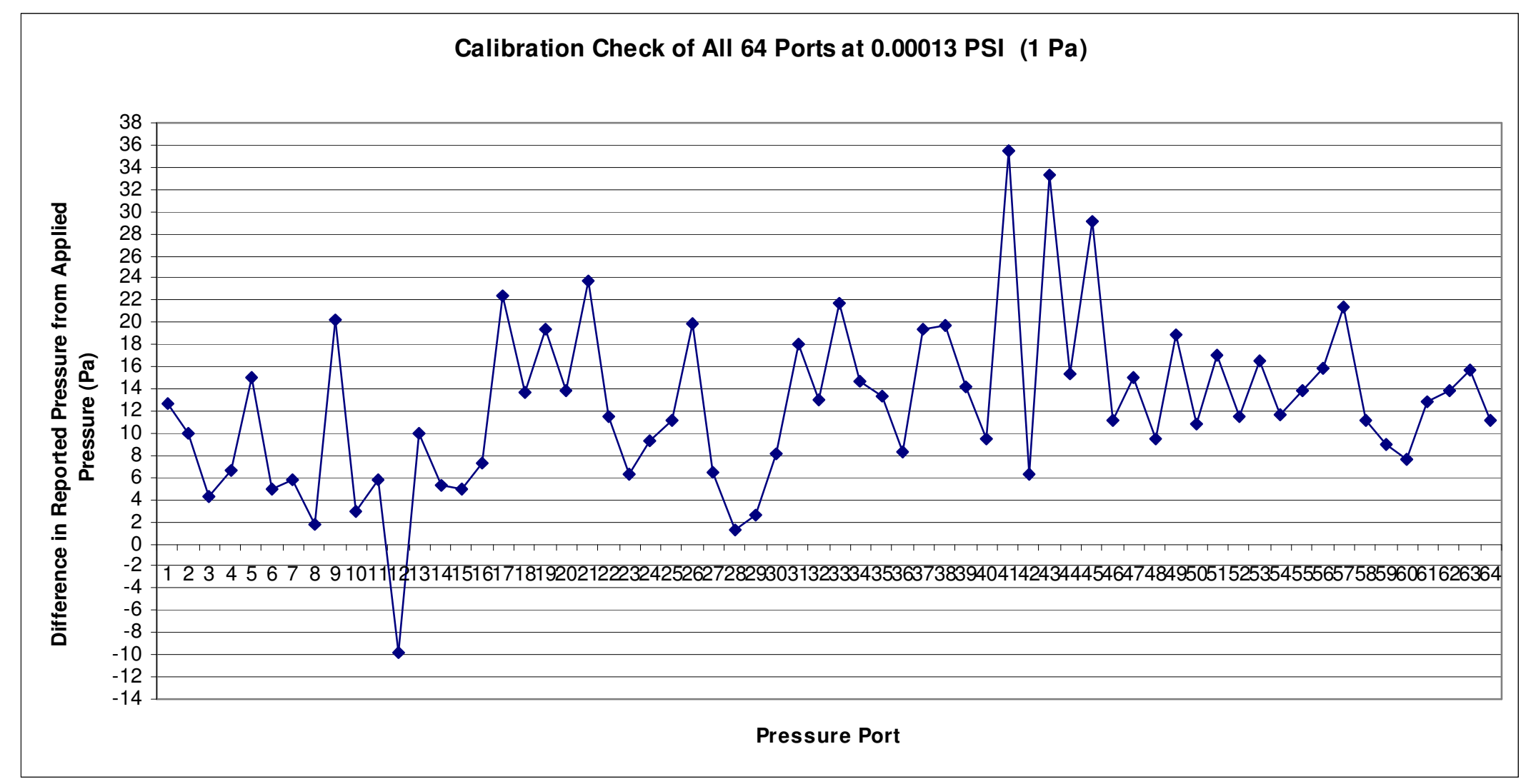

Figure A.129 Error during Calibration Check at $0 \mathrm{kPa}$ (0 PSI) Prior to Wind Tunnel Tests 


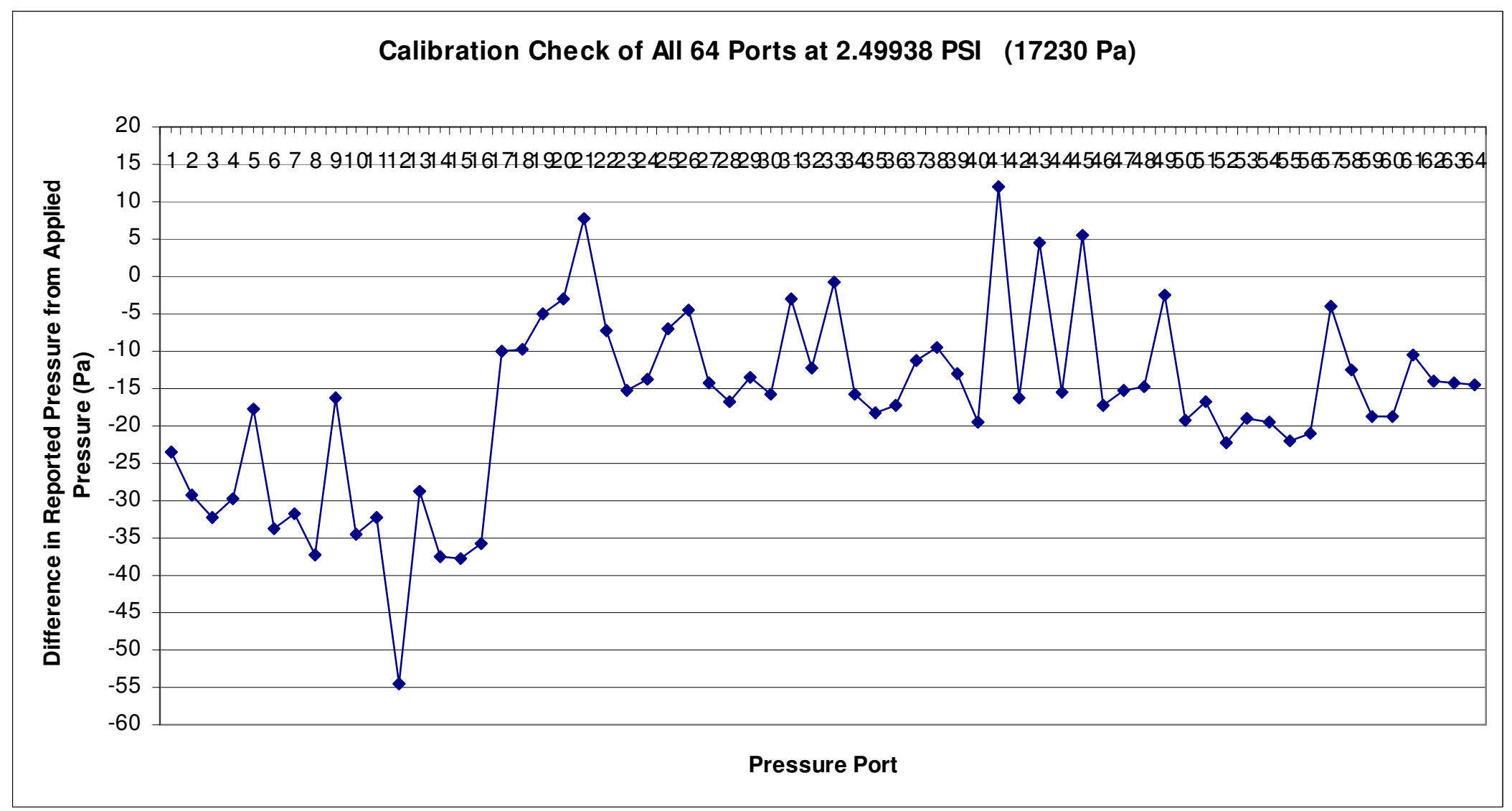

Figure A.130 Error during Calibration Check at $17 \mathrm{kPa}$ (2.5 PSI) Prior to Wind Tunnel Tests 


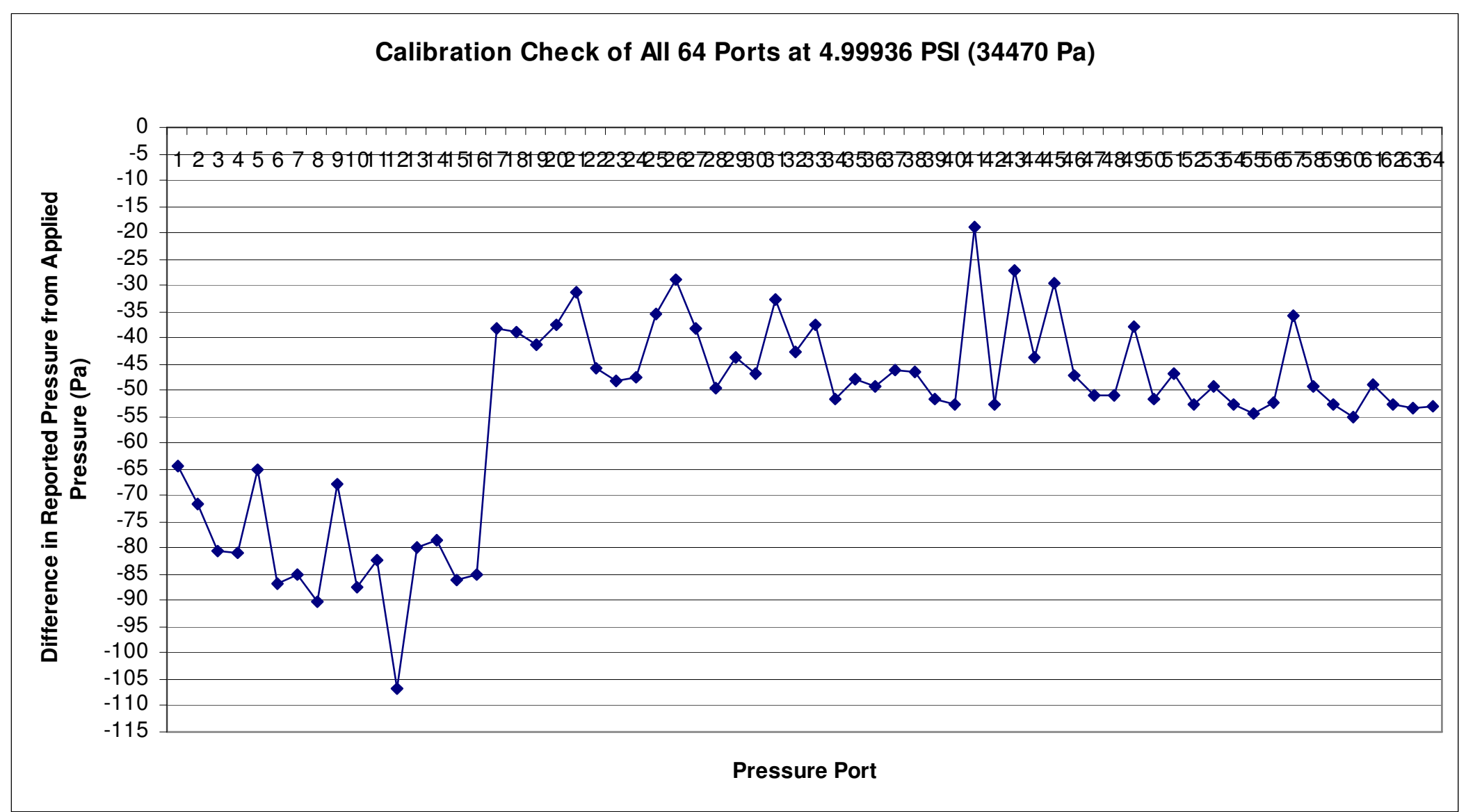

Figure A.131 Error during Calibration Check at 34 kPa (5 PSI) Prior to Wind Tunnel Tests 


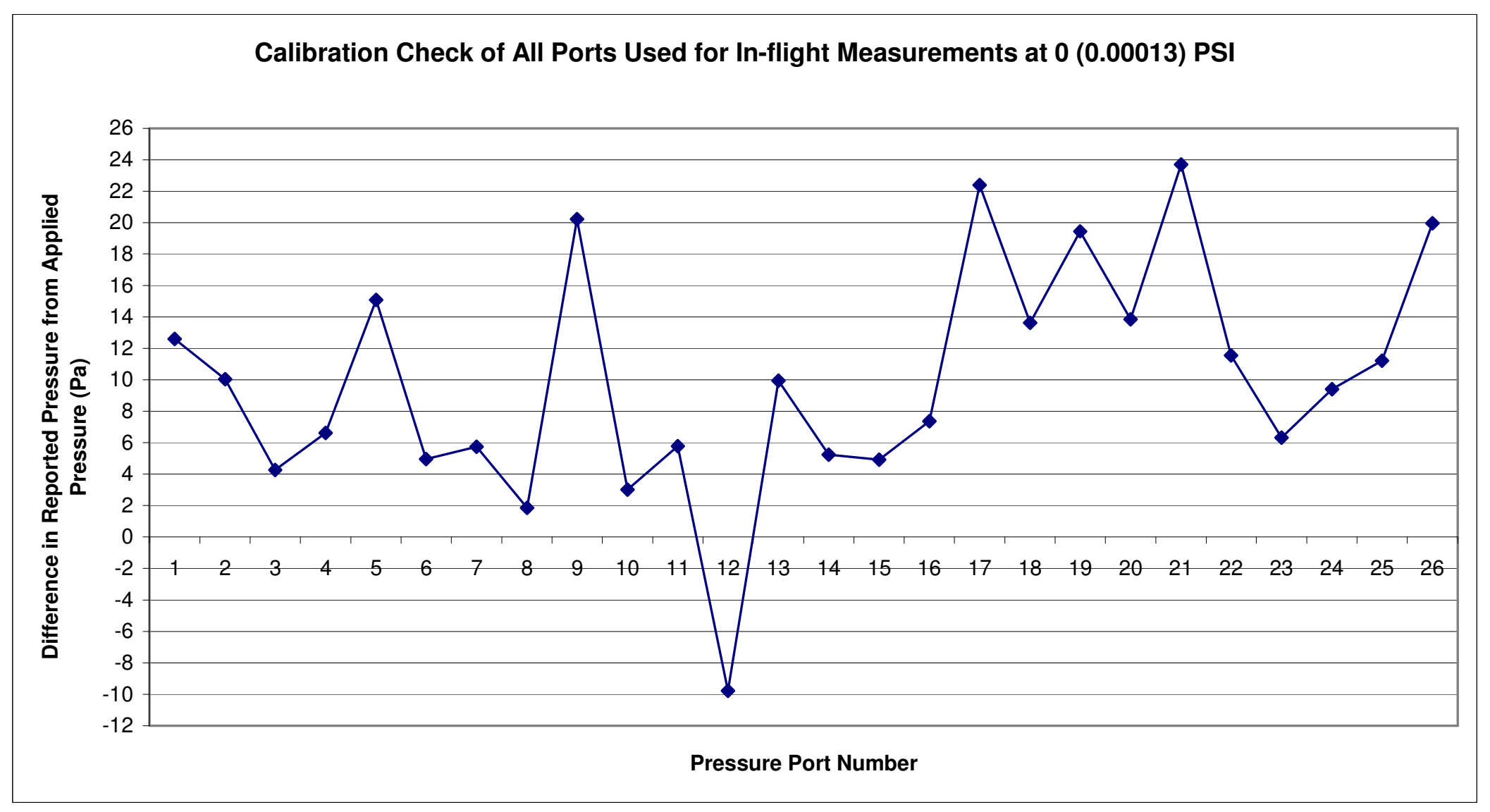

Figure A.132 Error during Calibration Check at $0 \mathrm{kPa}$ (0 PSI) of the Pressure Ports Used in the Flight Experiment

Prior to Wind Tunnel Tests 


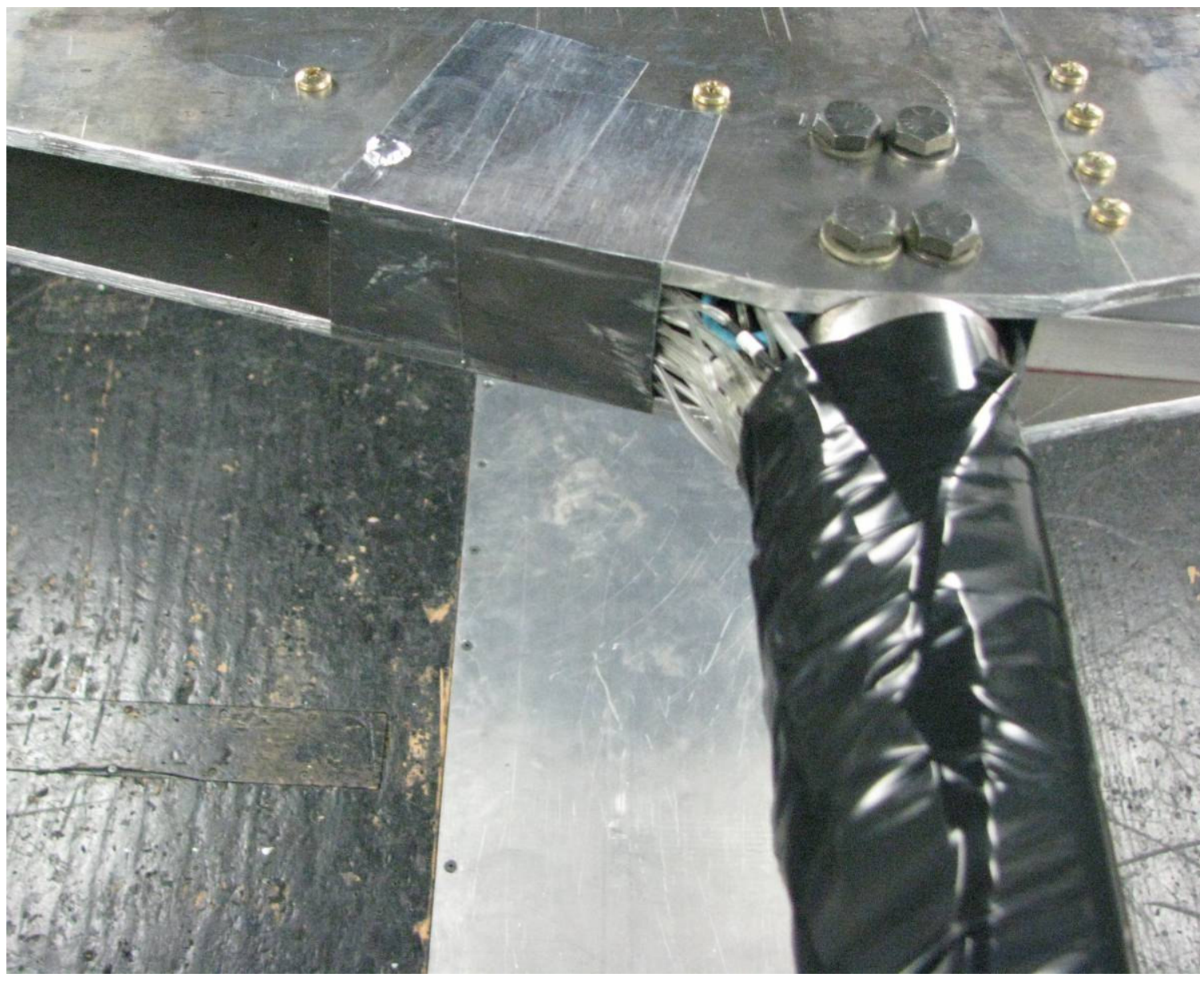

Figure A.133 Mounting of Pressure Rake to the Sting with Pressure Lines and Data Cables Secured in the Wind Tunnel 


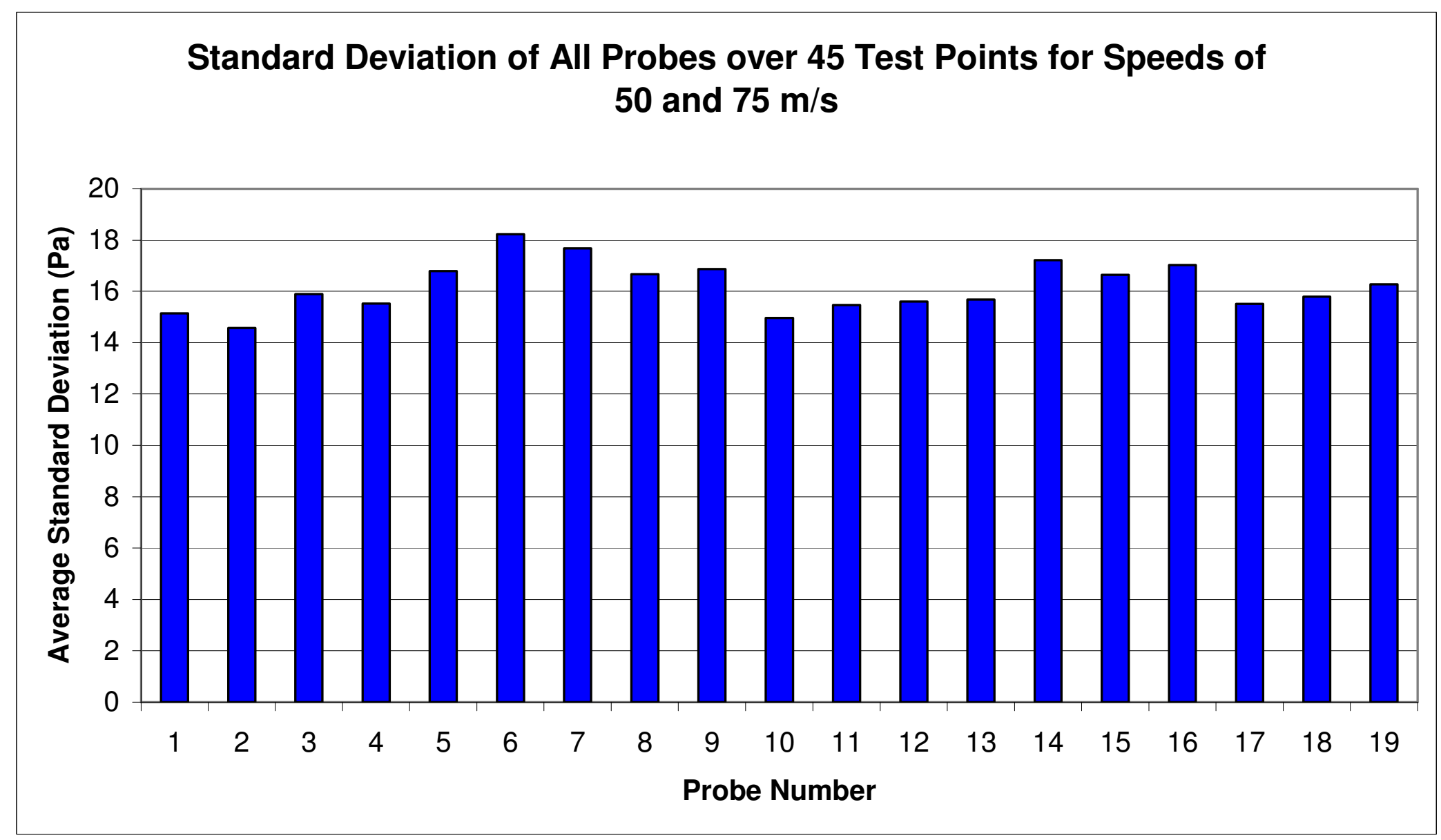

Figure A.134 Average Standard Deviation of All Probes in the Pressure Rake 


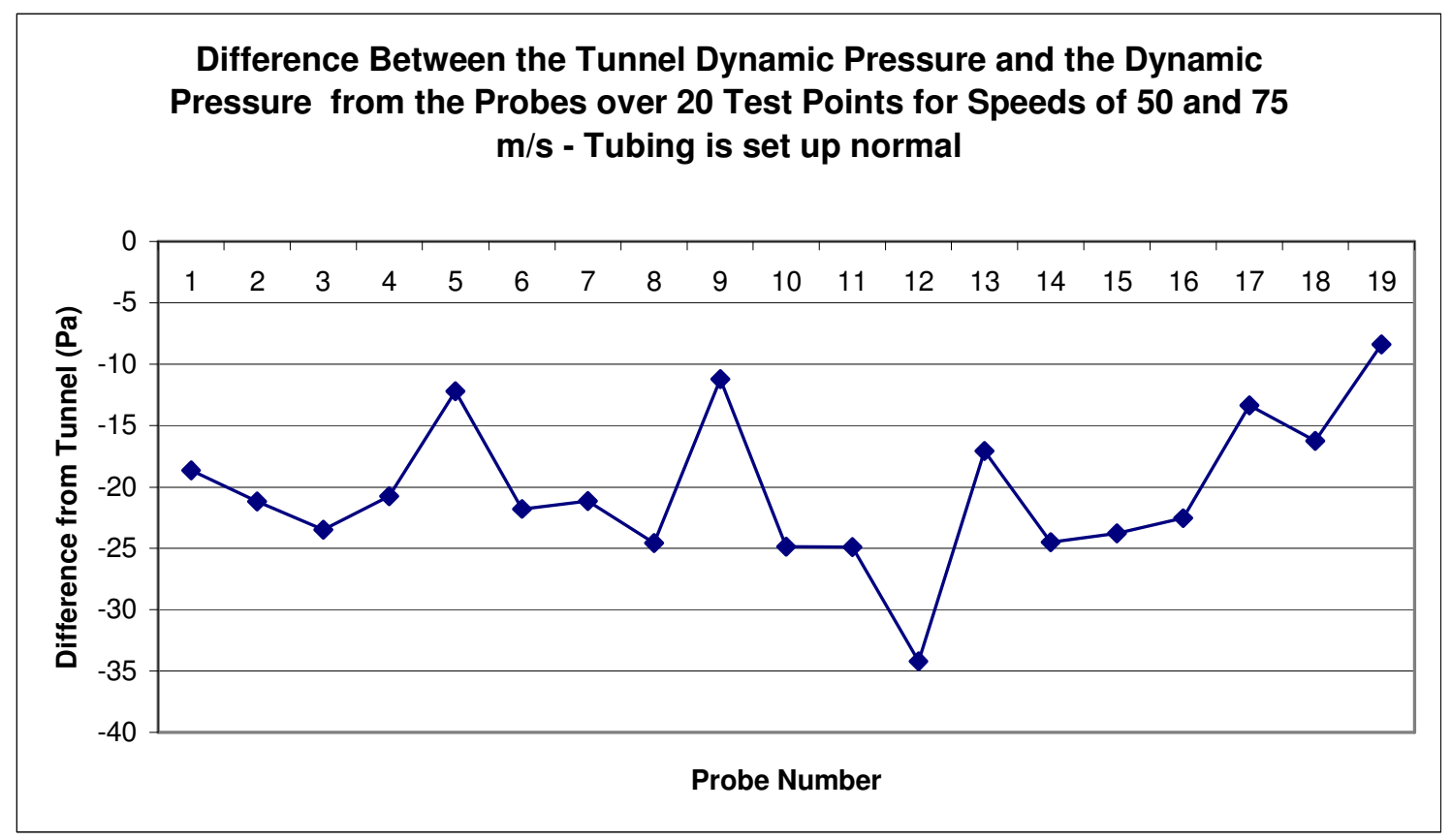

(a)

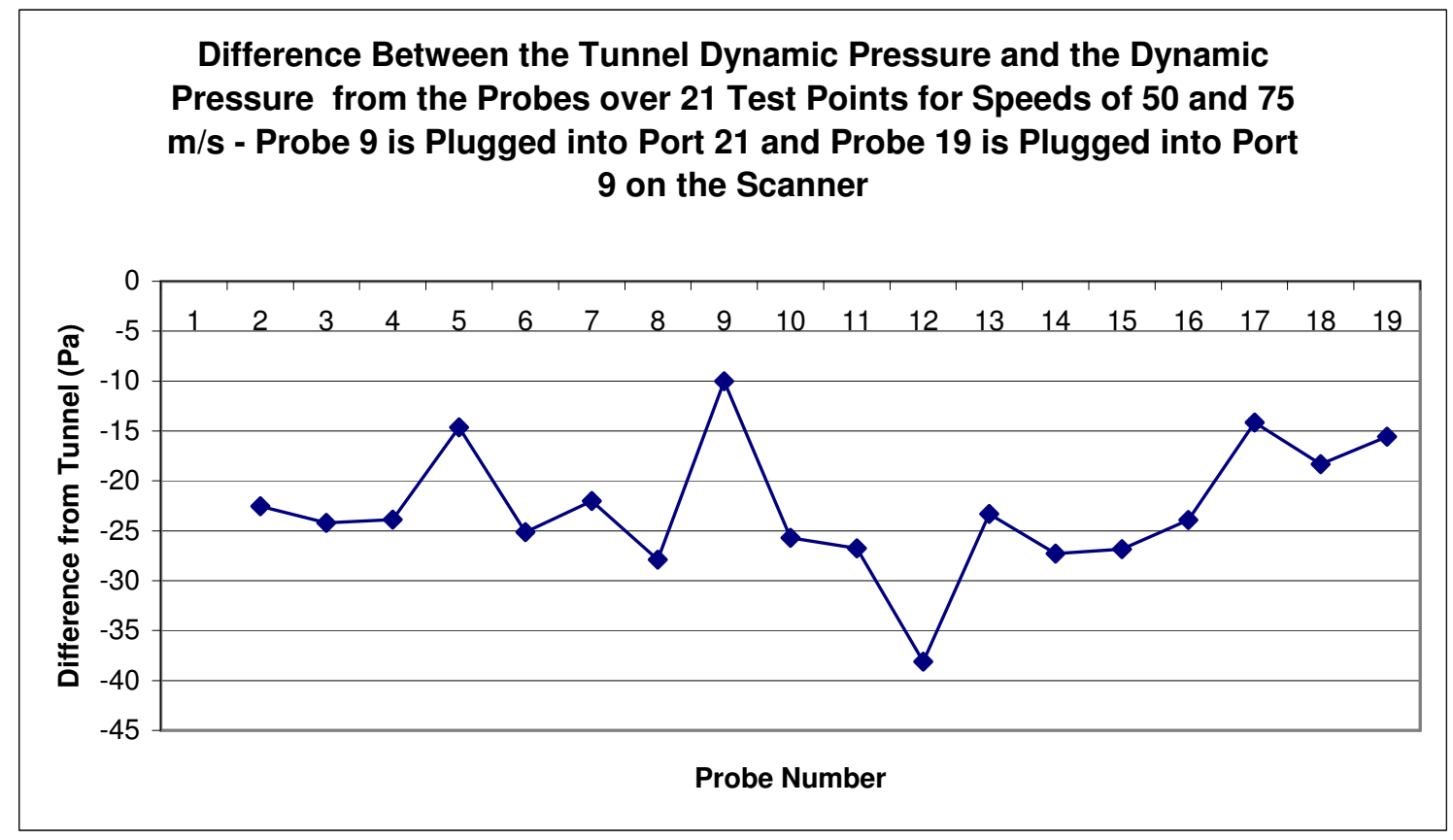

(b)

Figure A.135 Results of Simulations Aimed at Testing the Average Offset of Port \#21, Used as the 5-hole Total Pressure during the Flight Tests 


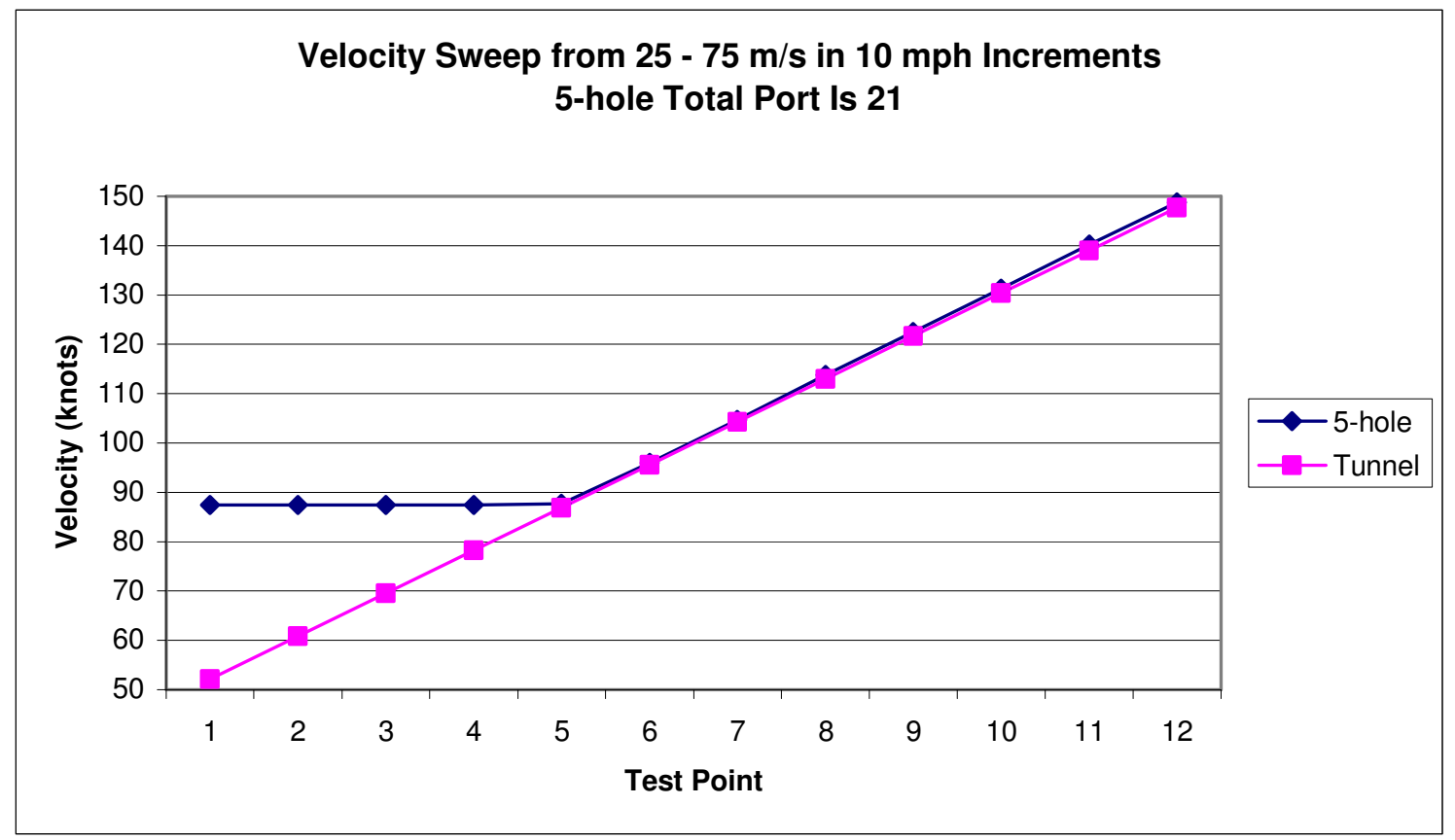

(a)

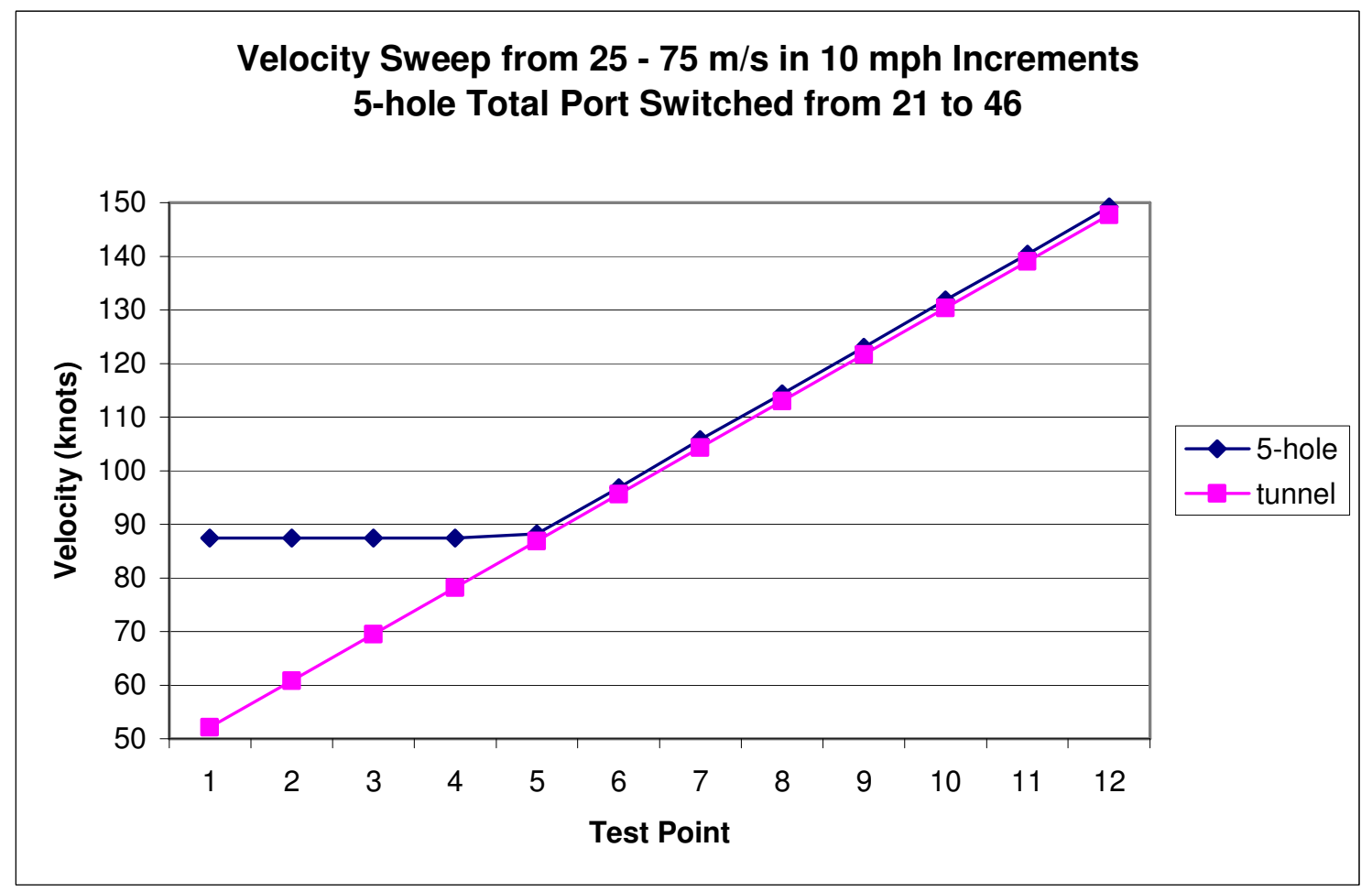

(b)

Figure A.136 Plots of the Comparison between the Tunnel Velocity and the 5-hole Velocity during Wind Tunnel Tests 


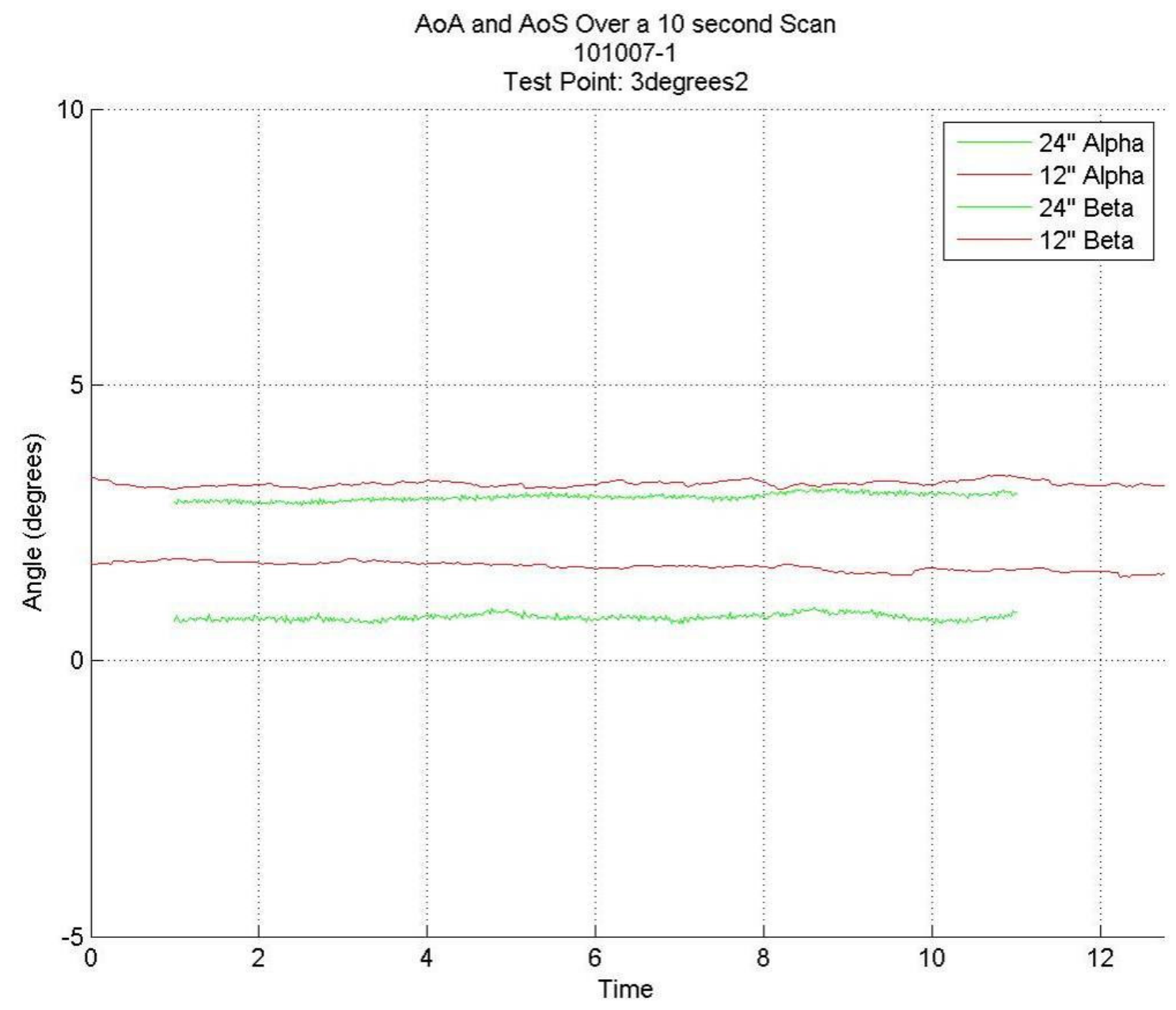

Figure A.137 Pressure Rake and Freestream $A o A$ and $A o S$ Time Traces for Test Point \#1 
Aircraft Velocity Over a 10 second Scan $101007-1$

Test Point: 3degrees2

24 inch Probe Freestream and Averaged 12 in Probe in Wake

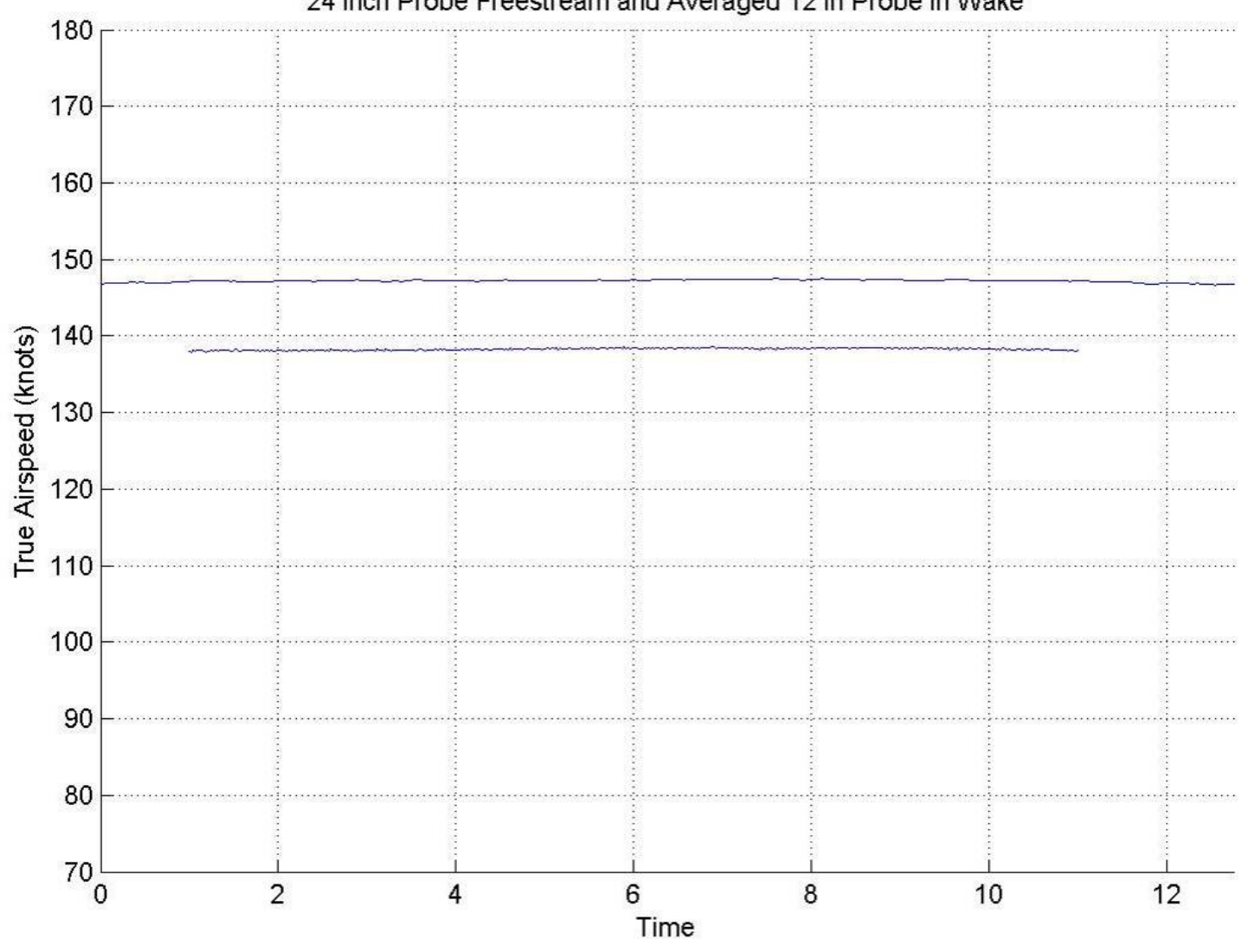

Figure A.138 Pressure Rake and Freestream Airspeed in Knots for Test Point \#1 


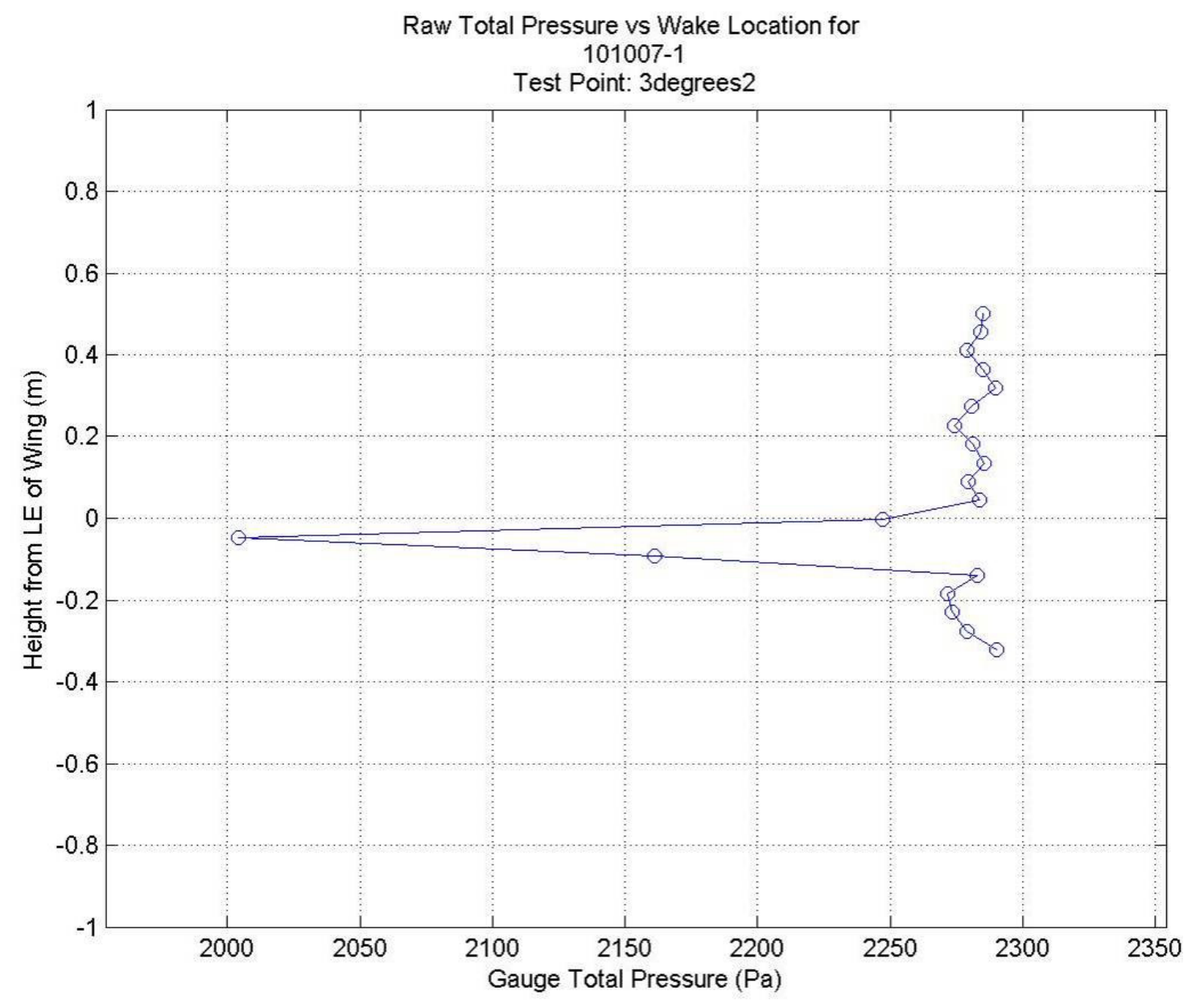

Figure A.139 Averaged Total Pressures from the Pressure Rake at Test Point \#1 
AOA and AoS Over a 10 second Scan

101007-1

Test Point: 4degrees1

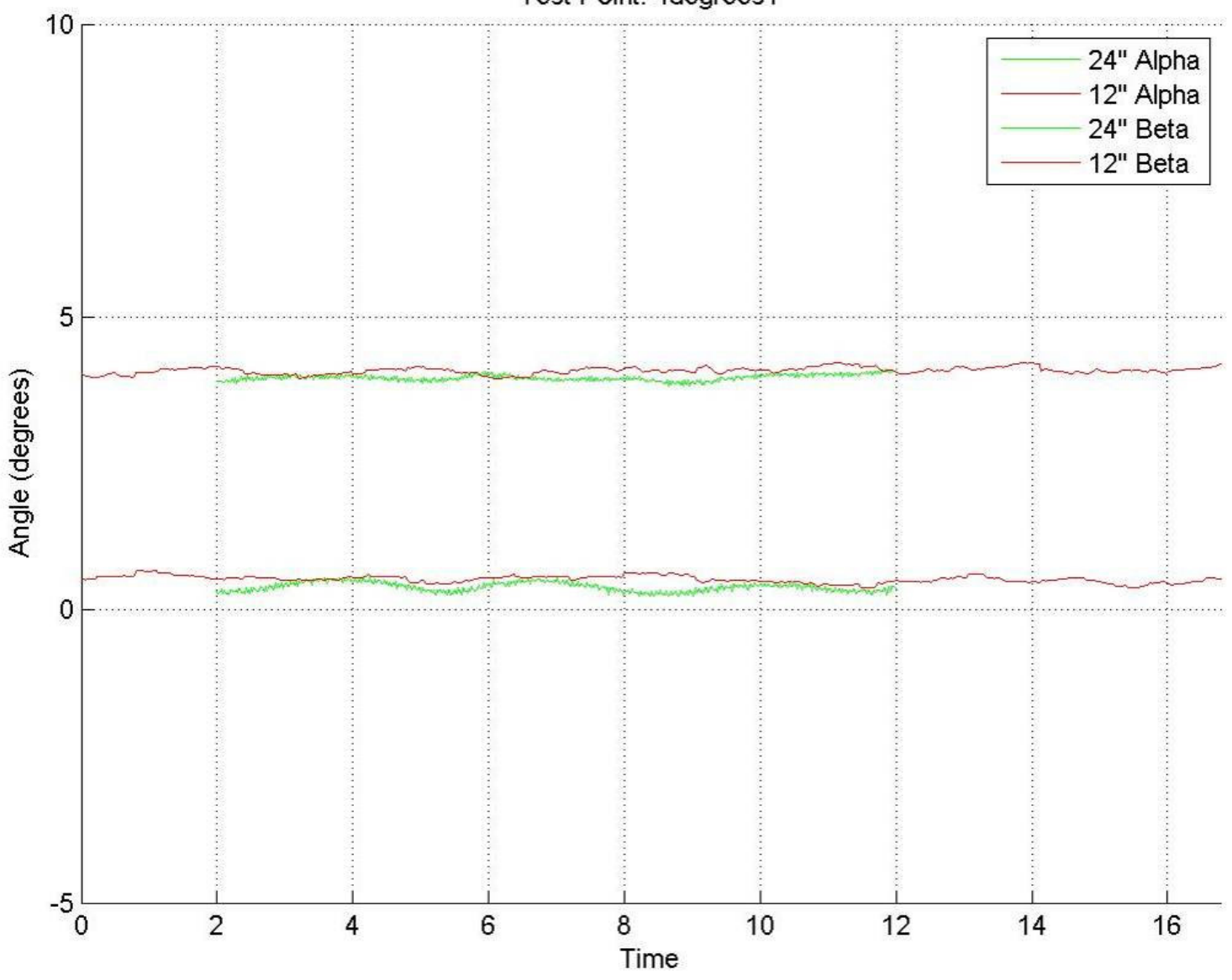

Figure A.140 Pressure Rake and Freestream $A o A$ and $A o S$ Time Traces for Test Point \#2 
Aircraft Velocity Over a 10 second Scan 101007-1

Test Point: 4degrees1

24 inch Probe Freestream and Averaged 12 in Probe in Wake

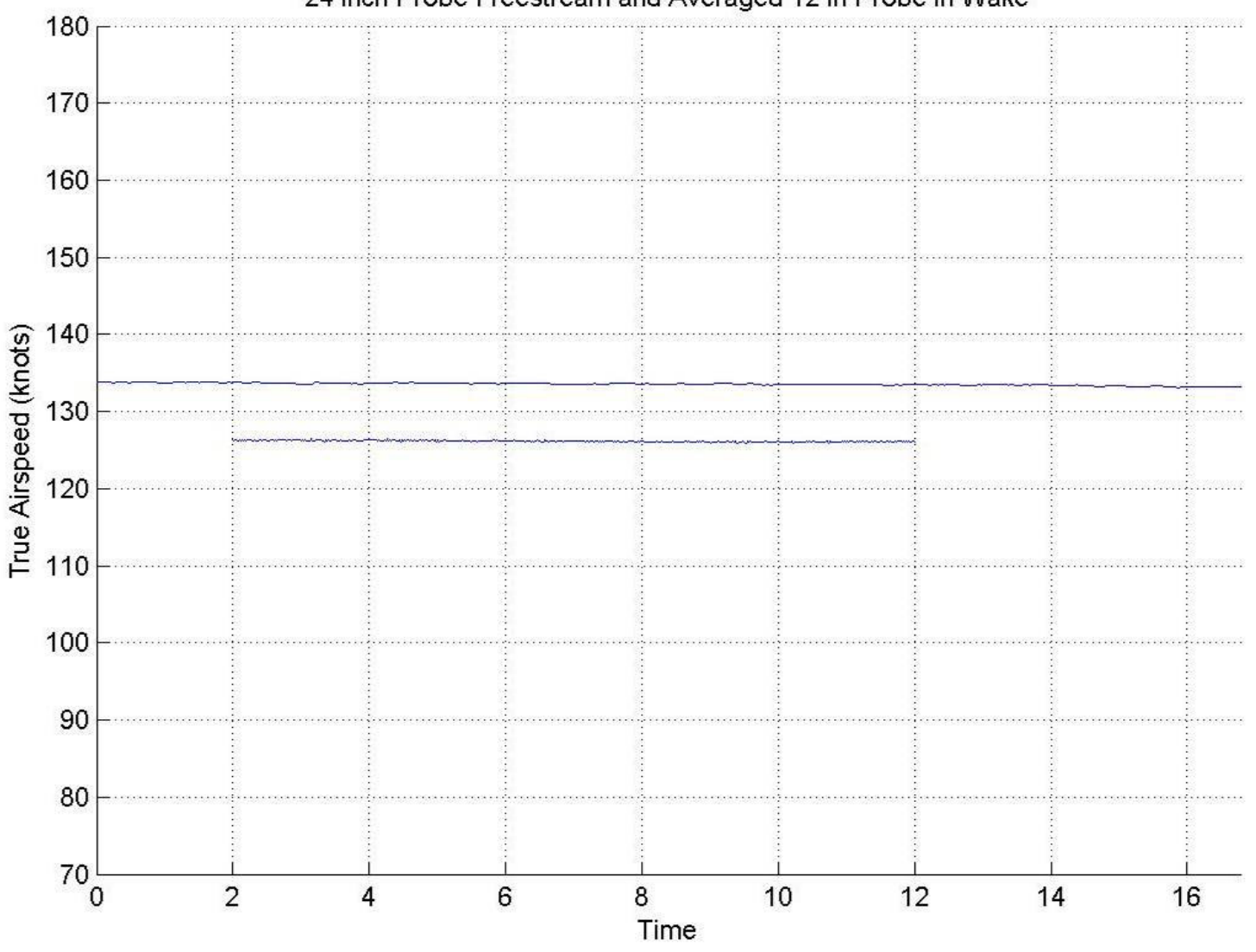

Figure A.141 Pressure Rake and Freestream Airspeed in Knots for Test Point \#2 


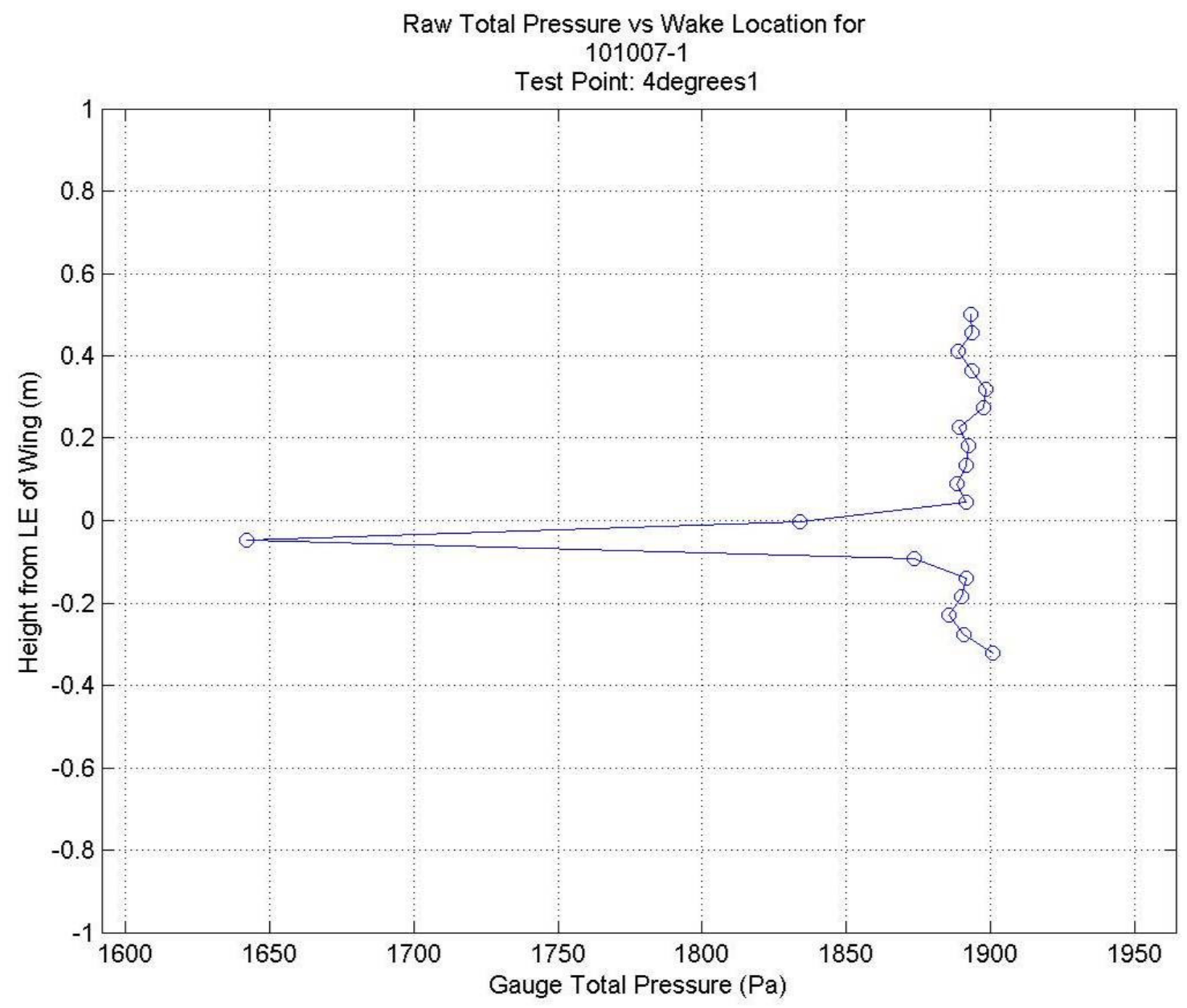

Figure A.142 Averaged Total Pressures from the Pressure Rake at Test Point \#2 


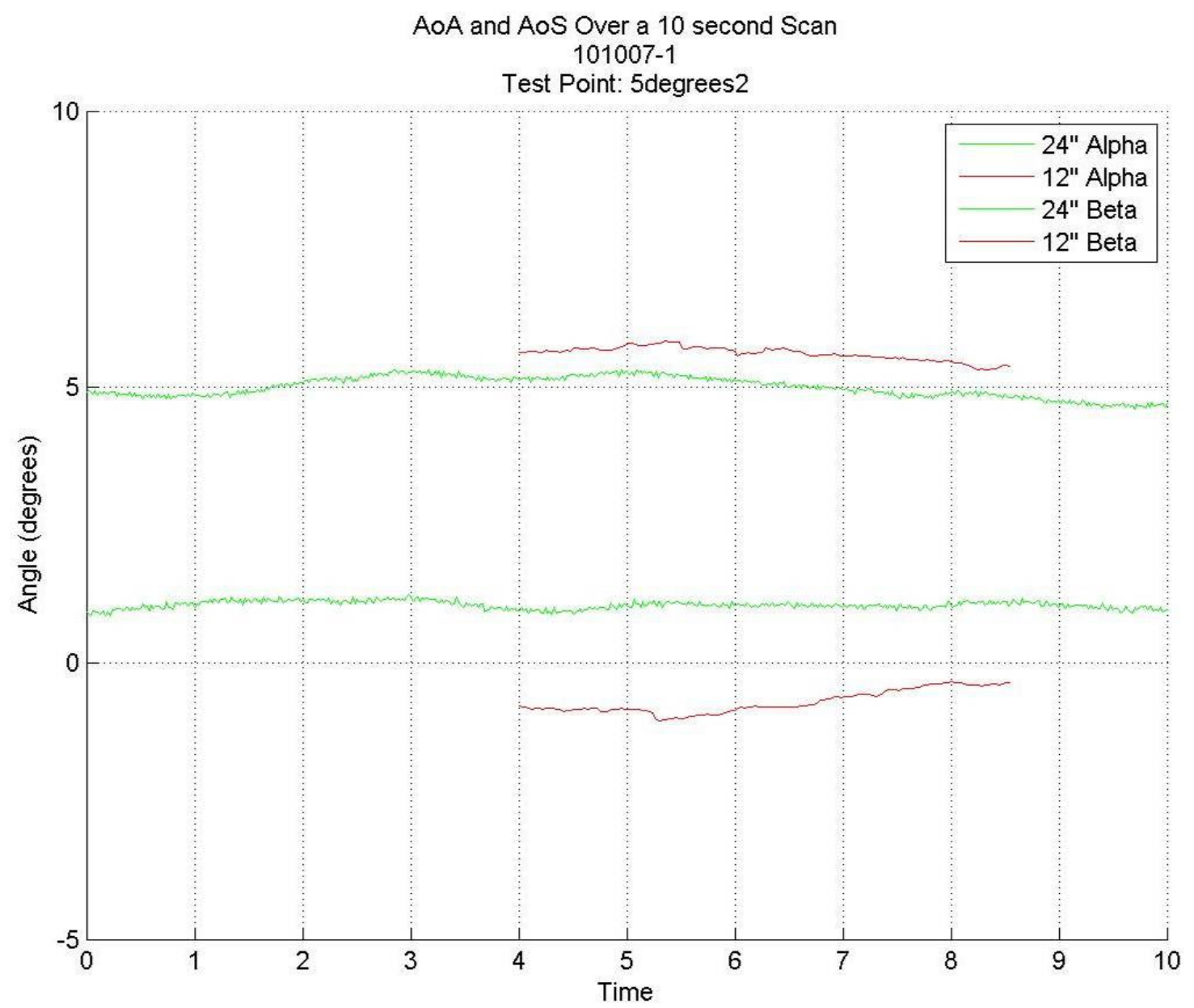

Figure A.143 Pressure Rake and Freestream AoA and AoS Time Traces for Test Point \#3 


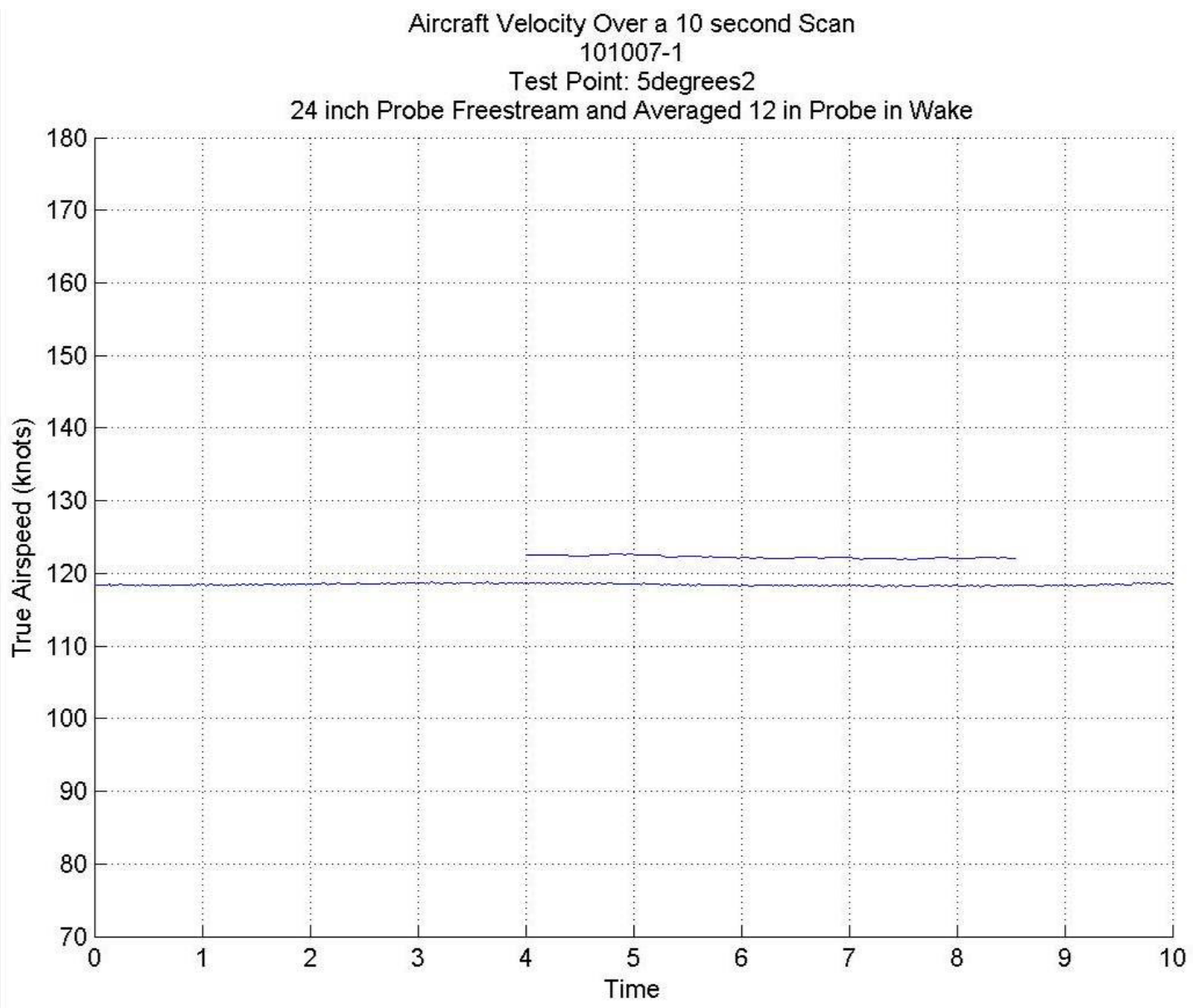

Figure A.144 Pressure Rake and Freestream Airspeed in Knots for Test Point \#3 


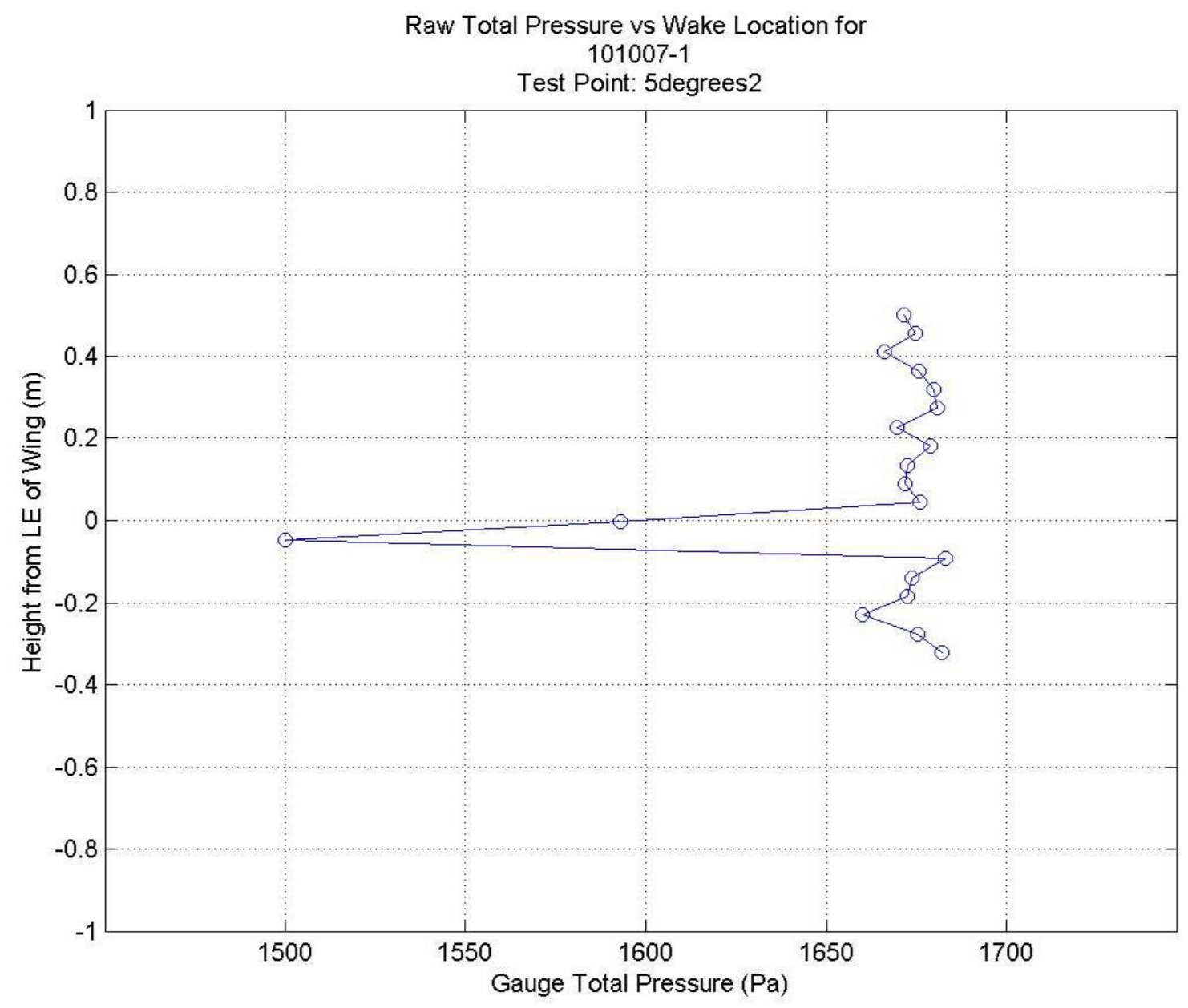

Figure A.145 Averaged Total Pressures from the Pressure Rake at Test Point \#3 


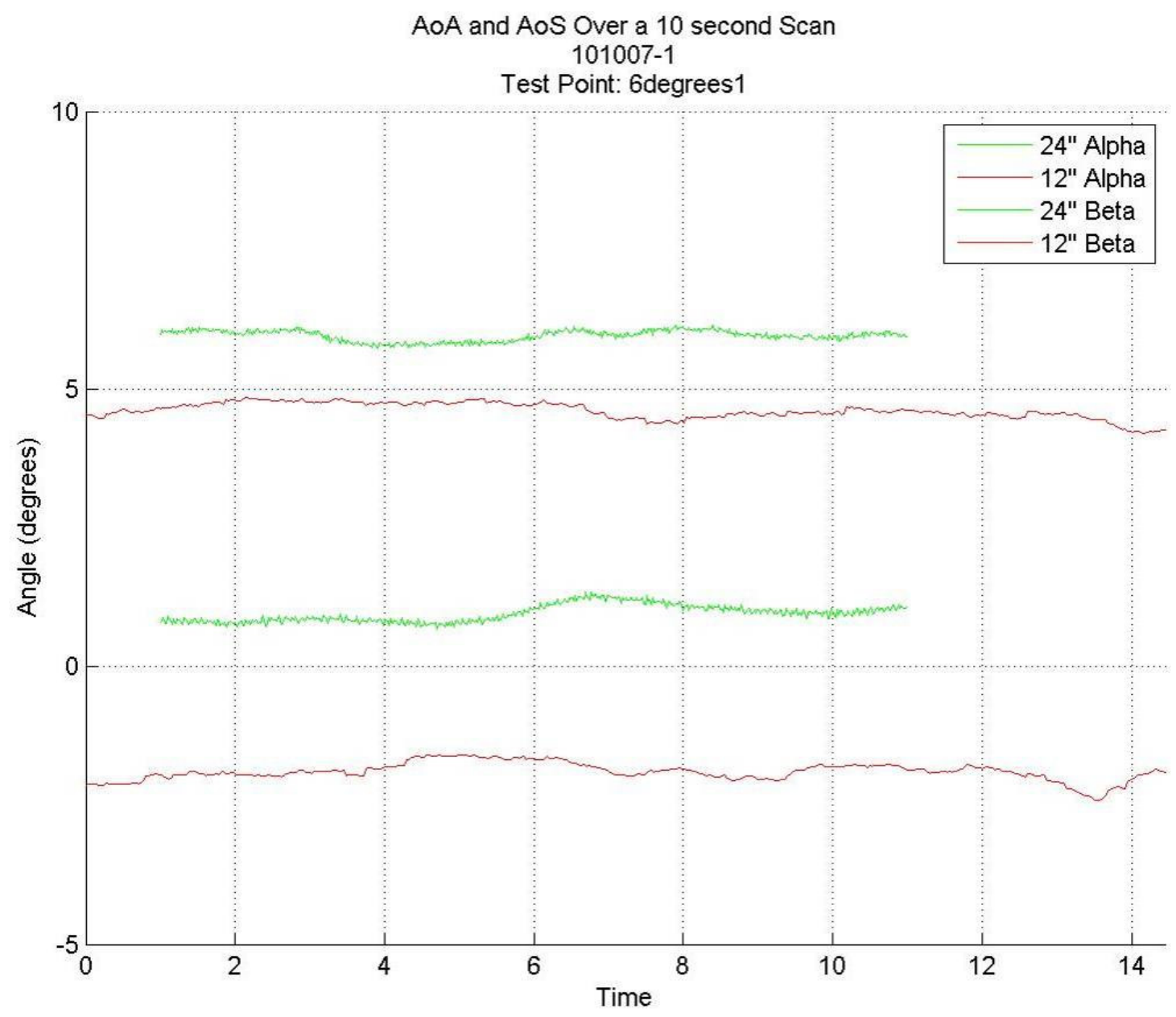

Figure A.146 Pressure Rake and Freestream AoA and AoS Time Traces for Test Point \#4 


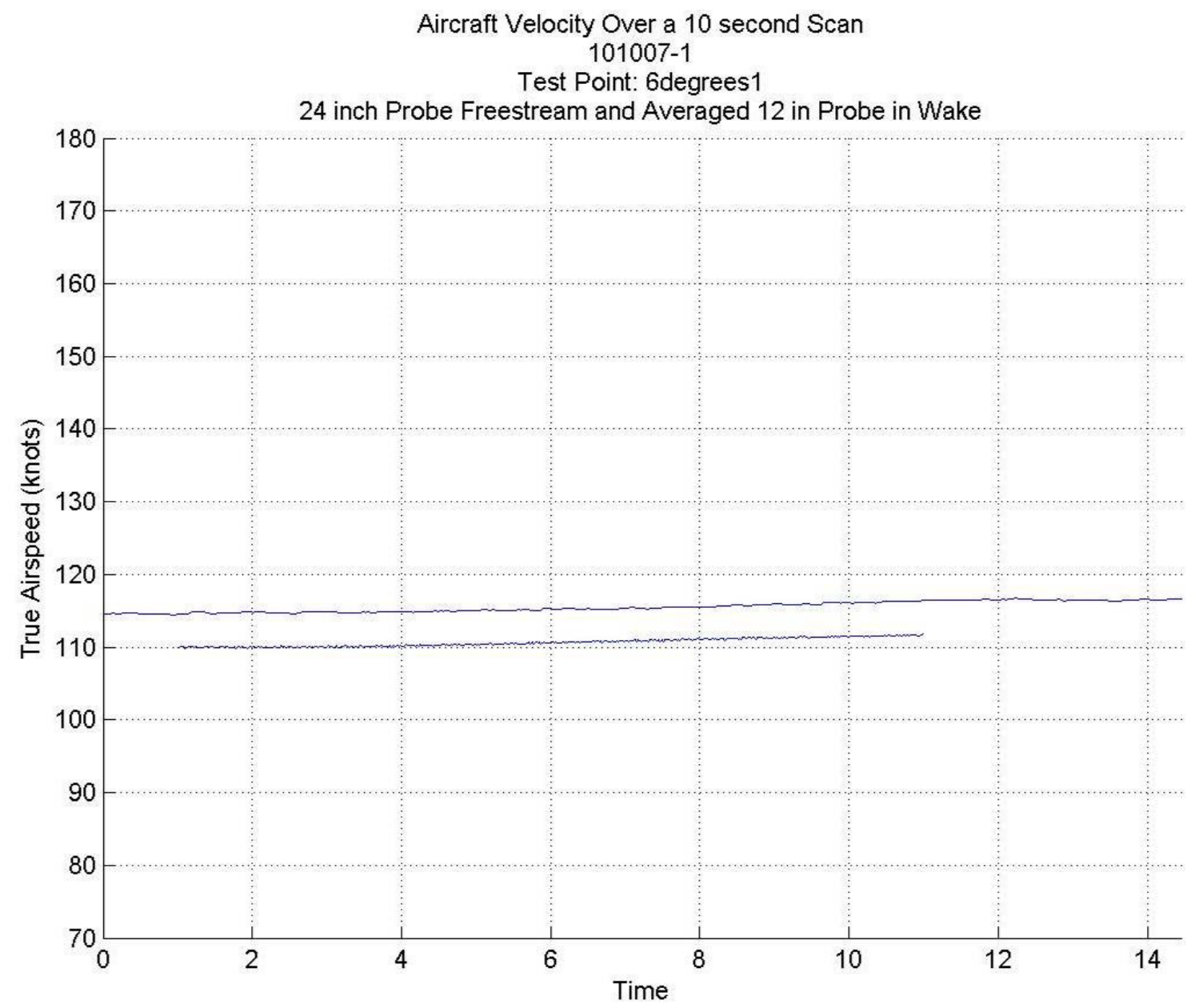

Figure A.147 Pressure Rake and Freestream Airspeed in Knots for Test Point \#4 


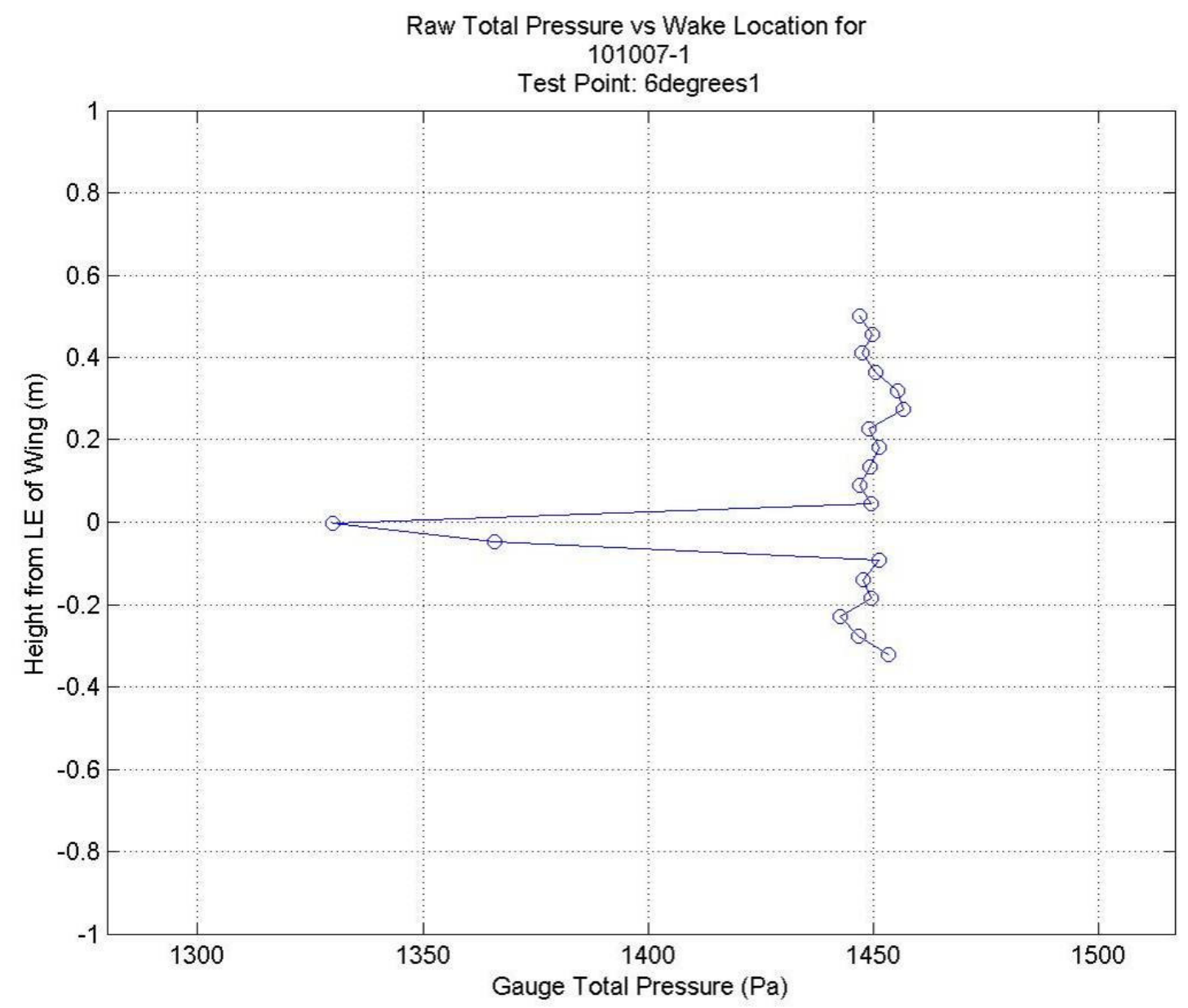

Figure A.148 Averaged Total Pressures from the Pressure Rake at Test Point \#4 


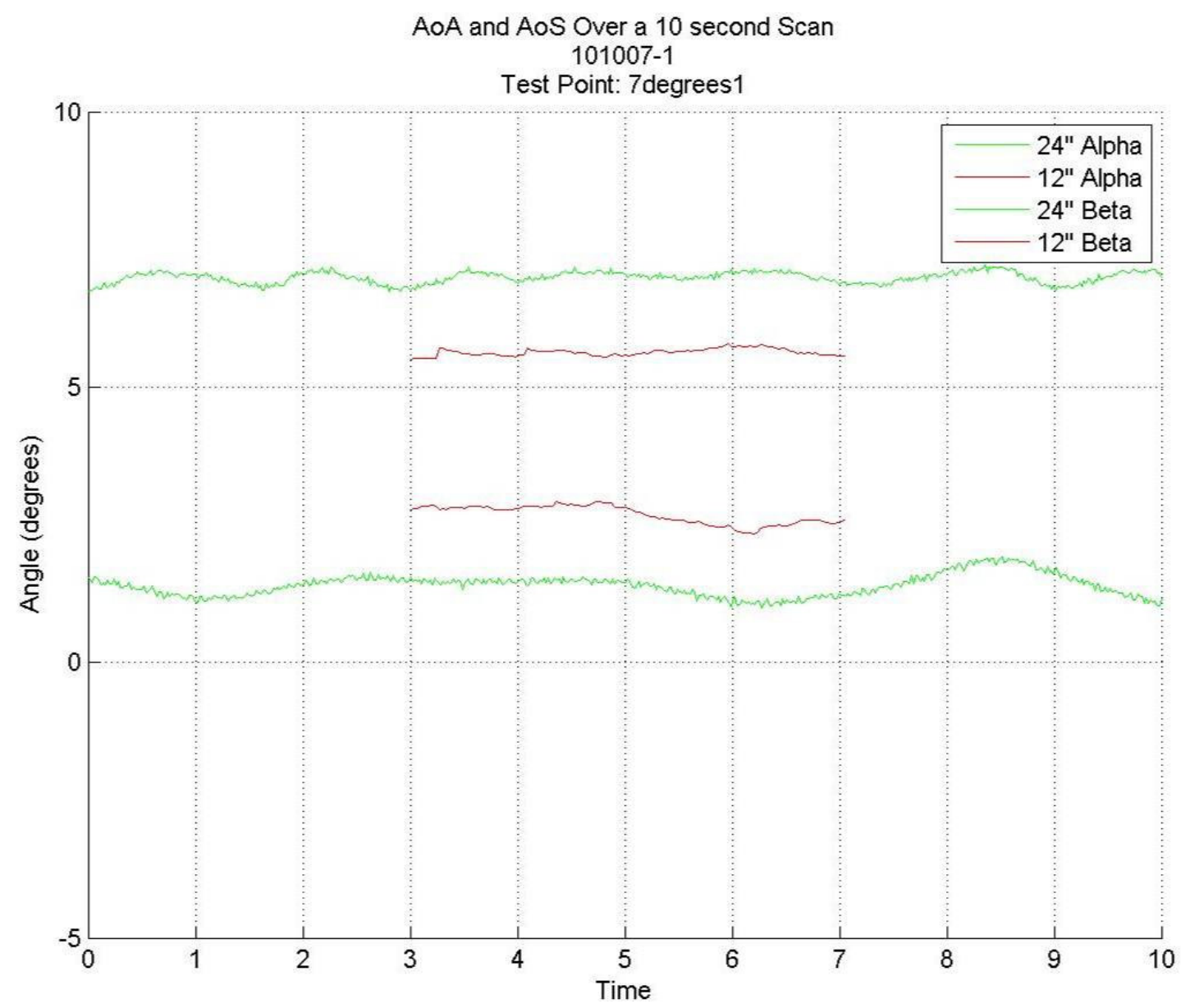

Figure A.149 Pressure Rake and Freestream AoA and AoS Time Traces for Test Point \#5 


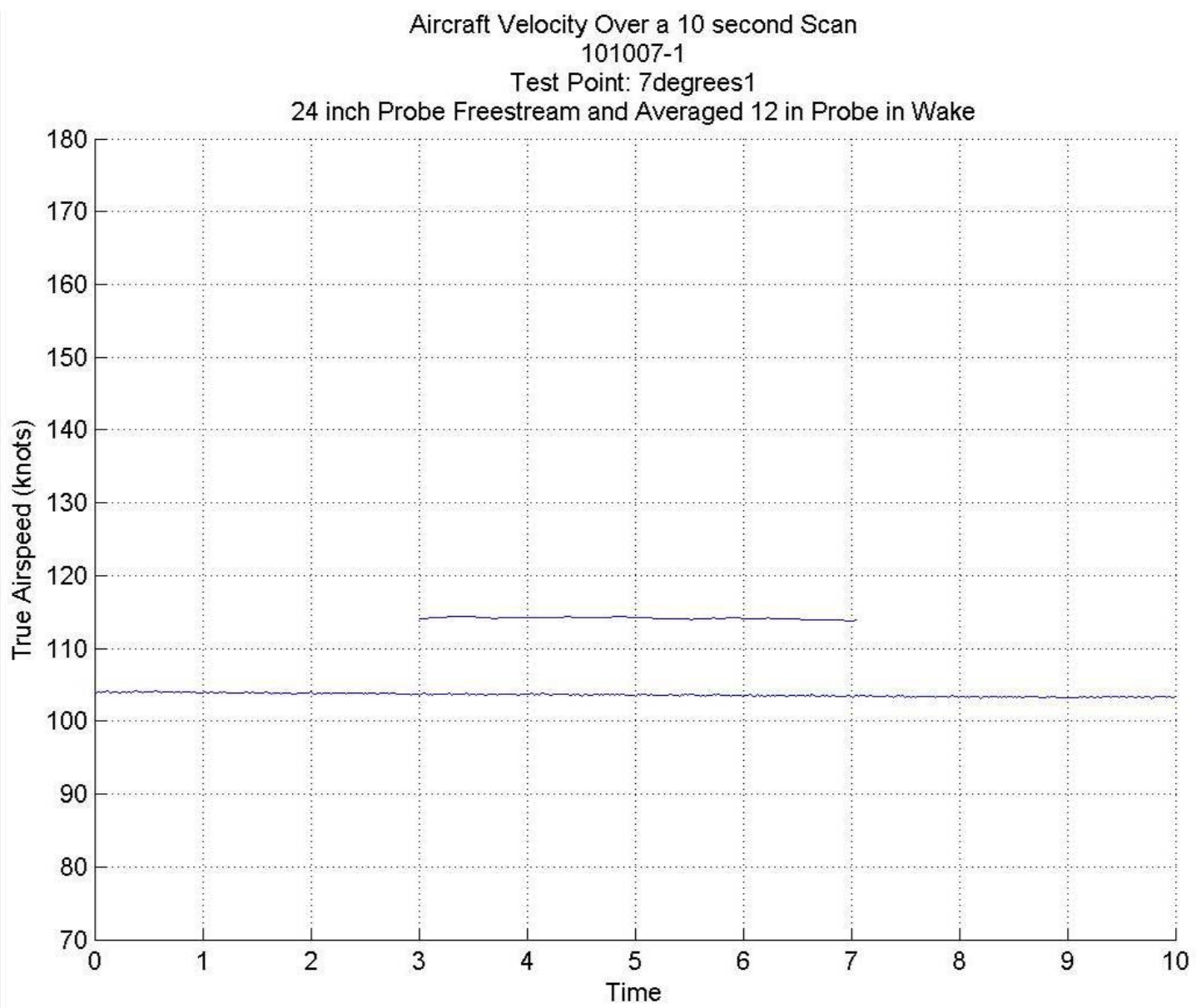

Figure A.150 Pressure Rake and Freestream Airspeed in Knots for Test Point \#5 


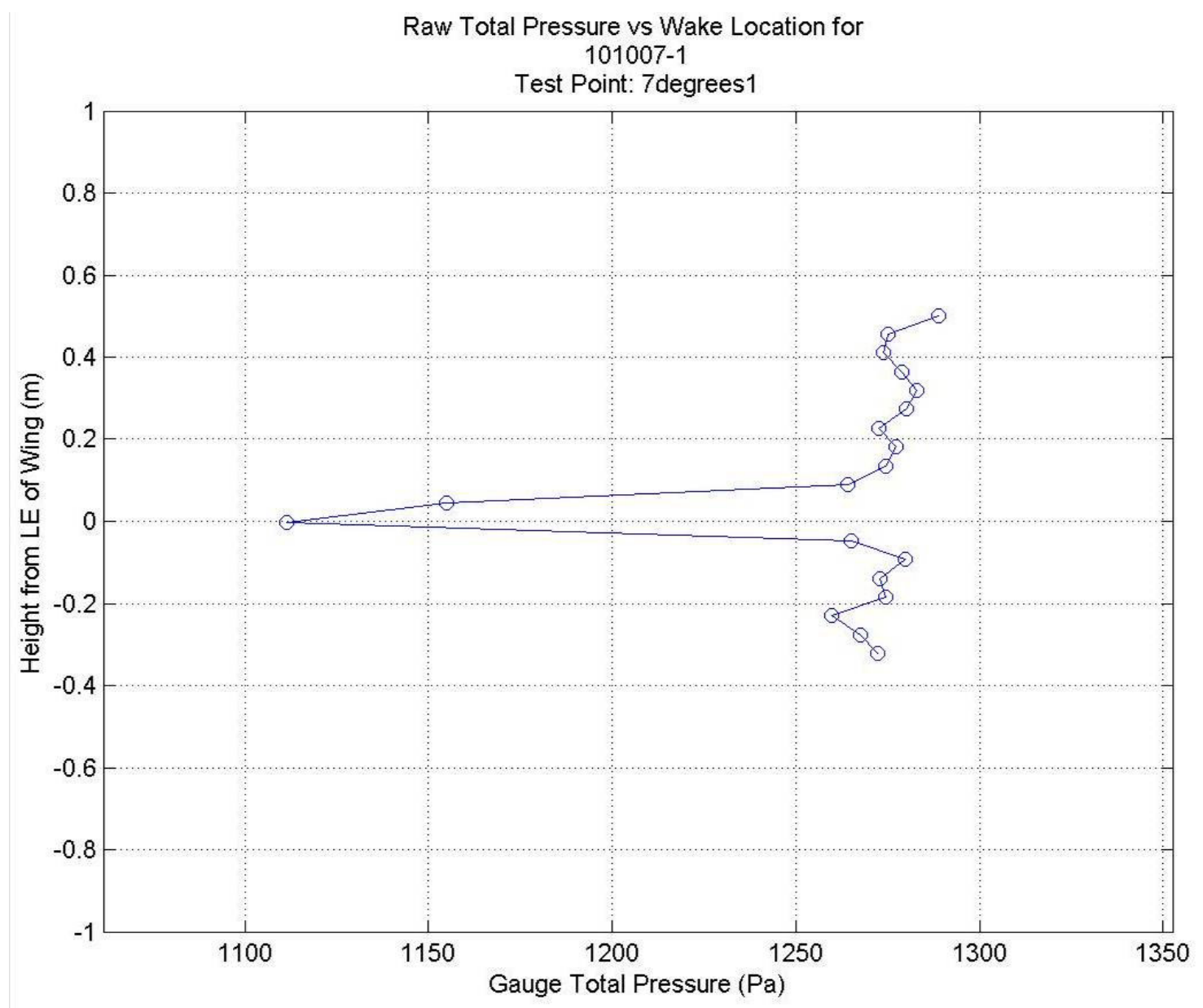

Figure A.151 Averaged Total Pressures from the Pressure Rake at Test Point \#5 
Raw Total Pressure vs Wake Location with Error Margins for 101007-1

Test Point: 3degrees2

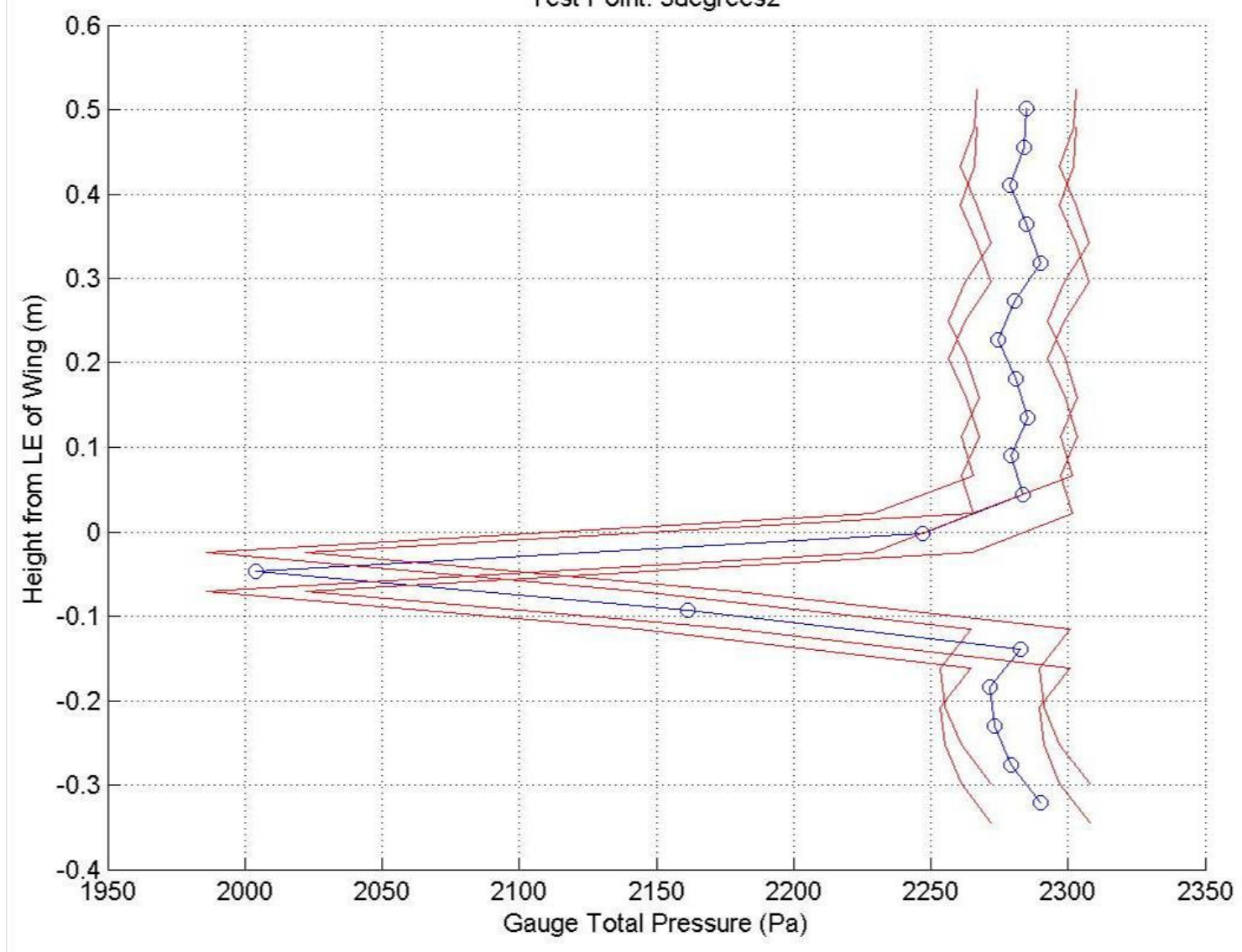

Figure A.152 Averaged Total Pressures from the Pressure Rake with Red Lines Signifying the Experimental Error Margins for Test Point \#1 


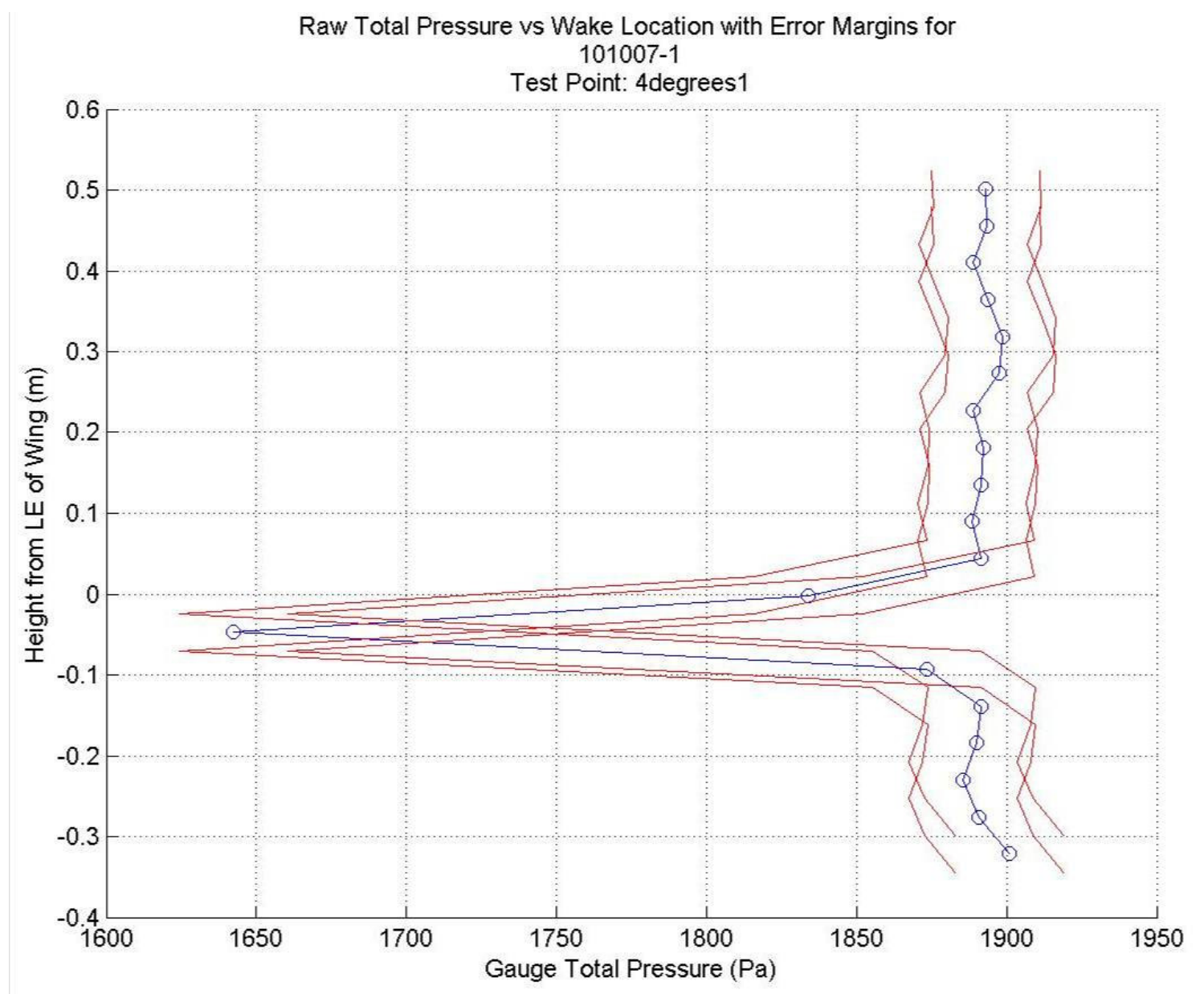

Figure A.153 Averaged Total Pressures from the Pressure Rake with Red Lines Signifying the Experimental Error Margins for Test Point \#2 


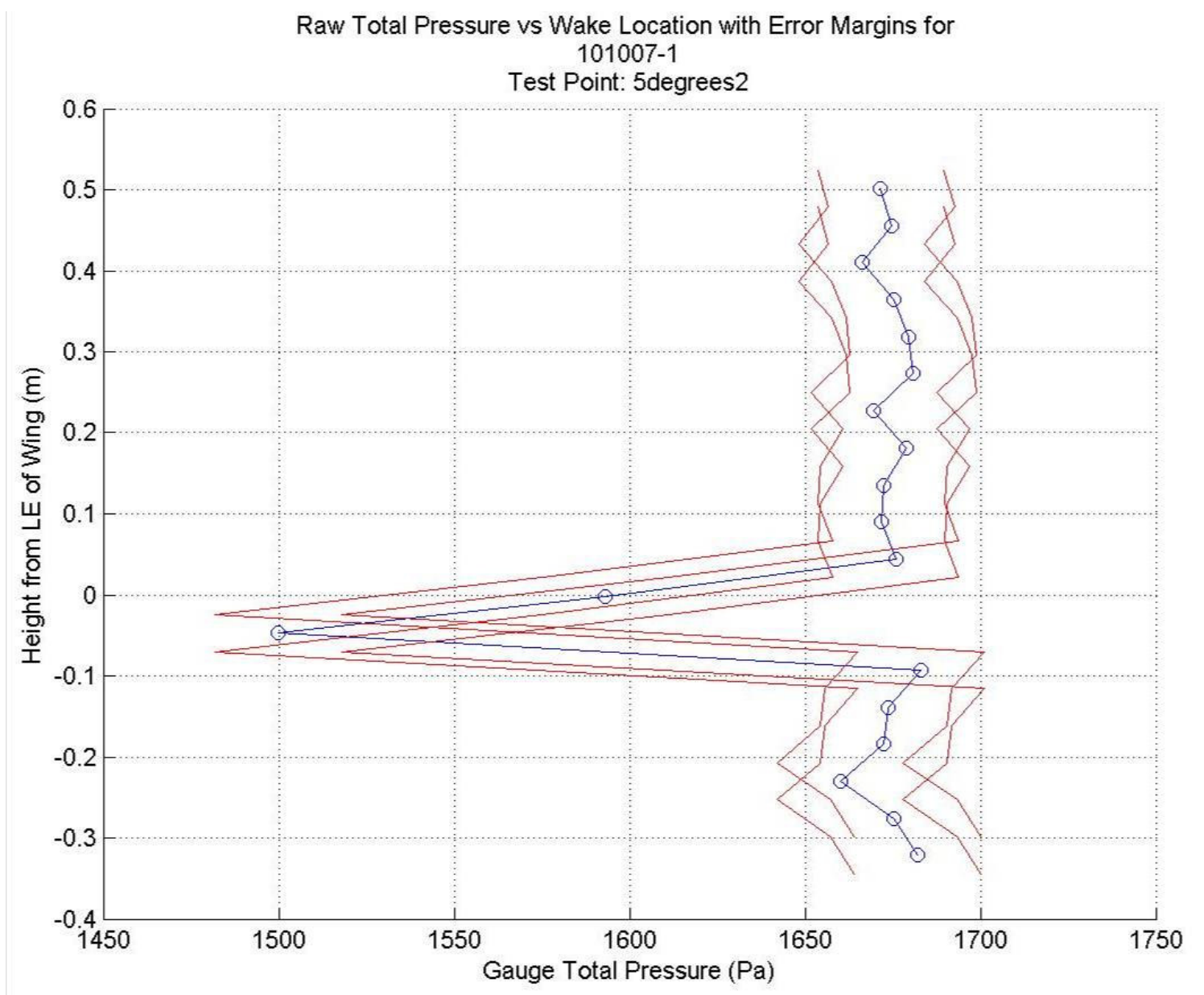

Figure A.154 Averaged Total Pressures from the Pressure Rake with Red Lines Signifying the Experimental Error Margins for Test Point \#3 


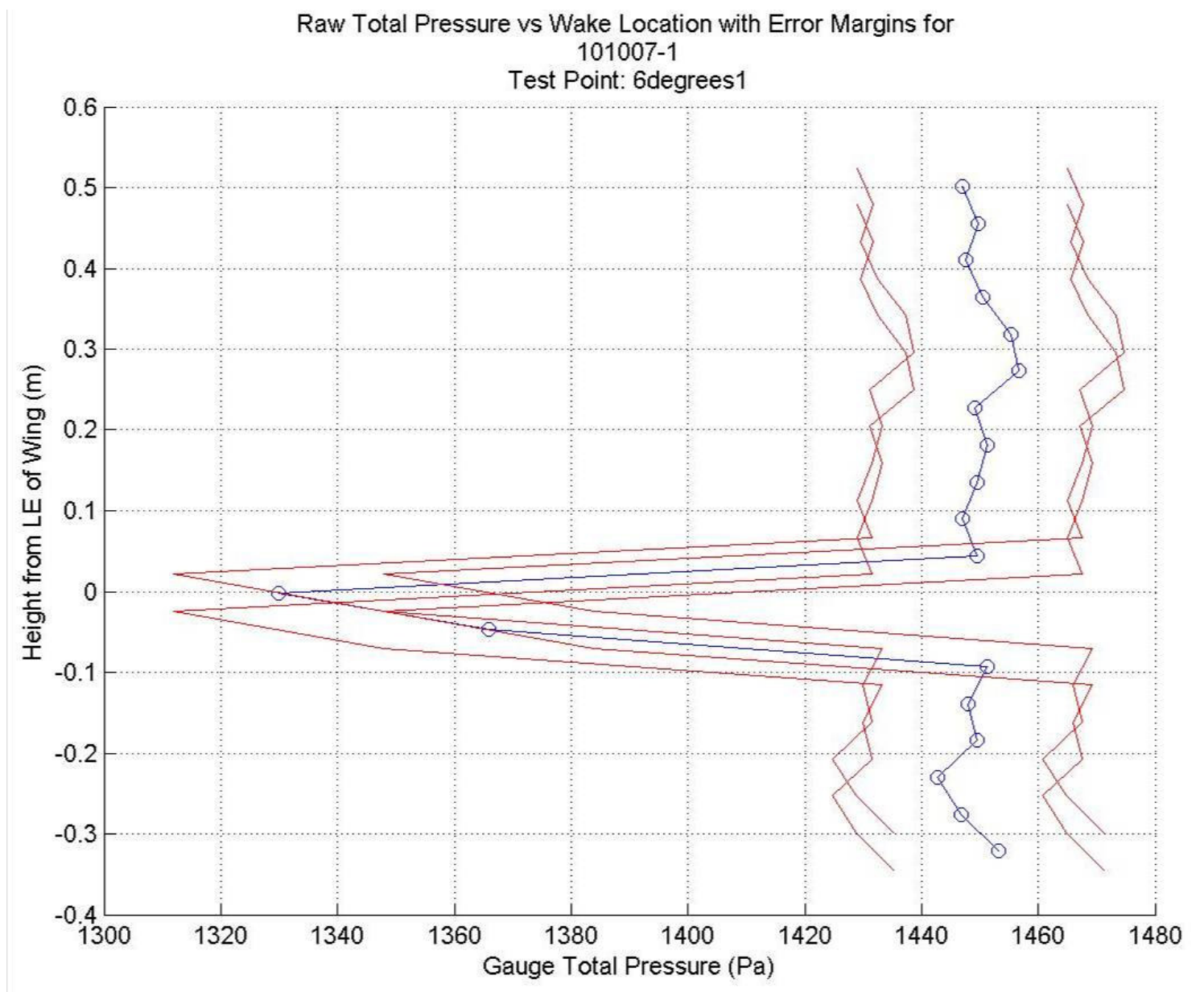

Figure A.155 Averaged Total Pressures from the Pressure Rake with Red Lines Signifying the Experimental Error Margins for Test Point \#4 


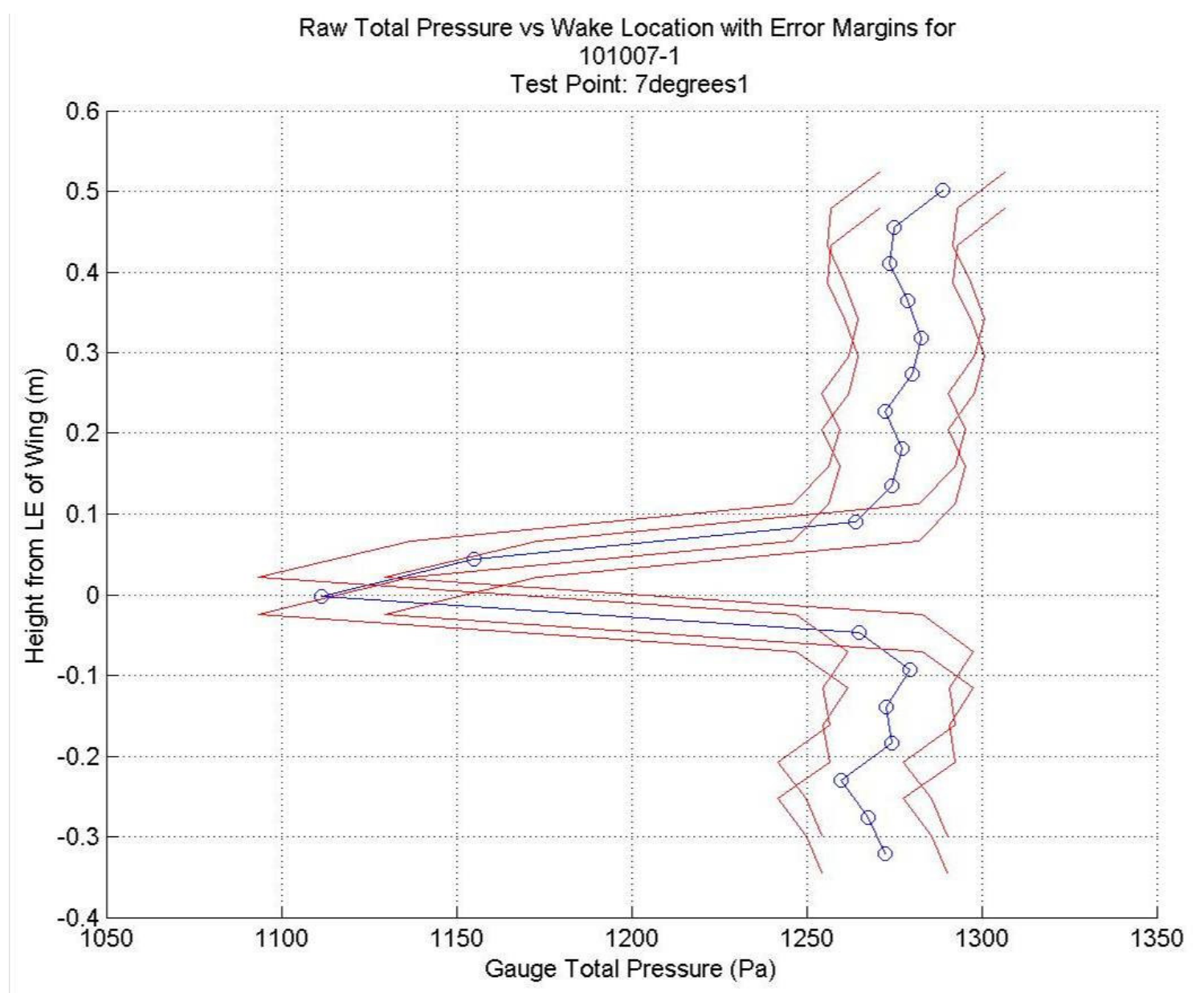

Figure A.156 Averaged Total Pressures from the Pressure Rake with Red Lines Signifying the Experimental Error Margins for Test Point \#5 


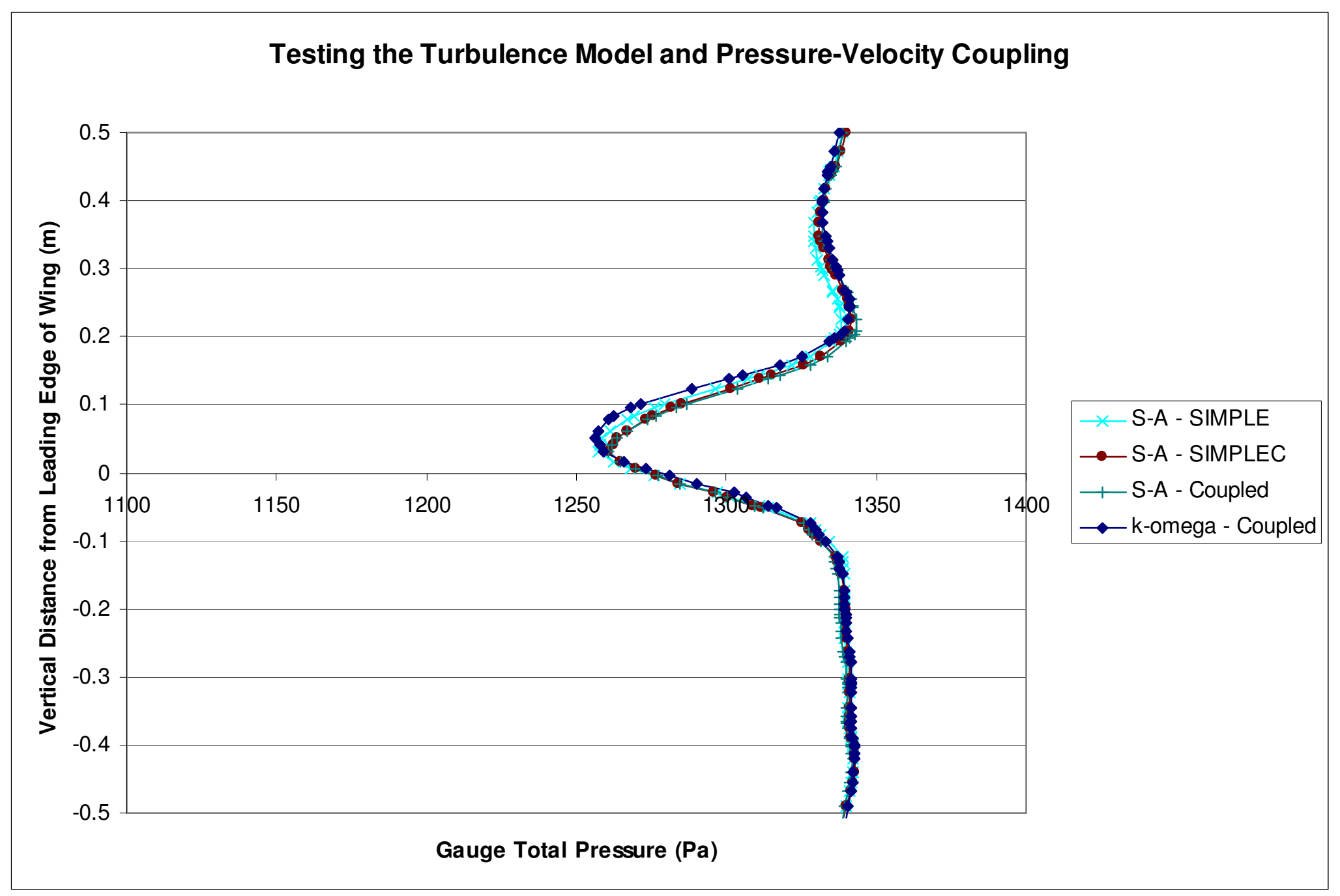

Figure A.157 Computational Differences due to Turbulence Model and Pressure-Velocity Coupling Scheme 


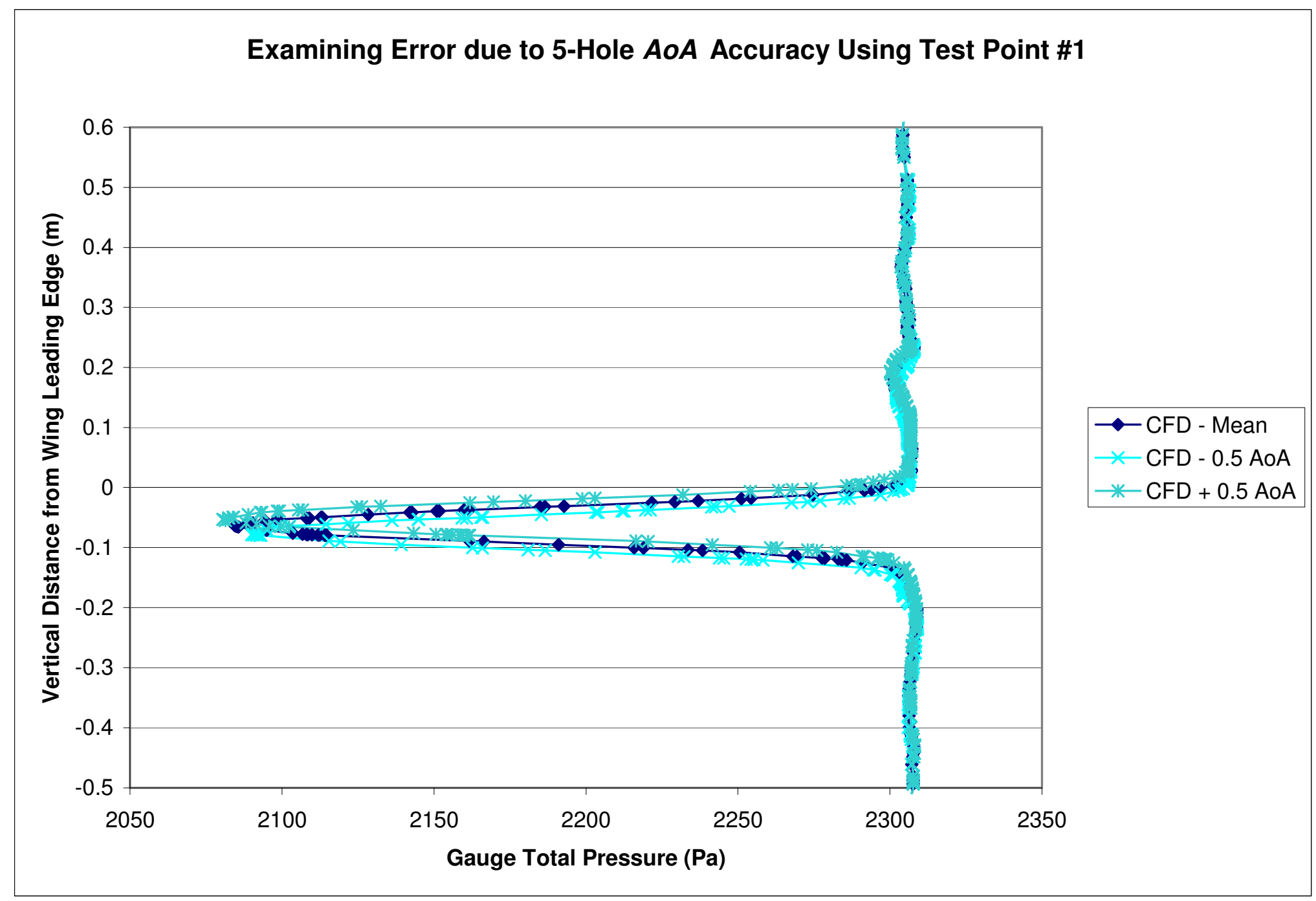

Figure A.158 Computational Differences due to Error in AoA Readings by the 5-Hole Probe 


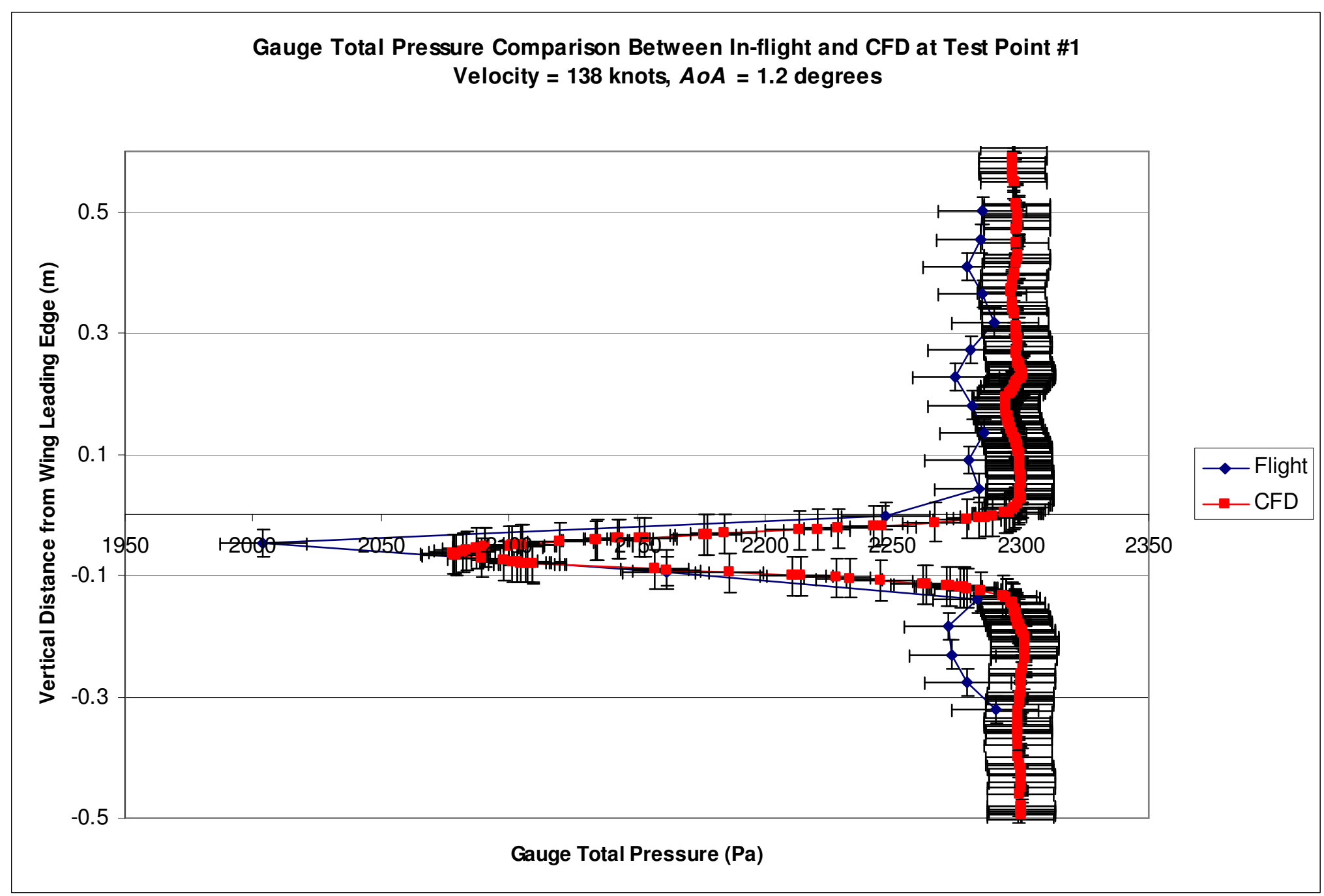

Figure A.159 Comparison between Experiment and CFD for Test Point \#1 Including Computed Error Bars 


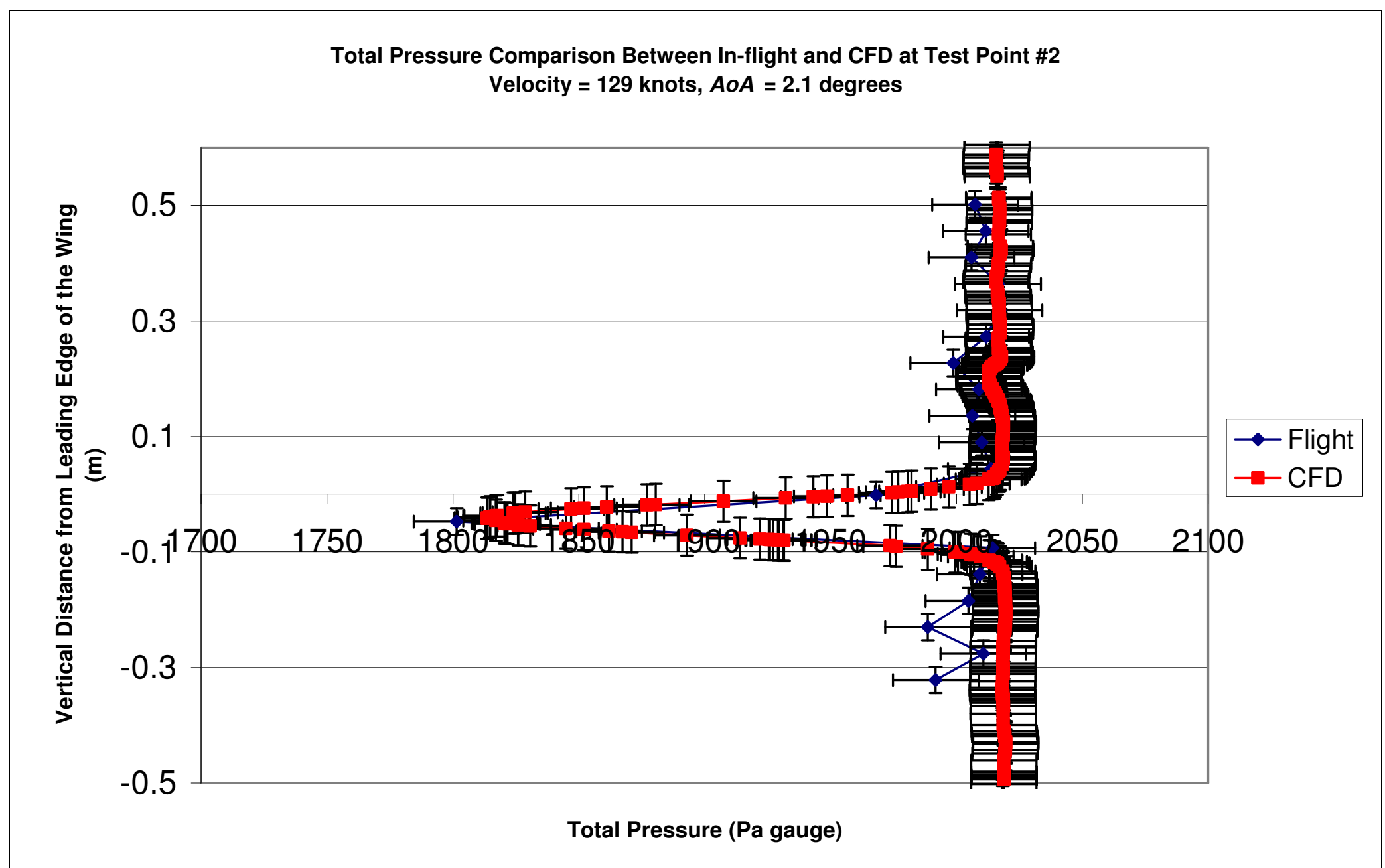

Figure A.160 Comparison between Experiment and CFD for Test Point \#2 Including Computed Error Bars 


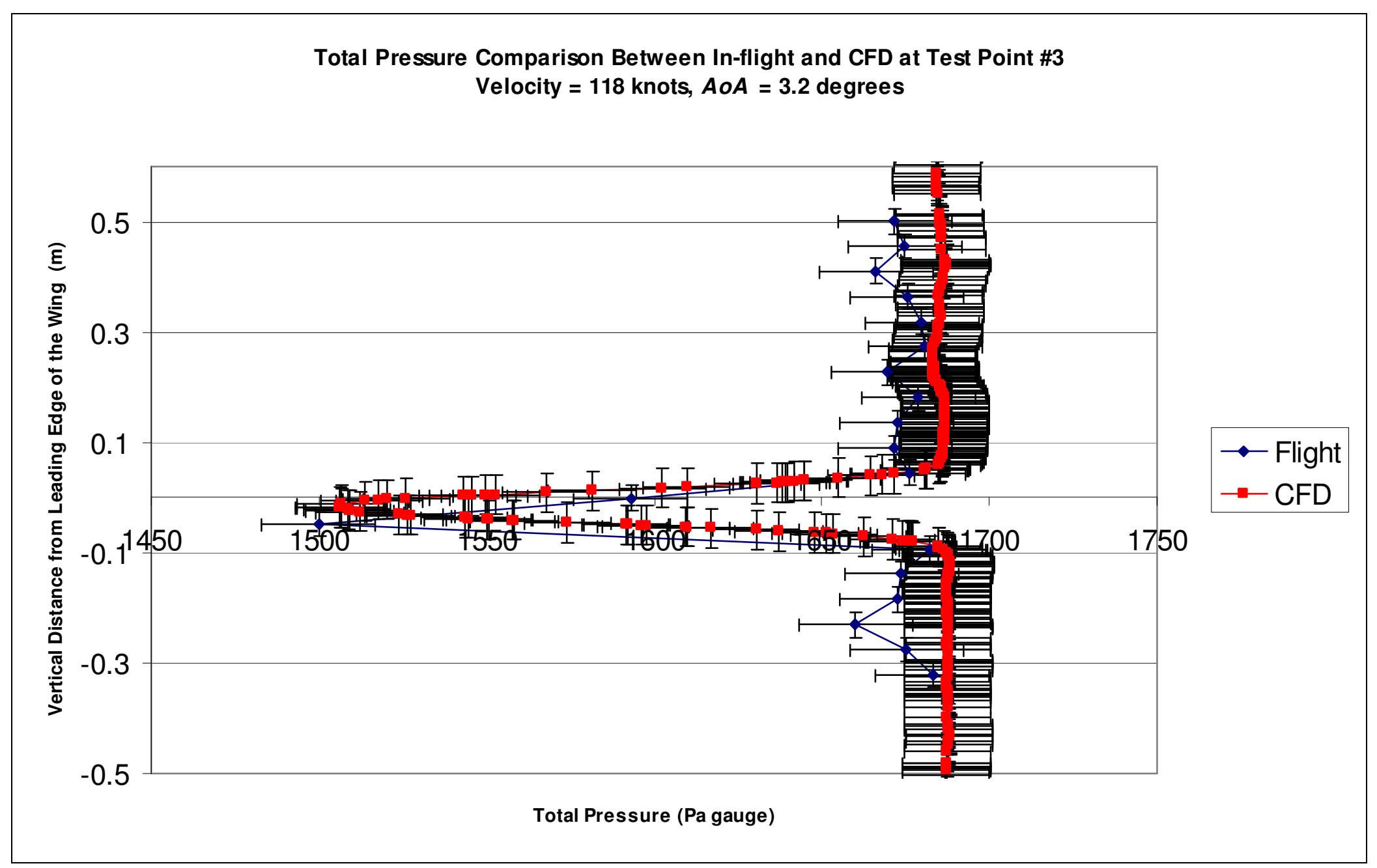

Figure A.161 Comparison between Experiment and CFD for Test Point \#3 Including Computed Error Bars 


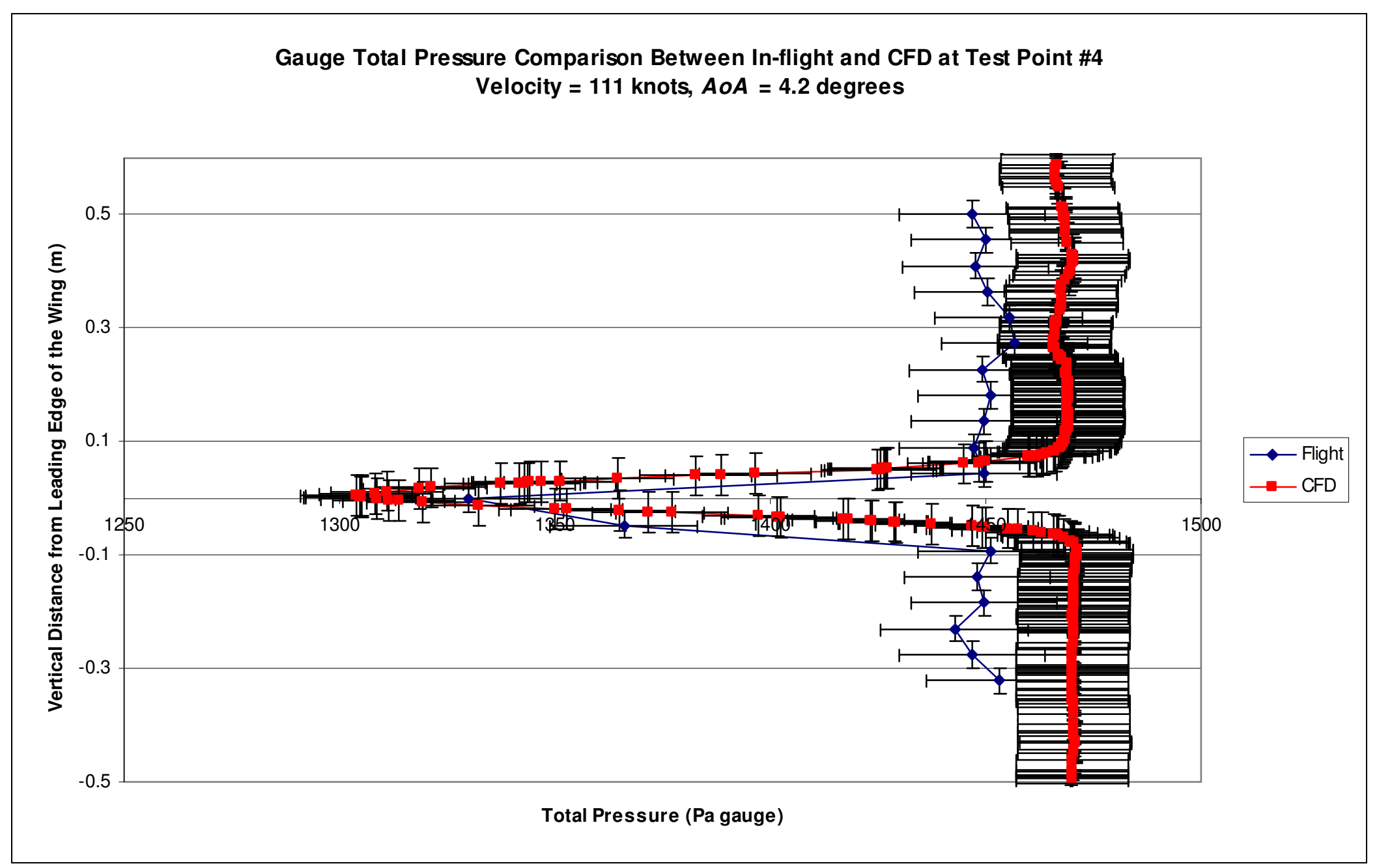

Figure A.162 Comparison between Experiment and CFD for Test Point \#4 Including Computed Error Bars 


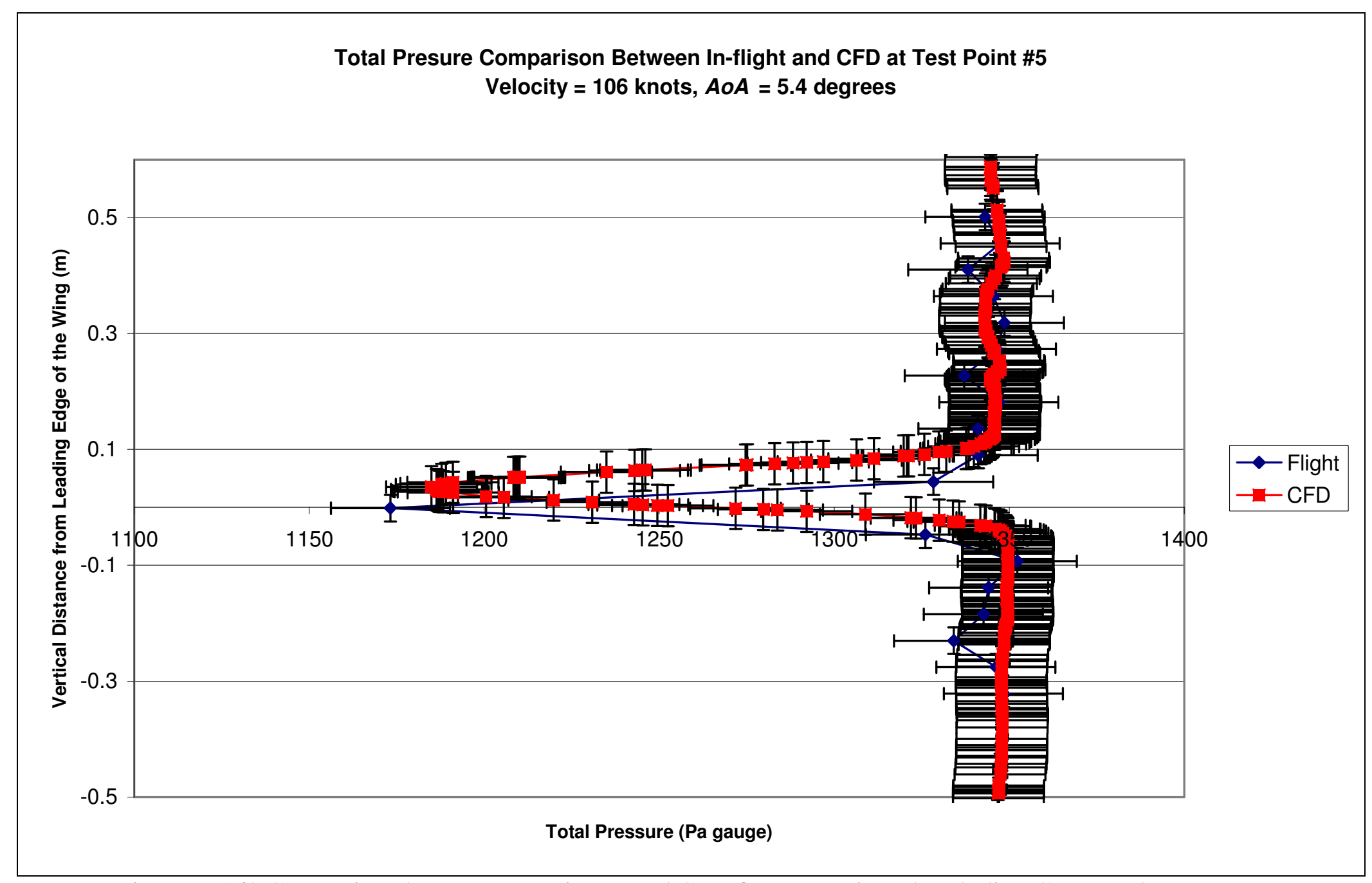

Figure A.163 Comparison between Experiment and CFD for Test Point \#5 Including Computed Error Bars 


\section{APPENDIX B}

EXPERIMENTAL RESOURCES 
Table B.1

List of Wind Tunnels Operated by Texas A\&M University Aerospace Engineering

\begin{tabular}{|l|c|c|}
\hline \multicolumn{1}{|c|}{ Wind Tunnel } & Cross-Section & Maximum Speed \\
\hline ELD Open-Circuit Model 402 Wind Tunnel & $0.31 \mathrm{~m} \times 0.31 \mathrm{~m}$ & $30.5 \mathrm{~m} / \mathrm{s}$ \\
\hline ELD Closed-Circuit Model 403 Wind Tunnel & $0.31 \mathrm{~m} \times 0.31 \mathrm{~m}$ & $55 \mathrm{~m} / \mathrm{s}$ \\
\hline Supersonic Wind Tunnel & $0.10 \mathrm{~m} \times 0.10 \mathrm{~m}$ & Mach 2 \\
\hline ELD Closed-Circuit Wind Tunnel & $0.91 \mathrm{~m} \times 1.22 \mathrm{~m}$ & $50 \mathrm{~m} / \mathrm{s}$ \\
\hline ELD Closed-Circuit Wind Tunnel & $0.61 \mathrm{~m} \times 0.91 \mathrm{~m}$ & $80 \mathrm{~m} / \mathrm{s}$ \\
\hline Water Tunnel & $0.61 \mathrm{~m} \times 0.91 \mathrm{~m}$ & $0.9 \mathrm{~m} / \mathrm{s}$ \\
\hline Oran W. Nicks Lowspeed Wind Tunnel & $2.13 \mathrm{~m} \times 3.05 \mathrm{~m}$ & $90 \mathrm{~m} / \mathrm{s}$ \\
\hline NASA-LRC M6QT & $0.2 \mathrm{~m}$ & Mach 6 \\
\hline High-Reynolds Number Blow-Down Tunnel & $0.15 \mathrm{~m} \times 0.15 \mathrm{~m}$ & Mach 6 \\
\hline Large Scale Hypersonic (MURI) Wind Tunnel & $0.33 \mathrm{~m}$ & Mach 7 \\
\hline Icing Physics Flow Icing Tunnel & $0.76 \mathrm{~m} \times 1.52 \mathrm{~m}$ & $17 \mathrm{~m} / \mathrm{s}$ \\
\hline Klebanoff-Saric Unsteady Wind Tunnel & $1.4 \mathrm{~m} \times 1.4 \mathrm{~m}$ & $35 \mathrm{~m} / \mathrm{s}$ \\
\hline
\end{tabular}

Texas A\&M University Flight Research Laboratory Equipment List for Flight-Testing

- PCB ICP® Triaxial Accelerometers

- Merlin Mid-wavelength Infrared Camera

- FLIR ThermaCAM IR Camera

- SONY HDR-HC3 HDV 1080i HANDYCAM

- KEMO Four Channel Filter and Amplifier

- A.A. Lab Systems AN-1003 Anemometry system (30 Channels)

- Tao Systems Senflex® Hotfilm Arrays

- Space Age Control Alpha-Beta Indicator

- 12" Aeroprobe 5-Hole Probe

- 24" Aeroprobe 5-Hole Probe

- Kulite Pressure Transducres

- MKS Dynamic Pressure Transducers

- MKS Absolute Pressure Tansducers

- Honeywell Differential Pressure Transducers

- Honeywell Absolute Pressure Tranducer

- Pressure Systems ESP-64HD Pressure Scanner

- DC - AC Power Inverters 
APPENDIX C

LIST OF WIND TUNNEL TESTS 
Table C.1

Summary of Tests Completed at the Oran W. Nicks Lowspeed Wind Tunnel

\begin{tabular}{|c|c|c|c|c|c|}
\hline File \# & Acquisition & $\begin{array}{l}\text { Tunnel } \\
\text { Speed }\end{array}$ & $\begin{array}{c}\text { Tunnel } \\
\text { AoA }\end{array}$ & $\begin{array}{c}\text { Tunnel } \\
\text { AoS }\end{array}$ & 5-Hole Probe Scanner Port \\
\hline 0 & \multicolumn{5}{|c|}{ Calibration at $-5.0,-2.5,0.0,2.5,5.0 \mathrm{psi}$} \\
\hline 1 & $10 \mathrm{mph}$ Increments & $60-170 \mathrm{mph}$ & 0.5 & 0 & Normal tubing configuration \\
\hline 2 & $10 \mathrm{mph}$ Increments & $60-170 \mathrm{mph}$ & 0.5 & 0 & 5-Hole total switched to port \#46 \\
\hline 3 & 5 minutes & $170 \mathrm{mph}$ & 0.5 & 0 & 5-Hole total switched to port \#46 \\
\hline 4 & 5 minutes & $170 \mathrm{mph}$ & 0.5 & 0 & Normal tubing configuration \\
\hline 5 & 5 minutes & $170 \mathrm{mph}$ & 0.5 & 0 & Normal tubing configuration \\
\hline 6 & 5 seconds & $170 \mathrm{mph}$ & 0.5 & 0 & Normal tubing configuration \\
\hline 7 & 5 seconds & $170 \mathrm{mph}$ & 0.5 & 0 & Normal tubing configuration \\
\hline 8 & 5 seconds & $170 \mathrm{mph}$ & 0.5 & 0 & Normal tubing configuration \\
\hline 9 & 5 seconds & $170 \mathrm{mph}$ & 0.5 & 0 & Normal tubing configuration \\
\hline 10 & 5 seconds & $170 \mathrm{mph}$ & 0.5 & 0 & Normal tubing configuration \\
\hline 11 & 5 seconds & $170 \mathrm{mph}$ & 0.5 & 0 & Normal tubing configuration \\
\hline 12 & 5 seconds & $170 \mathrm{mph}$ & 0.5 & 0 & Normal tubing configuration \\
\hline 13 & 5 seconds & $170 \mathrm{mph}$ & 0.5 & 0 & Normal tubing configuration \\
\hline 14 & 5 seconds & $170 \mathrm{mph}$ & 0.5 & 0 & Normal tubing configuration \\
\hline 15 & 5 seconds & $170 \mathrm{mph}$ & 0.5 & 0 & Normal tubing configuration \\
\hline 16 & 5 seconds & $120 \mathrm{mph}$ & 0.5 & 0 & Normal tubing configuration \\
\hline 17 & 5 seconds & $120 \mathrm{mph}$ & 0.5 & 0 & Normal tubing configuration \\
\hline 18 & 5 seconds & $120 \mathrm{mph}$ & 0.5 & 0 & Normal tubing configuration \\
\hline 19 & 5 seconds & $120 \mathrm{mph}$ & 0.5 & 0 & Normal tubing configuration \\
\hline 20 & 5 seconds & $120 \mathrm{mph}$ & 0.5 & 0 & Normal tubing configuration \\
\hline 21 & 5 seconds & $120 \mathrm{mph}$ & 0.5 & 0 & Normal tubing configuration \\
\hline 22 & 5 seconds & $120 \mathrm{mph}$ & 0.5 & 0 & Normal tubing configuration \\
\hline 23 & 5 seconds & $120 \mathrm{mph}$ & 0.5 & 0 & Normal tubing configuration \\
\hline 24 & 5 seconds & $120 \mathrm{mph}$ & 0.5 & 0 & Normal tubing configuration \\
\hline 25 & 5 seconds & $120 \mathrm{mph}$ & 0.5 & 0 & Normal tubing configuration \\
\hline 26 & 2 minutes & $120 \mathrm{mph}$ & 0.5 & 0 & Normal tubing configuration \\
\hline 27 & 5 seconds & $120 \mathrm{mph}$ & 0.5 & 0 & 5-Hole total switched with port 9 \\
\hline 28 & 5 seconds & $120 \mathrm{mph}$ & 0.5 & 0 & 5-Hole total switched with port 9 \\
\hline 29 & 5 seconds & $120 \mathrm{mph}$ & 0.5 & 0 & 5-Hole total switched with port 9 \\
\hline 30 & 5 seconds & $120 \mathrm{mph}$ & 0.5 & 0 & 5-Hole total switched with port 9 \\
\hline 31 & 5 seconds & $120 \mathrm{mph}$ & 0.5 & 0 & 5-Hole total switched with port 9 \\
\hline 32 & 5 seconds & $120 \mathrm{mph}$ & 0.5 & 0 & 5-Hole total switched with port 9 \\
\hline 33 & 5 seconds & $120 \mathrm{mph}$ & 0.5 & 0 & 5-Hole total switched with port 9 \\
\hline 34 & 5 seconds & $120 \mathrm{mph}$ & 0.5 & 0 & 5-Hole total switched with port 9 \\
\hline
\end{tabular}


Table C.1 continued

\begin{tabular}{|c|c|c|c|c|c|}
\hline File \# & Acquisition & \begin{tabular}{|l|} 
Tunnel \\
Speed \\
\end{tabular} & $\begin{array}{c}\text { Tunnel } \\
\text { AoA }\end{array}$ & \begin{tabular}{|c|} 
Tunnel \\
AoS
\end{tabular} & 5-Hole Probe Scanner Port \\
\hline 35 & 5 seconds & $120 \mathrm{mph}$ & 0.5 & 0 & 5-Hole total switched with port 9 \\
\hline 36 & 5 seconds & $120 \mathrm{mph}$ & 0.5 & 0 & 5-Hole total switched with port 9 \\
\hline 37 & 2 minutes & $120 \mathrm{mph}$ & 0.5 & 0 & 5 -Hole total switched with port 9 \\
\hline 38 & 5 seconds & $170 \mathrm{mph}$ & 0.5 & 0 & 5 -Hole total switched with port 9 \\
\hline 39 & 5 seconds & $170 \mathrm{mph}$ & 0.5 & 0 & 5 -Hole total switched with port 9 \\
\hline 40 & 5 seconds & $170 \mathrm{mph}$ & 0.5 & 0 & 5 -Hole total switched with port 9 \\
\hline 41 & 5 seconds & $170 \mathrm{mph}$ & 0.5 & 0 & 5 -Hole total switched with port 9 \\
\hline 42 & 5 seconds & $170 \mathrm{mph}$ & 0.5 & 0 & 5 -Hole total switched with port 9 \\
\hline 43 & 5 seconds & $170 \mathrm{mph}$ & 0.5 & 0 & 5-Hole total switched with port 9 \\
\hline 44 & 5 seconds & $170 \mathrm{mph}$ & 0.5 & 0 & 5-Hole total switched with port 9 \\
\hline 45 & 5 seconds & $170 \mathrm{mph}$ & 0.5 & 0 & 5 -Hole total switched with port 9 \\
\hline 46 & 5 seconds & $170 \mathrm{mph}$ & 0.5 & 0 & 5-Hole total switched with port 9 \\
\hline 47 & 5 seconds & $170 \mathrm{mph}$ & 0.5 & 0 & 5-Hole total switched with port 9 \\
\hline 48 & 2 minutes & $170 \mathrm{mph}$ & 0.5 & 0 & 5-Hole total switched with port 9 \\
\hline 49 & 15 seconds / degree & $120 \mathrm{mph}$ & 0.5 & 10 to -10 & 5-Hole total switched with port 9 \\
\hline 50 & 15 seconds / degree & $170 \mathrm{mph}$ & 0.5 & 10 to -10 & 5-Hole total switched with port 9 \\
\hline 51 & 15 seconds / degree & $120 \mathrm{mph}$ & 5.5 & 10 to -10 & 5-Hole total switched with port 9 \\
\hline 52 & 15 seconds / degree & $170 \mathrm{mph}$ & 5.5 & 10 to -10 & 5-Hole total switched with port 9 \\
\hline 53 & \multicolumn{3}{|c|}{ Calibration at-5, $-4,-3,-2,-1,0,1,2,3,4,5$} & psi & 5 -Hole total switched with port 9 \\
\hline
\end{tabular}




\section{VITA}

Name: $\quad$ Shane Michael Schouten

Address: $\quad 1006$ Live Oak Circle

Hico, TX 76457

Email Address: shane.schouten@gmail.com

Education: $\quad$ B.S., Aerospace Engineering, Texas A\&M University, 2005

M.S., Aerospace Engineering, Texas A\&M University, 2008 